The copyright of this thesis vests in the author. No quotation from it or information derived from it is to be published without full acknowledgement of the source. The thesis is to be used for private study or noncommercial research purposes only.

Published by the University of Cape Town (UCT) in terms of the non-exclusive license granted to UCT by the author. 


\title{
TRIBOLOGY IN COAL-FIRED POWER PLANTS
}

\author{
By
}

Donald Omphemetse Moumakwa

A thesis submitted to the Faculty of Engineering of the University of Cape Town in fulfilment of the requirements for the degree of Master of Science in Applied Science

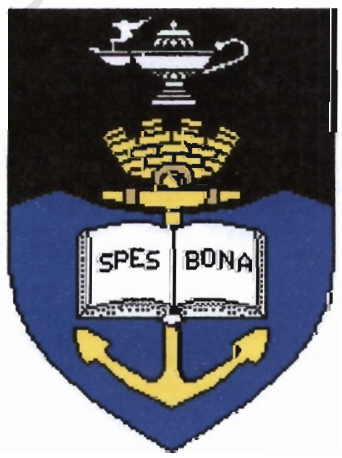

Centre for Materials Engineering Department of Mechanical Engineering University of Cape Town April 2005 


\section{ACKNOWLEDGEMENTS}

Any thesis depends on the co-operation and interest of many different people and this thesis is no exception. The quality of this work was greatly enhanced by the gracious assistance of the staff and students at the Centre for Materials Engineering. However, I am most indebted to the following:

- God, for his guidance throughout the duration of this work.

- My supervisor, Dr Kashif Marcus for his excellent guidance.

- My family, for their love, support and encouragement.

- Mr Glen Newins and Peter Jacobs for their technical support.

- Miss Miranda Waldron of the electron microscopy unit for her assistance with SEM.

- Dr Remy Butcher of iThemba Labs for his assistance with the XRD analysis.

- Dr Sigalas of Wits University for his excellent advice on the microstuctural analysis.

- Mr Ken Tuckey and Mr Tom Bubenzer of Multotec Wear Linings for supplying materials and useful information.

- Miss Khammy Dhaver and Dr Chris Gross for Eskom's financial support, as well as Mr Willy Gamet at Majuba Power Station for his technical advice. 


\section{ABSTRACT}

A series of alumina ceramics and silicon carbide ( $\mathrm{SiC}$ ) particulate composites were evaluated in terms of their erosive and abrasive wear behaviour under different conditions, with the aim of reducing wear damage in power plants. The alumina ceramics tested ranged in composition from $90 \%$ alumina to $97 \%$ alumina content. A nitride fired and an oxide fired $\mathrm{SiC}$ particulate composites were also tested for comparison. The impact angle, impact velocity, as well as particle size and type were varied for solid-particle erosion, whereas effects of the applied load, abrasive speed and type of abrasive were studied for abrasive wear. The target materials were also evaluated in terms of morphology and mechanical properties including hardness, flexural modulus and flexural strengths.

The erosion rates of the tested alumina ceramics increase with an increase in the impact angle, reaching a maximum at $90^{\circ}$. The high purity $96 \%$ alumina dry-pressed body has the best erosion resistance at most impact angles, while the $92 \%$ alumina dry pressed body has the worst erosion resistance. The erosion rates also increased with an increase in particle impact velocity, resulting in a velocity exponent $(n)$ value of 1.5. A decrease in the erosion rate was observed for both an increase in particle size range and a decrease in erodent particle hardness. At all angles of impact, solid particle erosion of the target materials is dominated by intergranular fracture and surfaces are typically characterized by erosion pits. The five alumina target materials also show a marked increase in erosion rates when the test temperature is increased from ambient to $150^{\circ} \mathrm{C}$.

The abrasive wear rates for the materials increased with both applied load and abrasive speed, owing to increased tribological stresses at the contacting asperities. There is also a general trend of increasing abrasion resistance with increasing alumina content. Severe wear, characterized by fracture and grain pullout, is the dominant mechanism of material removal during abrasive wear. This was accompanied by the formation of grooves on the wear surfaces. Although this study was successful in terms of material selection for wear damage reduction in power plants, it also highlighted significant factors and modifications that might need to be considered in future studies. 


\section{TABLE OF CONTENTS}

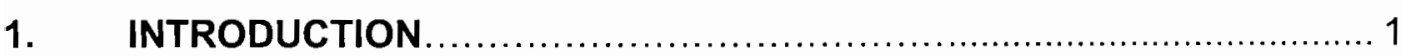

1.1 GENERAL INTRODUCTION......................................... 1

1.2 GENERATING ELECTRICITY FROM COAL .................... 2

1.3 PROBLEMS IN COAL-FIRED POWER PLANTS .................... 3

1.4 RESEARCH MOTIVATION.................................. 5

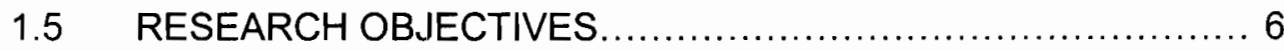

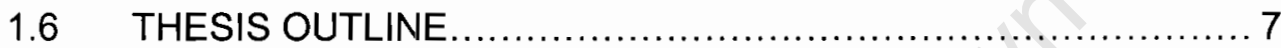

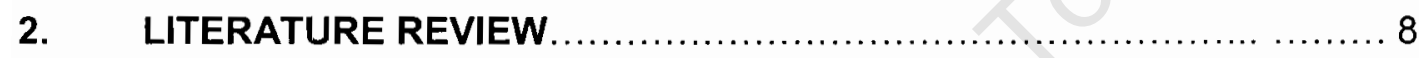

$2.1 \quad$ INTRODUCTION TO TRIBOLOGY $\ldots \ldots \ldots \ldots \ldots \ldots \ldots \ldots \ldots \ldots \ldots$

2.2 SOLID-PARTICLE EROSION ................................. 9

2.2.1 THE NATURE OF SOLID PARTICLE EROSION ............ 9

2.2.2 MODES OF MATERIAL REMOVAL....................... 10

2.2.3 THE EFFECT OF SYSTEM VARIABLES.................... 11

2.2.3.1 The Effect of Velocity............................... 11

2.2.3.2 The Effect of Impact Angle........................ 13

2.2.3.3 The Effect of Particle Flux.......................... 15

2.2.4 THE EFFECT OF TARGET MATERIAL PROPERTIES ....... 16

2.2.4.1 The Role of Microstructure........................ 16

2.2.4.2 Hardness and Fracture Toughness................. 17

2.2.4.3 The Effect of Second Phase........................ 19

2.2.5 THE EFFECT OF ERODENT PROPERTIES ................. 21

2.2.5.1 The Effect of Shape..............................21

2.2.5.2 The Effect of Size.................................. 22

2.2.6 LOCALISED MELTING DURING EROSIVE WEAR ..........22

2.2.7 ELEVATED TEMPERATURE EROSIVE WEAR............ 23

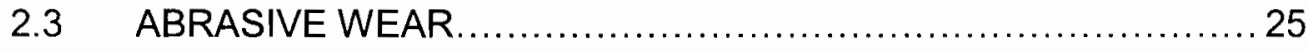

2.3.1 TYPES OF ABRASIVE WEAR......................... 25

2.3.2 MECHANISMS OF MATERIAL REIMOVAL ..................26

2.3.2.1 Cutting ........................................ 27 
2.3.3.2 Ploughing .......................................... 27

2.3.3.3 Fracture and Grain Pull-out........................ 27

2.3.3 THE EFFECT OF SYSTEM VARIABLES.....................28

2.3.3.1 The Effect of Applied Load..........................28

2.3.3.2 The Effect of Sliding Speed......................... 28

2.3.4 THE EFFECT OF MATERIAL PROPERTIES.................29

2.3.4.1 The Role of Microstructure........................29

2.3.4.2 Hardness and Fracture Toughness................. 30

2.3.4.3 The Effect of Second Phase........................ 31

2.3.5 THE EFFECT OF ABRASIVE PARTICLES PROPERTIES... 32

2.3.5.1 The Effect of Abrasive Particle Size............... 32

2.3.5.1 The Effect of Abrasive Particle Shape............... 33

2.4 RESEARCH SHORTCOMINGS.................................. 35

3. MATERIALS AND EXPERIMENTAL TECHNIQUES $\ldots \ldots \ldots \ldots \ldots \ldots \ldots \ldots$

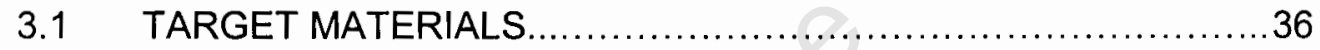

3.2 MORPHOLOGICAL CHARACTERISATION....................... 37

3.2.1 SCANNING ELECTRON MICROSCOPY .................. 37

3.2.2 X-RAY FLOURESCENCE SPECTOMETRY................ 37

3.2.3 WIDE-ANGLE X-RAY DIFFRACTION .........................38

3.3 PHYSICAL AND MECHANICAL CHARACTERISATION............. 38

3.3.1 DENSITY MEASUREMENTS ................................ 38

3.3.2 HARDNESS TESTS ...................................... 38

3.3.3 THREE POINT SUPPORT BENDING TESTS ............... 39

3.4 SOLID-PARTICLE EROSION TESTS ............................... 39

3.4.1 THE GAS BLAST EROSION TEST METHOD ............... 39

3.4.2 DETERMINATION OF PARTICLE VELOCITY.................... 41

3.4.3 ROOM TEMPERATURE TESTING PROCEDURE.............42

3.4.4 ELEVATED TEMPERATURE EROSION TESTS............. 44

3.5 ABRASIVE WEAR TESTS ...................................... 46

3.6 CHARACTERISATION OF WORN SURFACES .................. 47

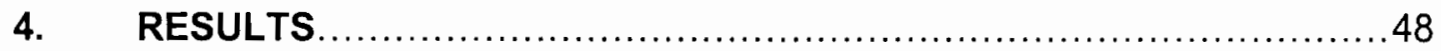

4.1 MORPHOLOGICAL CHARACTERISATION....................... 48

4.1.1 MORPHOLOGY OF ERODENT PARTICLES ............... 48

4.1.2 MORPHOLOGY OF TARGET MATERIALS ............... 49 
4.1.2.1 Scanning Electron Microscopy.................... 49

4.1.2.2 X-ray Fluorescence Spectrometry................. 52

4.1.2.3 Wide-Angle X-ray Diffraction...................... 53

4.2 PHYSICAL AND MECHANICAL PROPERTIES .................. 55

4.2.1 DENSITY ............................................... 55

4.2.2 HARDNESS AND FRACTURE TOUGHNESS ............... 55

4.2.3 THREE POINT BEND TESTS ............................. 56

4.3 SOLID PARTICLE EROSIVE WEAR ......................... 58

4.3.1 THE EFFECT OF IMPACT ANGLE ...................... 58

4.3.2 THE EFFECT OF IMPACT VELOCITY.................... 59

4.3.3 THE EFFECT OF ERODENT PARTICLE TYPE.............6 60

4.3.4 THE EFFECT OF ERODENT PARTICLE SIZE..............6 63

4.3.5 ROOM TEMPERATURE LONG TERM EROSION........... 64

4.3.6 ELEVATED TEMPERATURE EROSIVE WEAR.............6 65

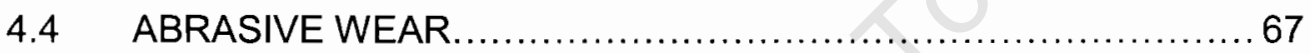

4.4.1 THE EFFECT OF APPLIED LOAD AND SPEED ..............67

4.4.3 THE EFFECT OF ABRASIVE BELT TYPE...................68

4.5 MECHANISMS OF MATERIALS REMOVAL.......................6 69

4.5.1 SOLID PARTICLE EROSION............................. 69

4.5.1.1 Room Temperature Erosive Wear................. 69

4.5.1.2 Elevated Temperature Erosive Wear............... 72

4.5.2 ABRASIVE WEAR ....................................... 73

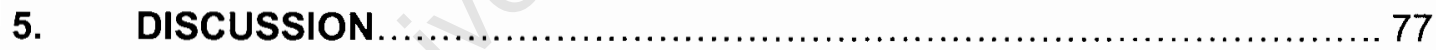

5.1 THE EFFECT OF EROSION TEST VARIABLES $\ldots \ldots \ldots \ldots \ldots \ldots . . \ldots 77$

5.1.1 THE EFFECT OF SYSTEM VARIABLES .................... 77

5.1.2 THE EFFECT OF ERODENT PARTICLES PROPERTIES....78

5.1.3 THE EFFECT OF MICROSTUCTURE.......................81

5.1.3.1 Room Temperature Erosive Wear................. 81

5.1.3.2 Elevated Temperature Erosive Wear................. 83

5.2 THE EFFECT OF LOAD AND SPEED ON ABRASIVE WEAR .......84

5.3 ABRASIVE WEAR BEHAVIOUR ...............................

5.4 COMPARISON BETWEEN EROSIVE AND ABRASIVE WEAR ... 86

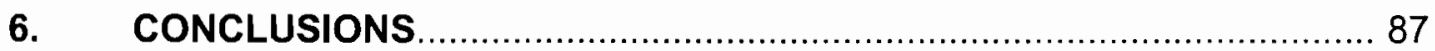

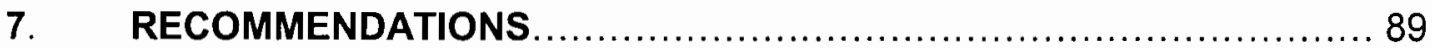


APPENDICES: COMPARATIVE VOLUME LOSS CURVES FOR BOTH

SOLID PARTICLE EROSION AND ABRASIVE WEAR $\ldots \ldots \ldots \ldots \ldots \ldots \ldots \ldots \ldots$

APPENDIX I : THE EFFECT OF IMPACT ANGLE......................95

APPEBDIX II : THE EFFECT OF VELOCITY.......................... 110

APPENDIX III : THE EFFECT OF PARTICLE SIZE AND DIFFERENT

ERODENT PARTICLES.................................. 113

APPENDIX IV : ELEVATED TEMPERATURE........................... 116

APPENDIX $V$ : THE EFFECT OF APPLIED LOAD AND SPEED .......... 120 


\section{LIST OF ABBREVIATIONS}

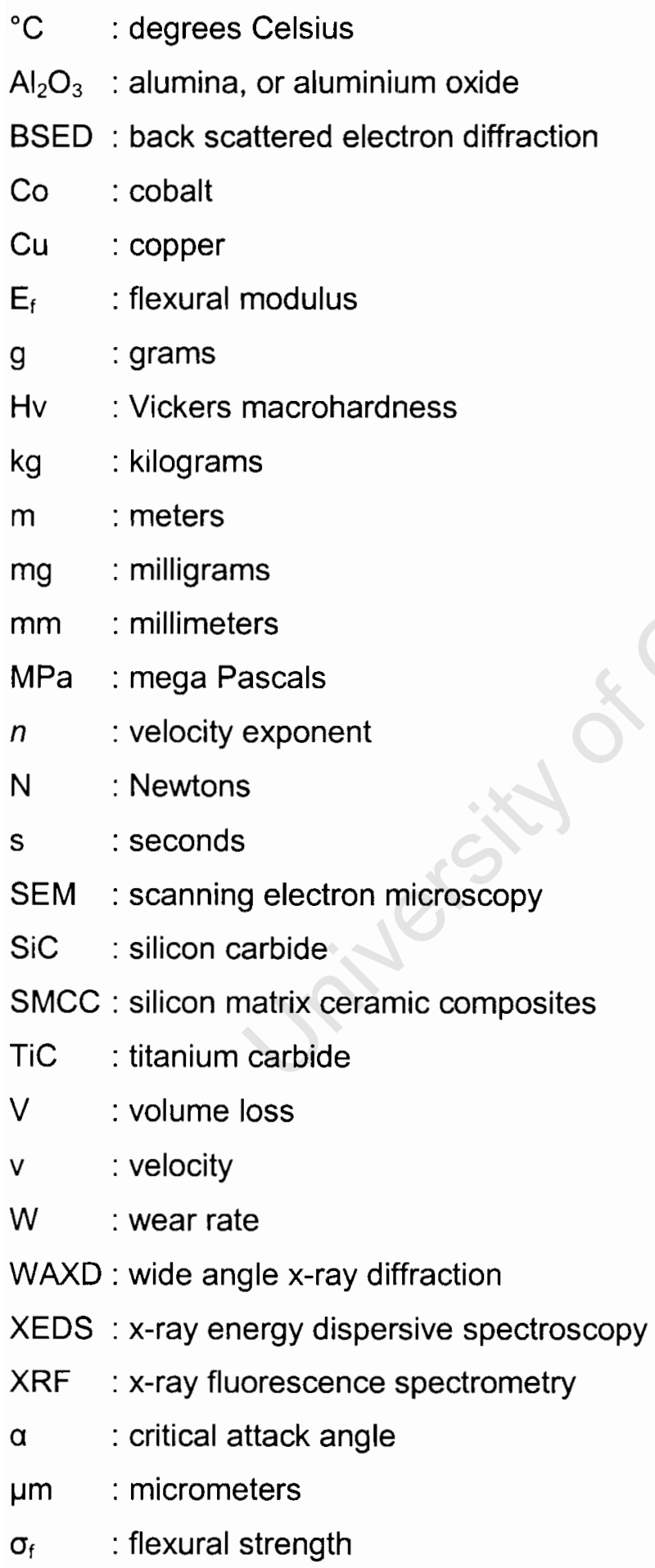




\section{CHAPTER 1}

\section{INTRODUCTION}

\subsection{GENERAL INTRODUCTION}

Coal is still regarded as an important component of the world's electricity market ${ }^{1}$. Although it is used in other applications such as transportation, commerce, agriculture and domestic applications, the most common use of coal remains power generation. As shown in figure 1.1, approximately $38 \%$ of the world's electricity is generated from coal-fired power plants ${ }^{2}$. This is because buming coal is the most cost-effective and energy efficient way of generating electricity ${ }^{3}$. Other fuels for electricity generation include nuclear, water, oil and natural gas.

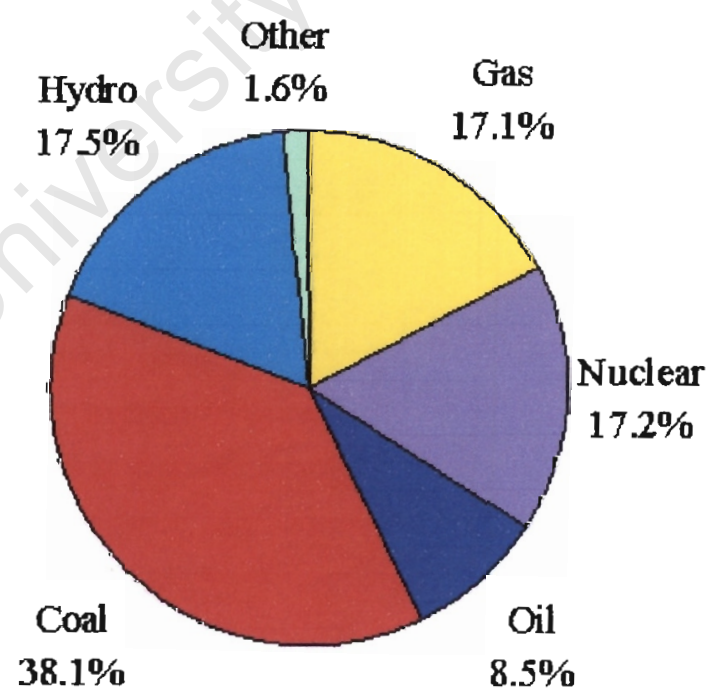

Figure 1.1: Contribution of different fuel sources to the worldwide production of electricity (after ref. 2). 
In South Africa, coal has played a major role in electrical production since the first power station became operational. Currently, coal-fired power stations account for the production of approximately $90 \%$ of South African electricity. This is attributed to the abundance of coal reserves and the relatively cheaper mining of such reserves as compared to other parts of the world ${ }^{3}$. Other countries that rely heavily on coal to produce the majority of their electricity include Poland, Australia, China and the Czech Republic ${ }^{2}$.

\subsection{GENERATING ELECTRICITY FROM COAL}

Figure 1.2 is a schematic representation of an electricity generation process in a coal-fired power plant. Firstly, coal is transported directly from the coal mines to the power station by conveyor belts. The process starts when coal is pulverized in huge mills into a fine powder, before it is blown into boilers where it is combusted. The burning coal heats the water in pipes that line the boiler into dry steam of very high temperature and pressure, typically $540{ }^{\circ} \mathrm{C}$ and $16.1 \mathrm{MPa}$, respectively. This dry steam blows with tremendous force onto turbine blades, which causes the turbine shaft to spin. The spinning turbine shaft then powers a generator to produce electricity. After passing through the turbines, dry steam is led into a condenser, where it is cooled to become water again. The cooled water is then retumed to the boiler to be heated once again and recirculated to the condenser ${ }^{3}$.

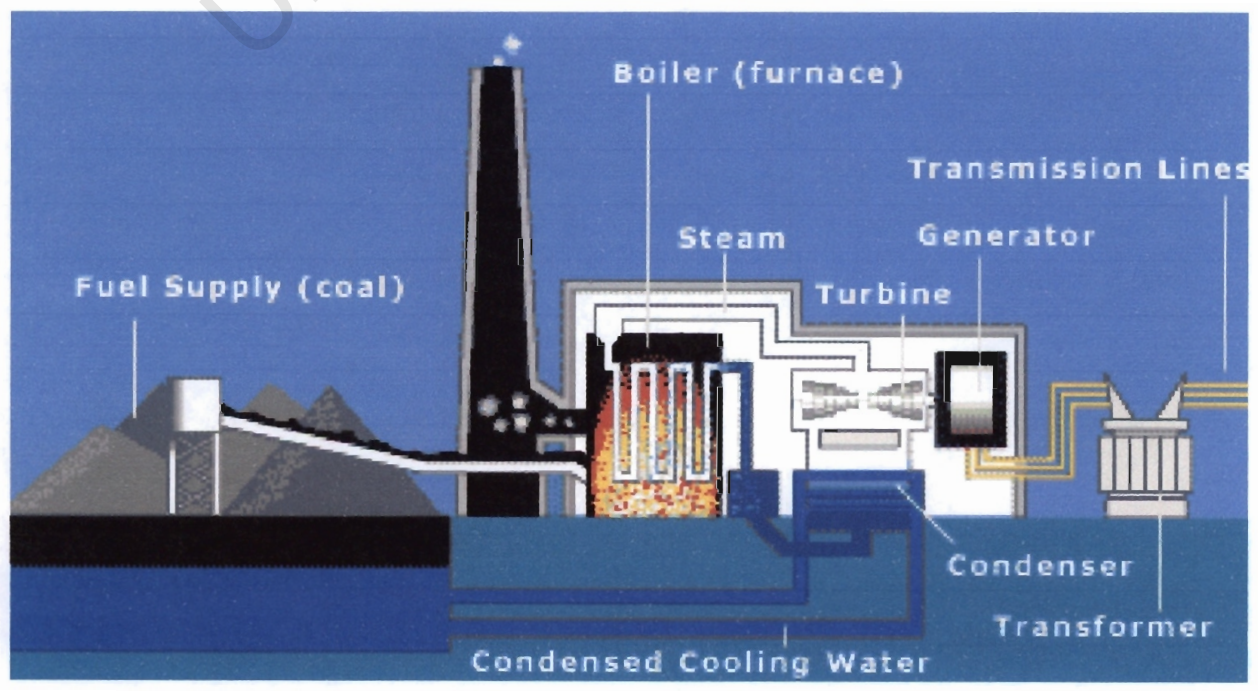

Figure 1.2: Schematic representation of electricity generation in a coal-fired power plant (after ref. 4). 


\subsection{PROBLEMS IN COAL-FIRED POWER PLANTS}

One of the disadvantages about South African coal is that it is of low quality, with largely incombustible mineral matter ${ }^{3}$. This is made up of large quantities of extremely abrasive particles such as quartz $\left(\mathrm{SiO}_{2}\right)$ and aluminosilicates. During the combustion of coal in the boiler, the mineral matter undergoes chemical changes such as the loss of water of crystallization. It may also undergo physical changes: the mineral within the coal itself may accrete to form hollow spheres ${ }^{5}$. These changes bring about a product called ash. Coarse ash drops to the bottom of the boiler where it is collected and removed by conveyor. Other parts of the ash are present as relatively small particles, which are collectively known as fly ash. These are sucked out of the boiler by the induced draft fan. The precipitator then attracts and collects the fly ash, which then falls into an ash hopper at the base of the precipitator. From here the fly ash is taken away by the chain conveyor.

As the fly ash passes through regions where temperatures are lower than in the boiler, such as in hoppers where temperatures range from $132-150^{\circ} \mathrm{C}$, it displays rebound behaviour ${ }^{6}$. This results in material removal from the ceramic tiles lining the ducts in the hoppers. The process is known as erosive wear damage and it is most notable at the Majuba power station in South Africa. The problem is that this kind of damage occurs on certain tiles only and also at specific locations within the conveying system. As figure 1.3 shows, single silicon carbide $(\mathrm{SiC})$ tiles have been eroded away while adjacent tiles are still in good condition. This has been attributed to the inconsistency of tile hardness and/or composition. 


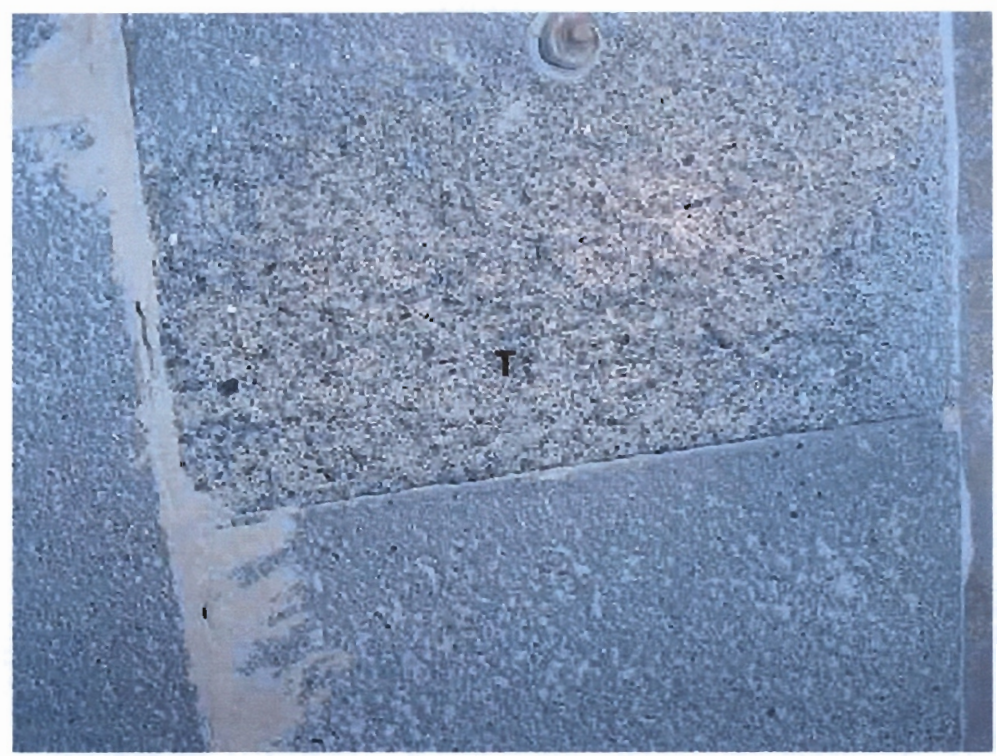

Figure 1.3: A picture showing the conditions of the SiC tiles on the Unit 6 Flue Gas Ducts at the Majuba Power Station. One tile, T, has been eroded away while adjacent tiles are still intact.

The loss of small amounts of material due to erosive wear is enough to cause serious damage and reduce the working lifetime of the tiles. In fact, more than $25 \%$ of all boiler tube failures worldwide are caused by fly ash erosion. In the US alone, fly ash erosion is the second largest cause of availability loss in fossil-fuel-fired power plants ${ }^{5}$. Understanding fly ash erosion is thus of great importance to the economy of South Africa, especially within the power generation field, where it is estimated that literally billions of rands are lost annually through material wear and degradation. In 2002 for example, Unit 6 duct tile inspection at the Majuba Power Station estimated a count of 499 and 245 for tile replacement and repair, respectively.

One of the disadvantages of a conventional conveyor is that it must lie in a standard line. For a change in direction, another conveyor must be installed. The material being transported, in this case ash, must be transferred from one conveyor to the next. The ash is dropped off the end of one conveyor and guided onto the next one by means of a chute. Ash is an abrasive substance and therefore its movement would normally result in abrasion of the chutes. Abrasion is defined as wear in which hard asperities or particles, moving across a softer body under some load, penetrate and remove material from a softer body, leaving a groove ${ }^{7}$. For this reason, abrasive wear is also known as grooving wear. To reduce the expenses of repairing or replacing the chutes, they are lined with wear resistant material, which in this case is ceramic tiling. Although the tiles are wear resistant, a certain amount of abrasion still 
takes place. The tiles can also become chipped or broken. As a result, the tiles need to be replaced from time to time.

\subsection{RESEARCH MOTIVATION}

The control and minimization of wear depends essentially on one of the three alternatives:

- Change the coal to one which is less abrasive.

- Protect the component surface or change the material.

- In the case of erosion, modify the structure to change the gas flow path.

This study is directed at exploring an alternative to changing the material. However, replacement of the worn-out equipment is expensive and usually the problem remains unsolved. Therefore the control and minimization of wear depends on the appropriate selection of materials. Over the years, several applications have employed ceramic materials because of their high hardness, low density, high strength, high chemical stability and high temperature tolerance. In coal-fired plants, particularly within South Africa, SiC particulates composite tiles have often been used to achieve optimal wear resistance and prevent catastrophic failure. Now alumina ceramics have proved to possess several advantages over other ceramic materials and expectations are that they can be largely used in coal-fired power stations to limit the effects of wear. However, these materials have a range of chemical compositions and are processed through several different routes. This may have an adverse effect on their microstructures and mechanical properties, which in turn affect their wear performance.

Although considerable research has focused on understanding the wear behaviour and relative ranking of different materials, very little has been done in terms of the tribological behaviour of alumina ceramic materials when tested against themselves. Furthermore, the available information may be misleading because it can change if the conditions are changed significantly. It therefore follows that quantitative studies of the combined wear effects on these materials should be very useful in predicting 
their lifetimes, comparing their performances and also understanding the underlying damage mechanisms involved.

The wear problems currently experienced in coal-fired power plants are believed to be partly dependent on erosive / abrasive particle properties such as hardness, size and their shape, all of which are a function of the coal and the combustion system ${ }^{5}$. However, an understanding of the properties of a material and its wear behaviour, under a specific set of conditions, is essential for material selection and design for any wear application.

\subsection{RESEARCH OBJECTIVES}

The broad aim of this study is to investigate solid particle erosion and abrasion of a range of alumina ceramic tiles. This entails carrying out experimental tests on inhouse built wear testing machines that simulate the problems encountered in the industry. A high temperature facility would be commissioned to simulate erosion at around $150^{\circ} \mathrm{C}$. Data relating to temperature, erodent / abrasive used, wear surface characteristics and most importantly, material characterization would be collected and synthesized together to establish improved ways of utilizing operating machinery. Specifically, the study aims to:

- Characterize different alumina grades.

- Determine the wear behaviour and wear rates under different operating environments.

- Investigate and identify the operative wear mechanisms under specific conditions.

- Correlate the wear performance with microstructural and property parameters.

- Make recommendations in terms of materials selection. 


\subsection{THESIS OUTLINE}

The approach taken towards this research project starts with a literature review in Chapter Two, which was undertaken in order to become familiar with the previous work carried out on the wear of materials, particularly ceramics. Chapter Three consists of a description of the experimental techniques employed, the results of which are outlined in Chapter Four. A discussion of such results can be found in Chapter Five, followed by conclusions and recommendations in Chapter Six and Chapter Seven, respectively. All the references that were used are listed in Chapter Eight, whereas the other data that was not included in the results chapter conclude this thesis in the Appendices section.

000000000000 


\section{CHAPTER 2}

\section{LITERATURE REVIEW}

\subsection{INTRODUCTION TO TRIBOLOGY}

Tribology is defined as the science of friction, wear and lubrication of interacting surfaces in relative motion ${ }^{8}$. The word is derived from the Greek word "tribos", which means rubbing or sliding. It consists of four systems: (i) smooth solids sliding on smooth solids; (ii) hard, sharp substances sliding on softer surfaces; (iii) surface fatigue caused by repeated stressing and (iv) relative motion between fluids, possibly with suspended solids, and a solid surface. These systems define the four types of wear that can occur: adhesion wear, abrasion, surface fatigue and erosion, respectively. Erosion is further classified as solid-particle erosion (impingement erosion), cavitation and slurry erosion, whereas abrasion is commonly classified as two-body and three-body abrasion.

The present study concerns solid-particle erosion and abrasion, with particular emphasis on ceramic materials. The two wear processes are often equated because of similarities in their wear mechanisms ${ }^{7}$. Another similarity is the fact that despite their physical nature, the two processes commonly occur with corrosion, an electrochemical process. However, they occur in quite different situations and for that reason they will be discussed separately.

The response of a material to both abrasive and solid-particle erosive wear is a complex process, strongly influenced by both mechanical and physical factors. These include system variables such as impact velocity, impact angle and particle flux for solid-particle erosion, as well as load, sliding speed and abrasion distance for abrasive wear. Both erodent and abrasive properties such as size, shape and hardness, and target material properties such as hardness, fracture toughness and microstructure ${ }^{5,9,10}$.

The wear resistance of a target material is evaluated in terms of the wear rate, defined as the mass loss in milligrams $(\mathrm{mg})$, per gram $(\mathrm{g})$ of the erodent used or per meter $(\mathrm{m})$ of abrasion distance. Mass loss from a target material is determined by weighing before and 
after each exposure to a wear process. The mass loss can be converted to volume loss (V) by dividing with the density of the material, in which case the wear rate will be calculated as $\mathrm{V} / \mathrm{g}$ or $\mathrm{V} / \mathrm{m}$.

\subsection{SOLID-PARTICLE EROSION}

\subsubsection{THE NATURE OF SOLID-PARTICLE EROSION}

Solid-particle erosion is a form of wear process characterised by the progressive loss of original material from a solid surface due to the mechanical interaction between that surface and solid particles ${ }^{9,11}$. It occurs in many applications when solid particles, usually entrained in a gas medium, strike a material surface as that shown in figure 2.1. The impacts cause local plastic deformation of the surface, with each particle causing a small crater and material removal. Problems of this nature are encountered in many practical situations. Examples include the ingestion of dirt or sand by aircraft engines, fans operating in dirty environments and repeated impact by fly ash in coal-fired power plants.

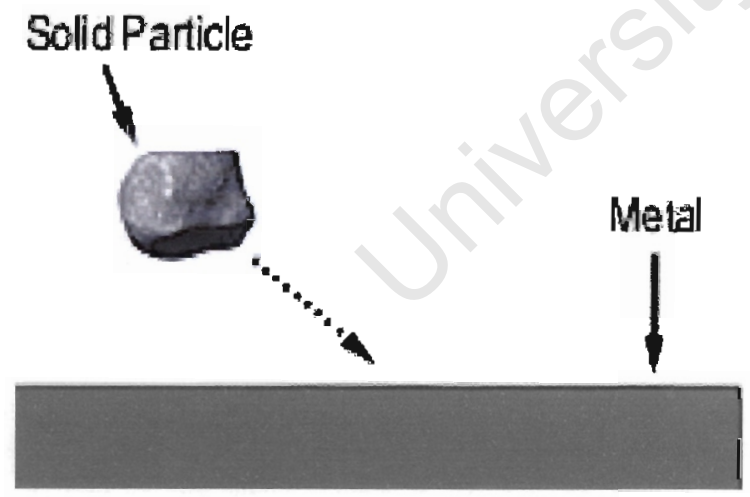

(a)

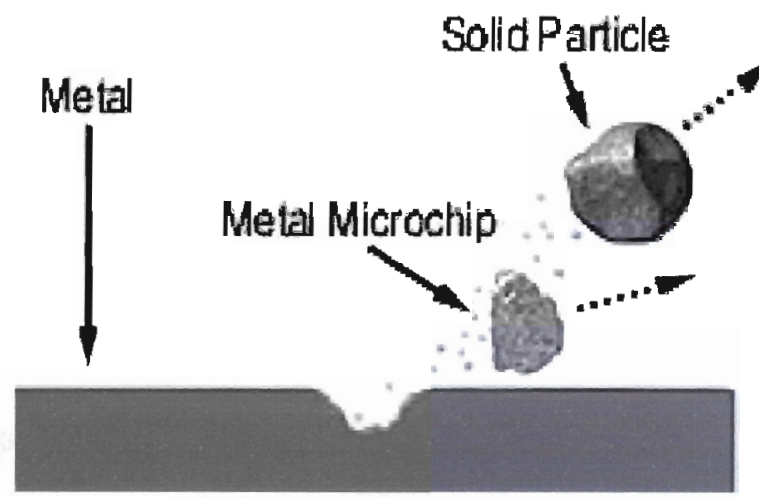

(b)

Figure 2.1: A schematic representation of solid-particle erosion. (a) A solid particle strikes a metal surface and (b) removes a chip of the material (after ref. 12). 


\subsubsection{MODES OF MATERIAL REMOVAL}

Solid particle erosion of materials occurs by micromechanical deformation processes. As a result, target material properties have been shown to be largely responsible for the modes of material removal in solid-particle erosion. Two relatively simple modes of material removal often encountered are brittle and ductile erosion ${ }^{13,14}$.

Brittle erosion is characterised by cracking and chipping off of micro size pieces, caused by the force of the erodent particles as they impact on the surface of the material ${ }^{13}$. During impact, high compressive and shear stresses cause the contact area to deform plastically, resulting in the formation of a radial crack. After the impact, plastic deformation leads to large tensile stresses that give rise to lateral cracks ${ }^{13,15}$. With each subsequent impact event, the cracks propagate and eventually link together, removing a piece of material from a surface $^{15}$. A schematic representation of such an event is shown in figure 2.2. Only one of each of lateral and radial cracks is shown, but in practice more than one of each are often present. Radial cracks are responsible for strength degradation and lateral cracks are the source of material removal. Brittle erosion is associated with high rates of material loss and is largely govemed by erodent properties such as kinetic energy and particle size, as well as the relative hardness and toughness of the erodent particles and target. ${ }^{15}$.

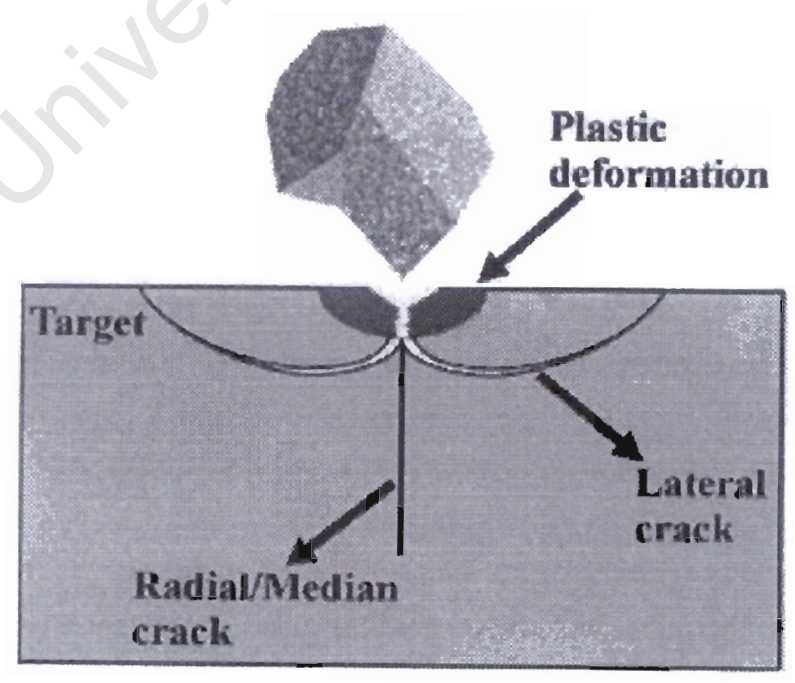

Figure 2.2: Schematic drawing of crack formation from a single particle impact (after ref. 13). 
Ductile erosion takes place at relatively lower kinetic energies of erodent particles ${ }^{15}$. The impact of the particles causes severe, localised plastic strain at the impact site. Material is subsequently removed from the surface when the localised strain exceeds the material's strain-to-failure ${ }^{16}$. Under such circumstances, very few, if any lateral cracks are observed and material removal takes place by cutting and/or ploughing. Cutting is based on the assumption that individual erodent particles traverse along the target surface, cutting out a portion of the material. Ploughing, on the other hand, is associated with platelet formation and remova ${ }^{17}$. Platelets formed on the surface are not removed directly, but rather require subsequent impacting particles to knock them from the material. The shape and kinetic energy of the erodent particles are the most important factors determining the erosion rate in this case ${ }^{15}$.

The above discussion may seem to suggest that the mechanism of material removal relies heavily on erodent particle properties. However, the whole solid particle erosion process is a result of a combination of several specific factors or conditions of the wear environment. Such factors include system variables such as velocity, impact angle and mass flux as well as target material properties such as hardness and fracture toughness, and erodent properties such as size and shape.

\subsubsection{THE EFFECT OF SYSTEM VARIABLES}

\subsubsection{The Effect of Velocity}

Velocity is generally regarded as a critical test variable in erosion, and can overshadow changes in other variables such as target material properties and impact angle ${ }^{9}$. The average velocity of the carrier gas at room temperature can be calculated simply by dividing the volume flow rate by the cross-sectional area of the gas carrying tube. Generally, the erosion rate $(W)$ has been shown to increase with an increase in particle impact velocity, according to an empirical power law relationship 9 .

$$
W=k V^{n} \quad \text { equation } 2.1
$$

where $k$ is a constant, $v$ is velocity and $n$ is the velocity exponent. This power law relationship between $W$ and velocity suggests that the logarithmic relationship between the two is linear. This is depicted in figure 2.3 for the erosion losses of $\mathrm{Cu}$ and $\mathrm{SiC}$, typical ductile and brittle materials, respectively ${ }^{10}$. It is evident that the erosion rate of both target 


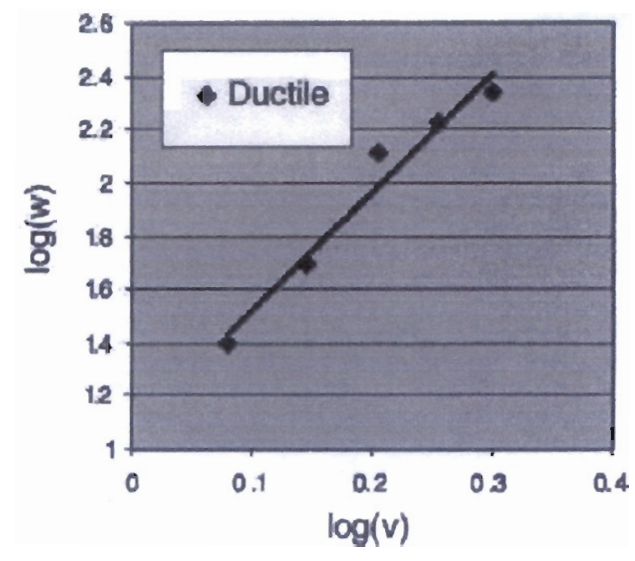

(a)

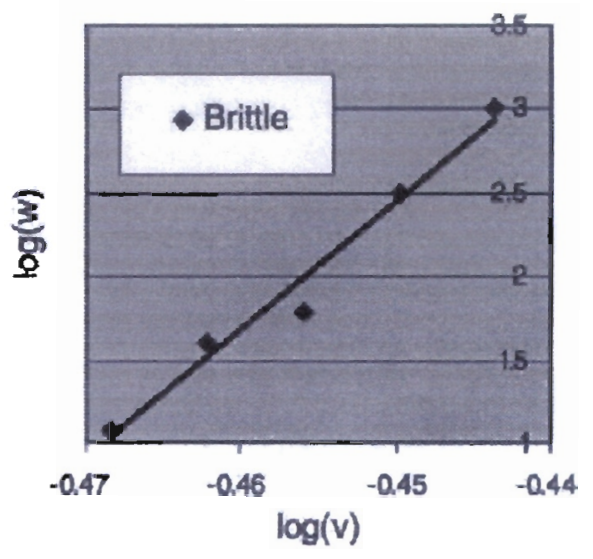

(b)

Figure 2.3: The influence of impact velocity on the erosion losses of (a) $\mathrm{Cu}$ and (b) SiC. The logarithmic relationship between erosion rate $(w)$ and velocity is linear (after ref. 10).

materials increases with an increase in velocity, and the logarithmic relationship between $W$ and velocity is linear. An increase in $W$ with velocity is attributed to the latter resulting in high kinetic energies and loading pressures, which have the potential to do more damage ${ }^{15}$.

The velocity exponent has values between 2 and 3.5 for metallic materials. Relatively brittle materials have larger $n$ values, ranging from 2 to 6.5 . Such $n$ values may be caused by target material properties that affect rebound, such as hardness, or by erodent particle variables such as size and shape ${ }^{9}$. Values of $n$ less than 2 are very rare in solid particle erosion, but values as low as 0.8 have been found in erosion-corrosion tests ${ }^{9}$. The general agreement amongst researchers is that the erosion rate is dependent on different variables, which in tum may influence the velocity exponent.

The velocity exponent $n$ is independent of both target material and erosion mechanism, but is highly dependent on erodent particle variables ${ }^{9}$. Ham et al measured the wear rate of a glass-ceramic matrix composite as a function of velocity at room temperature ${ }^{18}$. They reported a change in erosion mechanism at approximately $12 \mathrm{~m} / \mathrm{s}$, indicated by an uptum in erosion rate after this point. The same study showed that at low velocities, the material removal is by means of surface chipping mechanism, as opposed to lateral cracking mechanism observed at higher velocities. Despite this change in mechanism, an $n$ value of 2.6 was obtained for all the data. On the other hand, Feng and Ball showed an increase in the value of $n$ with decreasing hardness and toughness of erodent particles ${ }^{15}$. 
The value of $n$ is also dependent on erosion test conditions. After running erosion tests several months apart, Lindsley and Marder observed a change in the $n$ value from 2.85 to 2.64 for $\mathrm{Fe}-0.6 \% \mathrm{C}$ alloys in the water quenched conditions ${ }^{9}$. Such changes were attributed to, amongst other factors, the wearing away of the acceleration tube with use, which may change the particle flux. It is therefore clear that a slight change in one test rig can produce significant changes in the value of $n$. As a result, possibilities are that a completely different test apparatus will have a significant effect on $n$, a fact which has not been well-established. However, this may explain why different $n$ values have been found for similar materials.

Temperature is another factor which affects the velocity exponent, although its effect is not very well documented. It is therefore apparent that the velocity exponent can vary from experiment to experiment and therefore more experiments are required, using various erodents with different sizes and velocities. Furthermore, the power law relationship between the erosion rate and velocity, means that any slight changes regarding velocity can result in drastic changes in the erosion rate. As a result, it is critical that velocity be measured precisely and the test apparatus capable of reproducing a test velocity with little error?.

\subsubsection{The Effect of Impact Angle}

The erosion rate of materials is strongly affected by the impact or impingement angle, which is defined as the angle between the eroded surface and the trajectory of the particles immediately before impact. Since material removal occurs through microscopic deformation mechanisms, particle impingement angle affects each class of materials differently ${ }^{16}$. Ductile materials show maximum material loss at oblique impact angles, typically between $20^{\circ}$ and $30^{\circ}$. For brittle materials, material loss increases with an increase in impingement angle, with the maximum loss occurring at $90^{\circ} 10,16,19-21$. Such effects are shown in figure 2.4 . 


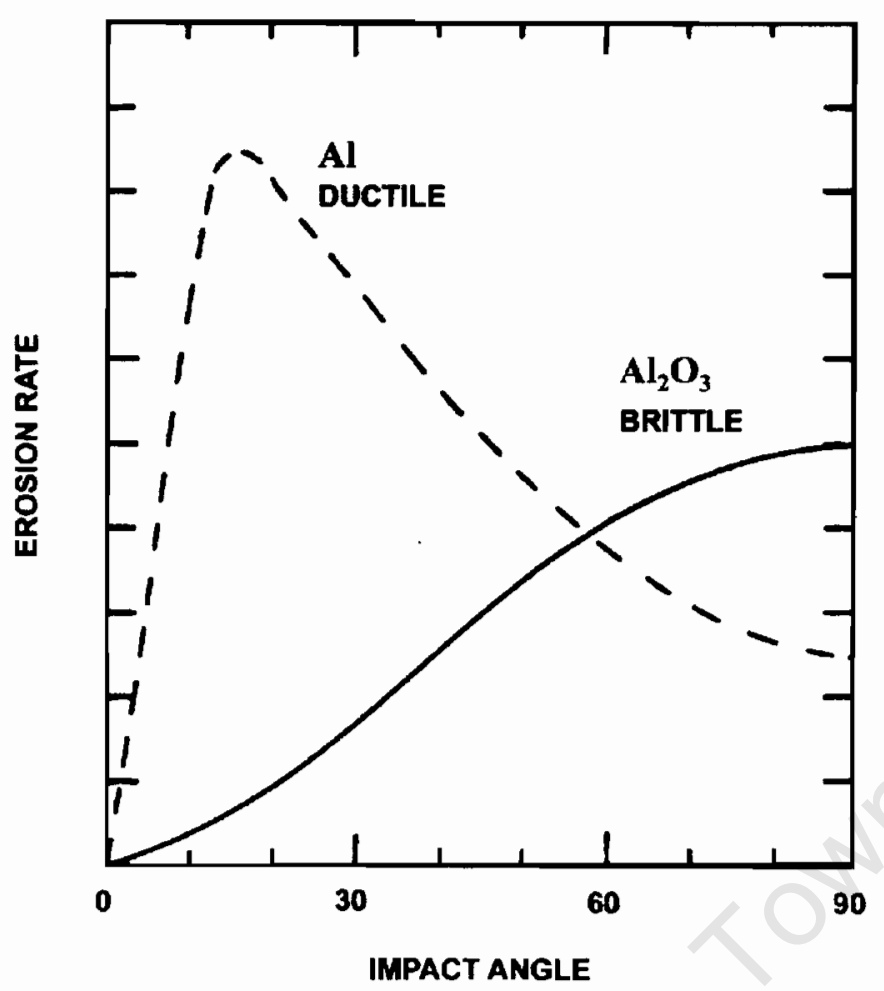

Figure 2.4: The effect of impact angle on aluminium (Al) and alumina $\left(\mathrm{Al}_{2} \mathrm{O}_{3}\right)$, typical ductile and brittle targets, respectively (in ref. 13).

Various researchers have confirmed the dependence of ductile and brittle materials on the impact angle. Among the materials that have been shown to behave in a ductile manner, under a specific set of conditions, are $\mathrm{Cu}, \mathrm{TiC}$ and carbon steel ${ }^{10,17,18}$. On the other hand, $\mathrm{SiC}$ and nickel coatings are some of the many materials which have been shown to behave in a brittle manner, also under a specific set of conditions ${ }^{15,21}$. At very low impact angles, typically less than $5^{\circ}$, erosion rates are normally undetectable $e^{22}$. Under such circumstances, erosion is equated to abrasion?

These contrasting responses to particle erosion for ductile and brittle materials have been explained in terms of the stresses involved during impact ${ }^{11}$. For a ductile material, fracture is generally caused by tensile or shear stresses. During impact by solid particles, the lateral tensile stress may not effectively result in fracture due to the large fracture strain of the ductile material. Thus, a ductile material should have less damage when impacted at $90^{\circ}$. On the other hand, the low ductility of brittle materials makes them susceptible to deformation. This makes brittle materials very sensitive to impact energy, which increases when the impact angle increases. As a result, the erosion rate increases as the impact angle increases, reaching a maximum at $90^{\circ}{ }^{11}$. 
The kinetic energy of the impacting particles is another factor responsible for the impact angle dependence of target materials. The horizontal component of the kinetic energy is mainly dissipated by means of a ploughing mechanism on the target material, whereas the vertical component is dissipated through the initiation and propagation of cracks, and possible fragmentation of erodent particles ${ }^{23}$. Therefore at shallow angles, the kinetic energy of the impacting particles contributes mainly to ploughing and very little to normal repeated impact. This results in very little energy available for initiating and propagating cracks, a process to which the majority of the kinetic energy is devoted during normal impacts $^{23}$.

In light of the various findings concerning the relationship between impingement angle and erosion rates, Wood defined the ductility factor as the ratio of erosion rates at $30^{\circ}$ and $90^{\circ}$, $W_{30}$ to $W_{90}{ }^{21}$. This ratio is useful in determining the erosion behaviour of materials. Values of less than 1 are brittle in nature, whereas values of more than 1 are ductile in nature. It must be mentioned that it is not uncommon for a material to have a mixed ductile/brittle response. Under such circumstances, the ductility factor will be approximately equal to $1^{21}$. In addition, Wensink and Elwenspoek defined the erosion classification value, $E_{\mathrm{cv}}$. This is the ratio of the erosion rate at $45^{\circ}$ and $90^{\circ}$. The value for brittle materials is about 0.45 , depending on the velocity exponent. Normal ductile materials have an $E_{\mathrm{cv}}$ of above $1^{13}$.

\subsubsection{The Effect of Particle Flux}

Particle flux is defined as the mass flow rate $\left(\mathrm{kg} \cdot \mathrm{min}^{-1}\right)$ of the erodent into the system divided by the cross-sectional area $\left(\mathrm{mm}^{2}\right)$ of the erodent carrying tube. Past research has shown that particle flux is an important parameter to consider in erosive wear testing, as it may explain some of the differences in erosion rates. Theoretically, however, the particle flux should have no effect on the erosion rate of materials. This is based on the assumption that all erodent particles impact on the target with the same velocity and angle of impact, and that target material properties affecting erosive wear are independent of the flux ${ }^{24}$. However, previous research has proved otherwise, showing that a higher particle flux leads to lower erosion rates ${ }^{25}$.

The variation of erosion rate with particle flux has been attributed to the effects of particle interactions in the vicinity of the eroding surface. Apart from increased interactions between particles, high fluxes also cause shielding of the specimen by particles rebounding from the surface, which then interact with incoming particles ${ }^{25,26}$. In other words, the specimen 
becomes protected to a certain extent by the very barrage of erodent that is supposed to damage it. These effects become negligible at low fluxes. As a result, a low particle flux is suggested for erosion experiments, to avoid significant effects of particle interactions ${ }^{24}$.

\subsubsection{THE EFFECT OF TARGET MATERIAL PROPERTIES}

\subsubsection{The Role of Microstructure}

Microstructure plays a very significant role in solid-particle erosive wear. For polycrystalline ceramics such as alumina, solid-particle erosion manifests itself as transgranular or intergranular crack propagation ${ }^{23,27}$. The latter is also known as grain boundary microcracking and is normally followed by whole grain removal ${ }^{23}$. This leads to increased amount of material removed in coarse grained microstructures because of the increased flaw size $^{28}$. Thus, it is fine, ceramic microstructures that possess the highest erosion resistance because of their greater ability to absorb energy from impact ${ }^{27}$. Even when multiple grains are removed, the amount of material removed is small compared with the loss of a single large grain ${ }^{28}$.

It must be mentioned that grain size is not the only microstructural parameter responsible for erosion behaviour. Porosity also influences the erosion performance of materials, particularly ceramics. Generally, the erosion rate increases as the porosity increases ${ }^{29}$. The pores are regarded as stress concentrators and are therefore preferred sites for crack initiation. Thus lower porosity coupled with stronger bonding between individual grains makes grain ejection more difficult. This leads to plastic smearing of the grains before they are ejected during repeated impact by the particles ${ }^{23}$.

Generally, the above discussion suggests that fine, dense microstructures give rise to superior erosion resistance, whereas the opposite is true for coarse, less dense microstructures. These effects can be attributed to the close relationship that exists between the microstructure and mechanical properties such as hardness and fracture toughness. 


\subsubsection{Hardness and Fracture Toughness}

Hardness is characterised by resistance to penetration. There has been contrasting views in the literature about the effect of target hardness on solid-particle erosion. Some researchers have found that a positive correlation exists between hardness and erosion, while others are convinced that no correlation exists between the two. Huang et al have shown that the erosive wear behaviour of silicone matrix composite coatings (SMCCs) is greatly influenced by the coating hardness ${ }^{20}$. The introduction of hard reinforcing particles dispersed evenly in the matrix of SMCC resulted in the change in erosion failure from a ductile mode to a brittle one. The coating could not be ploughed and cut easily by the erodent particles, owing to an increase in hardness ${ }^{20}$. As a result, the maximum hardness corresponds with the best erosive wear resistance. By contrast, Alman et al found that the hardest of all the ironaluminide cermets tested was the least erosive wear resistant ${ }^{16}$. Microstructural examination and evaluation of the mechanisms of material removal revealed that the hardest cermet contained relatively coarse TiC particles, which were easily fractured during erosion.

Hussainova et al performed solid-particle erosion tests on eight ceramic-metal composites

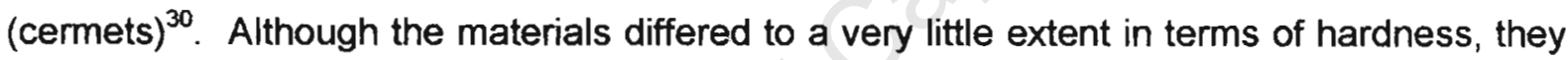
showed remarkable differences as far as erosion rates are concerned. Furthermore, the relationship between hardness and erosion rate differed substantially from the linear relationship, as shown in figure 2.5. The interpretation thereof is that an increase in hardness does not always result in an increase in wear resistance and therefore this shows the inconclusive influence of hardness on erosion rate in composites.

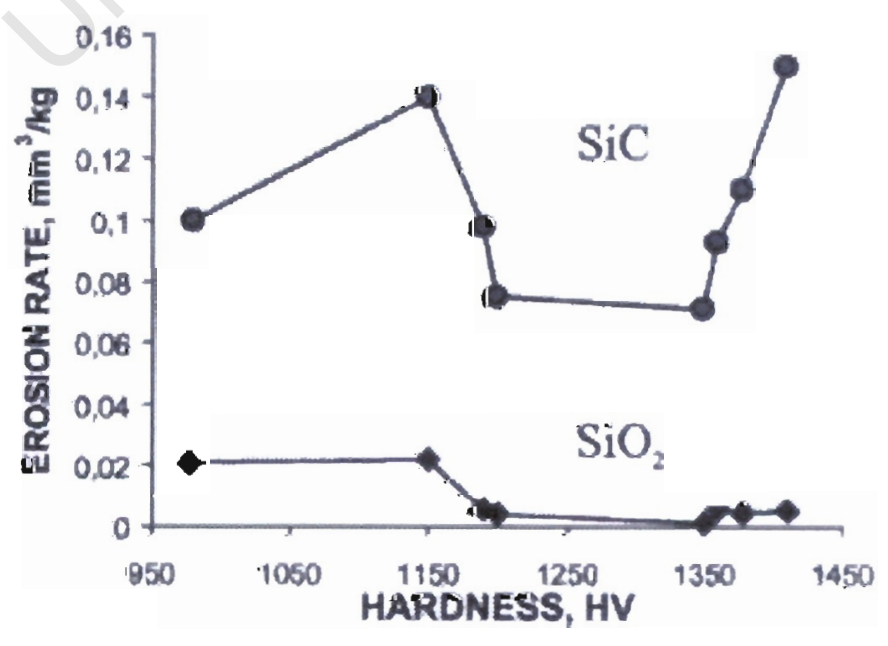

Figure 2.5: Erosion rate vs. hardness for cermets. The relationship between the two differs substantially from the linear relationship (after ref. 30). 
It is evident from the above discussion that the hardness of the target material alone cannot be reliably used as a measure of erosion resistance ${ }^{31}$. This calls for the consideration of the relative hardness between the erodent and target material. If the target material is much harder than the erodent, the latter can hardly cause plastic flow in the target and therefore selective erosion occurs ${ }^{30}$. Under such circumstances, the degree of elastic penetration will depend on the elastic modulus of the target material i.e. if the elastic modulus is high, less elastic penetration occurs. It therefore turns out that the elastic modulus is an even more important parameter of erosive wear resistance than hardness. In addition, softer erodent particles are likely to undergo deformation and fragmentation when they impinge on harder targets $^{23}$.

If the erodent is harder than the target material, several processes can take place. These include penetration of the erodent into the target material, cutting or ploughing and failure of large grains (in the case of cermets), resulting in the detachment of small chips and thus increased erosion rates ${ }^{30}$. The erodent particles have the greater ability to penetrate into the target without suffering plastic deformation or fragmentation themselves. They need more stress to be fragmented and thus cause more damage than the softer, more friable erodent particles. This results in higher residual crack driving forces for the initiation and propagation of lateral cracks ${ }^{15}$. Under such conditions, therefore, crack propagation is the controlling factor $^{30}$.

The differences in wear resistance between materials, particularly those with equal hardness levels, can be attributed to differences in their fracture toughness ${ }^{30}$. However, other researchers have pointed out that hardness is only a factor during low-angle erosion whereas fracture toughness becomes an important parameter at higher angles. However, it has been previously demonstrated that the use of both hardness and fracture toughness to explain the erosion behaviour of ceramics has not always been satisfactory. As a result, it has been greatly appreciated that it is the microstructure of ceramics that have a controlling effect on their erosion behaviour, although the general agreement is that a superior combination of hardness and toughness is required in applications requiring high erosion resistance ${ }^{23,30}$. One way of achieving that is to employ materials in which hard second phase particles are cemented together by the relatively ductile binder phase. 


\subsubsection{The Effect of a Second Phase}

The relatively soft binder phase serves to bind the hard brittle particles together while adding ductility to the material. This typically reduces the bulk hardness but increases the fracture toughness. It has been shown that there exists a critical mass fraction of the binder phase and/or hard particles at which a superior combination of hardness and fracture toughness is attained, thereby leading to lower erosion rates.

As mentioned earlier, Huang et al investigated SMCCs, the results of which are shown in figure $2.6^{20}$. It is clear that the erosion resistance of the silicone matrix was greatly improved by the presence of reinforcing particles, with the best erosion resistance attained at the reinforcing particles mass fraction of $60-75 \%$, known as the critical concentration. This is due to the fact that the particles prevent the intrusion of erodent and blocks the propagation of micro-cracks. The bad erosion resistance shown by the coating above the critical concentration can be attributed to a lack of sufficient adhesive matrix. However, when reinforcing particles in the coating are scarce, the erodent particles can easily intrude into the coating and cause mass loss.

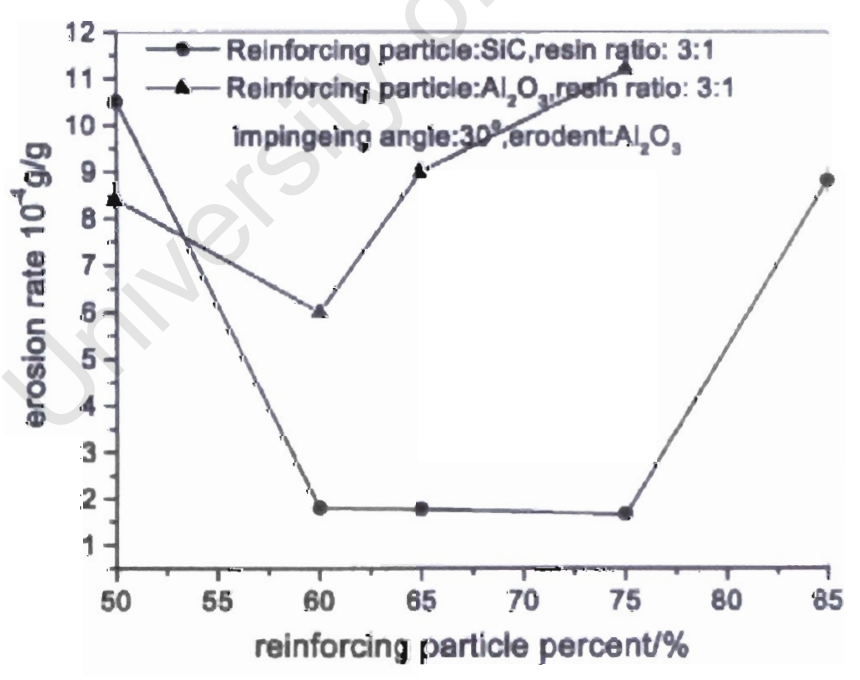

Figure 2.6: Variation in erosion rate of SMCC's with mass fraction of reinforcing particle \% (after ref. 20).

The above results are consistent with the work done by Beste et al, who noted a shift in the general trend of erosion resistance from positive to neutral to negative effect as more Co binder was added to the cemented carbides ${ }^{32}$. Since it is quite apparent that mechanical 
properties change significantly just before and just below the critical concentration, it is important to strike a good balance between reinforcing particles and the binder phase to optimise erosion resistance.

The differences in critical concentration can be attributed to differences in the interaction between reinforcing particles and the matrix. The strong interaction between $\mathrm{SiC}$ and the silicon matrix made the erosion rate of the SMCC change uniformly with the content in the range shown ${ }^{20}$. On the other hand, the alumina SMCC shows a critical concentration only at $60 \%$, indicating that the alumina was not compatible with the matrix ${ }^{20}$.

Contrary to above results, Levin et al observed the highest erosion rate for a $\mathrm{Ni}-\mathrm{Al}_{2} \mathrm{O}_{3}$ composite with the largest volume fraction (45\%) of $\mathrm{Al}_{2} \mathrm{O}_{3}$, while pure $\mathrm{Ni}$ showed the lowest erosion rate ${ }^{33}$. It is suspected that both cracking and debonding of the $\mathrm{Al}_{2} \mathrm{O}_{3}$ particles were responsible for the observed trend. Cracked and debonded particles lost their load carrying capacity, and the matrix around them experienced a larger stress that resulted in accelerated erosion rates ${ }^{33}$. Another interesting observation is that small $\mathrm{Al}_{2} \mathrm{O}_{3}$ particles in $\mathrm{Ni}$ matrix were more beneficial in terms of erosion resistance than large $\mathrm{Al}_{2} \mathrm{O}_{3}$ particles. This was attributed to small particles having fewer pre-existing defects, which create stress concentrations and cause rapid crack propagation and fracture during impact. Therefore, smaller reinforcement particle size coupled with stronger interfacial bond may offer improved erosion resistance ${ }^{33}$.

The benefits of smaller reinforcement particle size have been confirmed elsewhere ${ }^{34}$. The smallest size ratio of the erodent to the reinforcing phase resulted in the largest erosion damage, while the opposite is true for the largest size ratio. Such a trend is explainable. A small size ratio allows the erodent to strike the matrix and reinforcing phase separately. It therefore becomes easier for the matrix to be cut and ploughed without protection from the reinforcing phase. By analogue, the reinforcing phase can be easily damaged with less protection from the matrix ${ }^{34}$.

It is apperent that the same modes of material loss that take place in monolithic materials have also been observed in multiphase materials. This is also exemplified by the work done by Hussainova et al, when they eroded carbide-based cermets with two kinds of erodent, silicon carbide and silica ${ }^{30}$. The former resulted in lateral fracture as the main method of material removal, while the latter resulted in the gradual extrusion of the binder phase and subsequent removal of unsupported carbide grains. 
In their work on cemented carbides with low Co content, Beste et al found the material removal mechanism to be related to the number of carbide grains removed per hitting erodent particle, where brittle fracture dominates for small numbers and ductile mechanisms dominate for large numbers ${ }^{32}$. It is therefore logical to seriously consider erodent particles properties when dealing with erosive wear, particularly for cemented particles.

\subsubsection{THE EFFECT OF ERODENT PROPERTIES}

\subsubsection{The Effect of Shape}

Solid-particle erosion is strongly influenced by the shape of erodent particles, although this effect is said to have little influence on brittle targets when compared to its effect on ductile targets ${ }^{15}$. Different particle shapes result in the energy of the erodent particle to be transferred to the target materials over different volumes, thereby causing different energy densities and subsequent erosion rates in the target ${ }^{9}$. For instance, computer simulation has shown that for a ductile material, angular particles result in larger erosion loss than spherical particles ${ }^{10}$. This is attributed to smaller contact area, leading to larger contact stresses induced by angular erodent particles.

After an impact by a single particle, plastic deformation is generated in the target surface layer. This gives rise to an increase in surface roughness and consequently enhanced ploughing. Furthermore, the change in orientation between an angular particle and a target surface would result in enhanced cutting and ploughing, resulting in increased erosion loss. Although the increased surface roughness also makes the surface easier to be ploughed by the spherical particles, the lower contact stresses result in reduced erosion losses ${ }^{10}$.

There is a relatively less common school of thought amongst researchers that cracking only occurs when a flaw is present. Also, it has been argued that sharp or angular erodents can create their own flaws on brittle targets ${ }^{13}$. Since the brittle mode of material removal takes place through crack initiation and propagation, it makes logical sense that impact by angular particles would lead to enhanced lateral cracking and subsequent erosion losses. It would therefore not be unreasonable to conclude that only angular erodent particles have an effect on brittle target materials. 


\subsubsection{The Effect of Size}

The particle size of erodent has a large effect on brittle materials, whereas it has very little or no effect on ductile materials ${ }^{15}$. This is consistent with findings by Dundar et al, who observed no reduction in erosion rate at the small angular particle size limit for a ductile material ${ }^{35}$. It is therefore clear that very angular small particles are capable of causing significant cutting. However, the same study showed a significant change in the amount of damage by spherical particles as the particle size decreased. It would therefore not be unreasonable to regard the erodent particle size dependence of ductile materials as true for spherical erodent particles only.

It has been pointed out that the brittle mode of deformation can only occur if a flaw is present on the surface of a target material ${ }^{36}$. As a result, when the size of the particles is reduced, the chance of encountering or completely covering a flaw and initiating a crack decreases. The particles will therefore only plastically deform the target, resulting in reduced erosion rate. This is consistent with findings by Feng and Ball, who showed the erosion rate of glass to increase with increasing particle size ${ }^{15}$. This is attributed to more surface contact area and contact time for bigger erodents, which have a higher probability for encountering larger flaws on the surface of glass.

Computer simulation of solid-particle erosion has also shown an increase in the extent of erosion damage with increasing erodent size ${ }^{34}$. This is attributed to the large impact force exerted on a small area by a sharp edge of a large particle. This results in large impact stresses, which can easily generate cracks and inflict greater damage. On the other hand, the low erosion rate observed for smaller erodent sizes is attributed to a lower striking force $^{34}$.

\subsubsection{LOCALISED MELTING DURING EROSIVE WEAR}

It has been shown that high kinetic energy erodent particles impacting on a target material can cause adiabatic heating to high temperatures ${ }^{23,37}$. This may result in melting of the target material, as has been observed in the case of alumina and mullite targets when impacted by $\mathrm{SiC}$ erodent particles ${ }^{37}$. In addition, localised heating may cause melting of the erodent particle. This is exemplified by the work done by Zhang et al when they impacted alumina with gamet particles ${ }^{23}$. In this case, $X$-ray Energy Dispersive Spectroscopy (XEDS) analysis of the melted materials suggested that localised heating caused melting of the 
garnet particle rather than the alumina target. This was attributed to the relatively lower melting point of the garnet erodent particles ${ }^{23}$.

\subsubsection{ELEVATED TEMPERATURE EROSIVE WEAR}

The test temperature has been shown to have an effect on the particle velocity. This is because at higher temperatures, the carrier gas tends to expand. Ham et. al have shown that during heating, the expansion of the gas leads to an increase in gas velocity, which leads to an increased particle velocity as illustrated in figure $2.7^{18}$. This would give rise to increased erosion rates and therefore, the effect of gas expansion must be taken into account during high temperature erosive wear tests ${ }^{18}$.

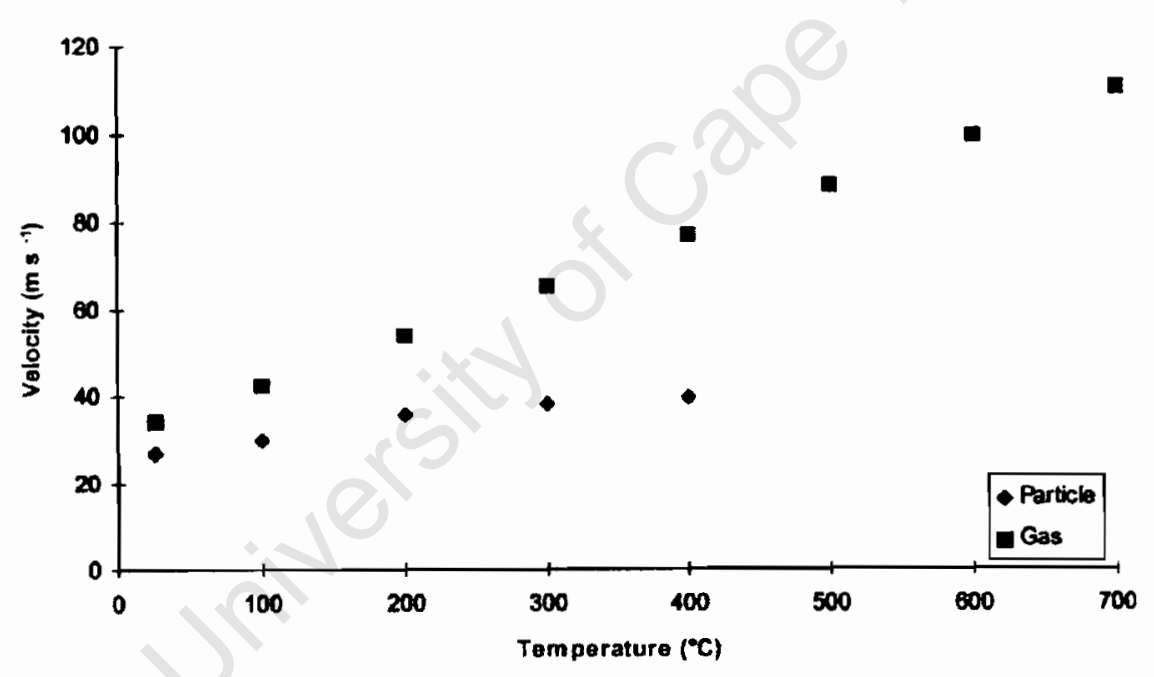

Figure 2.7: Gas and particle velocities as a function of temperature at a constant flow rate (after ref. 18)

Previous erosion experiments performed on alumina ceramics have shown that erosion rates are almost unaffected by the changes in temperature from ambient temperatures to approximately $400^{\circ} \mathrm{C}^{38}$. Above this temperature, erosion rates were found to be affected quite significantly and their rate of increase were greater at higher temperatures. These variations in erosive wear as a function of temperature are best explained in terms of changes in relevant material properties. It was found that the strength and hardness of alumina ceramics decreases with temperature ${ }^{38}$. This would lead to increased surface damage and penetration of particles on impact, as well as enhanced subcritical crack 
growth. This was a very interesting finding considering the fact that there was evidence of plasticity, which normally results in decreased rates, at elevated temperatures as opposed to purely brittle mechanisms at room temperature. The explanation is that at high temperatures, an improvement in ductility competes with a decrease in strength and hardness of a material. The former reduces erosion rates while the latter results in increased erosion rates.

The above findings are consistent with the work done by Colclough and Yeomans, who reported an increase in erosion rate with the test temperature up to $1000^{\circ} \mathrm{C}$, for $\mathrm{SiC}-16$ vol. $\%$ titanium diboride particle toughened ceramic matrix composite ${ }^{39}$. Interestingly, the argument is that these results are consistent with materials becoming softer, leading to larger plastic zone sizes and thus increased driving force for lateral crack propagation and deflection as a result of increased residual stresses. In this case, the process is said to partly arise from a reduction in toughness, which results from a decrease in the mismatch in the coefficients of thermal expansion of the particles and the matrix ${ }^{39}$.

Contrary to the above findings, research on cerarric matrix composites has revealed that an increase in temperature should lead to a reduction of residual tensile stresses in the matrix $^{18,40}$. This leads to a decrease in lateral cracking, which results in reduced erosion rates. Furthermore, an increase in plasticity due to softening of the matrix should also lead to a reduction in erosion rate. This is evident from the work done by Ham et. al who, after normalization with respect to velocity, reported a decrease in erosion rate from room temperature to $400^{\circ} \mathrm{C}$, for $\mathrm{SiC}$ continuous fibre reinforced calcium aluminosilicate glassceramic matrix composites ${ }^{18}$. At higher temperatures, however, the erosion rate was constant even though residual stresses continued to decrease. It is therefore possible that the softening of the matrix was increasing in significance and balancing the effect of stress reduction $^{18}$. 


\subsection{ABRASIVE WEAR}

\subsubsection{TYPES OF ABRASIVE WEAR}

Abrasive wear occurs during relative motion of contacting surfaces which are significantly dissimilar in hardness. Figure 2.8 depicts two types of abrasive wear that are normally distinguished in the commonly used classification scheme. Two-body abrasion implies unconstrained abrasive material, where the load is supplied by gravity or by the abrasive medium's own resistance to deformation. This interpretation is exemplified by transport of loose abrasive material such as coal along conveyors.

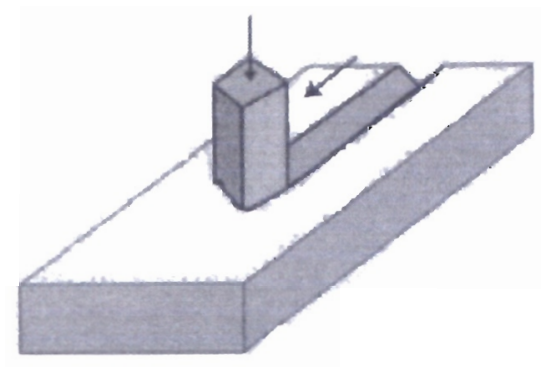

(a)

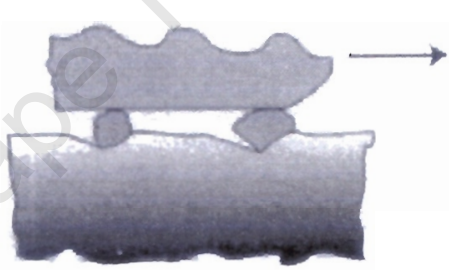

(b)

Figure 2.8: Types of abrasive wear. (a) Two-body and (b) Three-body abrasive wear.

By contrast, three-body abrasion implies that the abrasive is constrained by the counterbody. As a result, three-body abrasion is also known as grinding abrasion ${ }^{7}$. Two-body and threebody abrasion are sometimes referred to as low stress and high stress abrasion respectively, although in some cases the distinction between low stress and high stress centres on whether or not the abrasive particles are fractured during abrasion. Other researchers have considered two-body abrasion to be a special case of three-body abrasion $^{41}$. The explanation for this is that during three-body abrasion, abrasive particles can not only slide, but also roll. When all particles slide, three-body abrasion becomes twobody abrasion ${ }^{41}$.

It must be mentioned that this classification scheme comprising both two-body and threebody abrasion has been deemed by other researchers as seriously flawed ${ }^{7}$. The argument is that distinctions in abrasive wear situations should determine microscopic wear mechanisms and the manifested severity of the wear process. As a result, a replacement by 
an alternative classification scheme that focuses directly on the manifest severity of wear has been suggested. This led to mild, severe and extreme abrasive wear as a suggested classification scheme ${ }^{7}$.

It is therefore apparent that there exists some complications regarding the use of the terms two-body and three-body. However, the rest of this chapter will be on both types of wear but, for the purpose of convenience, the words "two-body" and "three-body" will be abandoned and only the words "abrasion" and "abrasive wear" will be used instead.

\subsubsection{MECHANISMS OF MATERIAL REMOVAL}

As mentioned earlier, the most obvious manifestation of abrasive wear is the formation of grooves on the surface. This takes place through several mechanisms, which can involve both plastic flow and brittle deformation, depending on the mechanical properties of the target material. Plastic deformation involves two well-known mechanisms of groove formation, cutting and ploughing as shown in figure $2.9^{42}$. These two mechanisms give rise to a relatively smooth surface profiles and for that reason, they are both classified as mild wear $^{43,44}$. By contrast, brittle deformation gives a relatively rough wear surface through fracture and grain pull-out ${ }^{8,44}$. Thus, the latter mechanisms are classified as severe wear.

(a)

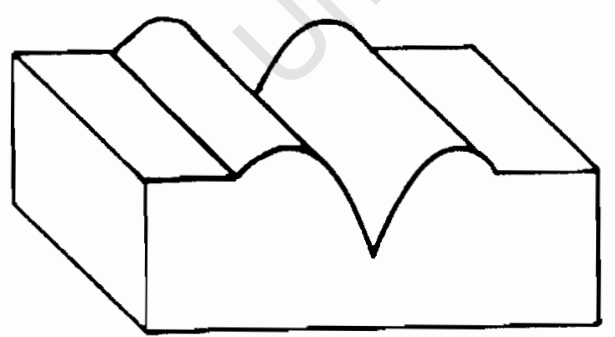

(b)

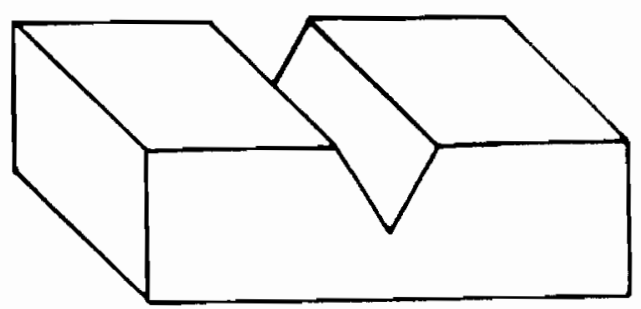

Figure 2.9: Plastic deformation mechanisms in abrasive wear. (a) Ploughing and (b) cutting (in ref. 42). 


\subsubsection{Cutting}

Cutting is associated with high rates of material loss because of removal of chips from the surface during the process. The chips may be either short and discontinuous, or long and continuous, depending on the conditions. The process of cutting is particularly important in stock removal and shaping of ceramic and glass components and semi-conductor wafers ${ }^{45}$. Material is removed from the surface by the production of lateral chips as the abrasive particles are dragged across the surface.

\subsubsection{Ploughing}

Ploughing is characterised by accumulation of material on the sides of the groove and therefore is associated with very little material loss. The magnitude of ploughing load required to plastically deform and remove material is proportional to the depth of penetration of the abrasive medium ${ }^{46}$.

\subsubsection{Fracture and Grain Pull-out}

Brittle fracture takes place by crack generation and it is particularly common in ceramic materials. Movement of grits across the surface results in the formation of cracks near the trailing edges of the grits, where stresses are tensile. Radial cracks may also emanate from the indentation and, if the material is more brittle, subsurface lateral cracks may also develop below the indentation ${ }^{47,48}$. Successive movement of grits results in the accumulation and convergence of such cracks, leading to the release of large quantities of material. The amount of cracking is said to increase with the size of the indentation.

For polycrystalline solids, material removal takes place predominantly by intergranular fracture, which takes place as a result of grain boundary cracking ${ }^{48}$. This is known as grain pull-out and although it is relatively rare, it is common amongst ceramics. It can become extremely rapid when inter-grain bonding is weak and the grain size is large ${ }^{8}$. 


\subsubsection{THE EFFECT OF SYSTEM VARIABLES}

\subsubsection{The Effect of Applied Load}

The applied load on the abrasive grit is regarded as the dominant experimental variable in $a_{\text {abrasion }}{ }^{35}$. Several researchers have shown that the wear rate is directly proportional to the load, but the relationship is not necessarily linear ${ }^{50,51}$.

Wang and Hsu studied the effect of load on the wear mechanisms of ceramics ${ }^{48}$. They attributed the low wear rates at low loads to low asperity contact stresses. This leads to the occurrence of elastic deformation only and no wear can be observed. As the load or contact stress increases, more abrasive particles fracture and penetration by such particles becomes deeper, leading to a more severe damage by radial and lateral cracking ${ }^{52,48}$. At higher applied loads, however, fewer particles will penetrate between the sample and backing plate, resulting in reduced wear rates ${ }^{52}$.

The same non-monotonous variation of the abrasive wear rate with the applied load was also observed under dry sand/rubber wheel abrasion condition for D2 (12\% $\mathrm{Cr}-1 \% \mathrm{Mo}-1 \% \mathrm{~V}$ $1.5 \% \mathrm{C})$ tool stee ${ }^{53}$. Such behaviour was attributed to changes in the abrasive particles condition. This suggests that under high loads, the abrasive particles are not strong enough to significantly damage the material. The particles become damaged considerably and hence their abrading capability is greatly reduced ${ }^{53}$.

\subsubsection{The Effect of Sliding Speed}

Sliding speed is considered a very important parameter in abrasive wear. Both an increase and a decrease in the wear rate with increasing speed have been reported in the literature ${ }^{54,55}$. The former was reported for low purity alumina ceramics, with materials presenting mild wear at the lowest sliding speeds. At higher sliding speeds, severe wear, characterised by fracture and grain pull-out, was the dominant mechanism. These effects are attributed to larger stresses induced at higher speeds ${ }^{54}$.

A decrease in both wear rate and friction coefficient with increasing sliding speed was reported for aluminium metal matrix composites, reinforced with ceramic particles ${ }^{55}$. In this case, the higher sliding speed helped form a stable mixed layer, which mostly consisted of constituents of the counterbody material. This layer acted as a protective cover and helped 
reduce both wear rate and friction coefficient. Furthermore, reinforcing particles carried a significant part of the load, thereby preventing surface plastic deformation. By contrast, the load caused plastic deformation in pure aluminium. This leads to severe delamination wear and subsequent dislodgement of aluminium debris particles. The consequence was renewal of the aluminium surface and the process was repeated, leading to enhanced wear rates.

\subsubsection{THE EFFECT OF MATERIAL PROPERTIES}

\subsubsection{The Role of Microstructure}

Microstructure plays a very important role in abrasive wear in much the same way as it does in solid-particle erosion. It has been suggested that the total microstructure, not simply the grain size, must be considered particularly when determining the abrasion resistance of most polycrystalline ceramics ${ }^{28}$. High alumina ceramics, for example, have a residual glassy phase at the grain boundaries, the composition of which determines whether the stresses at the boundary are tensile or compressive and thus determine whether fracture of the material is inter-granular or intra-granular.

Unlike in solid particle erosion where fine ceramic microstructures have been show to have better wear behaviour, it is alumina ceramics with larger grain size that have better abrasive wear behaviour ${ }^{56}$. The explanation is that the frictional heat, which is generated during abrasive wear, in turn generates plastic deformation particularly in the grain boundary phases, thereby increasing the toughness of the material. As a result, fatigue associated with higher loads and speeds is reduced and the wear loss under more severe conditions becomes less

Another interesting argument, based on pin-on-disk tests, is that the large amount of grain boundaries in a material means there is a large number of sites for crack nucleation, particularly if the weak component of the microstructure is the grain boundaries such as in alumina ceramics ${ }^{56}$. Therefore materials with smaller grain size and hence larger amounts of grain boundaries will behave worse than materials with larger grains. By contrast, dry sand rubber wheel tests have suggested that a high level of wear resistance of some ceramics is explained by a very uniform small-crystalline microstructure, with a small amount of a glassy phase ${ }^{57}$. It is therefore suggested that the abrasive wear resistance may be explained by the optimal ratio between crystalline and glassy phases. The choice of the test method may also have an effect on the performance of materials and therefore extreme care 
must be taken in choosing the correct method. Failure to do so may result in misleading results relating to the intended application of the material.

\subsubsection{Hardness and Fracture Toughness}

Hardness and fracture toughness are generally regarded as the most important mechanical properties in the wear of brittle materials such as ceramics. However, it is the fracture toughness that is considered superior in importance when it comes to abrasive wear. This is exemplified by the work done by Mao et al, in which some ceramics $\left(\mathrm{Al}_{2} \mathrm{O}_{3}+30 \mathrm{wt} \% \mathrm{TiC}-\mathrm{Co}\right.$, ATC) with relatively low hardness values have showed higher abrasion resistance than their high hardness counterparts such as $\mathrm{Al}_{2} \mathrm{O}_{3}+30 \mathrm{wt} \% \mathrm{TiC}(\mathrm{AT} 30)^{51}$. This is attributed to the superior fracture toughness of the ATC ceramic, coupled with small grain sizes and low porosity.

Contrary to the above findings, Dogan and Hawk reported a much poorer wear resistance for a silicon nitride ceramic that had relatively higher measured indentation fracture toughness ${ }^{58}$. As a result, they warn against the use of techniques that measure the bulk or long crack fracture toughness. It is therefore the short crack toughness of the ceramics and ceramicbased composites that is the important parameter in determining the wear resistance. By analogy, it is the surface hardness and not the bulk hardness that is more closely related to abrasion resistance ${ }^{47}$.

It appears as if the variation of the wear rate with both fracture toughness and hardness of ceramics is unpredictable. Furthermore, it is rather surprising that the effect of hardness seems to play second fiddle to that of fracture toughness when it comes to abrasive wear, whereas hardness was considered somewhat important during low angle erosion, which has been equated to abrasion ${ }^{31}$. By contrast, the abrasive wear resistance of ductile metals has been shown to increase with an increase in the material's hardness ${ }^{49,50}$. It is therefore likely that hardness is only a factor during the abrasive wear of ductile materials. In the case of brittle materials, a combination of hardness and fracture toughness is important. 


\subsubsection{The Effect of a Second Phase}

Multiphase materials, usually formed of a ductile matrix reinforced by a dispersion of hard particles, are employed in situations where wear resistance is a major requirement. Such composites are some of the best abrasive wear resistant materials, owing to a combination of the toughness of the matrix and the hardness of reinforcement particles. Other factors that determine the abrasive resistance of such materials are microstructural parameters such as volume fraction of reinforcement particles, as well as the interfacial bonding between such particles and the matrix.

A great deal of past research on multiphase materials has yielded contrasting results. A monotonic increase or decrease in abrasive wear resistance with increasing volume fraction of reinforcement particles ${ }^{59,60}$. This is best explained by the model proposed by Colaco and Vilar $^{57}$. According to the model, an increase in the proportion of reinforcement particles leads to an increase in material's hardness, resulting in improved abrasion resistance. By contrast, the extent of wear can also increase if the extent of damage, by cracking or extraction from the matrix, of the reinforcement particles is greater in significance as compared with the effect due to an increase in material's hardness.

In addition, it has also been shown that there exists a non-monotonic variation between abrasion resistance and the volume fraction of reinforcing particles, where the former initially increases, reaches a maximum and then decreases again with a further increase in the proportion of reinforcement particles ${ }^{60}$. In this case, an increase in abrasion resistance is attributed to an increase in material's hardness as explained before. On the other hand, deficient bonding between the matrix and reinforcement particles, which leads to spalling, is responsible for the observed decrease in abrasion resistance.

The above-mentioned observations are consistent with the model developed by Lee et al based on multiphase materials with a weak interface between the matrix and the reinforcement ${ }^{46}$. The model is based on the simple notion that any portion of reinforcement that is removed as wear debris cannot contribute to the wear resistance of the material. According to the model, the abrasive medium reduces the level of the wear surface until such a time when the tip of the interfacial crack reaches the bottom of the reinforcement particle. As the process continues, the crack will further propagate around the particle, leading to complete removal of such a particle. For a relatively strong interface, the crack will penetrate into the particle, leading to removal of a portion of such a particle ${ }^{46}$. 
Volume fraction of the reinforcement particles and the interfacial bonding between such particles and the matrix are not the only factors responsible for the wear resistance of multiphase materials. Other important factors include shape and interparticle spacing, although their effects have enjoyed very little attention in past research.

\subsubsection{THE EFFECT OF ABRASIVE PROPERTIES}

\subsubsection{The Effect of Abrasive Particle Size}

The effect of abrasive grit size has been well documented ${ }^{62-66}$. Generally, it has been shown that for finer grit sizes the abrasive wear rate increases with increasing grit size. For coarser grit sizes, the wear rate becomes insensitive to changes in grit size. In other words, there exists a critical grit size, often approximately $100 \mu \mathrm{m}$, above which the wear rate remains constant, irrespective of any further changes in grit size $e^{60-62}$. These effects are shown in Figure 2.10.

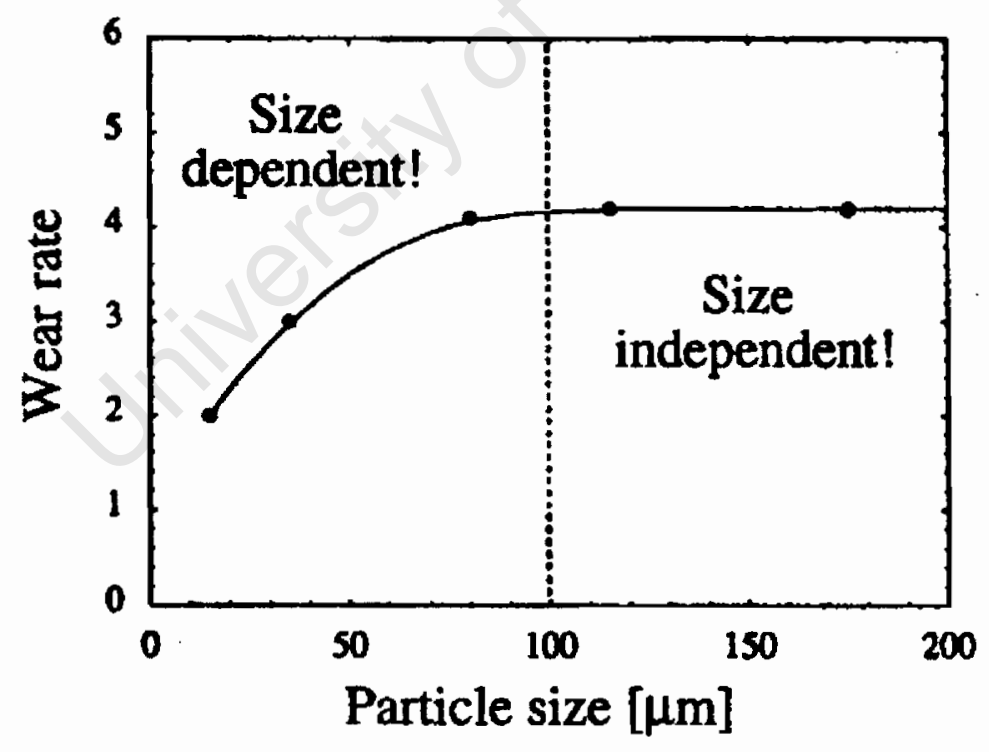

Figure 2.10: The size effect in abrasion. There exists a critical grit size, above which the wear rate remains constant. For finer grit sizes, the wear rate increases with increasing size (after ref. 63).

Several explanations have considered the effect of decreasing wear rate with decreasing grit size to be due to clogging of the coated abrasives by wear debris ${ }^{62.53}$. This would decrease the number of abrasives in contact with the material, leading to decreased wear rates. 
Furthermore, with finer grit sizes, most of the abrasive grains do not penetrate deep enough into the material for cutting to occur ${ }^{62}$. This is based on the fact that the most important effect of varying particle sizes on ordinary abrasive papers is the variation of the packing density, and smaller particles pack more closely. As a result, the load becomes distributed over more abrasive particles, resulting in shallow average penetration ${ }^{63}$. These observations are consistent with the relative bluntness model ${ }^{66}$, which is based on the simple notion that blunt shapes give rise to less wear than do sharp. According to the model, only the blunt part of an abrasive particle is engaged when the penetration is shallow, and therefore the wear rate becomes low. This suggests that the size effect should not be observed for sharp abrasives.

It has also been shown that with time, the wear rate is different for small and large abrasive particle sizes $^{66}$. For small abrasives, the wear rate decreases with time, whereas the wear rate remains constant with time for large abrasives. This is attributed to smaller abrasives being stronger than larger ones. As a result, small abrasives become blunt with time during abrasion, leading to decreased wear rates. Large abrasives, on the other hand, fracture and therefore remain sharp. This gives rise to constant wear rates.

\subsubsection{The Effect of Abrasive Particle Shape}

The abrasive wear of materials is greatly influenced by the abrasive particle shape. Since the shape has an effect on the depth and cross-sectional area of the grooves, it is obvious that it has a strong influence on the wear rate ${ }^{47}$. As it was mentioned earlier, sharp shapes produce more wear than do blunt shapes. The two terms, blunt and sharp, are related to the attack angle, defined as the angle between the front face of the abrasive particle and the abraded surface, as shown in figure $2.11^{42}$. Therefore chips will only form if the attack angle is sufficiently sharp. This is attributed to large strains induced by sharp tips onto the material, which have the capacity to do efficient cutting ${ }^{67}$. If the attack angle is blunt, the material is either removed as lumps that form in front of the abrasive particle, or pushed to the sides of the groove ${ }^{47}$. 


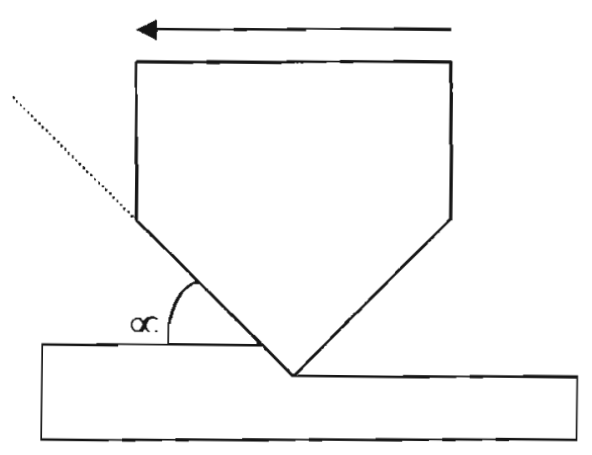

Figure 2.11: The attack angle $(\propto)$ of the abrasive particle. The arrow indicates the direction of abrasive movement (after ref. 42).

From the above explanation, it would not seem unreasonable to expect sharp abrasive particles to do more damage than would rounded particles. However, it has been pointed out that sharp protuberances on otherwise rounded grains may cause as much damage as sharp particles. This is because only a small part of any abrasive particle is responsible for the cutting action ${ }^{46,66}$. Furthermore, it has been shown that the bluntness decreases with increasing penetration depth ${ }^{63}$ i.e. when the load on a rounded cone is increased, such a cone will behave more like a sharp cone as shown in figure 2.12. It is for this reason that blunt particle tips exhibit a size effect as explained earlier, whereas sharp particles do not.

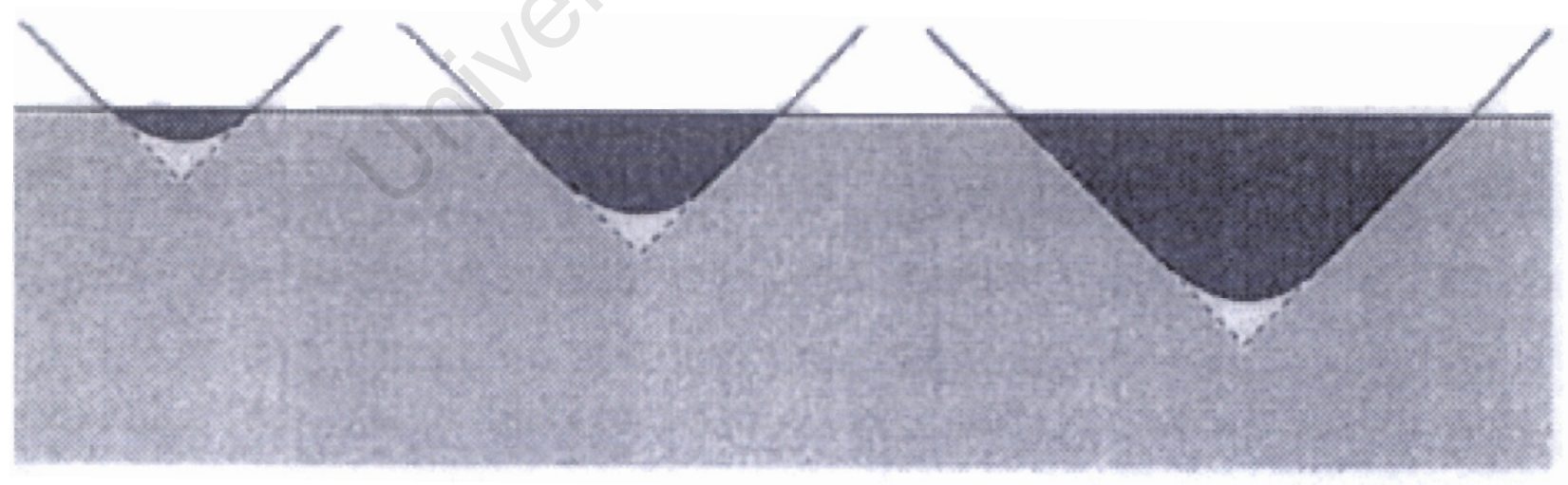

Figure 2.12: With increasing load, a rounded cone behaves more like a sharp cone (after ref. 63). 


\subsection{RESEARCH SHORTCOMINGS}

Although much research has been done on the wear of alumina ceramics, the information available may be misleading as it can change if conditions are changed. Furthermore, there exist several contrasting evidences regarding the effect of some properties, for example the effect of hardness, composition and abrasion speed. This makes it difficult to predict the behaviour of materials under a specified set of conditions. As a result, it is imperative to ensure that test conditions are as close as possible to the intended service conditions. The following chapter outlines the conditions under which the materials were tested in this research project. 


\section{CHAPTER 3}

\section{MATERIALS AND EXPERIMENTAL TECHNIQUES}

\subsection{TARGET MATERIALS}

The target materials used in this study were five grades of alumina ceramics, ranging in composition from $90 \%$ to $97 \% \mathrm{Al}_{2} \mathrm{O}_{3}$. These are chemically inert materials that are stable up to their melting point of typically $2050^{\circ} \mathrm{C}$. In addition, two $\mathrm{SiC}$ particulate composites were also included as reference materials. The alumina ceramics were supplied by Multotec Wear Linings Pty Ltd, while SiC composites were obtained directly from Eskom. All the materials were of the dimensions $40 \mathrm{~mm} \times 25 \mathrm{~mm} \times 10 \mathrm{~mm}$. A description of the different grades is given in table 3.1 below.

Table 3.1: Target materials that were tested for solid-particle erosion and abrasion.

\begin{tabular}{|l|l|}
\hline Sample Code & Description \\
\hline M90 & $90 \%$ alumina extruded body \\
\hline MP92 & $92 \%$ alumina dry pressed body \\
\hline M94 & $94 \%$ alumina slip cast body \\
\hline MP96 & High purity 96\% alumina dry pressed body \\
\hline M97 & Fine grained 97\% alumina slip cast body \\
\hline QN2-1G & Nitride-fired SiC particulate composite tile \\
\hline QO6-1G & Oxide-fired SiC particulate composite tile \\
\hline
\end{tabular}

The process of manufacturing alumina ceramics investigated entails receiving calcined alumina and wet milling it, with the addition of certain fillers. This takes place in a mill lined with alumina and using alumina grinding media. The resulting powder is then shaped into a "green" shape using one of the four commonly recognised methods: dry pressing, isostatic 
pressing, slip casting and extrusion. The "green" shape is then sent through a finishing area where it is refined to produce the final desired shape, while at the same time taking into account the shrinkage that occurs during the sintering process that would follow. Sintering takes place in the kilns at $1500^{\circ} \mathrm{C}$ over a period of approximately 48 hours to give a dense alumina ceramic tile. In this product, different types of coordinations are possible between aluminium and oxygen: $\mathrm{y}-\mathrm{Al}_{2} \mathrm{O}_{3}$ has tetrahedral $\left(\mathrm{AlO}_{4}\right)$ and $\mathrm{a}-\mathrm{Al}_{2} \mathrm{O}_{3}$ has octahedral $\left(\mathrm{AlO} \mathrm{O}_{6}\right)$ coordinations. The latter is a high temperature phase and is commonly known as corundum.

\subsection{MORPHOLOGICAL CHARACTERISATION}

\subsubsection{SCANNING ELECTRON MICROSCOPY (SEM)}

The morphology of erodent particles and microstructure of all the grades were studied using LEO STEREOSCAN 440 SEM operating at an acceleration voltage of $10 \mathrm{kV}$, in combination with chemical analysis by X-ray Energy Dispersive Spectroscopy (XEDS). The target materials were first mounted on a cold setting resin and automatically ground for 5 minutes on a diamond pad, using water as a lubricant. This was followed by polishing on cloths, first using a $3 \mu \mathrm{m}$ diamond paste for 5 minutes, followed by a $1 \mu \mathrm{m}$ diamond paste for another 5 minutes. The specimens were then removed from the resin and chemically etched by being placed in phosphoric acid $250^{\circ} \mathrm{C}$ for 2 minutes. Prior to examination, specimens were sputter coated with a gold / palladium mixture for 10 minutes in order to render them conductive. The Joyce Loebl Image Analysis software package was used to estimate the grain sizes.

\subsubsection{X-RAY FLOURESCENCE SPECTROMETRY (XRF)}

$\mathrm{XRF}$ is regarded as a good technique for chemically analysing ceramic oxides, as it allows analysis of all major elements present with satisfactory results. In this case, the analysis was carried out using the Phillips 1480 "X"Unique" Side Window Wavelength Dispersive Spectrometer. Prior to the analysis, the specimens were ground into a very fine powder using the laboratory jaw crusher. These were then prepared as fusion disks and pellets for the analysis of major oxides. Corrections for background were made by counting disks made from "blank" materials in the same fusion mixture at the analyte peak positions. 
Volatile constituents were determined from a loss-on-ignition (LOI) value, determined by heating the sample in a muffle furnace for 12 hours at $850^{\circ} \mathrm{C}$.

\subsubsection{WIDE ANGLE X-RAY DIFFRACTION (WAXD)}

After the analysis of the major elements present, it was necessary to identify the phases present in the target materials. This required the use of the WAXD technique, which makes use of a Philips PW1390 Powder Diffractometer. The specimens were scanned from $20^{\circ}$ to $120^{\circ}$ Bragg angles $(2 \theta)$ at a scan rate of $0.04^{\circ} / 10.0 \mathrm{~s}$. A high voltage of $40 \mathrm{kV}$ and a tube current of $40 \mathrm{~mA}$ were used. Graphs of x-ray intensity plotted against $2 \theta$ were obtained and these, together with the d-spacing data, were used to identify phases represented by different peaks.

\subsection{PHYSICAL AND MECHANICAL CHARACTERISATION}

\subsubsection{DENSITY MEASUREMENTS}

The bulk density of the target materials was determined from the specimen dimensions and masses. A total of five sets of measurements were taken and the results averaged.

\subsubsection{HARDNESS TESTS}

Vickers macro-hardness $(\mathrm{Hv})$ tests were performed on ground and polished specimens using a load of $50 \mathrm{kgf}$. An ESEWAY macro-hardness tester, equipped with a diamond indentor, was employed for the tests and the $\mathrm{Hv}$ was calculated as:

$$
H v=1.854 w / d^{2} \quad \text { equation } 3.1
$$

where $w$ is the load (kgf) and $d$ is the diameter of the diagonal indent. Only the alumina ceramics were tested, owing to the physically inhomogeneous nature of the SiC-based composites. A total of ten measurements were taken for each specimen and the results were averaged. 


\subsubsection{THREE-POINT SUPPORT BEND TESTS}

Three point bend tests were carried out using the Zwick/Roell Materials Testing Machine, on specimens of dimensions $40 \times 25 \times 10 \mathrm{~mm}$. The specimens were subjected to a load at a crosshead speed of $2 \mathrm{~mm} / \mathrm{min}$, on a support whose separation was $30 \mathrm{~mm}$. Both the flexural modulus $\left(E_{f}\right)$ and the flexural strength $\left(\sigma_{f}\right)$ were determined by the computer programme. In accordance with the ASTM standards, a total of ten measurements were taken and the results averaged.

\subsection{SOLID-PARTICLE EROSION TESTS}

\subsubsection{THE GAS BLAST EROSION TEST METHOD}

Figure 3.1 shows a schematic diagram of the gas blast erosion test apparatus. The basic principle is that solid erodent particles entrained in a gas stream impact onto a specimen enclosed in a test chamber. Compressed air passes through a regulator, which can be adjusted to the necessary pressure to achieve the desired gas velocity, and hence the erodent particle velocity. The air stream flows directly into the test chamber. The erodent particles are fed through a hopper onto a revolving turntable, from which they are drawn by a venturi into the air stream. The desired particle feed rate (mass flux) is achieved by adjusting power to the electric motor, which controls the rotation speed of the turntable. Erodent particles impact the specimen mounted on an angled block in the test chamber.

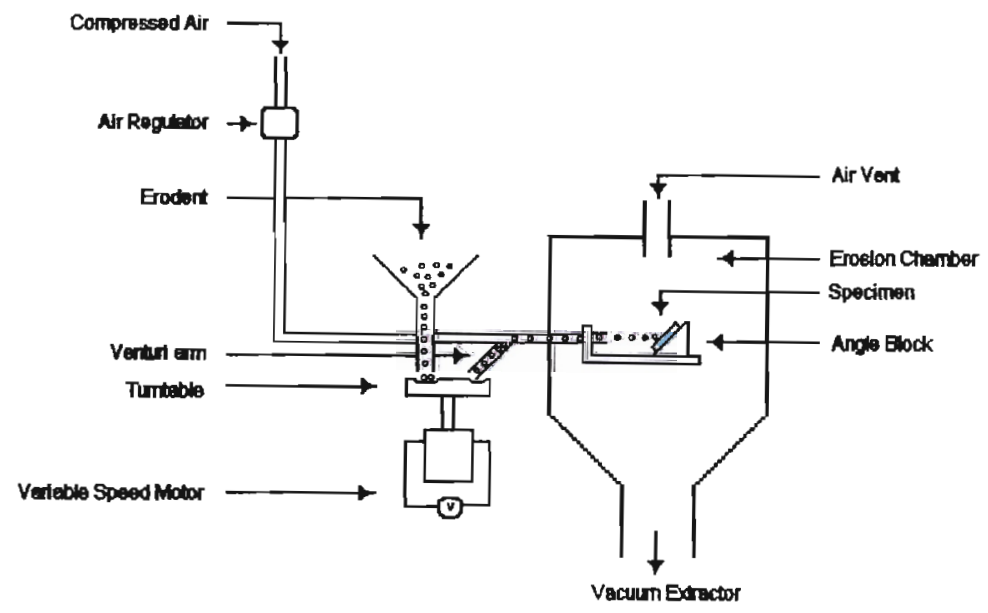

Figure 3.1: Schematic diagram of the room temperature gas-blast erosion apparatus. 
Changing the angled specimen mounting block allows different impact angles to be tested. The gas-blast erosion apparatus used in this study is shown in figures 3.2a-c.

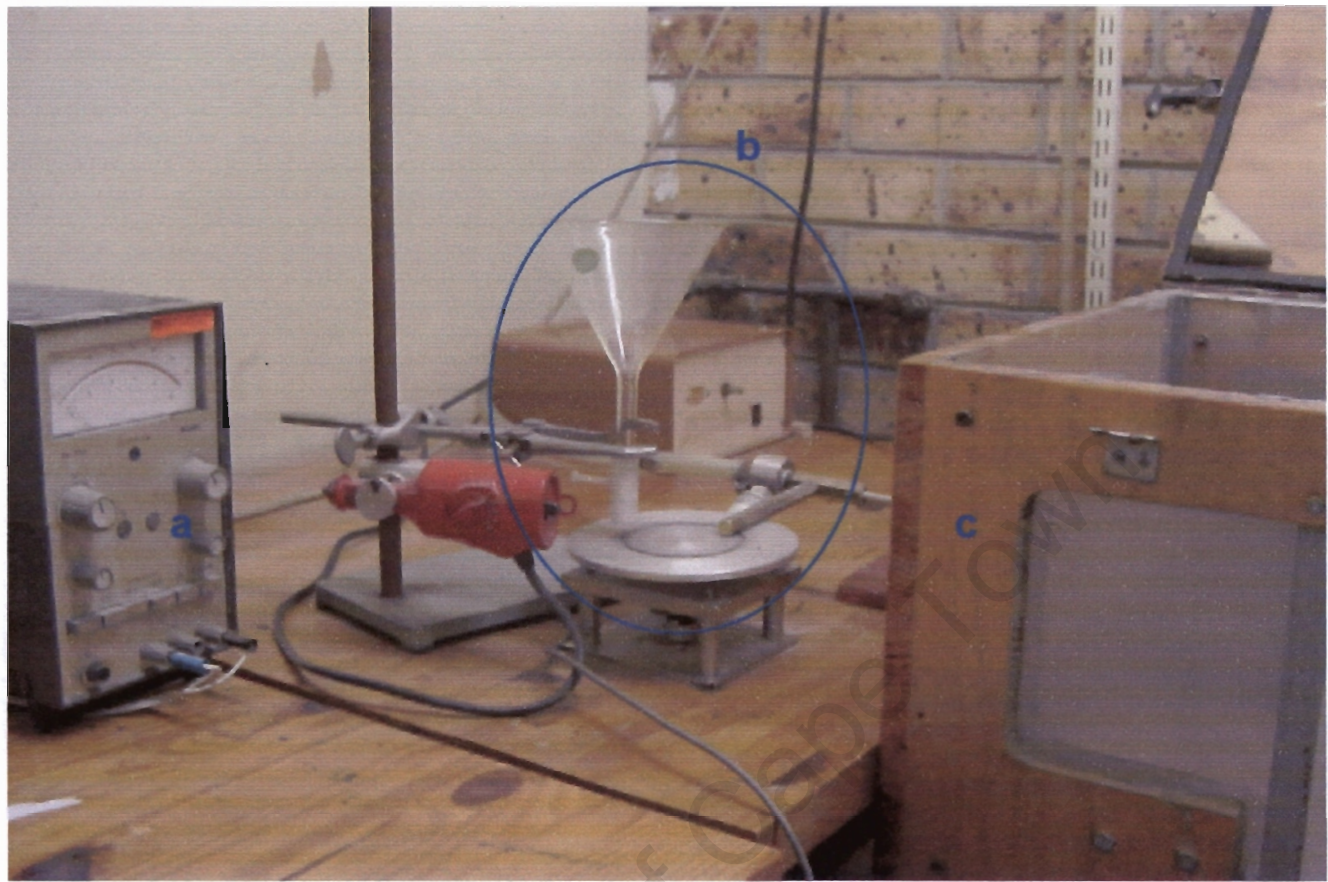

Figure 3.2a: The actual room temperature gas-blast erosion apparatus used in the study. a - voltmeter, b - particle feed system, c - test chamber.

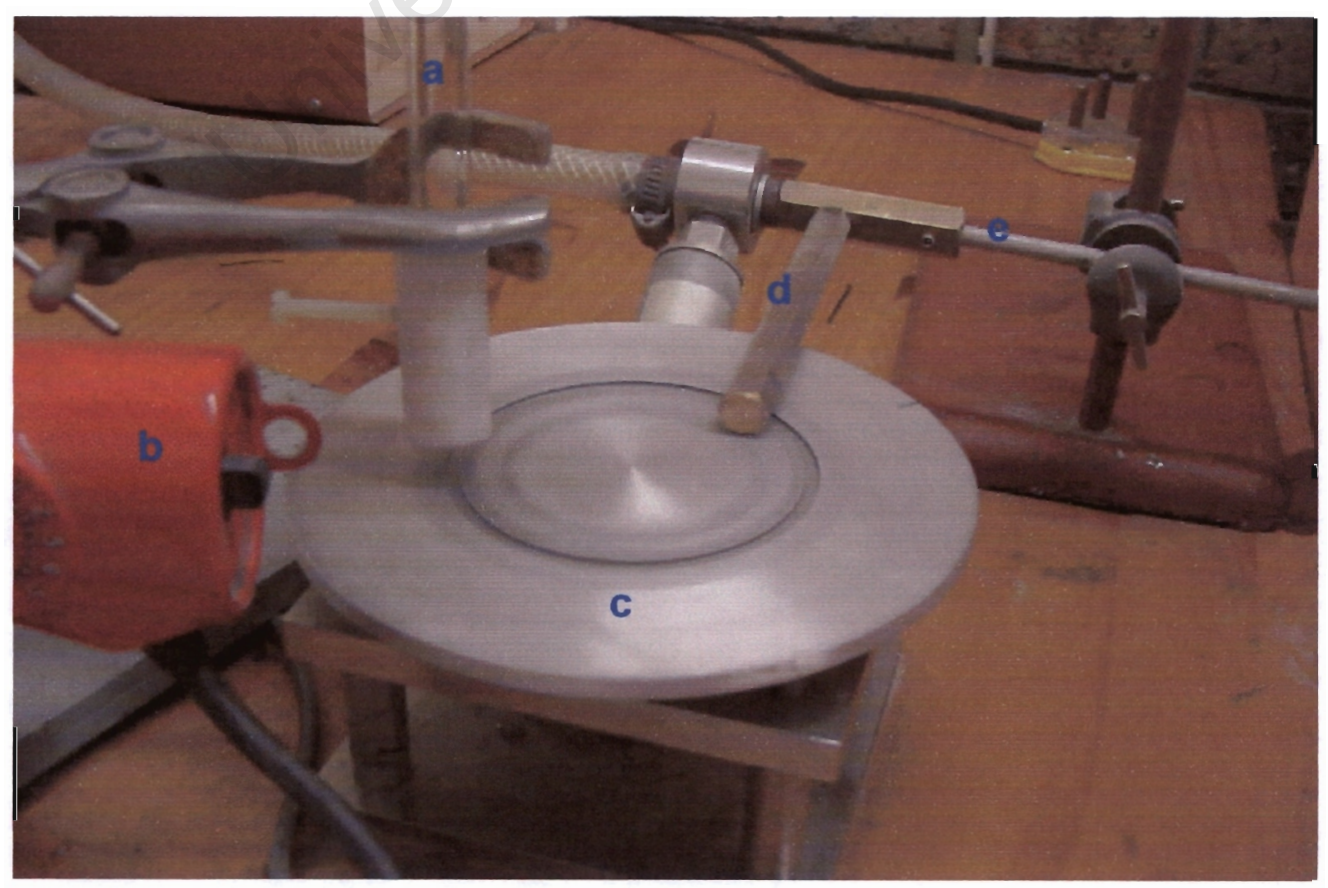

Figure 3.2b: The particle feed system. a - erodent hopper, b - hopper vibrator, c turntable with grooves, $\mathrm{d}$ - venturi arm, $\mathrm{e}$ - acceleration tube. 


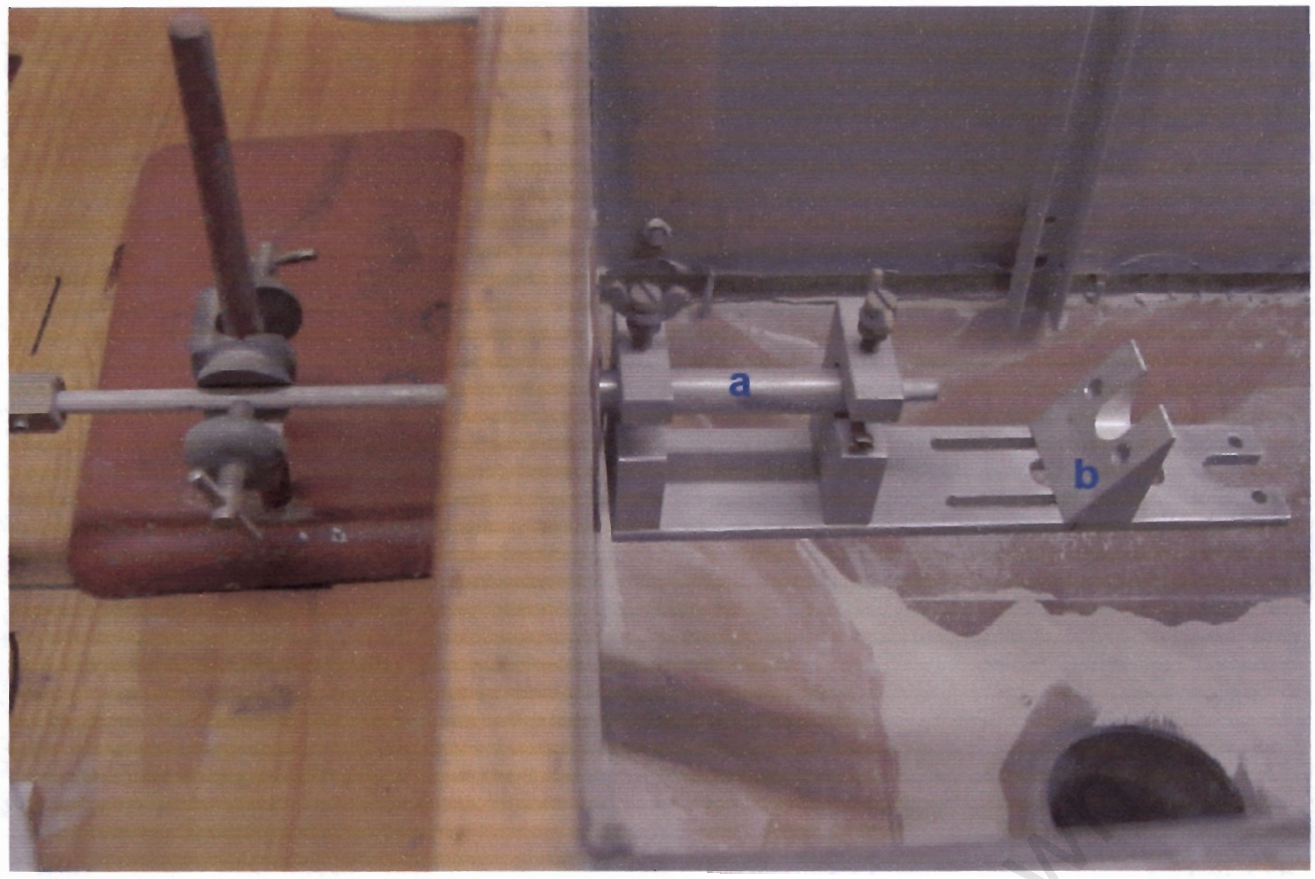

Figure 3.2c: The test chamber. a - acceleration tube, b- $60^{\circ}$ angled block.

\subsubsection{DETERMINATION OF PARTICLE VELOCITY}

The particle velocity was estimated by the rotating disc method, shown schematically in figure 3.3. The method estimates the particle velocity by measuring wear scars caused by impacts with a target (the two discs), simulating impact velocity conditions in testing. A particle stream exits the nozzle of the gas blast apparatus, passes through the slit of the first disc and strikes the second disc. A variable speed motor and electronic counter, control the speed and direction of rotation of the disks. The direction of rotation is then reversed and the process is repeated to produce two wear scars on the second disc. Care was taken in selecting an appropriate angular speed of the discs, to ensure sufficient separation of the wear scars. Particle velocities achieved in the gas blast erosion apparatus were calibrated for a range of gas pressures, using 120 grit $\mathrm{SiC}$ particles. 


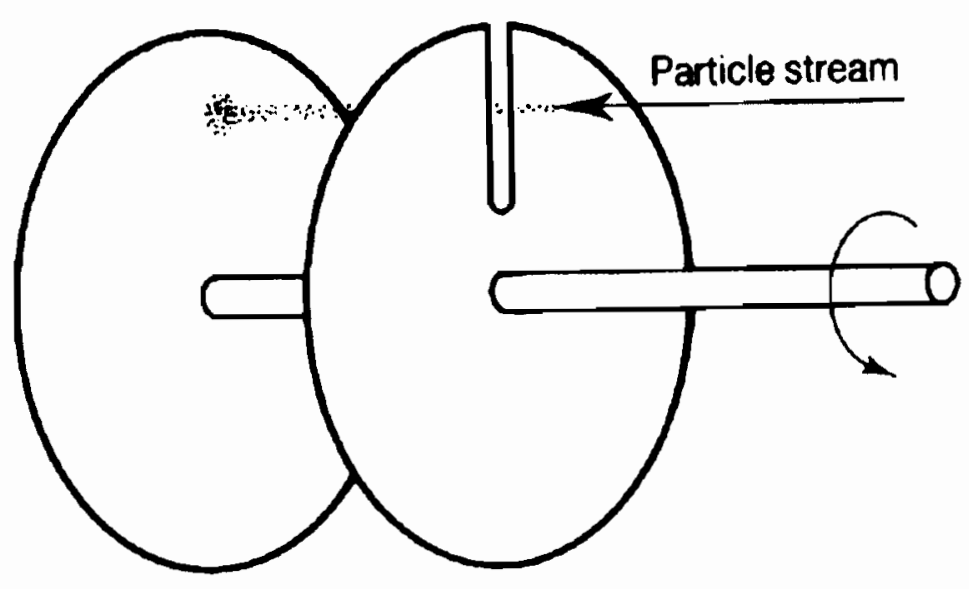

Figure 3.3: Schematic illustration of the double-disc method of measuring erodent particle velocity in gas-blast erosion testing.

The particle velocity is calculated according to the following equation:

$$
v=\frac{4 \Pi U r L}{\delta} \quad \text { equation } 3.2
$$

Where: $\quad v\left(m \cdot \mathrm{s}^{-1}\right) \quad=$ calculated particle impact velocity

$r(\mathrm{~mm}) \quad=$ radius at which the measurement is taken

$L(\mathrm{~mm}) \quad=$ linear separation of the two discs

$U$ (r.p.m) = rotational velocity of the discs

$\delta(\mathrm{mm}) \quad=$ linear separation of the wear scars

\subsubsection{ROOM TEMPERATURE TESTING PROCEDURE}

Erosion tests were carried out on all five grades of alumina ceramics, which were tested in the as-received condition. In this case, however, the materials were impacted with the relatively harder and angular 120 grit $(106-125 \mu \mathrm{m}) \mathrm{SiC}$ erodent particles in order to obtain measurable volume loss. Although this was bound to give rise to higher erosion rates than is observed in practice, it would not affect the relative ranking of the target materials. In carrying out the tests, the correct erodent charge was weighed out using a Mettler PC440 electronic balance, accurate to $10^{-3} \mathrm{~g}$. All specimens were weighed on a more accurate electronic balance, to an accuracy of $10^{-4} \mathrm{~g}$ before being placed on the specimen holder with the correct angled block, at a distance of $45 \mathrm{~mm}$ from the nozzle exit. 
The specimens were initially eroded past an incubation period with a charge of $40 \mathrm{~g}$, thus allowing the steady state erosion rate to be measured. Since incubation period tends to decrease as impact velocity increases, an erosion rate measurement that does not account for incubation will lead to lower erosion rates at the lower velocities, resulting in an incorrect $n$ value. Thus an additional four cycles of $40 \mathrm{~g}$ each were sufficient to establish the steadystate erosion rate. Therefore, a total of $200 \mathrm{~g}$ of particles was used.

A stopwatch was used to record the test time, which was used to calculate the mass flux. Most of the experiments were performed at $90^{\circ}$ impact angle since maximum erosion in brittle materials occurs under normal impact. However, the impact angle was also varied between $20^{\circ}$ and $90^{\circ}$ to study its effect on the erosion rate. Similarly, the impact velocity remained constant at $50 \mathrm{~m} . \mathrm{s}^{-1}$ but was varied in the range of $20-60 \mathrm{~m} . \mathrm{s}^{-1}$ to study the effect of changes in dynamic energy of erodent particles on the erosion rate.

Silica sand and alumina particles of 120 grit size were employed to study the effect that the erodent particle hardness has on the erosion rate. In addition, the 220 grit $(63-106 \mu \mathrm{m})$ and 80 grit $(125-180 \mu \mathrm{m})$ silica sand were used to study the dependence of erosion rate on the erodent particle size. MP92 was also impacted with $400 \mathrm{~g}$ of SiC particles to study the effects of long term erosion. The relatively high hardness of SiC particles ensured that the behaviour of MP92 was investigated under extreme erosive conditions over a prolonged period. The particle flux remained constant at $23.8 \mathrm{~kg} \cdot \mathrm{m}^{-2} \cdot \mathrm{s}^{-1}$ for all the experiments. The experimental matrix is summarised in table 3.2. Note that, for reasons which will become clear later, the effect of velocity on erosion was tested on MP92 only and the effect of particle size was only tested on M94.

Table 3.2: Experimental matrix for room temperature solid-particle erosion testing.

\begin{tabular}{|c|c|c|c|c|c|}
\hline \multicolumn{6}{|c|}{ System Conditions } \\
\hline Velocity $\left[\mathrm{m} \cdot \mathrm{s}^{-1}\right]$ & 20 & 30 & 40 & 50 & 60 \\
\hline Impact Angle $\left[^{\circ}\right]$ & 20 & 45 & 60 & 80 & 90 \\
\hline Mass Flux $\left[\mathrm{kg} \cdot \mathrm{m}^{-2} \cdot \mathrm{s}^{-1}\right]$ & \multicolumn{5}{|c|}{23.8} \\
\hline Temperature $\left[{ }^{\circ} \mathrm{C}\right]$ & \multicolumn{5}{|c|}{25} \\
\hline No. of tests @ ea. angle & \multicolumn{5}{|c|}{2} \\
\hline \multicolumn{6}{|c|}{ Erodent Particles } \\
\hline Material & \multicolumn{5}{|c|}{ Size } \\
\hline $\mathrm{SiC}$ & \multicolumn{5}{|c|}{120 grit } \\
\hline Alumina & \multicolumn{5}{|c|}{120 grit } \\
\hline Silica sand & \multicolumn{2}{|c|}{80 grit } & 120 grit & \multicolumn{2}{|c|}{220 grit } \\
\hline
\end{tabular}


After the tests, specimens were cleaned with compressed air and then reweighed. This process was typically repeated two times for each grade. The mass loss of the specimens was obtained as the difference in mass obtained prior to and after testing. The volume loss was subsequently calculated by dividing the average mass loss with the density. This was plotted against the mass of the erodent used and the resulting slope signified the erosion rate.

\subsubsection{ELEVATED TEMPERATURE EROSION TESTS}

The specimens were subjected to high temperature erosive wear, the rig of which is shown in figure 3.5. The rig, designed by Suckling, is one in which compressed air is preheated in the preheat chamber, has erodent particles introduced into it and is then passed through a duct in which a hydrocarbon gas is combusted ${ }^{68}$. This provides most of the heating power required to achieve the specimen temperatures. The gas and erodent mixture then impinges on the target, whereafter the mixture is cooled and the particles recovered.

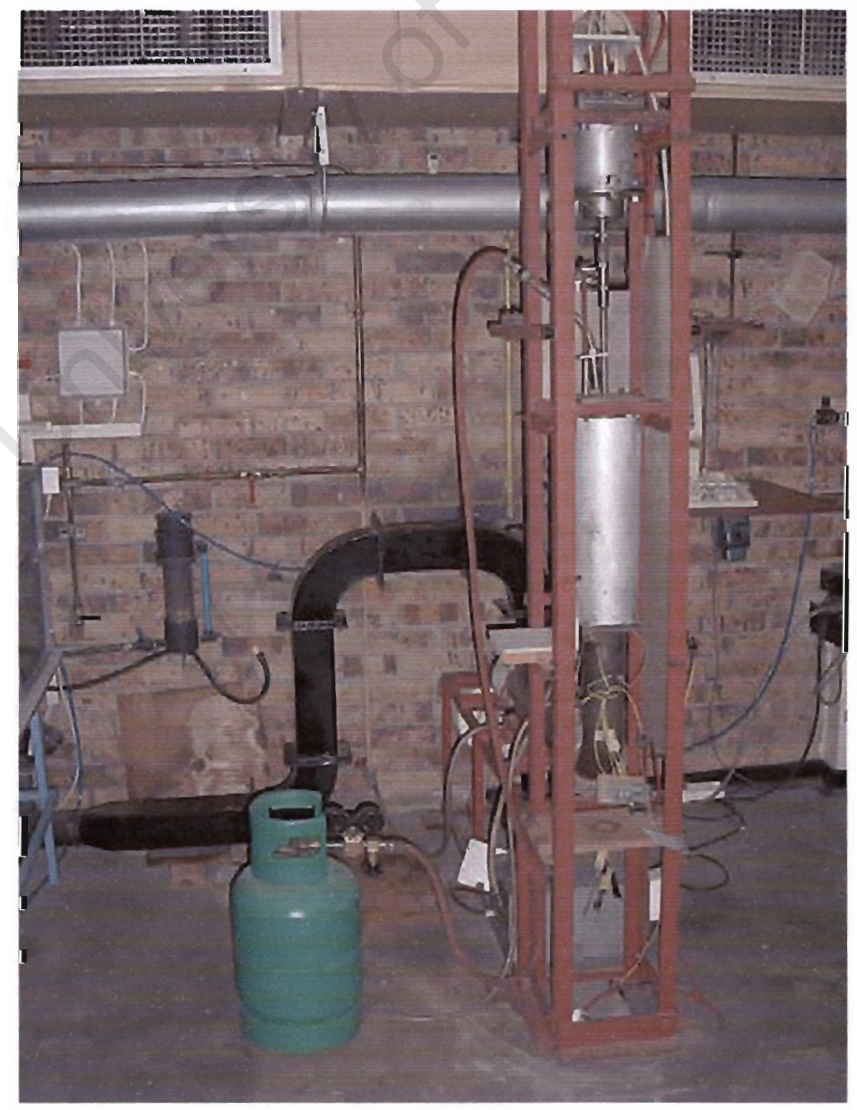

Figure 3.5a: The high temperature erosion rig. 


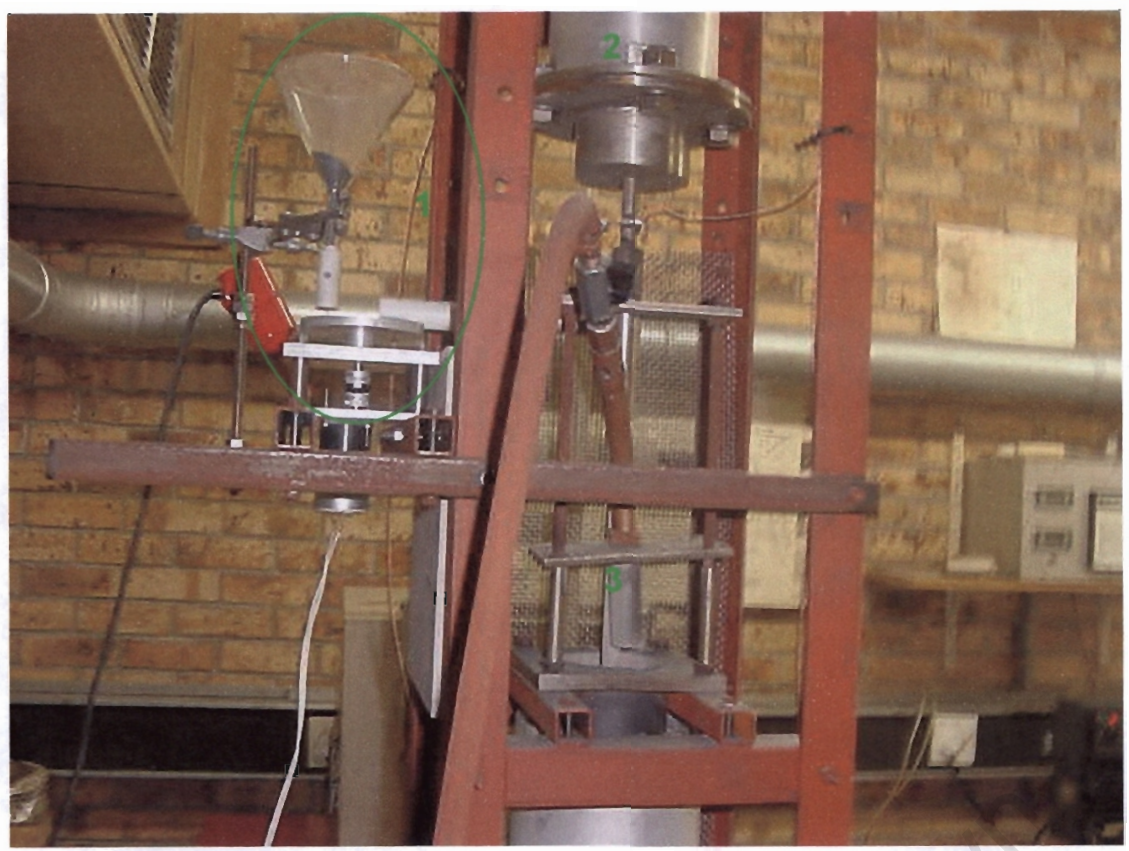

Figure 3.5b: Some important components of the high temperature erosion rig: 1 - erodent feeder, 2 pre-heat chamber, 3 - hydrocarbon gas flame.

The preheat chamber heats the air to $\pm 80^{\circ} \mathrm{C}$ before its entry into the venturi and the acceleration tube. The heating power is supplied by six ceramic heating elements, which hang freely in the preheat chamber. A setting of $150^{\circ} \mathrm{C}$ was used for the preheat chamber. Temperature control is provided by a Eurotherm thermostat, which receives its power from an isolation transformer.

The heating of the specimens and particles takes place through three additive processes. Firstly, the radiant heat from the hydrocarbon gas flame heats the specimen up such that its surface is at a higher temperature than the impinging air/erodent mixture until equilibrium is reached. Then the flame impinges directly onto the acceleration tube and heats it to temperatures exceeding $800^{\circ} \mathrm{C}$. The hot surface heats the passing air and particles by convection and radiation. Finally, the combustion gases from the flame mix with the intake of the air through the flame duct, maintaining the temperature of the specimen chamber.

The same procedure that was followed for room temperature erosion testing was also followed during high temperature testing. The tests were performed at approximately $150^{\circ} \mathrm{C}$, which is the reported highest temperature attained in the hoppers. A particle velocity of 50 $\mathrm{m} / \mathrm{s}$ was used, with a mass flux of $23.8 \mathrm{~kg} \cdot \mathrm{m}^{-2} \cdot \mathrm{s}^{-1}$. The angle of impact remained constant at $90^{\circ}$. SiC of 120 grit size was employed as the erodent.

Gas temperatures in the specimen chamber as well as the specimen temperature were displayed on the computer during all tests. Specimens were left in the apparatus until the 
temperature had stabilised to within $\pm 15^{\circ} \mathrm{C}$ of the control temperature. Readings were taken at the start and finish of a test and the average quoted as the test temperature. After blasting with the erodent, the specimen was allowed to remain in the specimen chamber until it was cold enough to be handled for weighing purposes.

\subsection{ABRASIVE WEAR TESTS}

The abrasive wear tests were carried out using the pin-on-belt apparatus, shown in figure 3.6. The specimen is locked in a bracket that could be loaded with a desired weight, and placed in contact with an abrasive belt. A motor drives the belt continuously in one direction, while the specimen bracket moves simultaneously across the belt perpendicular to the motion of the belt. In this way the specimen surface is continually exposed to fresh, dry abrasive for the duration of the test. The contact load, belt speed and type of abrasive can be varied.

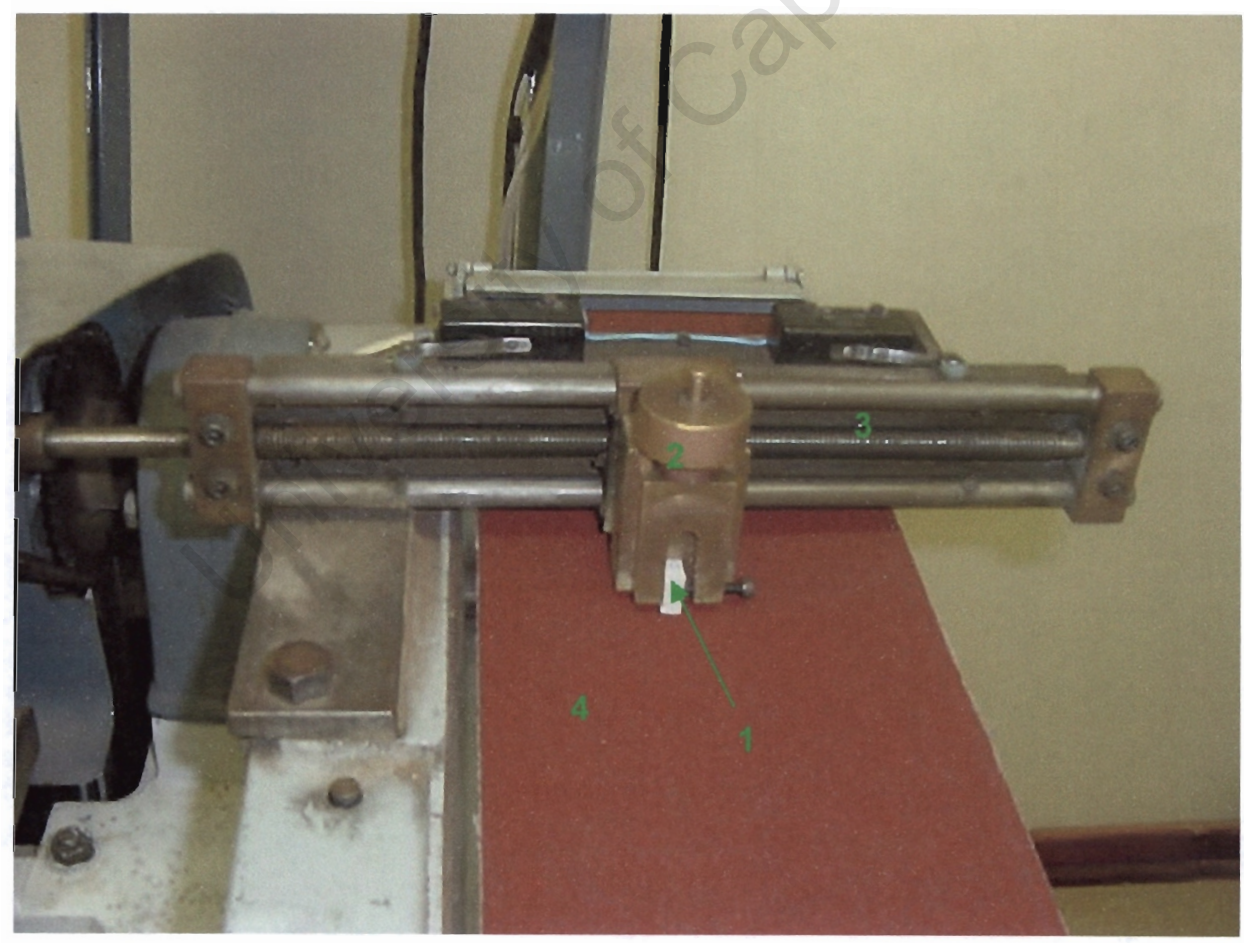

Figure 3.6: The room temperature pin-on-belt abrasion test rig. 1 - specimen, 2 - specimen bracket, 3 - the screw, 4 - abrasive belt.

During abrasion, the kinetic energy of the abrasive belt acts horizontally across the surface of the target material. Therefore, small differences in surface irregularities between target materials are likely to result in considerable differences in terms of abrasive wear rates. As 
a result, the specimens were polished to $1 \mu \mathrm{m}$ diamond finish prior to testing, cleaned in acetone to ensure testing under dry conditions and weighed. They were abraded against a bonded 80 grit $\mathrm{SiC}$ abrasive belt under a constant load of $30 \mathrm{~N}$. Each test consisted of three runs each with a tract length of $0.8 \mathrm{~m}$, with the belt running at a constant speed of $8 \mathrm{~cm} . \mathrm{s}^{-1}$. The dependence of abrasive wear on speed and load was determined by varying belt speeds from 8 to $45 \mathrm{~cm} . \mathrm{s}^{-1}$ and the contact loads from 15 to $40 \mathrm{~N}$. In addition, specimens were abraded against a bonded 80 grit alumina abrasive belt under a constant load and speed, to determine the dependence of their wear rates on the type of abrasive used. At predetermined distance intervals, the tests were interrupted for cleaning and weighing the specimen, and to replace the belt if necessary. This allowed determination of abrasive wear rates, measured as volume loss per abrasion distance. All the tests were conducted at room temperature.

\subsection{CHARACTERISATION OF WORN SURFACES}

The eroded and abraded surfaces of all specimens were examined using the SEM. In this case, however, the specimens were not subjected to any form of physical treatment prior to examination. SiC particulate composite tiles were also examined under the Leica MZ8 optical microscope, equipped with a camera.

000000000000 


\section{CHAPTER 4}

\section{RESULTS}

\subsection{MORPHOLOGICAL CHARACTERISATION}

\subsubsection{MORPHOLOGY OF ERODENT PARTICLES}

As mentioned earlier, three different erodent particles SiC, alumina and silica sand, were employed in this study. It is evident from the SEM micrographs in figure 4.1 that both the $\mathrm{SiC}$ and alumina particles are very angular, as opposed to the fairly rounded edges of silica sand particles. By comparison the fly ash, which is the main cause of erosive wear damage in power plants, exists as very small, rounded particles.
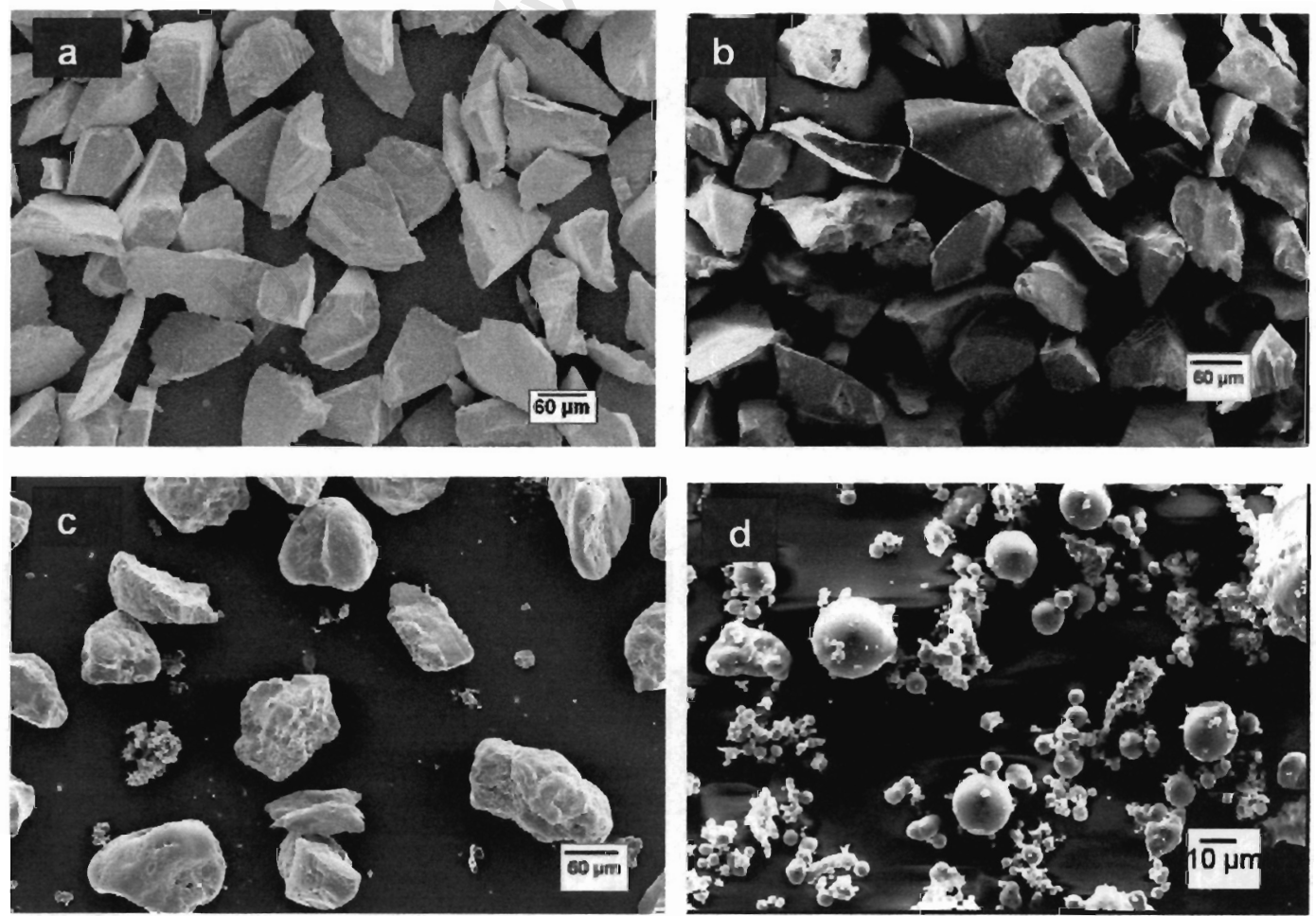

Figure 4.1: SEM micrographs of erodent particles. Note (a) the angular SiC particles, (b) angular alumina particles, (c) round-edged silica sand particles and (d) rounded fly-ash particles. Note the differences in scales. 


\subsubsection{MORPHOLOGY OF TARGET MATERIALS}

\subsubsection{Scanning Electron Microscopy}

The morphological characterisation of target materials was carried out using SEM. The materials are clearly characterised by an anisotropic shape of grains as shown in figure 4.2. A plot of the average grain sizes of individual materials is shown in figure 4.3. Since the materials have average grain sizes in the range 3.81 to $5.06 \mu \mathrm{m}$, they were, according to Dogan and Hawk's classification scheme, classified as fine-grained (average grain size $\leq$ $5 \mu \mathrm{m}$ ) or medium grained (between $5 \mu \mathrm{m}$ and $20 \mu \mathrm{m})^{28}$. The average grain sizes suggest that all the target materials are fine grained. However, the error bars in figure 4.3 suggests that this information may be misleading as there is clearly an overlap in grain sizes, which makes the materials not significantly different from one another. It must also be mentioned that care must be taken in using this classification scheme as there are clearly some grains that differ significantly from the average grain size.

XEDS analysis of the materials reveals the dominance of $\mathrm{Al}$ and $\mathrm{O}$ in all the grains. As figure 4.4 shows, some grains in MP96 also contain significant amounts of magnesium (Mg) and these are probably spinel $\left(\mathrm{MgAl}_{2} \mathrm{O}_{4}\right)$ grains. The occurrence of such grains has also been observed in other commercial alumina ceramics ${ }^{23}$. Other grains in M90 contain, in addition to alumina, significant amounts of silicon. These grains are likely to be mullite $\left(\mathrm{Al}_{4} \mathrm{Si}_{2} \mathrm{O}_{10}\right)$, which is known to be made up of approximately $64.8 \% \mathrm{Al}_{2} \mathrm{O}_{3}$ and $35.2 \% \mathrm{SiO}_{2}$. Most of the non-alumina components added during processing of high alumina ceramics combine to form the boundary phase, which is a silicate glassy phase in most cases. However, there is no evidence of a silicate glassy phase in these materials but its precense cannot be ruled out. 

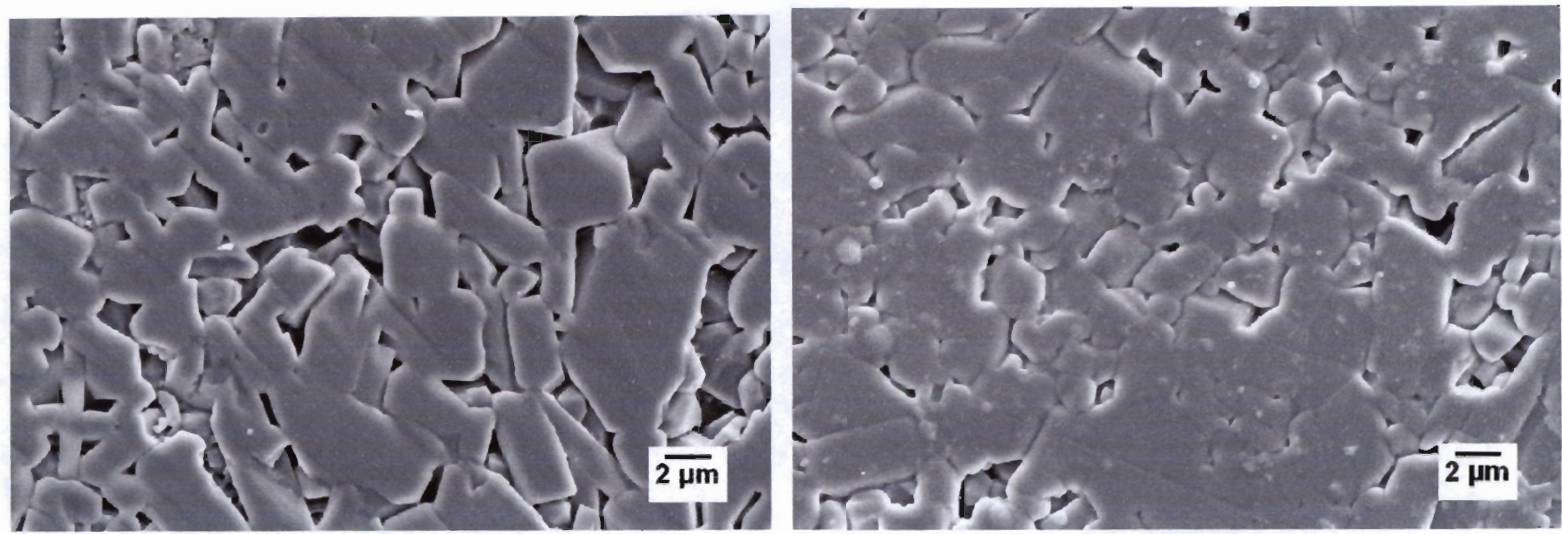

M90

MP92

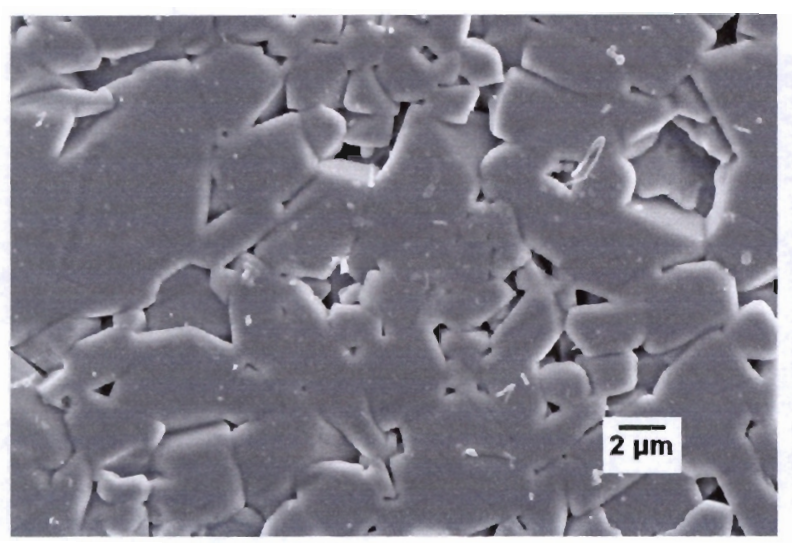

M94

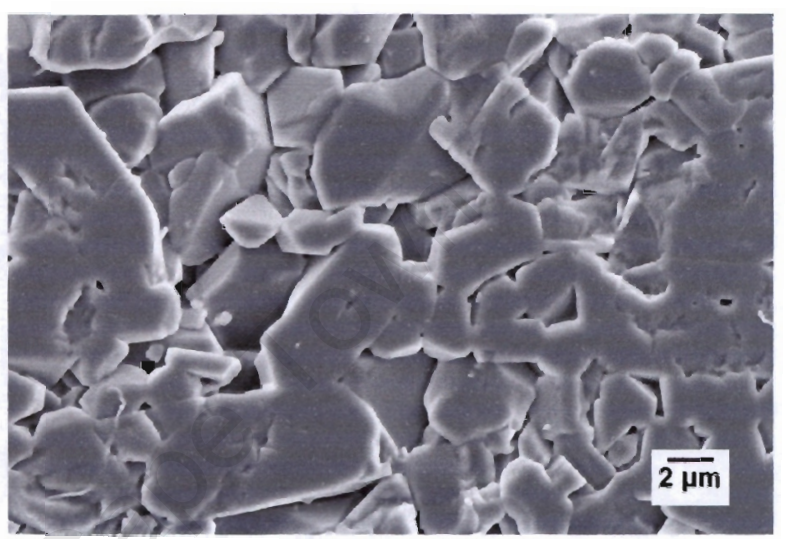

MP96

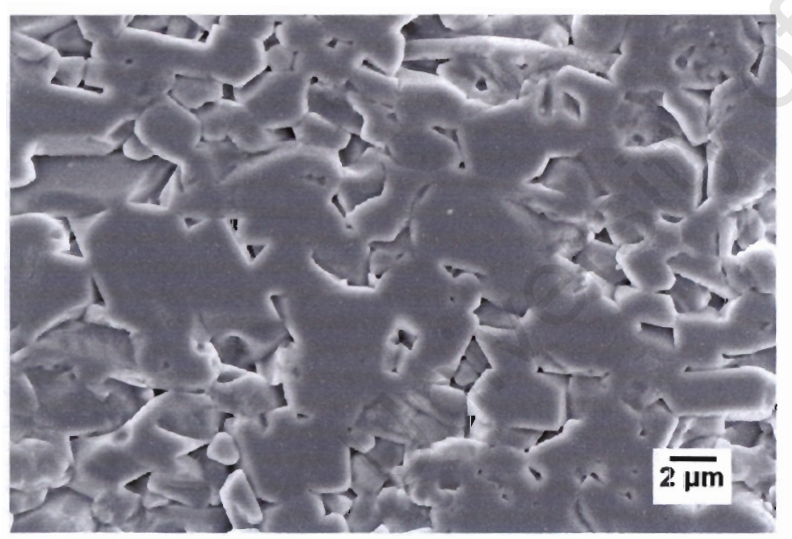

M97

Figure 4.2: SEM micrographs of polished and chemically etched surfaces of alumina samples. 


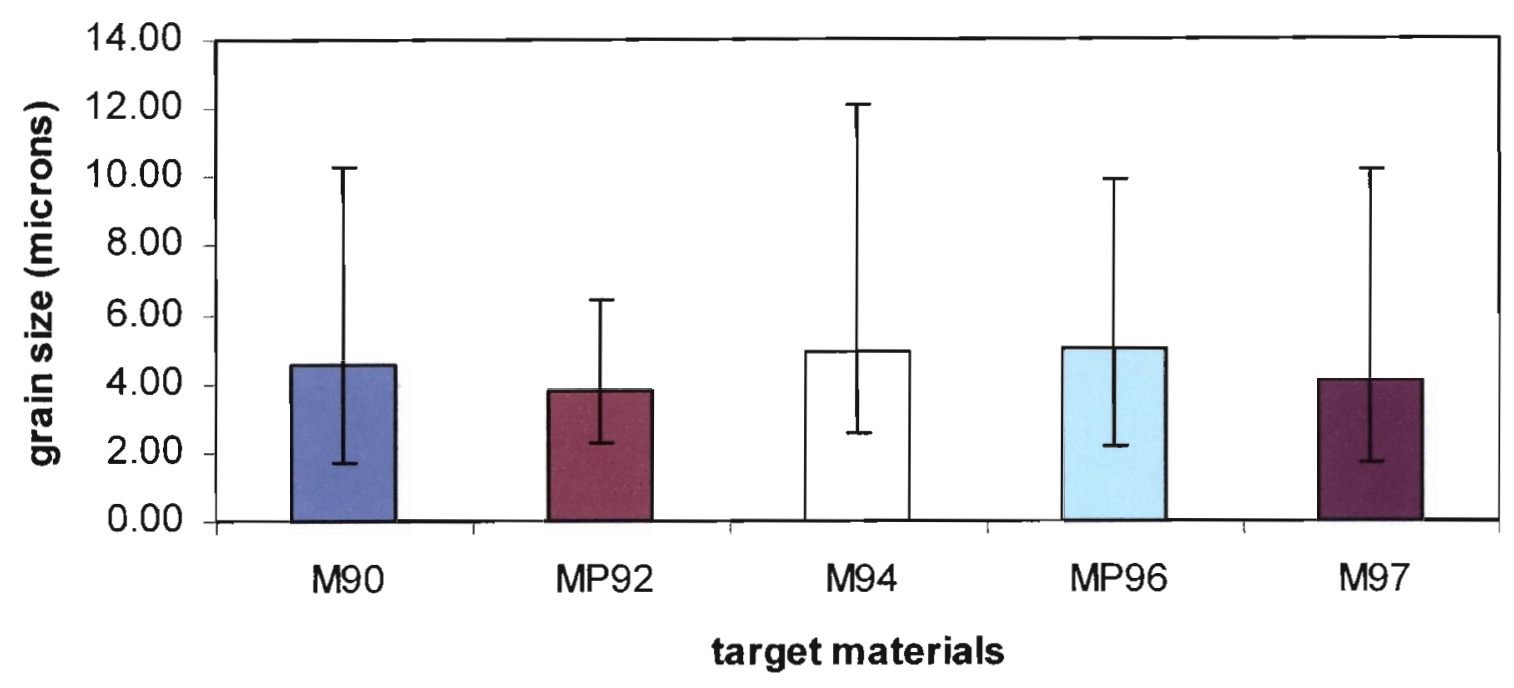

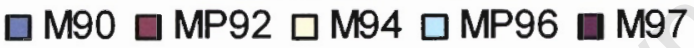

Figure 4.3: The measured average grain sizes for different alumina materials. The error bars indicate maximum and minimum grain sizes measured.
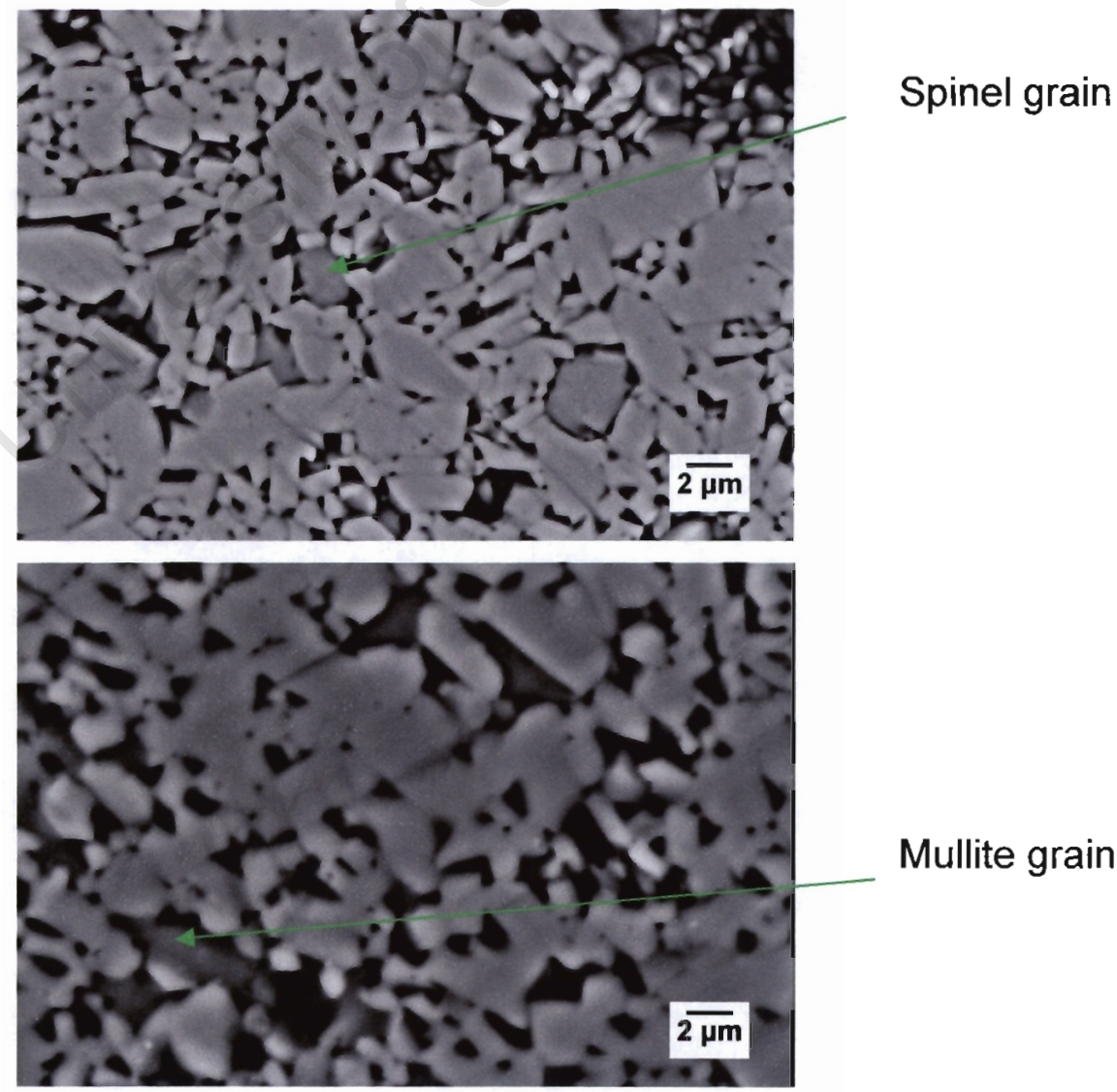

Mullite grain

Figure4.4: BSED images showing some representative features of the specimens. Light cloloured grains are alumina grains, while dark regions are holes or pores 


\subsubsection{X-RAY FLOURESCENCE SPECTOMETRY (XRF)}

Following the similar microstructural characteristics obtained for the target materials, XRF analysis was performed on only two target materials. Such materials were chosen as the two extremes in terms of the $\mathrm{Al}_{2} \mathrm{O}_{3}$ content so that reasonable generalisations could be made. Thus, only M90 and M97 were analysed and the results are tabulated below. The materials are dominantly made up of $\mathrm{Al}_{2} \mathrm{O}_{3}$ as expected, with the remaining portion made up of mainly $\mathrm{SiO}_{2}, \mathrm{MgO}$ and $\mathrm{Na}_{2} \mathrm{O}$. However, it is not clear whether the last three oxides occur as separate phases or are embedded in alumina grains. The presence of other oxides other than $\mathrm{Al}_{2} \mathrm{O}_{3}$ is the result of the typical addition of non-alumina components during the processing of high-alumina ceramics. However, such oxides are present in negligible amounts and therefore are unlikely to have any effect on the physical properties and subsequent wear behaviour of the target materials. $\mathrm{H} 2 \mathrm{O}$ - is moisture lost at $110^{\circ} \mathrm{C}$ while $\mathrm{LOI}$ is loss on ignition at $850^{\circ} \mathrm{C}$.

Table 4.1: Major oxides composition of both $M 90$ and $M 97$ as determined by XRF analyses.

\begin{tabular}{|l|c|c|}
\hline \multicolumn{1}{|c|}{ Major Oxides (wt. \%) } & M90 & M97 \\
\hline $\mathrm{SiO}_{2}$ & 7.266 & 2.074 \\
\hline $\mathrm{Al}_{2} \mathrm{O}_{3}$ & 90.087 & 96.018 \\
\hline $\mathrm{TiO}_{2}$ & 0.116 & 0.057 \\
\hline $\mathrm{Fe}_{2} \mathrm{O}_{3}$ & 0.170 & 0.145 \\
\hline $\mathrm{MnO}$ & 0.030 & 0.021 \\
\hline $\mathrm{MgO}$ & 1.656 & 0.627 \\
\hline $\mathrm{CaO}$ & 0.157 & 0.069 \\
\hline $\mathrm{Na}_{2} \mathrm{O}$ & 0.274 & 0.772 \\
\hline $\mathrm{K}_{2} \mathrm{O}$ & 0.185 & 0.102 \\
\hline $\mathrm{P}_{2} \mathrm{O}_{5}$ & 0.004 & 0.008 \\
\hline $\mathrm{SO}_{3}$ & 0.016 & 0.022 \\
\hline $\mathrm{Cr}_{2} \mathrm{O}_{3}$ & 0.018 & 0.020 \\
\hline $\mathrm{NiO}$ & 0.007 & 0.010 \\
\hline & & \\
\hline $\mathrm{H}_{2} \mathrm{O}-$ & 0.045 & 0.046 \\
\hline $\mathrm{LOI}$ & 0.093 & 0.046 \\
\hline & & \\
\hline $\mathrm{Total}$ & 100.125 & 100.039 \\
\hline
\end{tabular}




\subsubsection{Wide Angle X-ray Diffraction}

Figure 4.4 depicts the $x$-ray diffractograms that were obtained for the different alumina grades. It is clear that almost the same pattern was obtained for all the materials, the only difference being the relative intensity of the peaks. All the materials are dominantly made up of the crystalline phase, corundum $\left(\mathrm{Al}_{2} \mathrm{O}_{3}\right)$, and a small amount of iron oxide $\left(\mathrm{Fe}_{3} \mathrm{O}_{4}\right)$. These results are consistent with those from XRF analysis, which suggest the presence of significant amounts of $\mathrm{SiO}_{2}$ and very little iron oxide. Interestingly, the scans do not show any evidence of any Si-rich or Mg-rich phases. It is therefore possible that the Si-rich phase is either amorphous or present in very small amounts, as would be expected in alumina ceramics.

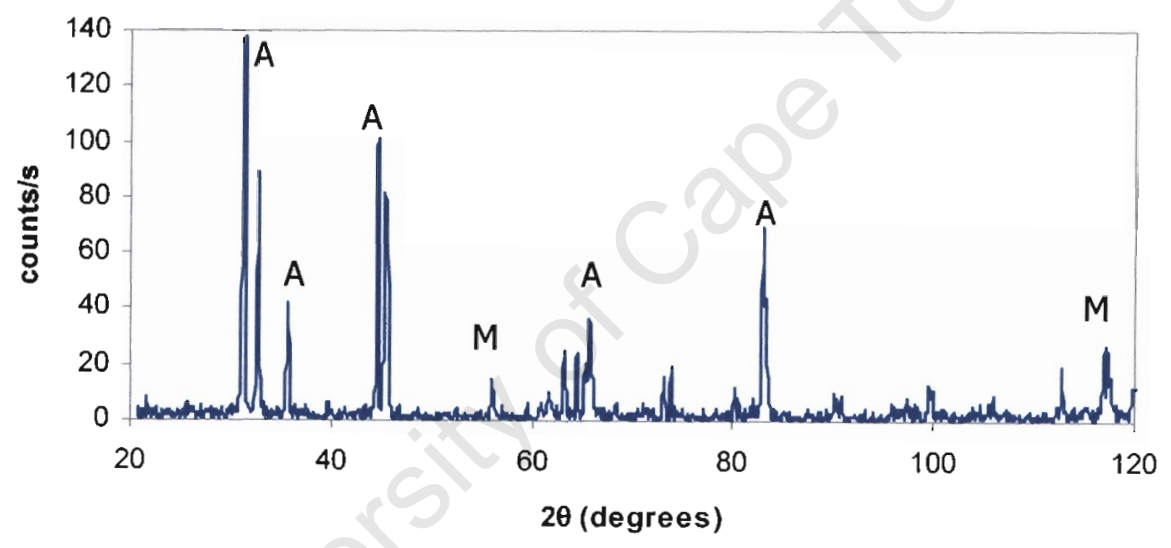

M90

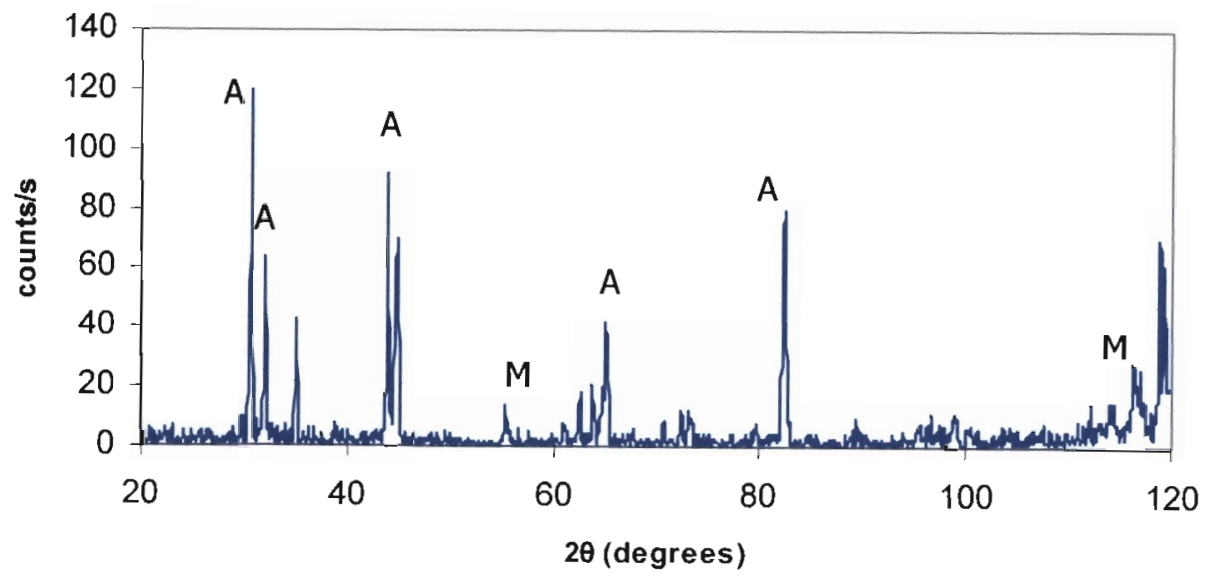




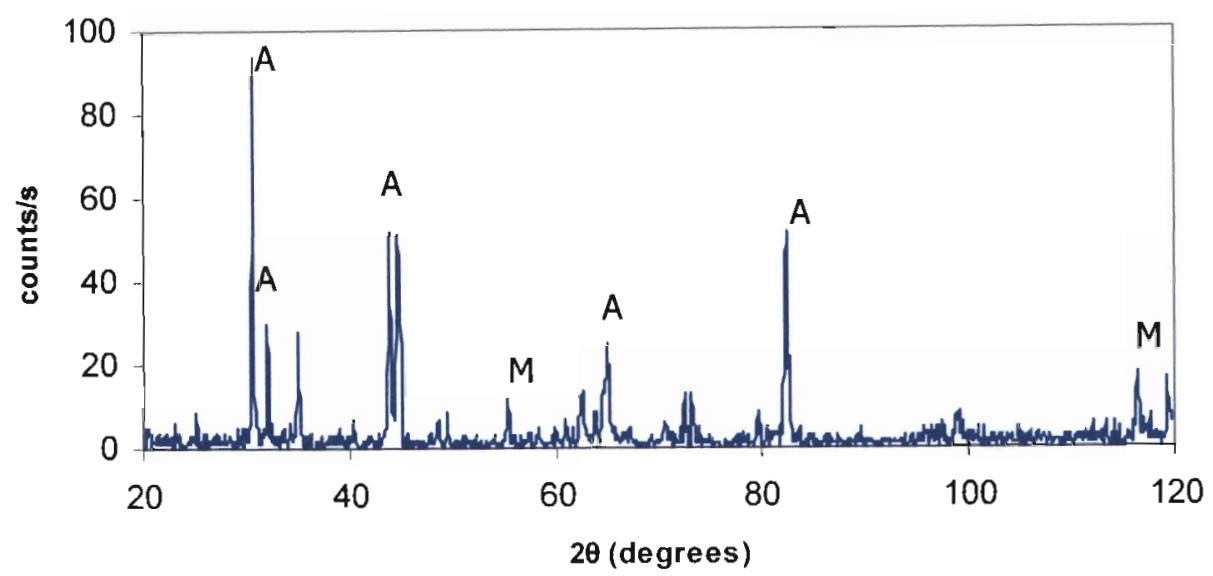

M94

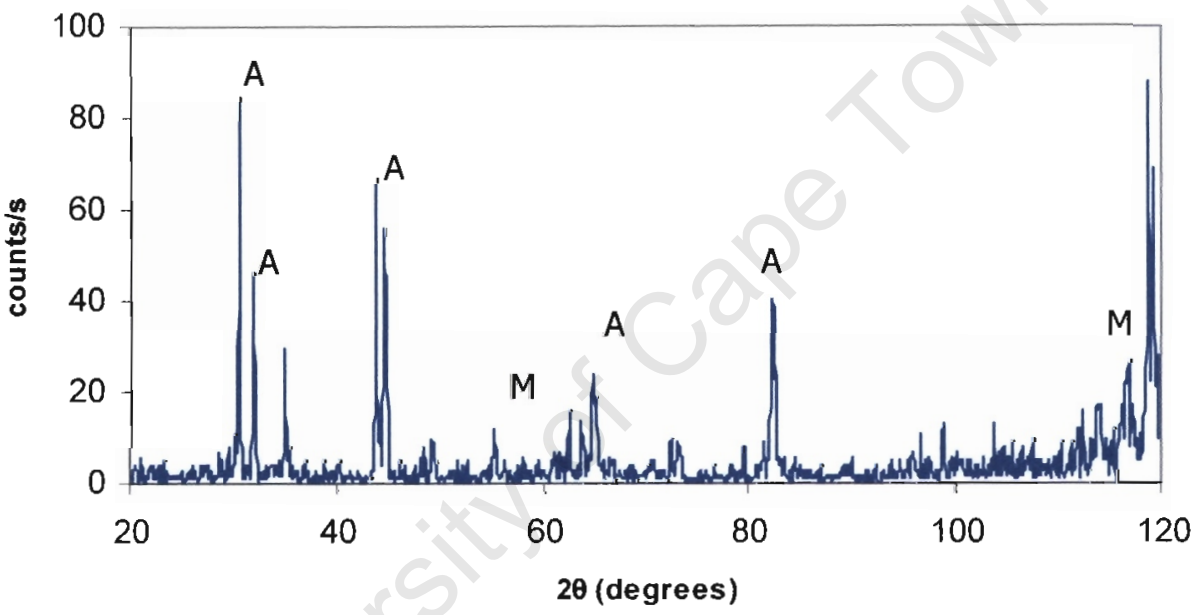

MP96

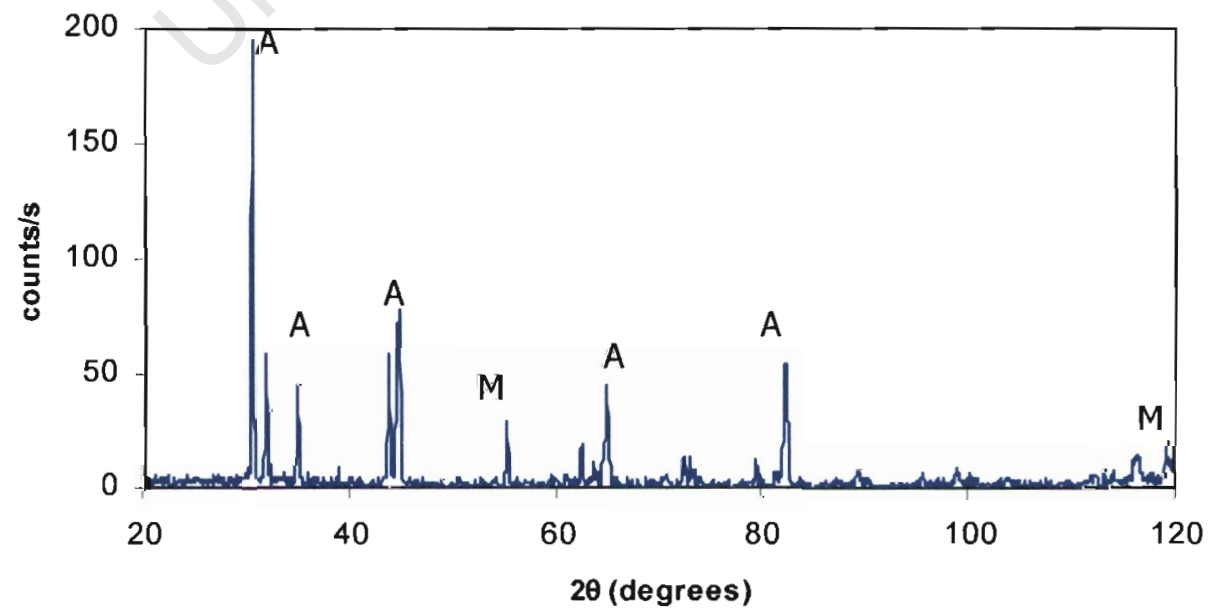

M97

Figure 4.4: XRD diffractograms of the target materials. $A=$ alumina, $M=$ magnetite. 


\subsection{PHYSICAL AND MECHANICAL PROPERTIES}

\subsubsection{DENSITY}

The bulk density of the target materials was determined from specimen dimensions and mass. In the case of alumina ceramics, the results were compared with those supplied by the manufacturer. As figure 4.5 shows, no significant differences between the alumina ceramics can be noted, with all the tested materials having densities of between 3.0 and 4.0 $9 . \mathrm{cm}^{-3}$. This is in agreement with the data supplied by the manufacturer. The two SiC-based composites have comparatively lower densities of less than $3.0 \mathrm{~g} \mathrm{~cm}^{-3}$, but there is also no significant difference between them.

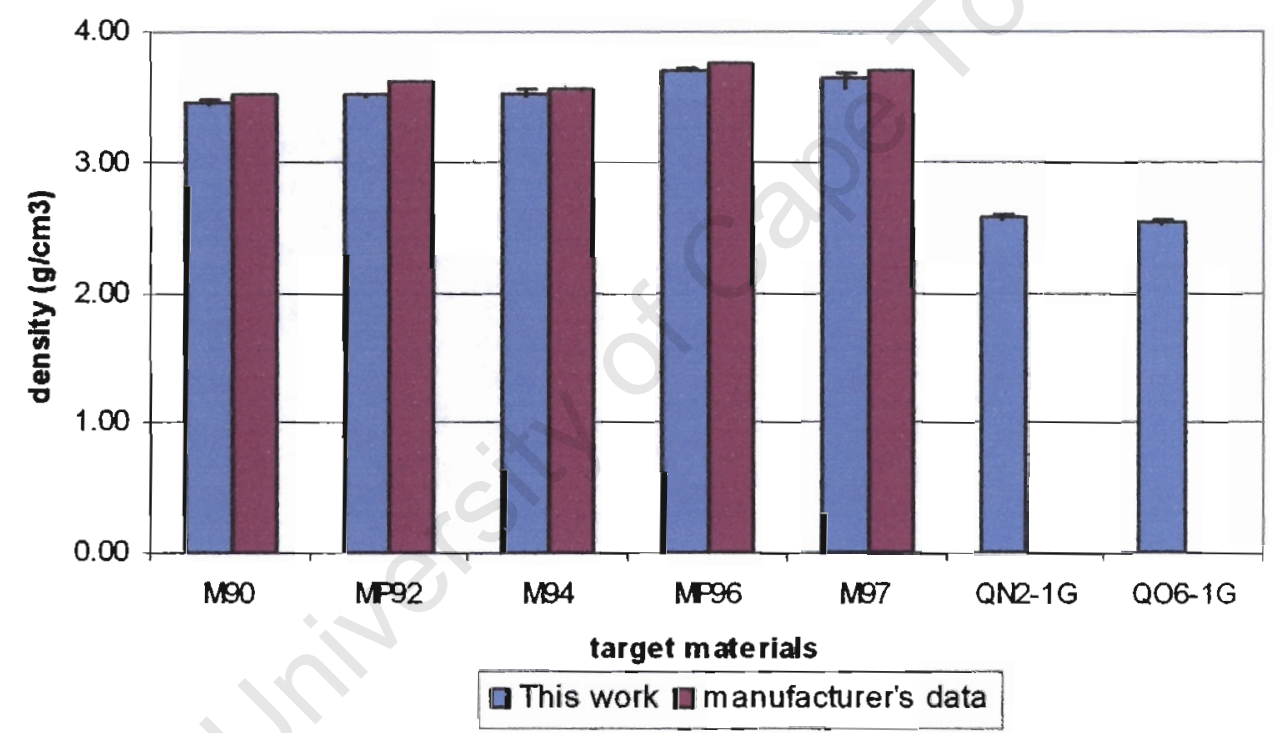

Figure 4.5: A comparison between density values determined in this study and the data supplied by the manufacturer. In this study the values obtained are an average of five measurements.

\subsubsection{HARDNESS AND FRACTURE TOUGHNESS}

Vickers macro-hardness values depicted in figure 4.6 suggest that the five alumina grades may be divided into two groups. One group comprises both M90 and MP92, which have values of less than 1200. All the other three grades have HV values of more than 1200 . Within each each group, error bars suggest that there is an overlap in the experimental values, hence there are no significant differences between the individual grades. 


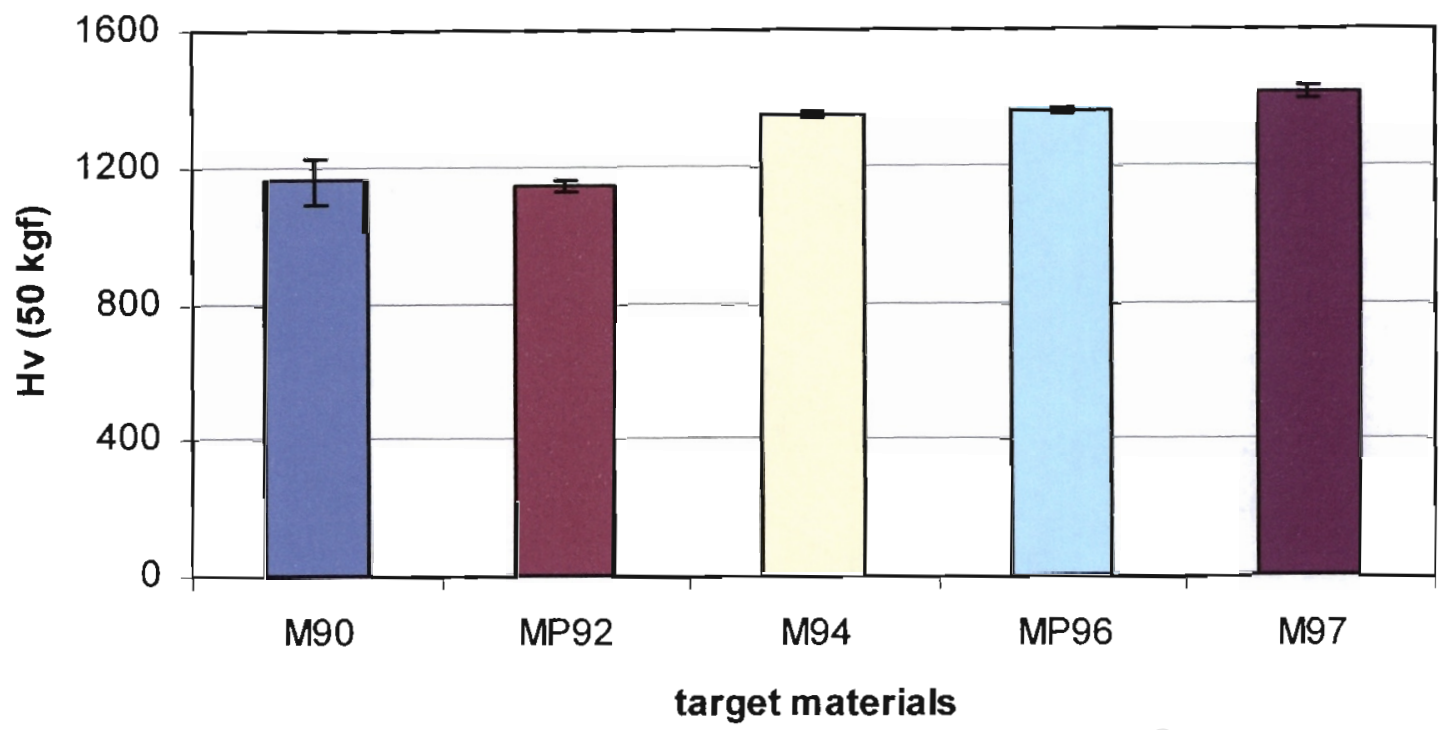

Figure 4.6: Vickers macro-hardness values obtained as an average of ten measurements.

Fracture toughness values were supplied by the manufacturer and all the values are partitioned between 2.6 and $3.5 \mathrm{MN} . \mathrm{m}^{-3 / 2}$. M90 has the lowest fracture toughness value at

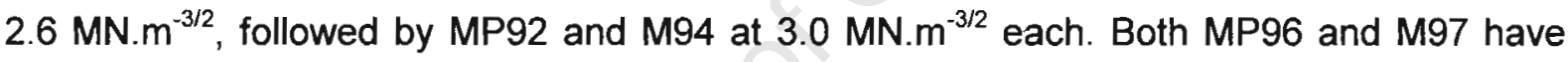
the highest values at $3.5 \mathrm{MN} \cdot \mathrm{m}^{-3 / 2}$ each. However, the lack of statistical data makes it impossible to decide whether the values are significantly different or not.

\subsubsection{THREE-POINT BEND TESTS}

The three-point bending tests were carried out in order to determine the dependence of the wear rate on the flexural moduli $\left(E_{f}\right)$ and flexural strengths $\left(\sigma_{f}\right)$ of the materials. The tests were performed on all five alumina grades and two SiC-based composites. All the specimens were tested to failure i.e. until fracture, and they all displayed an approximate linear stress-strain behaviour up to the point of fracture as shown in figure 4.7. The calculated values of flexural moduli $\left(E_{f}\right)$ and flexural strengths $\left(\sigma_{f}\right)$ are depicted graphically in figure 4.8. Once again, the data depicted in the above graph shows a lot of scatter and a high degree of overlapping. M97, for example, has a set of flexural moduli measurements ranging from less than $100 \mathrm{MPa}$ to more than $300 \mathrm{MPa}$. The two SiC-based composites clearly have the lowest values of flexural strengths, but their flexural moduli values compare reasonably well to those of the alumina ceramics. 


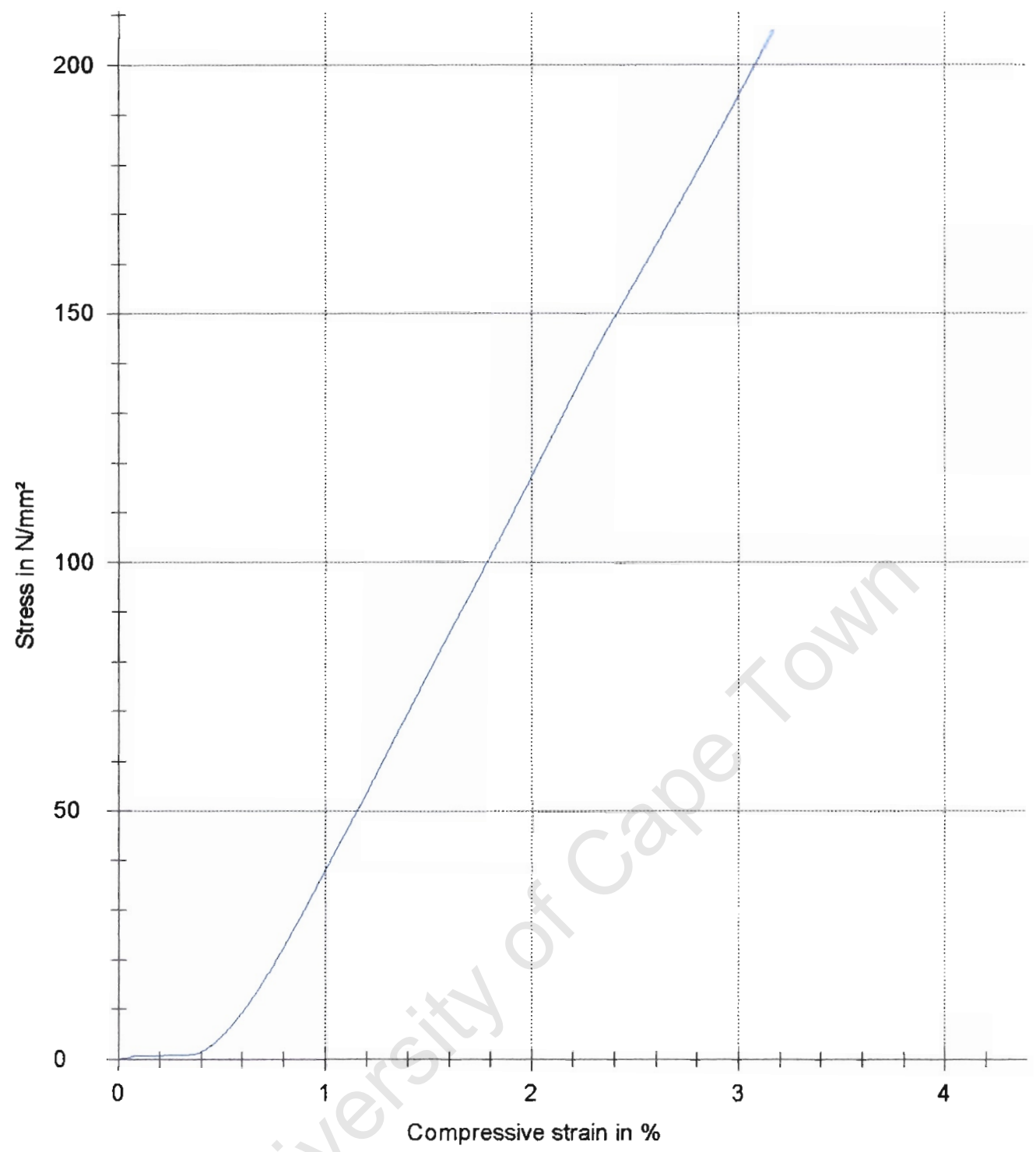

Figure 4.7: The typical trace obtained from three point bend tests. All the target materials displayed an approximate linear stress-strain behaviour up to the point of fracture. 


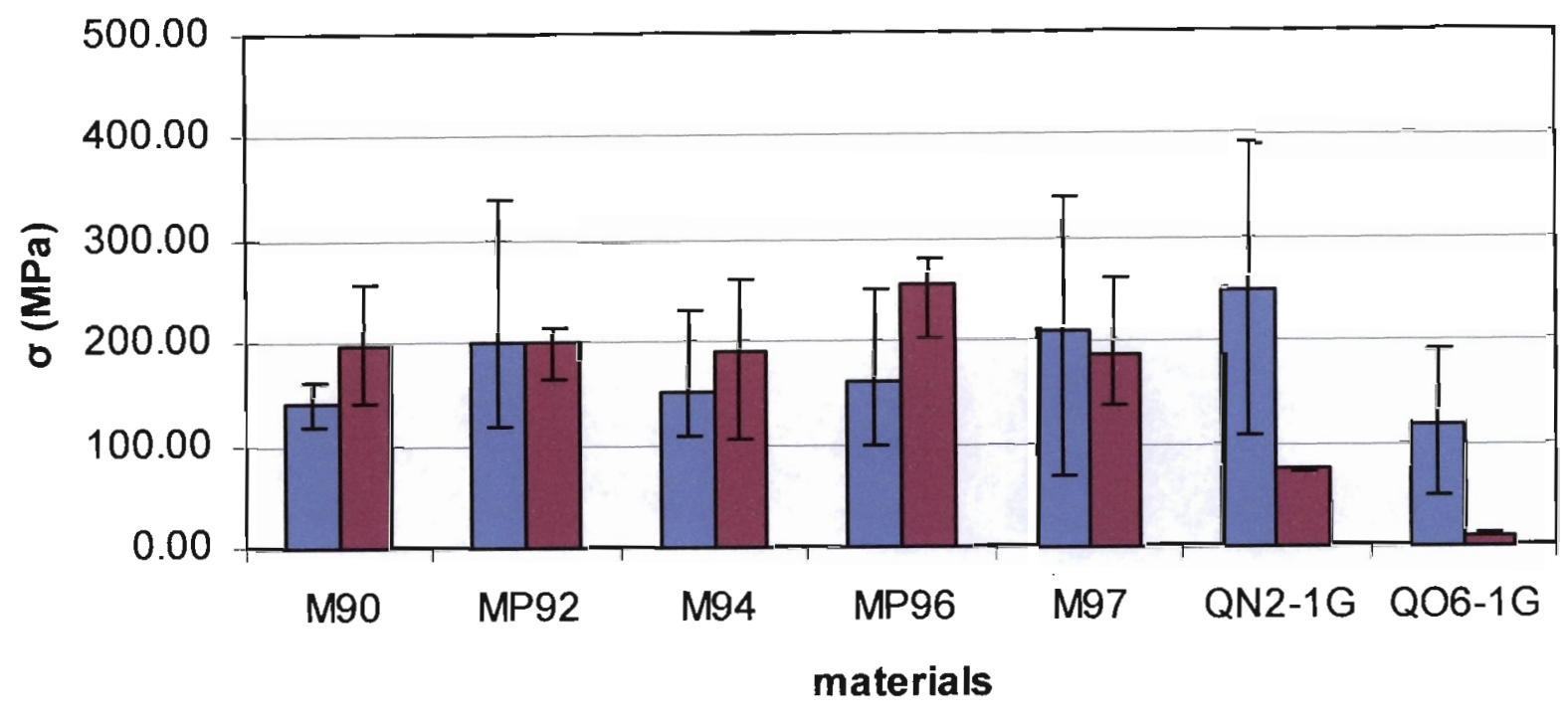

$\square E f \square$ of

Figure 4.8: Elastic moduli $\left(E_{f}\right)$ and flexural strengths $\left(\sigma_{f}\right)$ of target materials as calculated from threepoint bending tests.

\subsection{SOLID PARTICLE EROSIVE WEAR}

\subsubsection{THE EFFECT OF IMPACT ANGLE}

Figure 4.9 shows the dependence of erosion rate $(W)$ of all target materials on the impact angle. The materials were eroded with $\mathrm{SiC}$ at an impact velocity of $50 \mathrm{~m} . \mathrm{s}^{-1}$. All the materials exhibited a linear relationship between the volume loss and the mass of the erodent used (see for example Appendix I). The erosion rates were subsequently calculated from the slopes of the straight lines. It is clear from the figure that the erosion rates of all target materials increase with the impact angle, reaching a maximum at $90^{\circ}$. However, at each of the five impact angles, the erosion rates are not significantly different from one another. At each angle, the difference between the least and most erosion resistant materials is less than $20 \%$. It is also interesting to note that doubling the impact angle from $45^{\circ}$ to $90^{\circ}$ also increases the erosion rate by a factor of approximately two. 


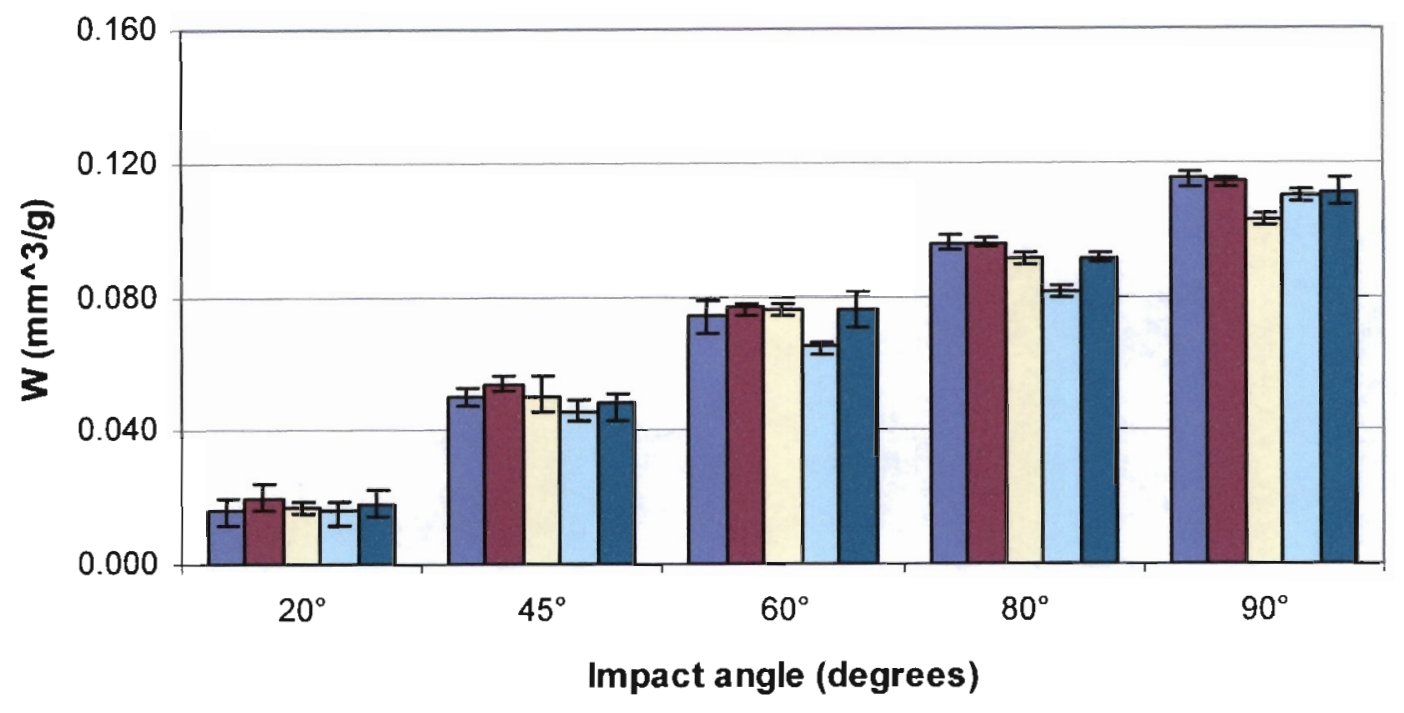

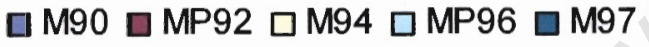

Figure 4.9: Variation of erosion rate as a function of impact angle. The tests were conducted at an impact velocity of $50 \mathrm{~m} \cdot \mathrm{s}^{-1}$.

It is interesting to note that at all the impact angles tested, MP92 appears to have the highest average erosion rate, but error bars suggest insignificant differences between the erosion rates of the target materials. On the other hand, MP96 seems to have the lower average erosion rate at $60^{\circ}$ and $80^{\circ}$, whereas at $90^{\circ} \mathrm{M} 94$ has the lowest average rate. M90 appears to have lowest average erosion rates at lowest angles of impact, but its resistance decreases at higher angles. The two slip cast materials, M94 and M97, have the same average erosion rates at $60^{\circ}$ and $80^{\circ}$, while M90 and MP96 have the same average erosion rates at $20^{\circ}$ angle of impact. This indicates the similarities that exist between the materials in terms of erosion behaviour.

\subsubsection{THE EFFECT OF IMPACT VELOCITY}

The variation of erosion rate with impact velocity was studied under normal impact conditions. Following the similar behavioural pattern displayed by the target materials at the studied angles of impact, it was inferred that any grade tested would be representative of the other four grades and therefore reasonable generalisations can be made. As a result, only MP92 was randomly chosen and studied in this case. The results are depicted in figure 4.10. 


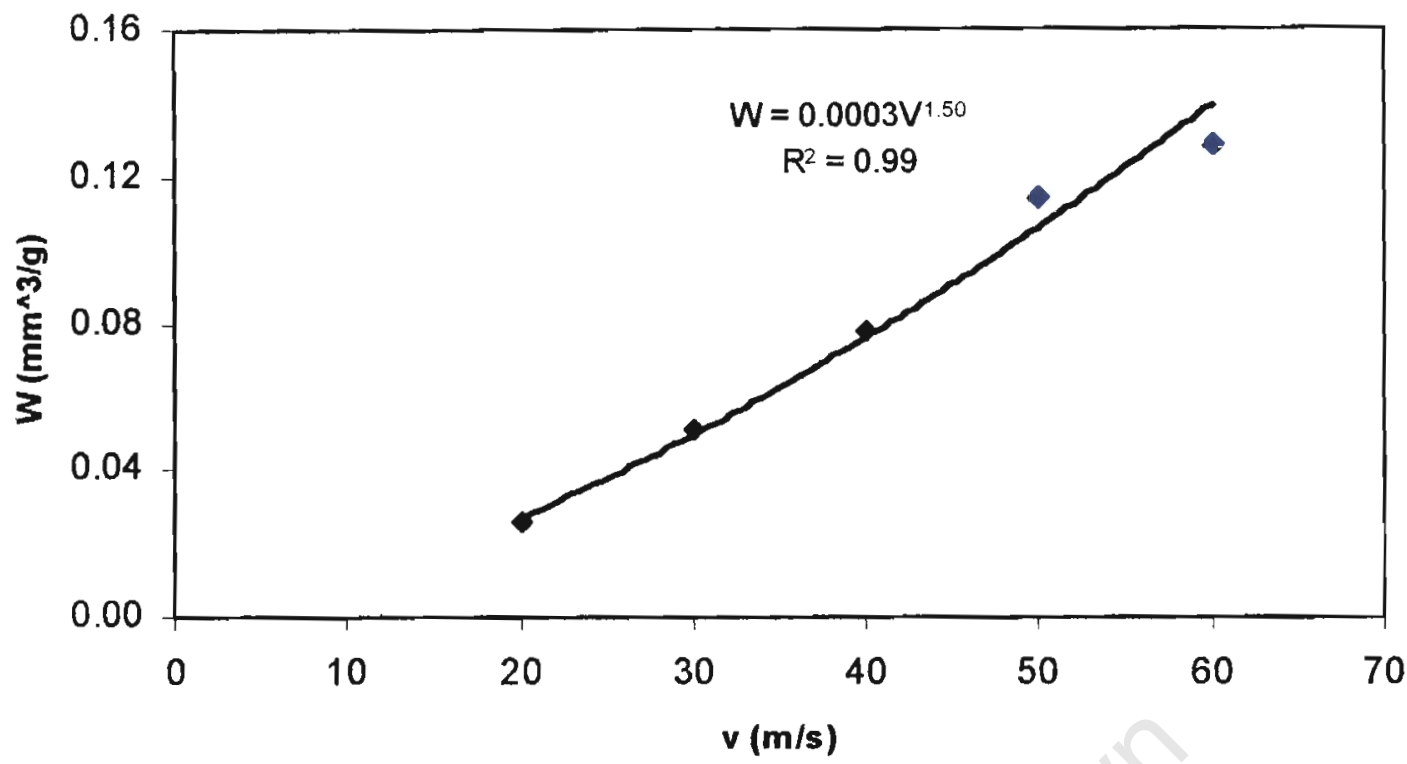

Figure 4.10: Variation of erosion rate of MP92 as a function of impact velocity under normal impact.

It is evident that the erosion rate increases with the impact velocity, with a good correlation coefficient $\left(R^{2}\right)$ of 0.99 . The curve predicts an uncommonly low velocity exponent of 1.50 according to the power law relationship:

$$
W=3 \times 10^{-4} v^{1.50}
$$

\subsubsection{THE EFFECT OF ERODENT PARTICLE TYPE}

In order to study the dependence of erosion rates on erodent particle hardness, the target material was impacted with silica sand and alumina at $90^{\circ}$ and the results were compared with the material response after impact with $\mathrm{SiC}$ particles. In this case, the target material

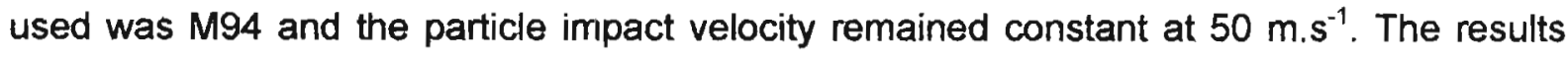
depicted in figure 4.11 indicate that the softer silica sand erodent particles give rise to very low erosion rates as opposed to more damage inflicted by the harder SiC particles. In fact, the erosion rate due to $\mathrm{SiC}$ particles is ten times more than that caused by silica sand. The wear rate due to alumina erodent particles lies between those due to SiC and silica sand. 


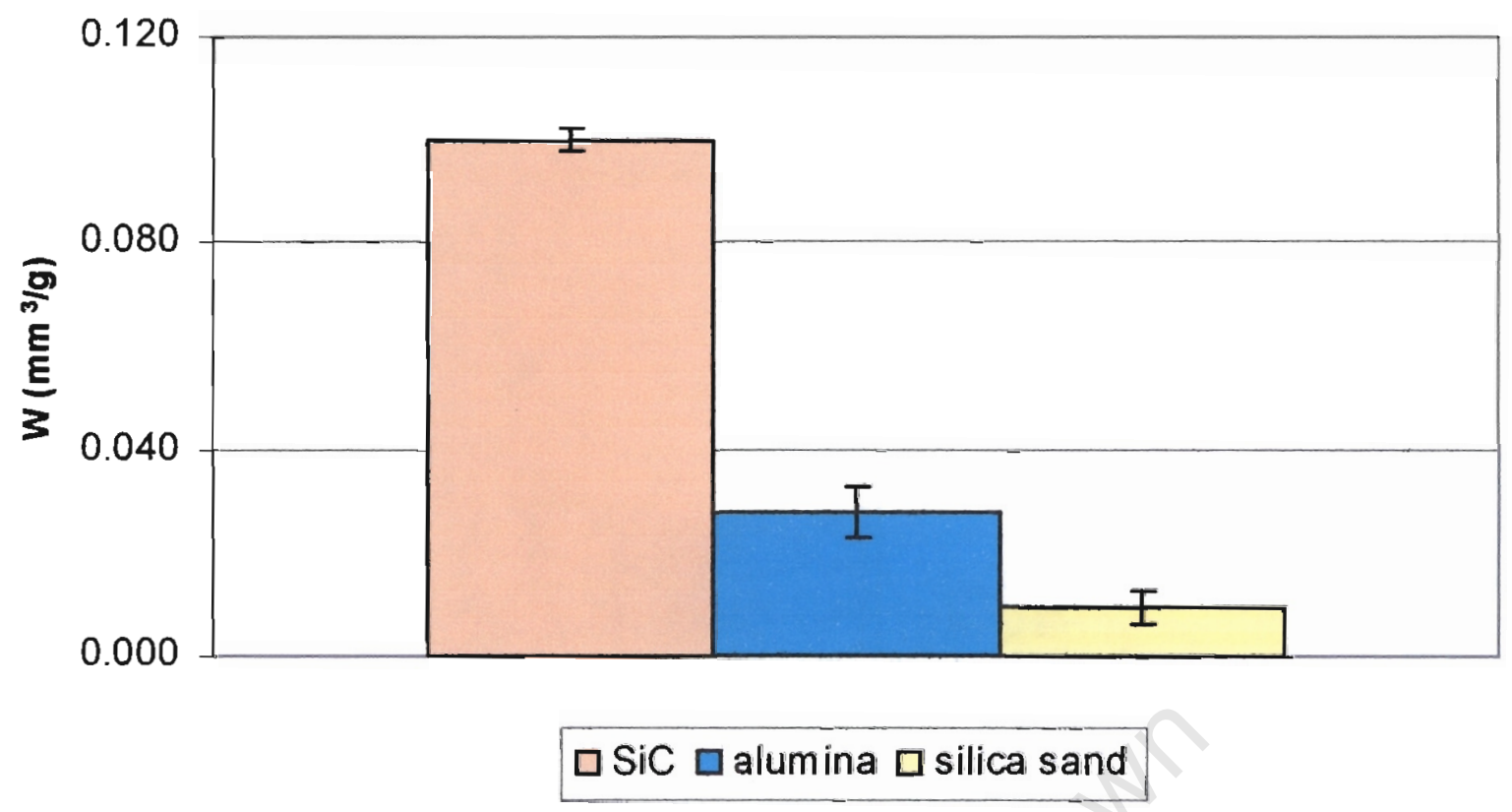

Figure 4.11: The variation of erosion rate as a function of different erodent particles at an impact velocity of $50 \mathrm{~m} . \mathrm{s}^{-1}$ under normal impact.

Such results are a good confirmation of the relative hardness of the three erodent particles and thus give a good indication of the relative friability of such particles, as SEM micrographs in figure 4.12 indicate. As expected, both $\mathrm{SiC}$ and alumina particles show negligible fragmentation after impact. With silica sand particles, a considerable amount of fragmentation is observed after impact. 


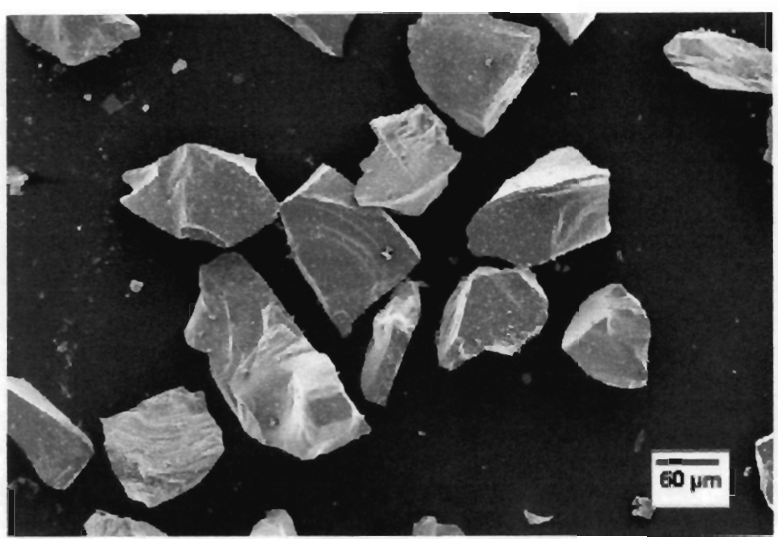

(a)

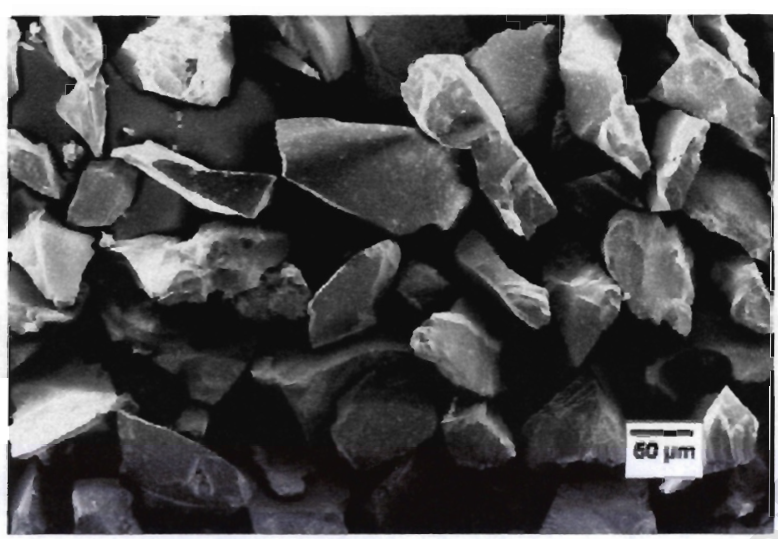

(b)

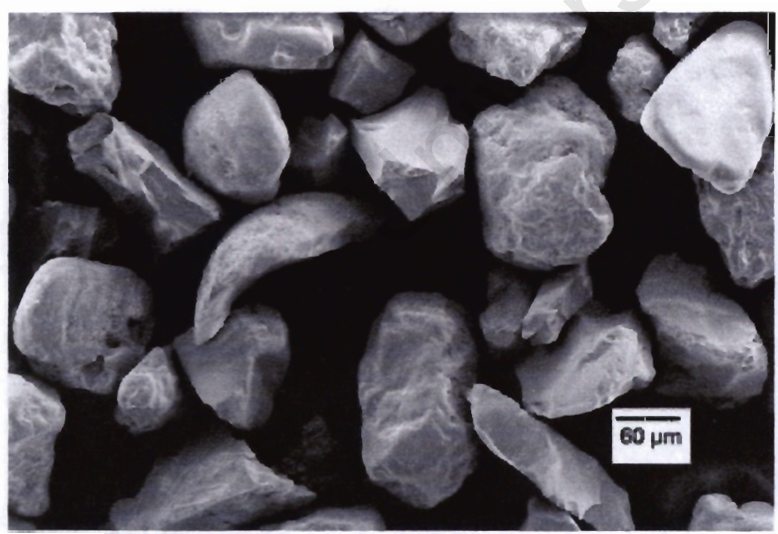

(e)

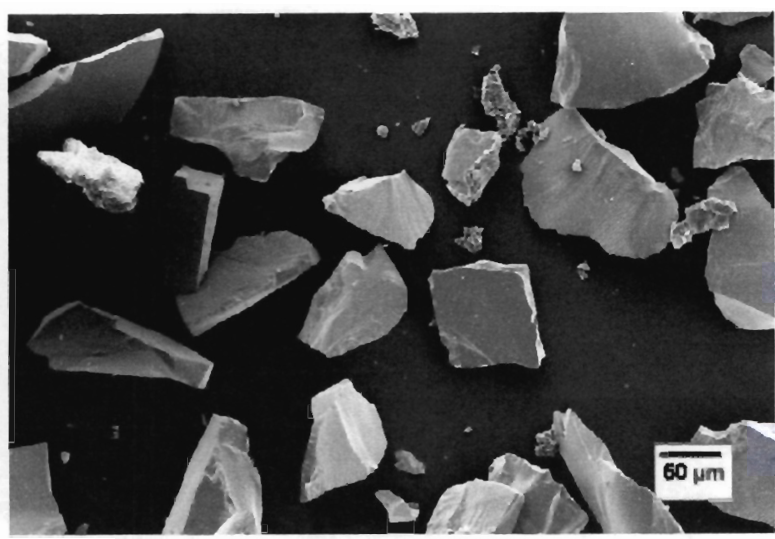

(b)

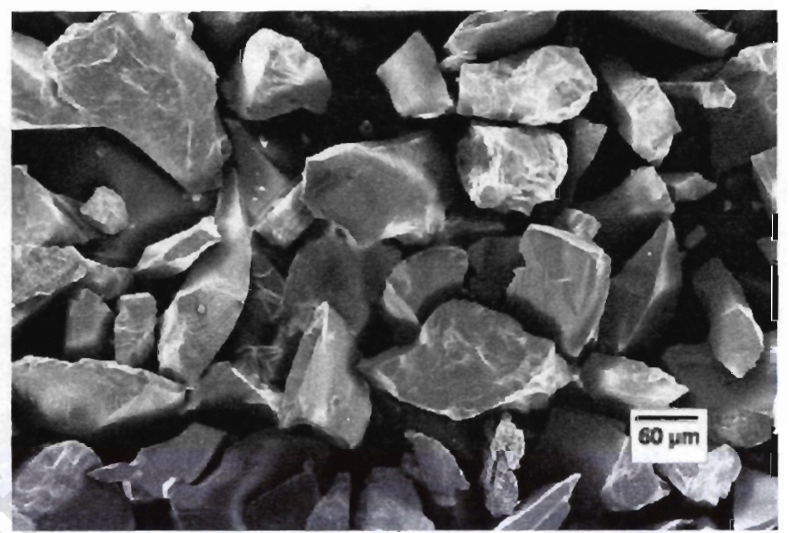

(d)

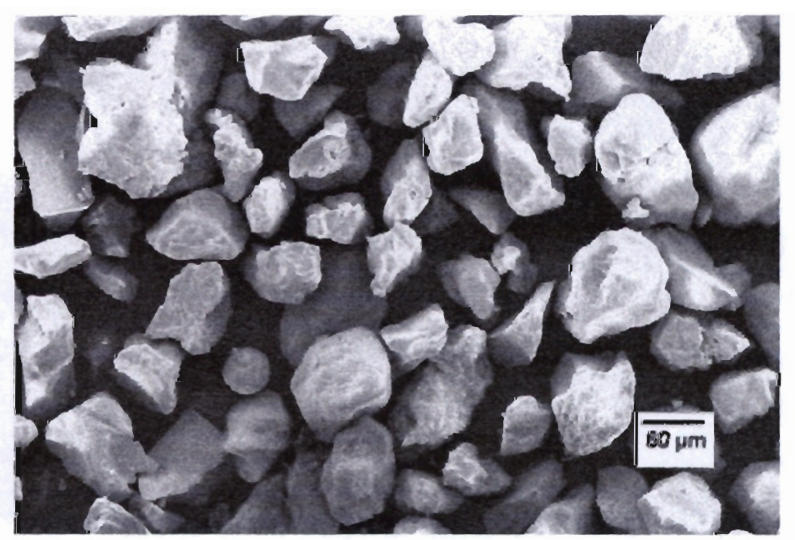

(f)

Figure 4.12: A comparison of the morphology of erodent particles before and after impact. (a), (c) and (e) are SiC, alumina and silica sand, respectively before impact, while (b), (d) and (f) are the respective erodent particles after impact. Silica sand particles show a considerable amount of fragmentation after impact. 
Silica sand was also used to compare the erosion rates of the two SiC-based composites with those of alumina ceramics and the results are depicted in figure 4.13. Clearly, the alumina ceramic is the most erosion resistant of the three materials by virtue of having the lowest erosion rate.

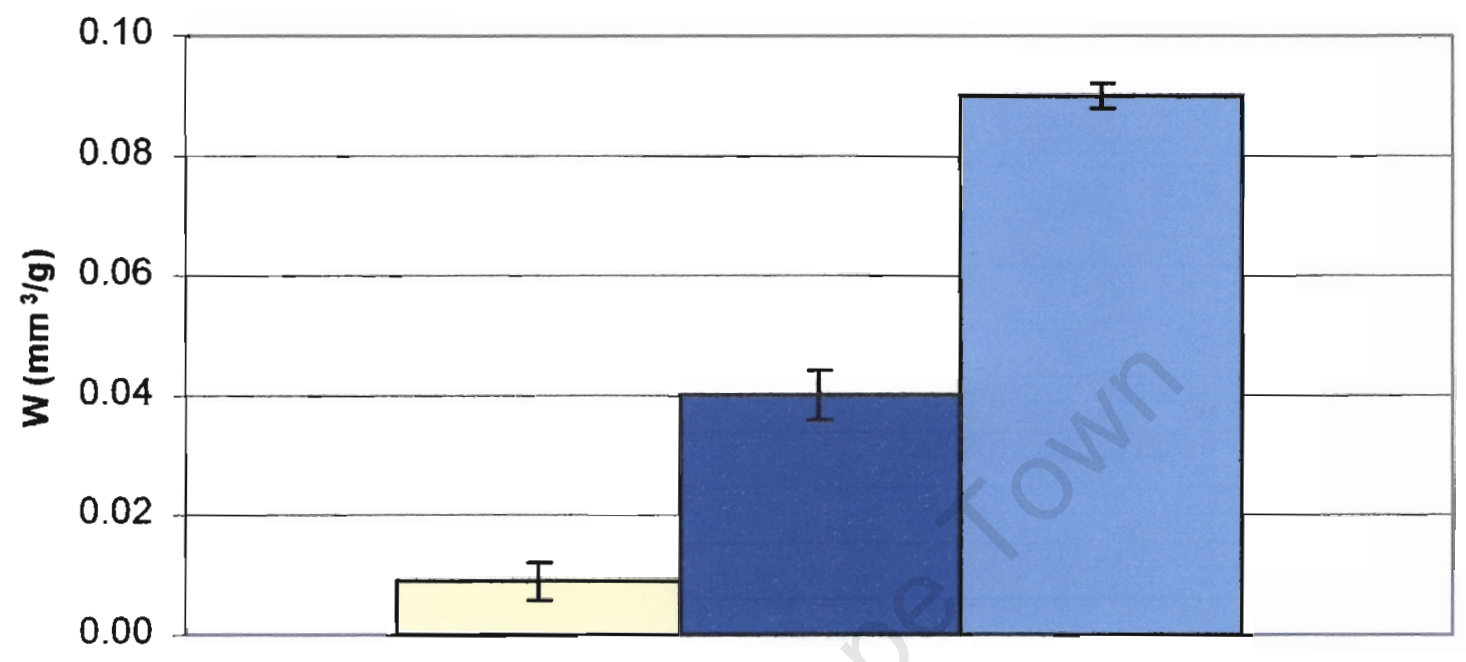

$\square$ M94 $\square$ QO6-1G $\square$ QN2-1G

Figure 4.13: A comparison of the erosion rates of SiC-based composites (QO6-1G and QN2-1G) and alumina ceramic (M94).

\subsubsection{THE EFFECT OF ERODENT PARTICLE SIZE}

The variation of erosion rate with erodent particle size was investigated by performing tests using three different sizes of silica sand. Such size ranges were $63-106 \mu \mathrm{m}, 106-125 \mu \mathrm{m}$ and $125-180 \mu \mathrm{m}$. All the tests were performed on M94 only under normal impact conditions at a particle velocity of $50 \mathrm{~m} . \mathrm{s}^{-1}$. The results of such tests are depicted in figure 4.14. 


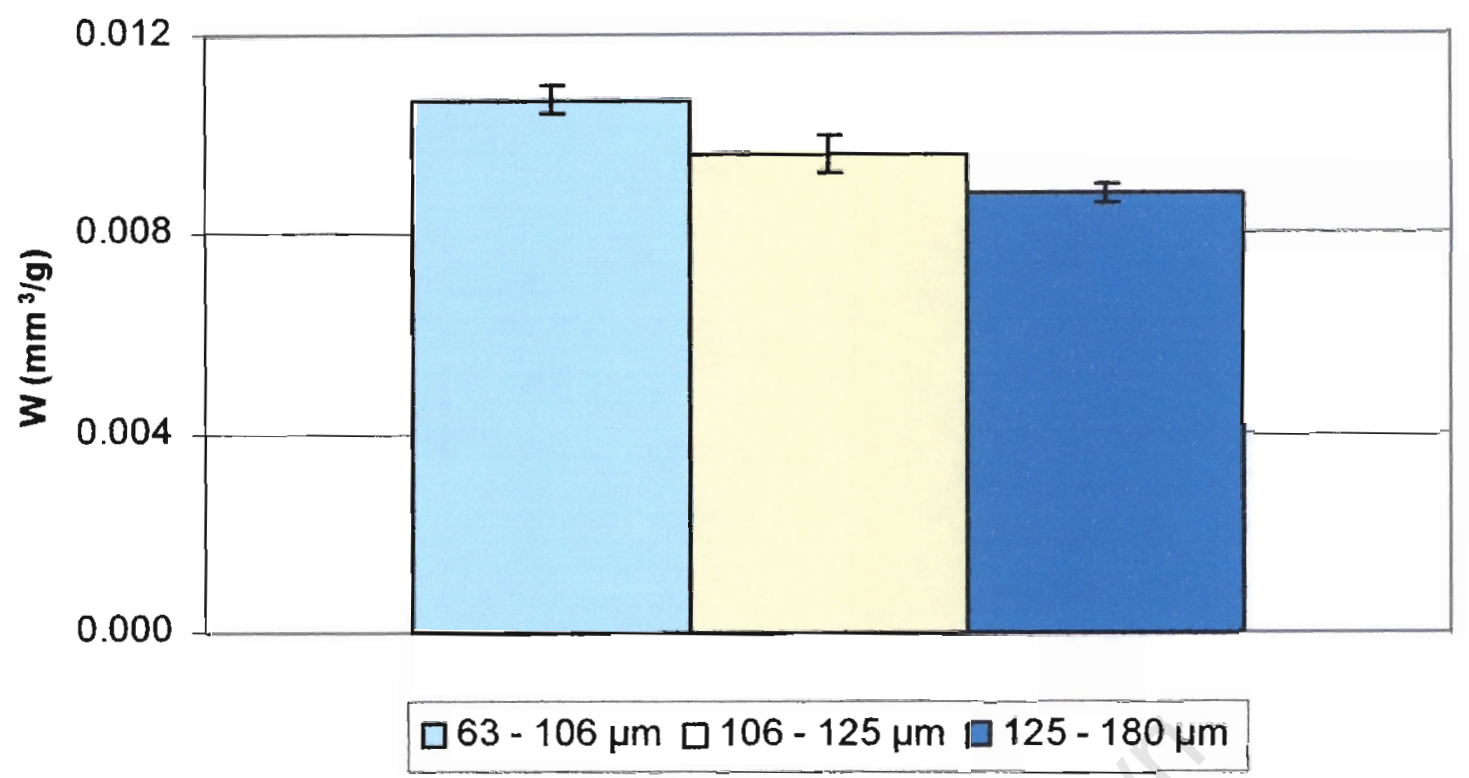

Figure 4.14: The variation of erosion rate as a function of erodent particle size at an impact velocity of $50 \mathrm{~m} \cdot \mathrm{s}^{-1}$ under normal impact.

The results clearly indicate a slight decrease in the erosion rate with increasing erodent particle size. However, it must be mentioned that the differences in erosion rates arising from two successive particle size ranges is not as marked as when comparing the smallest and the largest ranges.

\subsubsection{ROOM TEMPERATURE LONG TERM EROSION}

MP92 was also eroded with 10 cycles of $40 \mathrm{~g}$ each to study the effects of prolonged exposure to erosion. The target material was also impacted with a $\mathrm{SiC}$ particle velocity of $50 \mathrm{~m} . \mathrm{s}^{-1}$ under normal impact conditions. The graph in figure 4.15 shows that the erosion rate remains constant from the onset. However, the erosion rate is slightly lower than when the material was impacted with only $200 \mathrm{~g}$ of erodent particles. This can be attributed to different test conditions, since the tests were performed a few weeks apart. 


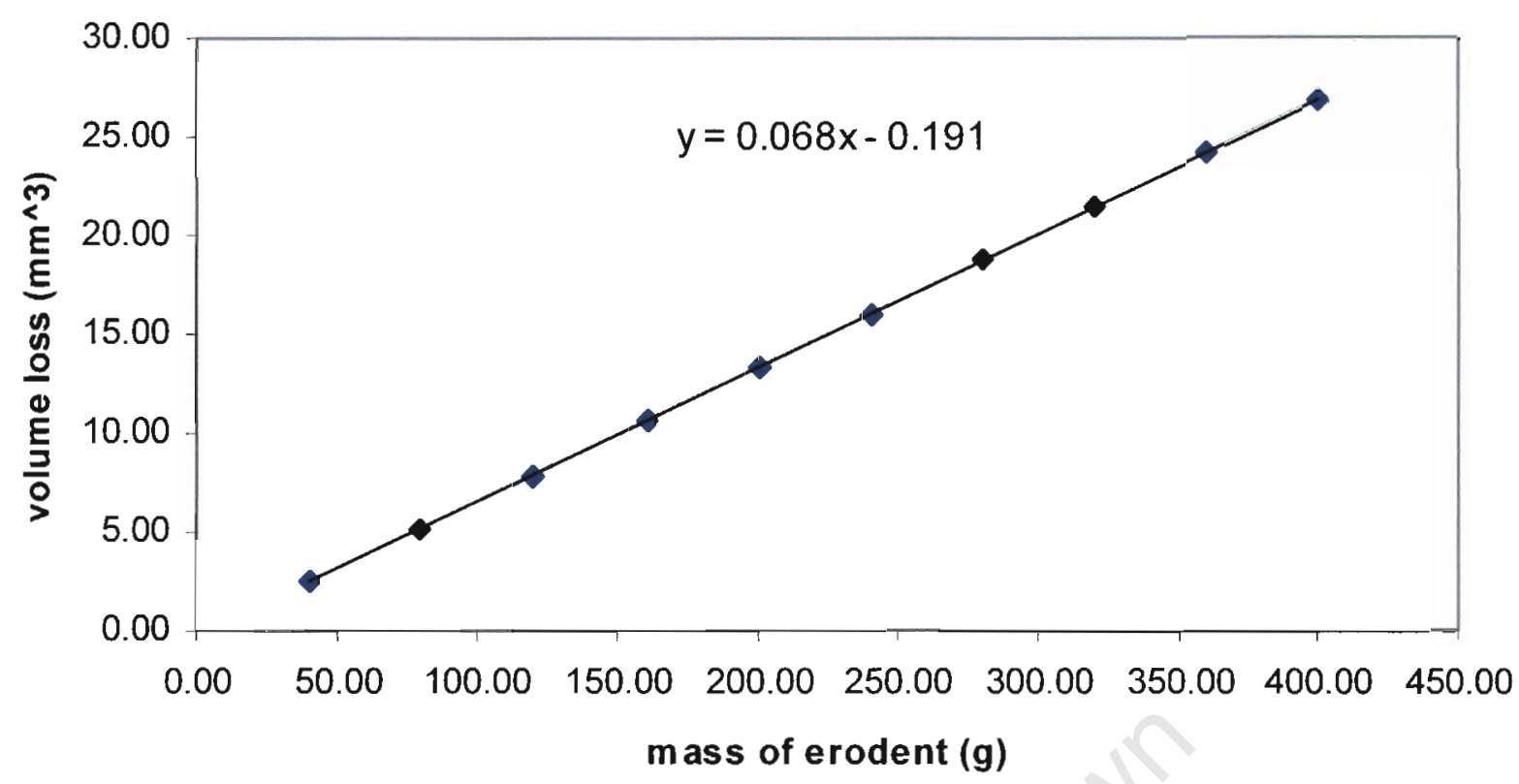

Figure 4.15: The linear relationship between volume loss and mass of erodent for MP92 after prolonged exposure to erosion under normal impact conditions.

\subsubsection{ELEVATED TEMPERATURE EROSIVE WEAR}

The effect of elevated temperature on solid particle erosion was performed on all five alumina grades using the in-house built high temperature erosion rig, which has a slightly larger nozzle exit. All the tests were performed at $150{ }^{\circ} \mathrm{C}$ under normal impact conditions using a particle velocity of $50 \mathrm{~m} \cdot \mathrm{s}^{-1}$. All the five grades were also tested at room temperature using the same rig and the results were compared to those obtained under elevated temperature conditions. The results are shown in figure 4.16. 


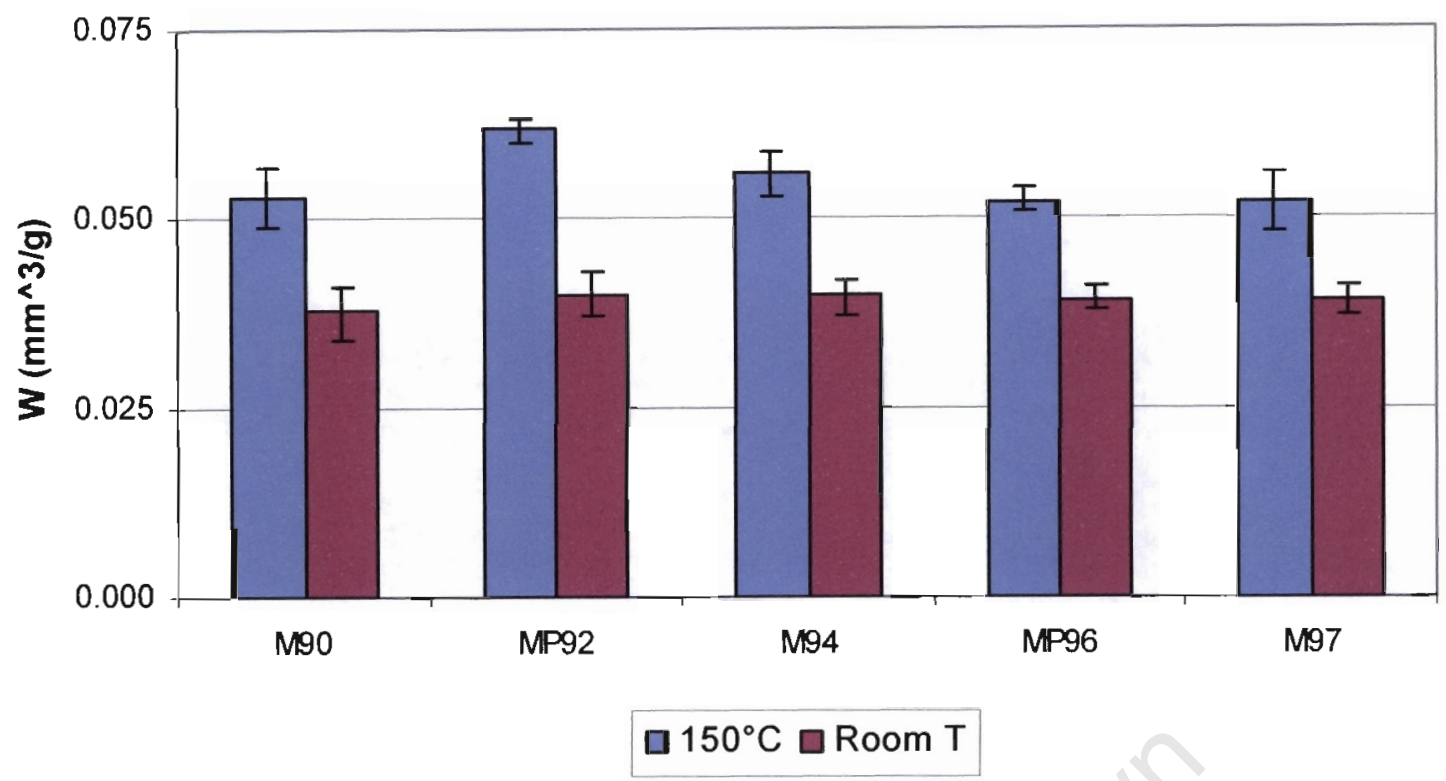

Figure 4.16: A comparison of elevated temperature and room temperature erosion rates obtained from the in-house built high temperature erosion rig.

It is interesting to note that the room temperature wear rates are different from those obtained with the first erosion rig, despite the fact that the two sets of tests were performed under the same conditions. With the high temperature erosion rig having a larger nozzle exit, one would expect higher erosion rates owing to decreased particle fluxes. This is not observed. It is therefore possible that there exists a critical particle flux, below which the erosion rates increase with an increase in particle flux and above which the erosion rates decrease with a further increase in particle flux owing to increased particle interactions.

It is also clear from the figure that the erosion rates of the five alumina grades are higher at elevated temperature than at room temperature. The erosion rates of all the materials increased by more than $30 \%$ from room temperature to elevated temperature tests. Furthermore, MP92 appears to stand out above the rest as having the highest erosion rate, having recorded the highest increase of $55 \%$. This is also consistent with room temperature testing results. Both M90 and M94 recorded increases of approximately $40 \%$ each, while the erosion rates of MP96 and M97 increased by 33\% from room temperature to elevated temperature testing. Generally, the more the alumina content, the less is the increase in the erosion rate. 


\subsection{ABRASIVE WEAR}

\subsubsection{THE EFFECT OF APPLIED LOAD AND SPEED}

Abrasive wear tests were performed on all five alumina grades at room temperature using the $\mathrm{SiC}$ abrasive belt. Both the applied load and the abrasive belt speed were varied and the results are depicted in figures 4.17 and 4.18. The abrasive wear rate increases with increasing load and speed. However, it is interesting to note that the materials display a similar behaviour in terms of wear rates at low loads and speeds. At higher loads and speeds, there are considerable differences in the wear rates of materials, with a general trend of decreasing abrasive wear rate with an increase in $\mathrm{Al}_{2} \mathrm{O}_{3}$ content. However, MP96 has the highest abrasion resistance at all speeds and loads, except for tests carried out under a load of $30 \mathrm{~N}$ where M94 has the highest resistance.

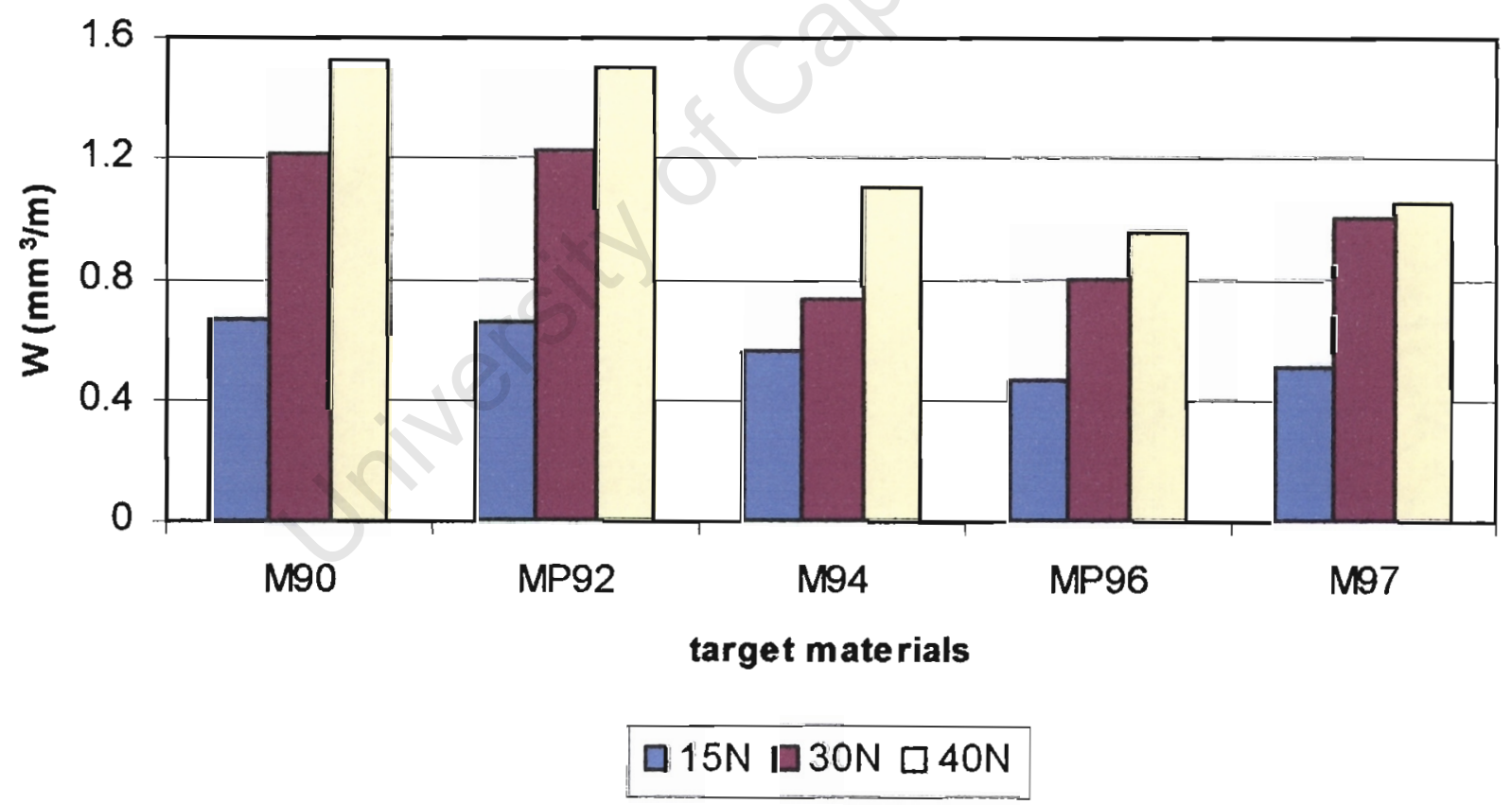

Figure 4.17: The effect of applied load on the volumetric abrasive wear rate of alumina materials. 


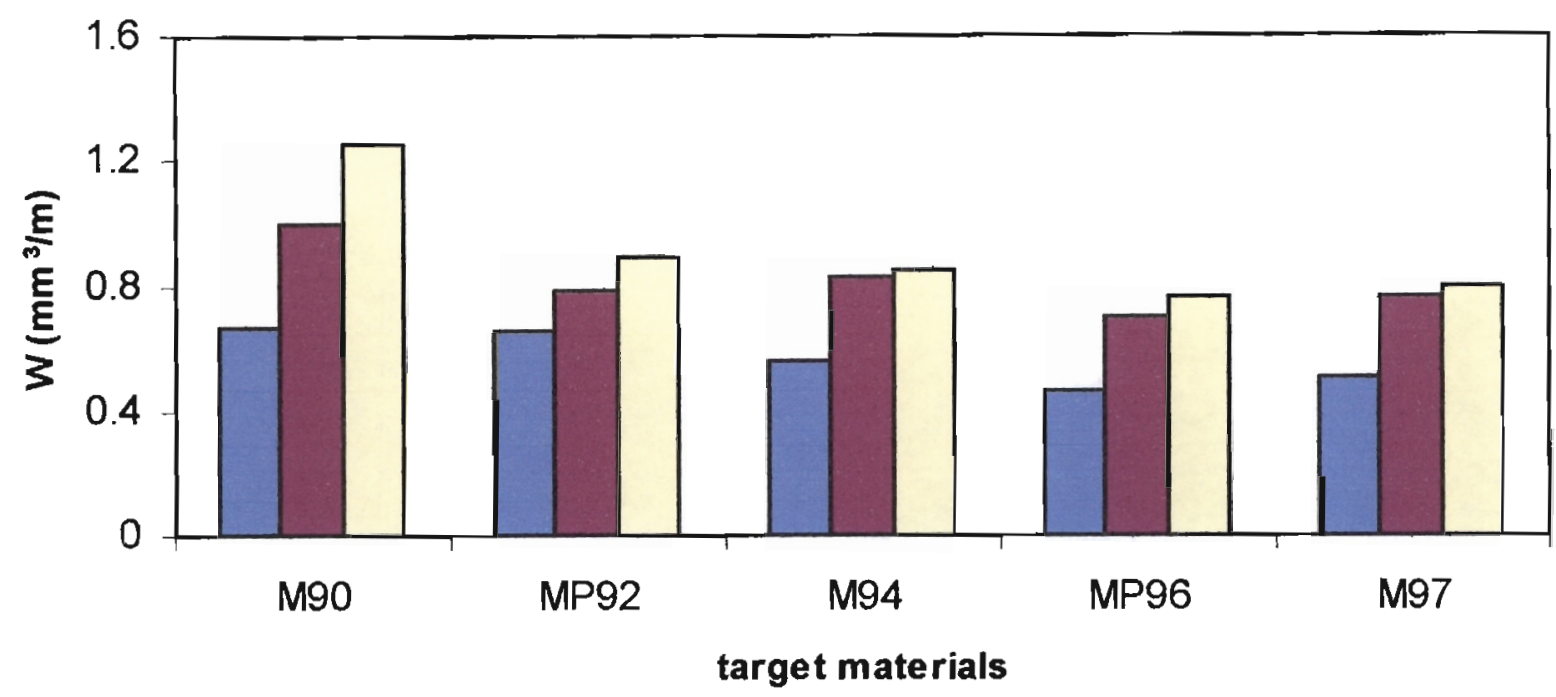

$8 \mathrm{~cm} / \mathrm{s} \square 25 \mathrm{~cm} / \mathrm{s} \square 45 \mathrm{~cm} / \mathrm{s}$

Figure 4.18: The effect of abrasive belt speed on the volumetric abrasive wear rate of alumina materials.

\subsubsection{THE EFFECT OF ABRASIVE BELT TYPE}

Abrading both M90 and M97 against a bonded 80 grit alumina abrasive belt allowed the study of the dependence of the abrasive wear rate on the type of abrasive used. As figure 4.19 indicates, abrading against alumina belt results in wear rates that are approximately three times less than those obtained when abrading against $\mathrm{SiC}$. However, it is clear that there is not much of a difference between the two materials in terms of the abrasion resistance, with the abrasion rate for M90 being greater than that of M97 by only $6 \%$. 


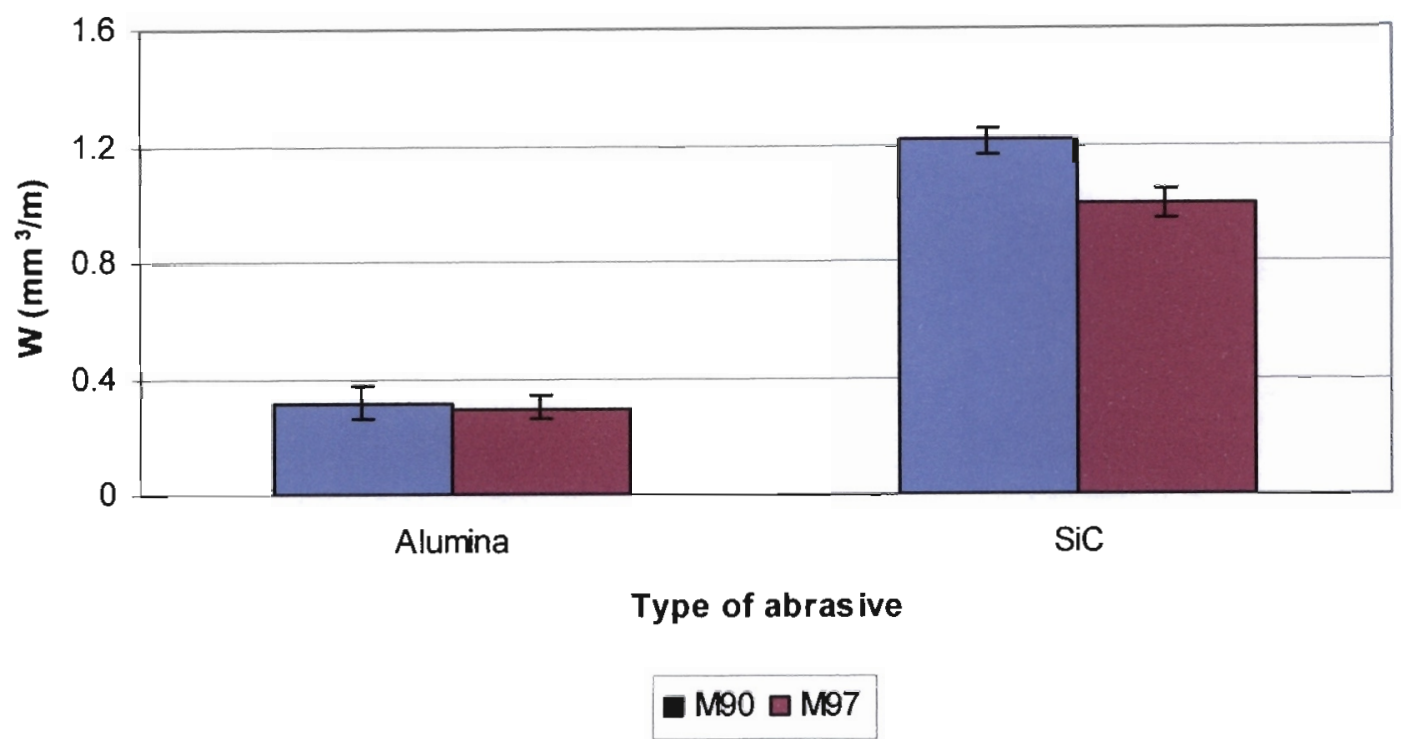

Figure 4.19: The dependence of the wear rate on the type of abrasive used. Tests were performed under constant load and speed of $30 \mathrm{~N}$ and $8 \mathrm{~cm} / \mathrm{s}$, respectively.

\subsection{MECHANISMS OF MATERIAL REMOVAL}

\subsubsection{SOLID-PARTICLE EROSION}

\subsubsection{Room Temperature Erosive Wear}

Visual examination of the eroded surfaces revealed circular erosion craters for normal impact and elliptical craters for $20^{\circ}$ impact angle. As expected, the latter have their major axes lying along the direction of particle impact. In between the two impact angles, the shapes of the craters are not clearly recognisable but have been inferred to lie somewhere between the two extremes. In addition, a ring surrounding the actual craters has been observed.

SEM micrographs showing representative features of the eroded surfaces of all five alumina grades are shown in figure 4.20. Only the centre of the erosion crater was examined since past research has revealed that the edge of the crater is much less eroded than its centre, which is severely damaged. Following the similar behaviour of the target materials in terms of erosion rates, it was not surprising that the eroded surfaces of all the grades also displayed similar characteristics. Figure 4.20 (a), (b), (c) and (d) show representative 


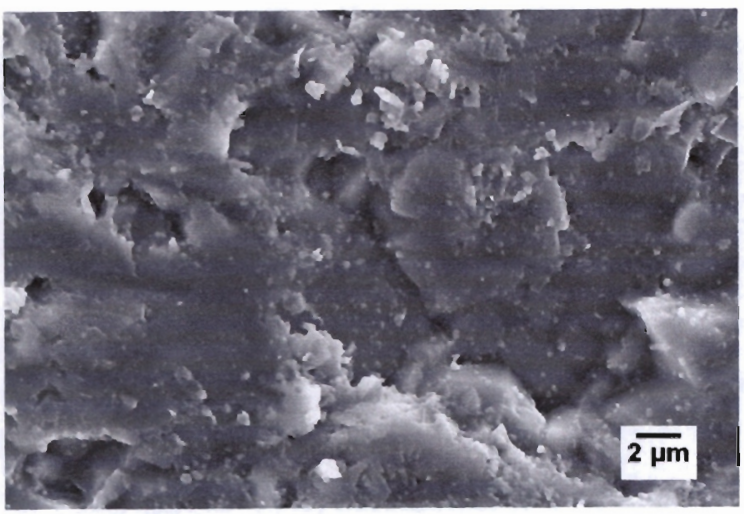

(a)

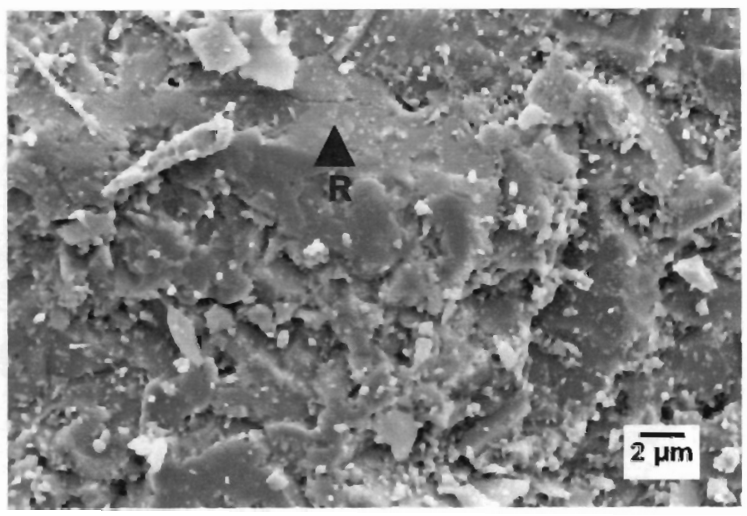

(c)

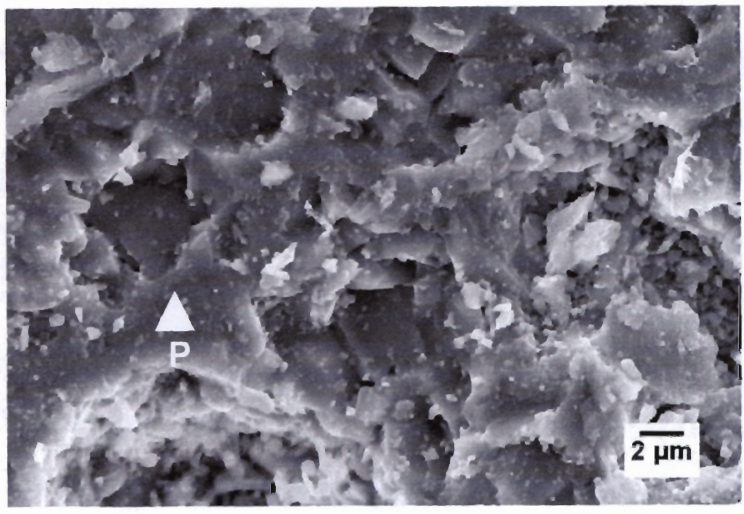

(b)

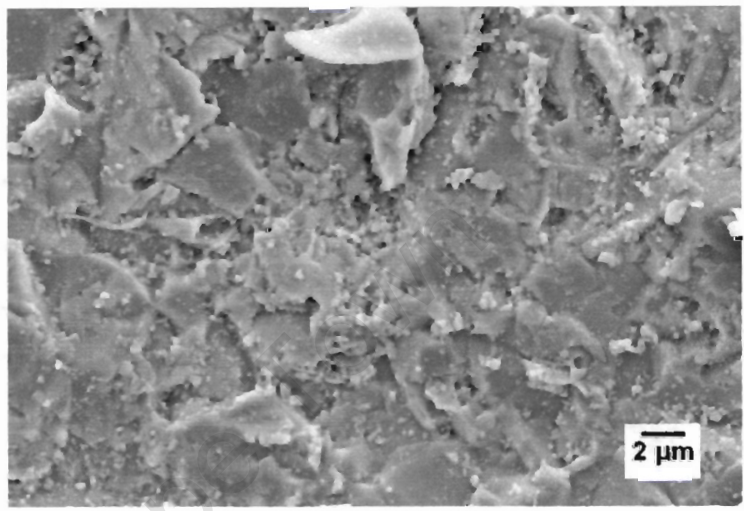

(d)

Figure 4.20: Typical SEM micrographs of surfaces of alumina samples eroded by SiC: (a) M90 at $20^{\circ}$ impact; (b) M94 at $45^{\circ}$ impact; (c) MP92 at $60^{\circ}$ impact; (d) M94 at normal impact. Note in (b) an erosion pit $P$ and a radial crack $R$ in (c).

features of the target materials eroded at $20^{\circ}, 45^{\circ}, 60^{\circ}$ and $90^{\circ}$, respectively. Note that similar features were observed on surfaces exposed to both normal and $80^{\circ}$ impact. The fact that the erosion rates of all target materials peaked at normal impact suggests that material removal was dominated by brittle fracture at such an impact angle, and by plastic deformation at shallow angles of impact. However, the above figures clearly show very little evidence of plastic deformation at shallow angles. Instead, the material seems to have been removed by brittle fracture, with a progressive increase in the degree of fracture as the impact angle is increased.

All surfaces are characterised by erosion pits, which are probably the result of grain ejection caused by radial and lateral cracking, and subsequent chipping of alumina grains. Radial cracks are evident at $60^{\circ}$ and normal impact. Despite the fact that specimens were cleaned with compressed air after each exposure to erosion, there are still some wear debris visible on the eroded surfaces. XEDS analysis of such debris showed high levels of $\mathrm{Al}$, confirming that they were chipped away from the target materials. 
Figure 4.21 shows SEM micrographs of the surfaces after exposure to erosion by both silica sand and alumina particles under normal impact. Surfaces are characterised by both plastic deformation and brittle fracture. However, the degree of fracture is very little when compared to surfaces impacted by $\mathrm{SiC}$ particles. This explains the relatively lower erosion rates inflicted by both silica sand and alumina particles. Also in the case of silica sand, plastic deformation dominates at $20^{\circ}$ impact angle and the material seems to have been removed mainly by ploughing, which is associated with platelet formation and removal and subsequent lower erosion rates. It is also evident that grain-sized features are not present on the eroded surface. At $90^{\circ}$ impact, erosion pits are evident on the eroded surface and the material has probably been removed by fracture.
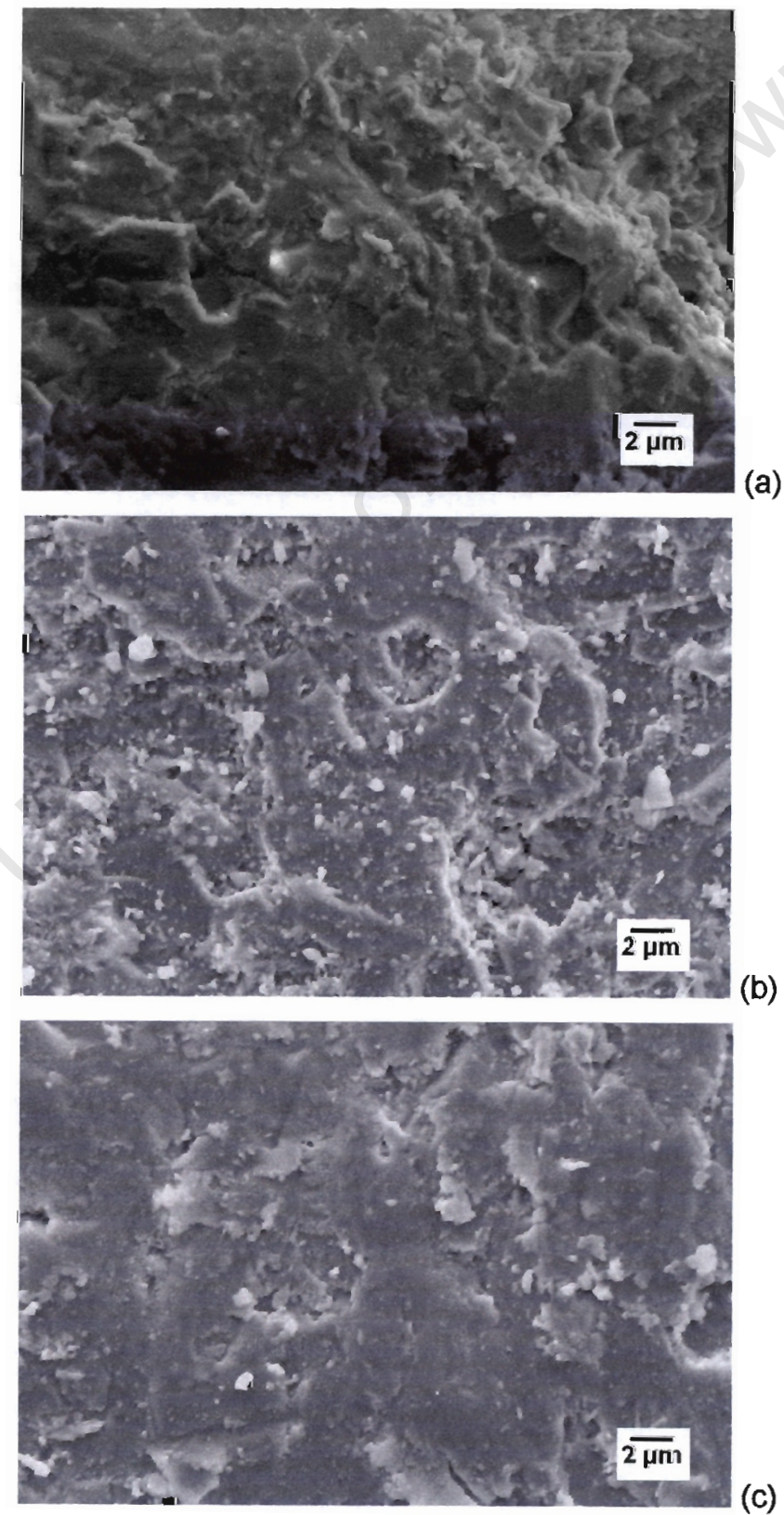

(c)

Figure 4.21: Typical SEM micrographs of surfaces of alumina samples eroded by: (a) alumina at $90^{\circ}$ impact; (b) silica sand at $90^{\circ}$ impact and (c) silica sand at $20^{\circ}$ impact. 
In the case of SiC-based composites, the $\mathrm{SiC}$ particulates are bound tightly by the matrix prior to erosion, as shown in figure 4.22. After erosion, the surfaces appear to be characterised by missing $\mathrm{SiC}$ particulates. The specimens probably experienced progressive removal of the matrix and subsequent removal of unsupported $\mathrm{SiC}$ particulates.

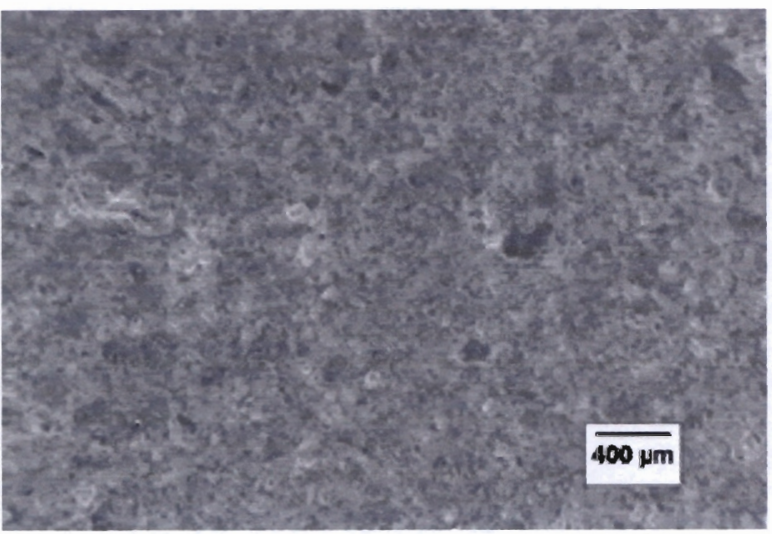

(a)

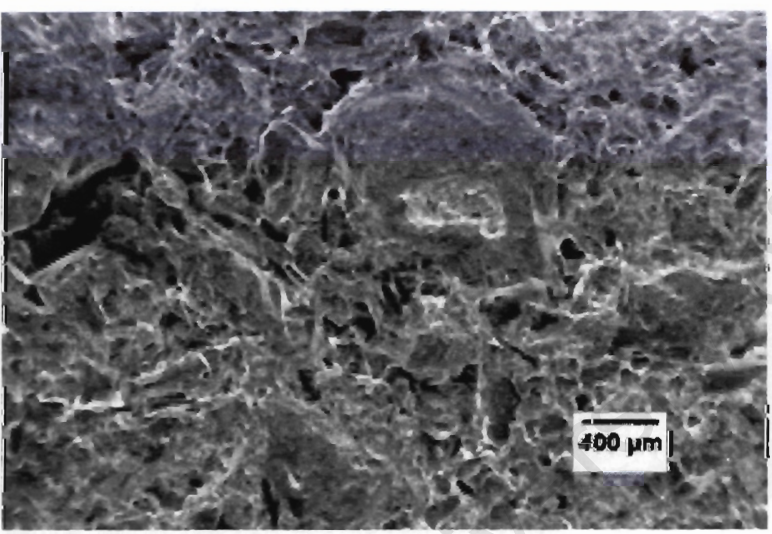

(c)

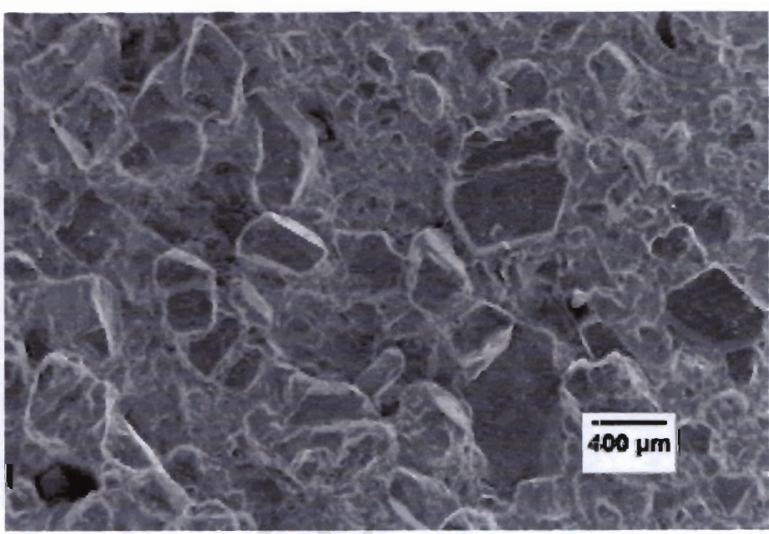

(b)

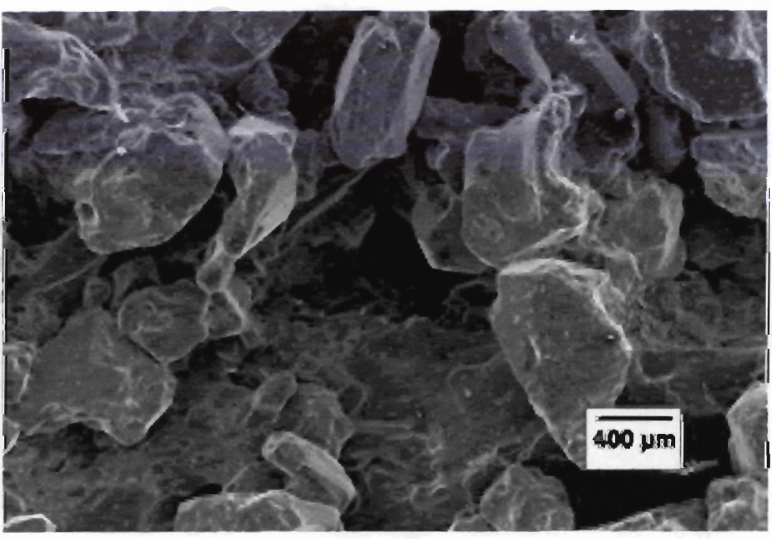

(d)

Figure 4.22: SEM micrographs of the surfaces of SiC based tiles, prior to and after erosion. (a) and (b) are nitride-fired tiles, while (c) and (d) are an oxide-fired tiles.

\subsubsection{Elevated Temperature Erosive Wear}

Figure $4.23(\mathrm{a})$ shows the surface features of alumina ceramics eroded at $150^{\circ} \mathrm{C}$ under normal impact and a velocity of $50 \mathrm{m.s}^{-1}$. The surfaces are characterised by plastic deformation, which resulted in the formation of localised rounded features. Some surfaces showed fracture with no evidence of cracking, but these were only found in trace amounts. By contrast, erosion features for room temperature erosion under the same conditions using the same rig, show a dominance of brittle fracture and very little plastic deformation. This resulted in the formation of erosion pits as figure 4.22(b) indicates. 


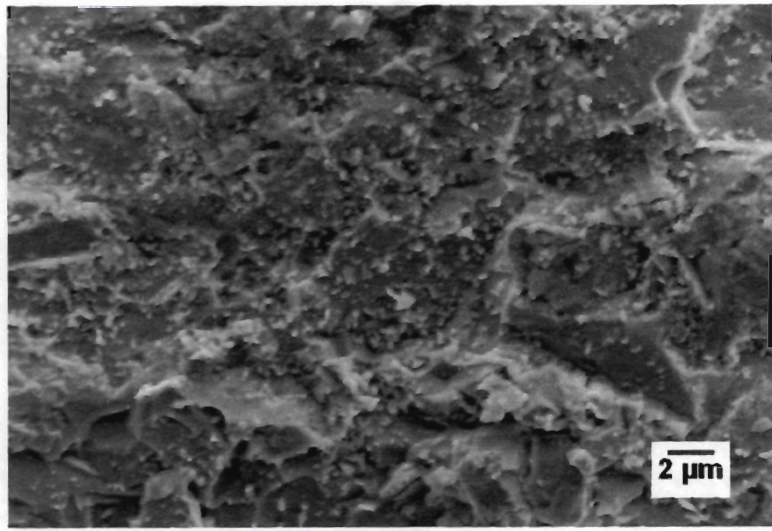

(a)

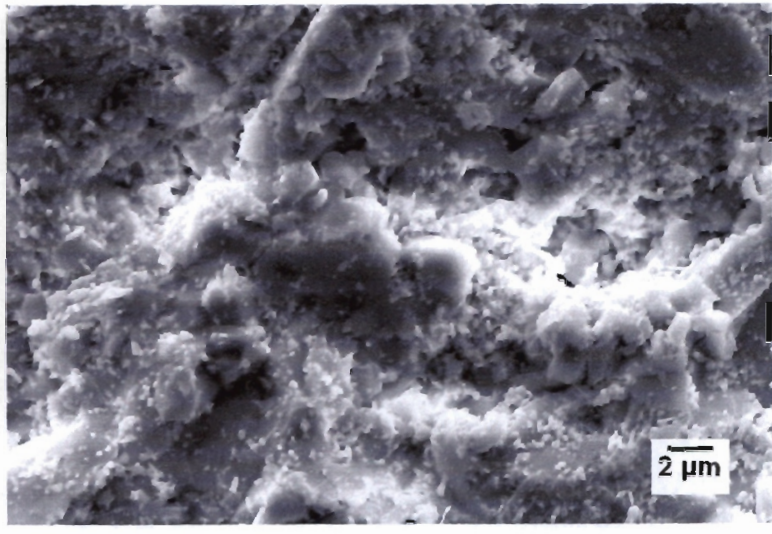

(b)

Figure 4.23: Typical SEM micrographs of surfaces of alumina samples eroded at: (a) $150^{\circ} \mathrm{C}$ and (b) room temperature, under normal impact and a velocity of $50 \mathrm{~m} . \mathrm{s}^{-1}$ using the same rig.

\subsubsection{ABRASIVE WEAR}

Visual examination of the abrasive belts reveals the presence of white lines perpendicular to the motion of the specimen. The lines are just the marks created by the specimens as they traversed across the belt. This serves to confirm that indeed, during testing, the alumina ceramics were vulnerable to removal of material, some of which resulted in the formation of the white lines observed on the abrasive belts as shown in figure 4.23.

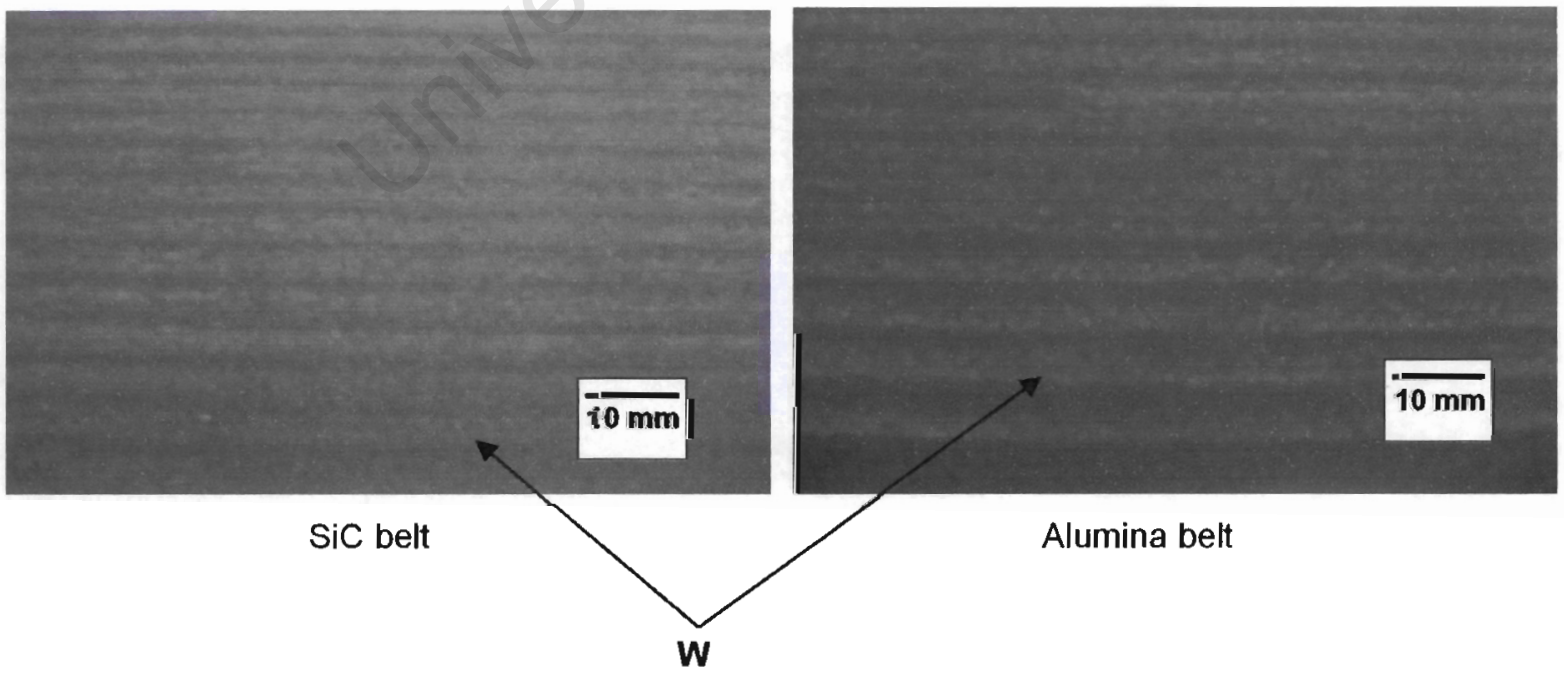

Figure 4.24: Optical micrographs showing the white lines $(W)$ that were created on the abrasive belts after abrasive wear testing. 
Pieces of material were cut from each belt and these were viewed under the optical microscope. The optical micrographs in Figure 4.25 show the surfaces of the two abrasive belts before and after abrading the alumina ceramics under a load of $30 \mathrm{~N}$ at $8 \mathrm{~cm} / \mathrm{s}$. It is clear that the two abrasive belts are characterised by a white "powder" after abrasive wear testing. As explained before, this is clearly the material removed from the alumina ceramics and although difficult to quantify, it looks as though there is more material in the SiC abrasive belt than in the alumina belt. This is consistent with the relatively higher rates of abrasion experienced by the target materials when abraded against the $\mathrm{SiC}$ belt.

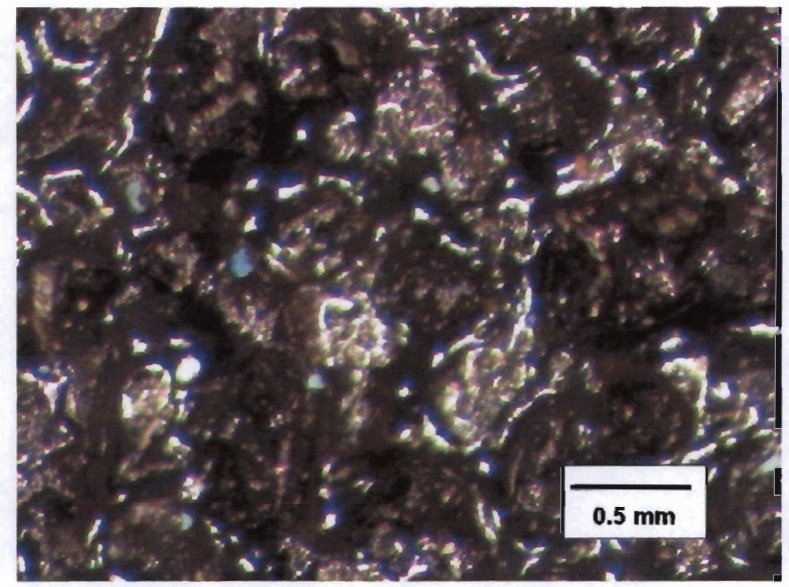

$\mathrm{SiC}$ - before

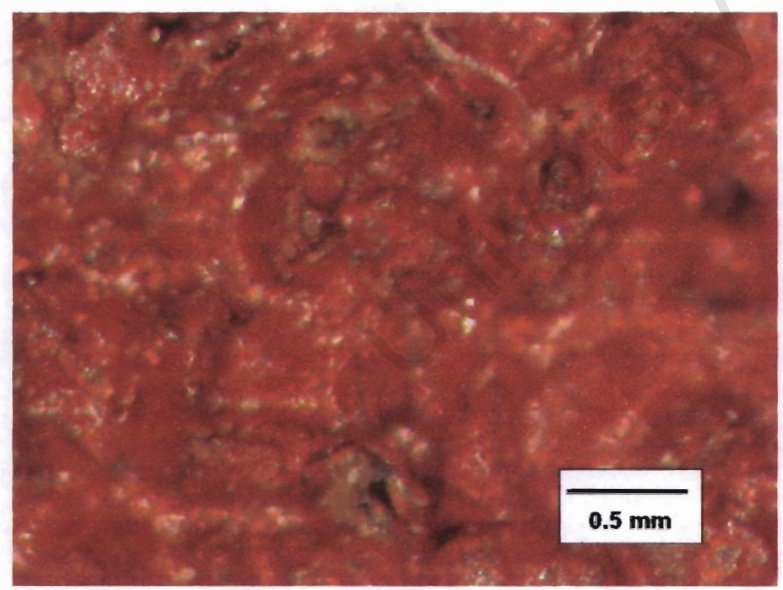

Alumina - before

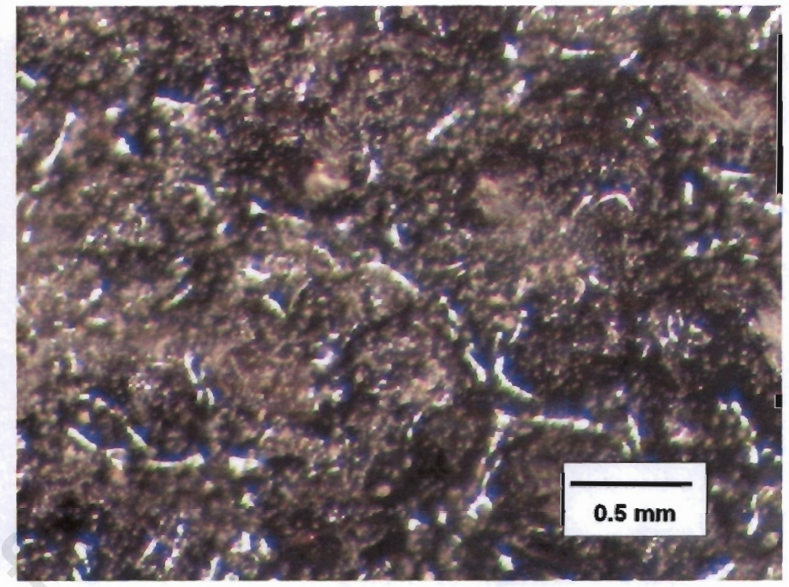

$\mathrm{SiC}$ - after

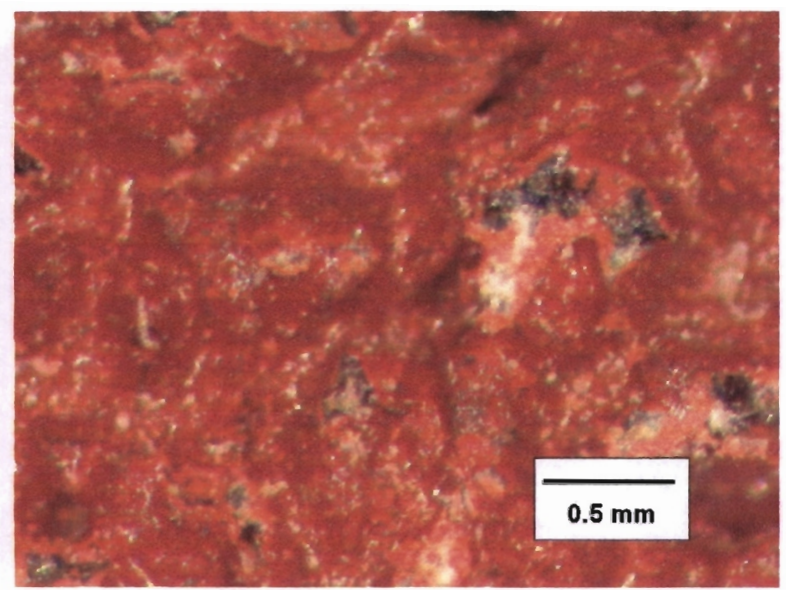

Alumina - after

Figure 4.25: Optical micrographs showing the surfaces of both $\mathrm{SiC}$ and alumina abrasive belts before and after abrading alumina targets under $30 \mathrm{~N}$ at $8 \mathrm{~cm} / \mathrm{s}$.

Figure 4.26 shows typical surfaces of alumina ceramics after being subjected to abrasive wear under varying loads and speeds. It is observed that the surfaces are characterised by two regions: one region is extensively fractured and another one has a relatively smooth profile. The degree of fracture correlates directly to the wear resistance of the materials and 


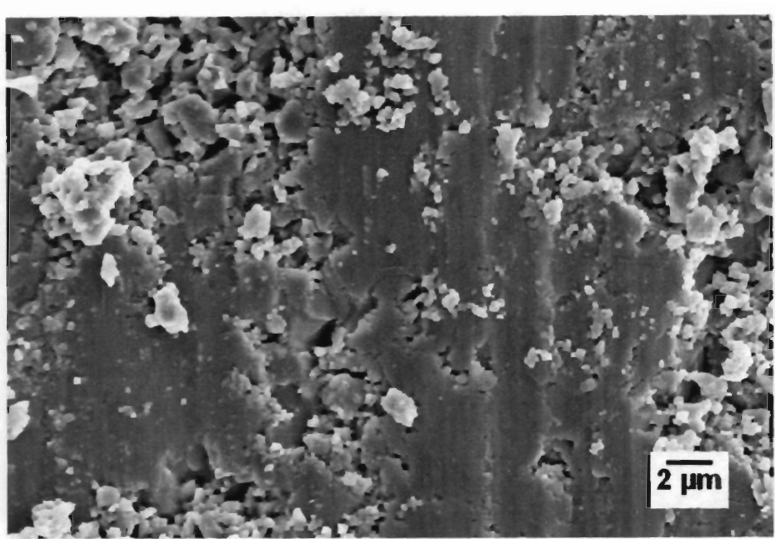

$15 \mathrm{~N}, 8 \mathrm{~cm} / \mathrm{s}$

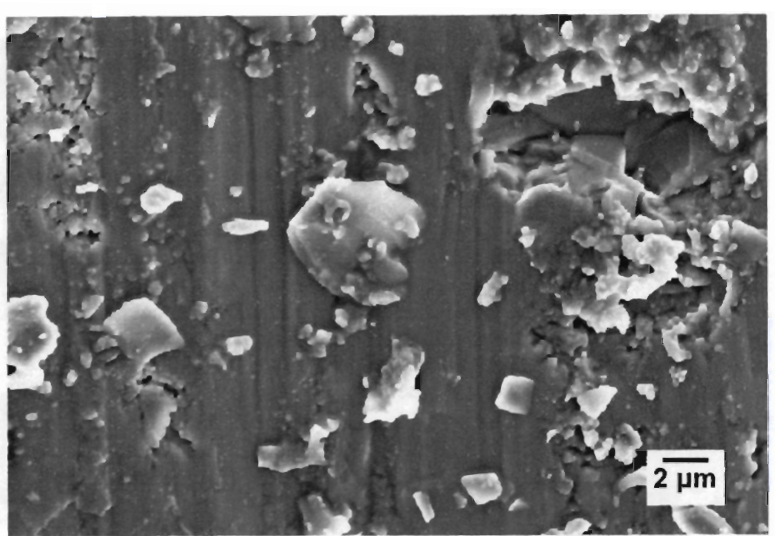

$8 \mathrm{~cm} / \mathrm{s}, 30 \mathrm{~N}$

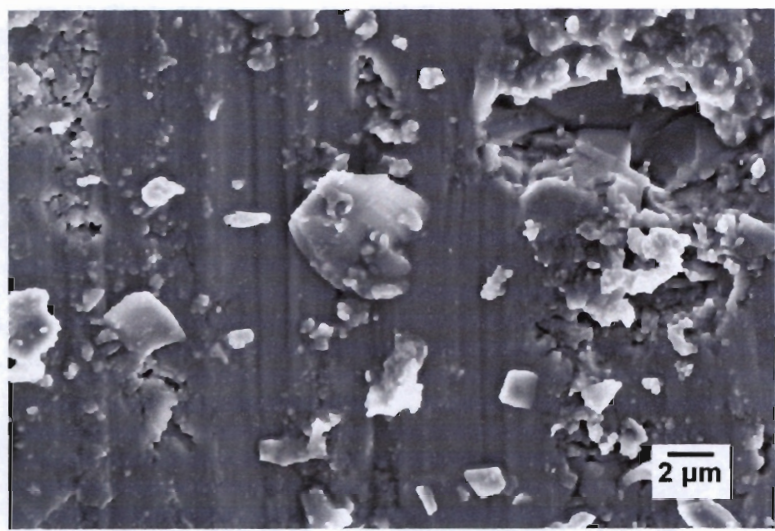

$30 \mathrm{~N}, 8 \mathrm{~cm} / \mathrm{s}$

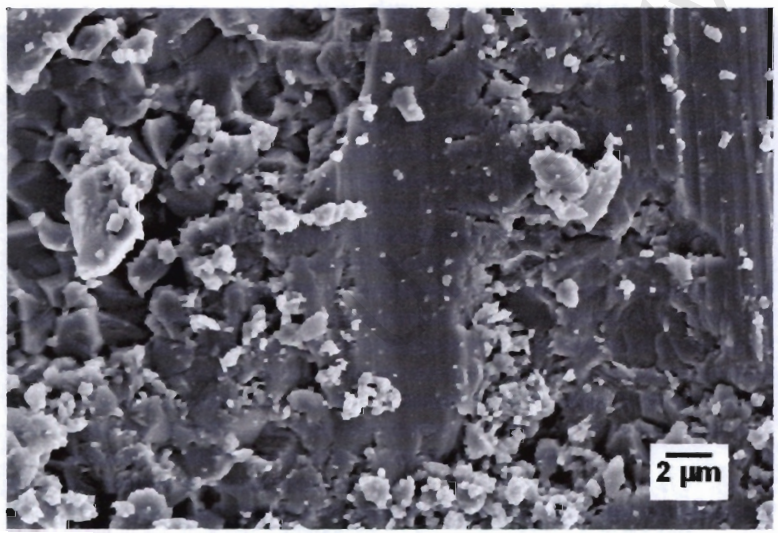

$40 \mathrm{~N}, 8 \mathrm{~cm} / \mathrm{s}$

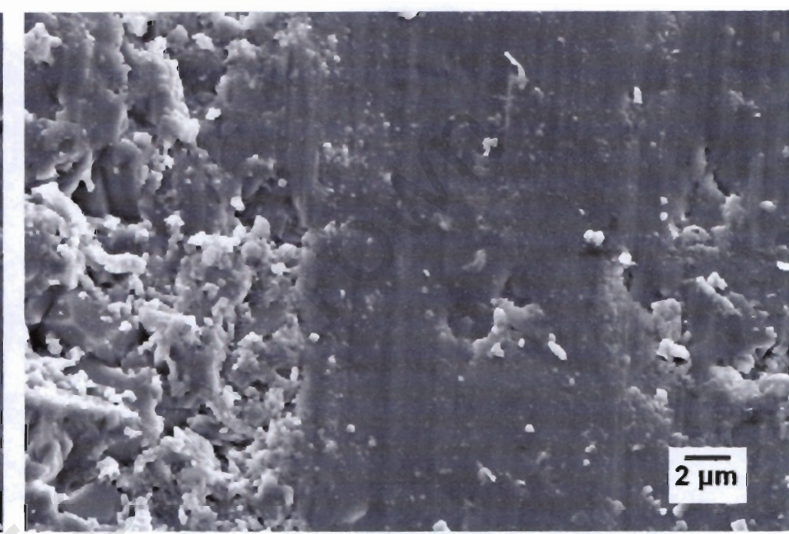

$25 \mathrm{~cm} / \mathrm{s}, 30 \mathrm{~N}$

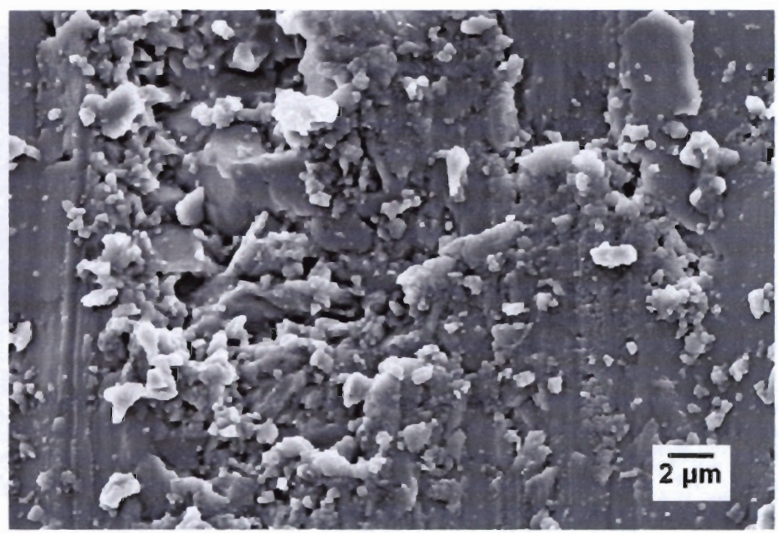

$45 \mathrm{~cm} / \mathrm{s}, 30 \mathrm{~N}$

Figure 4.26: Typical SEM micrographs of surfaces of alumina samples, which were abraded under 30 $\mathrm{N}$ constant load and $8 \mathrm{~cm} / \mathrm{s}$ constant speed at various speeds and loads, respectively.

it increases as both the load and the speed are increased. In addition, the surfaces are characterised by scattered little white particles and numerous long grooves parallel to the abrasion direction. XEDS analysis of the white particles revealed the dominance of $\mathrm{Al}$, indicating that such particles consist of gathered wear debris. The rough nature of the 
surfaces is a clear indication of severe wear, whereby wear proceeds predominantly by fracture. Cracks are clearly visible on all surfaces and the presence of craters suggests that material removal took place by intergranular fracture and subsequent grain dislodgement, particularly at high loads and speeds.

As mentioned earlier, only M90 and M97 were also abraded against a bonded 80 grit alumina abrasive and the resulting surface morphologies are shown in figure 4.27. Numerous grooves with scattered wear debris are still clearly visible in M90, but the material is not as extensively fractured as when abraded against a $\mathrm{SiC}$ belt. By contrast, grooves and fracture are not that prominent in M97, although scattered wear debris are clearly present. This explains the better abrasion resistance of M97.

M90

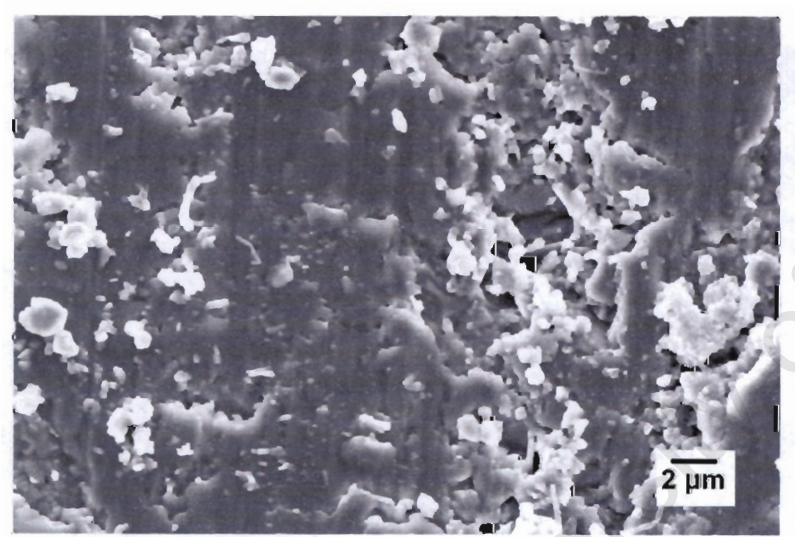

M97

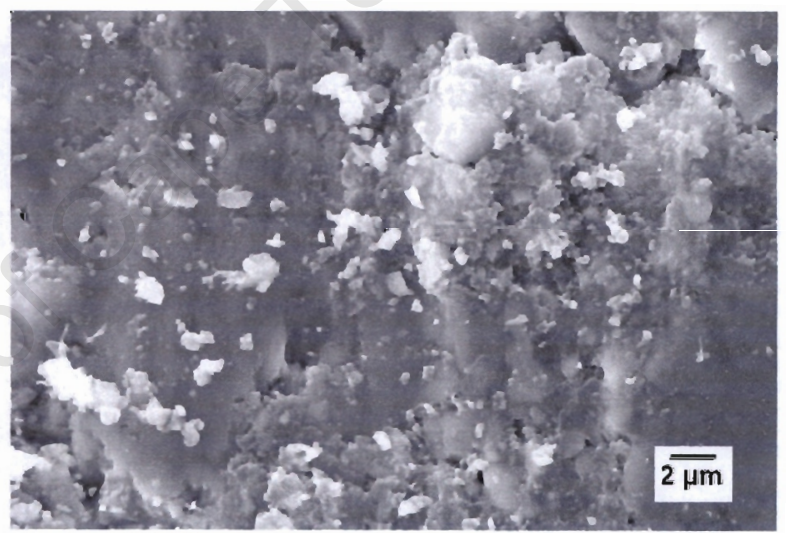

alumina abrasive belt
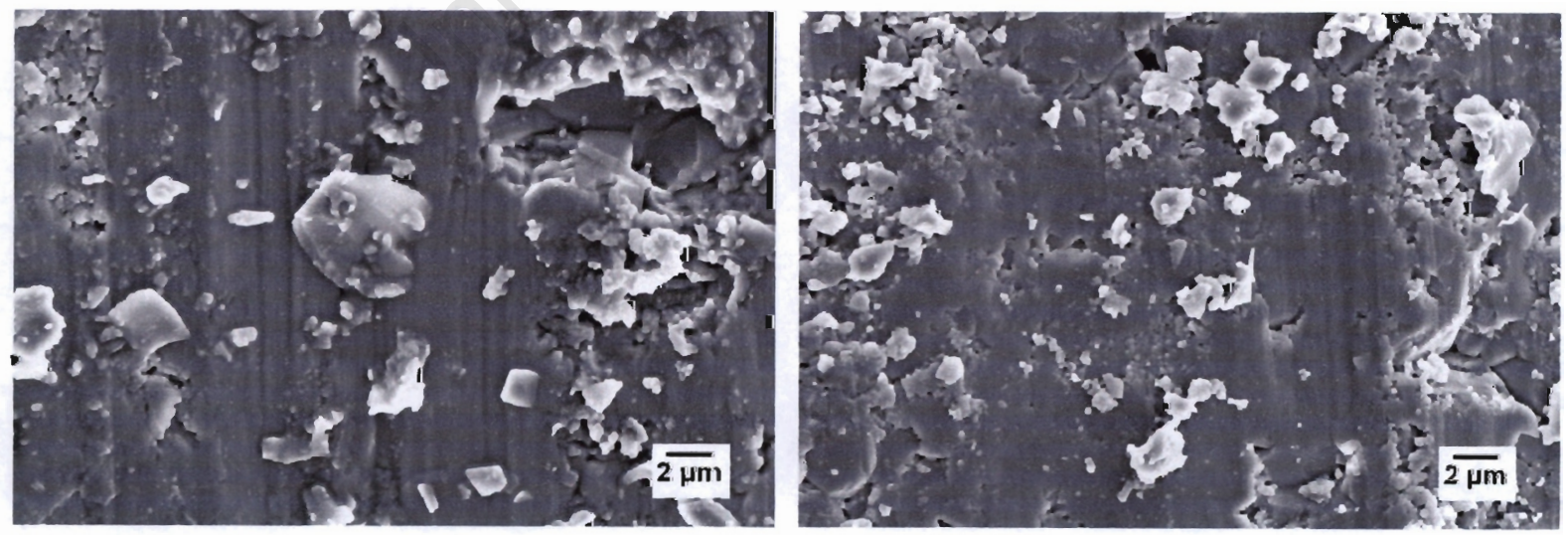

SiC abrasive belt

Figure 4.27: SEM micrograph of M90 and M97 showing the surface of the materials after exposure to abrasion against an alumina and $\mathrm{SiC}$ belts under constant loads and speeds of $30 \mathrm{~N}$ and $8 \mathrm{~cm} / \mathrm{s}$, respectively. 


\section{CHAPTER 5}

\section{DISCUSSION}

\subsection{THE EFFECT OF EROSION TEST VARIABLES}

\subsubsection{THE EFFECT OF SYSTEM VARIABLES}

There is general agreement amongst researchers that materials can be characterized according to the mode of failure. For ductile materials such as mild steel, one would expect the rate of erosion to decrease with impact angle of the erodent particles. Brittle targets such as ceramics would typically show an increase in the rate of erosion as the angle of impact is increased from $20^{\circ}$ to $90^{\circ}$. This is the general trend that was observed in this study, bearing in mind that the raw data showed very little scatter. Such a trend is consistent with literature results from work on other alumina ceramics ${ }^{23,38}$.

The explanation for the observed trend centers on the kinetic energy of the erodent particles. At high impact angles of $60^{\circ}, 80^{\circ}$ and $90^{\circ}$, the kinetic energy of the erodent particles contributes mainly to crack initiation and propagation, which are known to give rise to high erosion rates. On the other hand, the same kinetic energy contributes little to crack initiation and propagation at shallower angles of $20^{\circ}$ and $45^{\circ}$, but is instead dissipated through ploughing and cutting ${ }^{23}$. It is therefore not surprising that the erosion rates of the target materials are lower at such angles.

As expected, the erosion rate of the 92\% alumina dry pressed body (MP92) increased with an increase in impact velocity. However, of great interest was the low value of the velocity exponent $n$ of approximately 1.5. This is not typical of erosion tests, particularly for brittle materials, which tend to have an $n$ range of 2 to $6.5^{9}$. 
Equation 2.1 suggests that there is a direct correlation between the erosion rate $\mathrm{W}$ and the velocity exponent $n$, meaning that high erosion rates will result in high values of $n$. This means that any factor that affects the erosion rate has an effect on $n$. This includes system variables, target material properties and erodent particles properties. It is therefore not necessarily true to say the value of $n$ is independent of the target material, as some authors have mentioned in the past, when the same factor is considered important for the erosion rate.

The low vaue of $n$ obtained in this study is simply the result of the relatively low erosion rates experienced by the target materials, probably because of their microstructure and / or hardness and fracture toughness. It must be borne in mind that in most of the past research on the effect of velocity on erosion rates, the values of the latter are not mentioned ${ }^{15}$. It is therefore highly likely that the erosion rates obtained in those studies are much higher than those obtained in the present study. This could be attributed to completely different test conditions, including a different test rig.

\subsubsection{THE EFFECT OF ERODENT PARTICLES PROPERTIES}

There is evidence in the literature to support the significant role of erodent properties on erosion resistance. Such properties are hardness, size and shape. In this work, the effect of particle hardness was studied by comparing the erosion rates caused by silica sand, alumina and silicon carbide erodent particles. Microscopic observation of the eroded alumina surfaces revealed a change in erosion mechanism from lateral fracture-dominated to ploughing-dominated when the erodent particles were changed from the relatively harder SiC particles to the softer silica sand. Subsequently, the erosion rates decreased substantially, accompanied by a change in the surface morphologies from rough to relatively smooth.

The change in the erosion rate can be explained in terms of the efficiency of crack initiation in the target by the erodent particles, thereby pointing to the significant role of erodent particle hardness in erosion. It has been pointed out in the past that 
erosion by particles softer than the target can take place through lateral cracking, but that several repeated impacts would be necessary to build up the required stress ${ }^{14}$. In the present study, particularly at $20^{\circ}$ impact, the kinetic energy of the softer silica sand particles was mainly dissipated in ploughing and their fragmentation, owing to their friability. As a result, the particles are unable to inflict significant damage accumulation to build up the requisite stress levels to produce cracks. Instead, material removal occurred by a minor ploughing mechanism, which is associated with the observed low erosion rates. At $90^{\circ}$ angle of impact, the kinetic energy of silica particles was dissipated in crack formation and initiation, as well as particle fragmentation. On the other hand, the relatively higher hardness and toughness of both alumina and $\mathrm{SiC}$ erodent particles renders them able to damage the target material without suffering plastic deformation or fracture themselves. These erodent particles need more stress to be fragmented and thus cause more erosive damage than the friable silica sand.

The results also indicate that the erodent particle size is of importance, judging from a decrease in the erosion rate when the erodent particle size range is increased. For example, increasing the size range from $63-106 \mu \mathrm{m}$ to $106-125 \mu \mathrm{m}$ and from 106 $-125 \mu \mathrm{m}$ to $125-180 \mu \mathrm{m}$ decreased the erosion rate by $9 \%$ and $10 \%$, respectively. Even though the changes in erosion rates are small, they are nevertheless not consistent with past research, which shows the erosion rate to increase with increasing particle size $\mathrm{s}^{15,34,36}$. This has been attributed to more surface contact area and hence increased damage for larger erodent particles.

In cases where the erosion rates decrease with an increase in particle size, the angularity of the erodent particles has been deemed to be the cause. Several investigators have shown that erodent particles become more rounded as their size increase $^{17}$. In such a case, the more angular smaller particles will produce greater erosion damage than will more rounded larger particles. In this study, there is very little difference in the angularity of particles between the different size ranges, as shown in figure 5.1. This means that upon impact, all the particles are likely to have a similar contact area with the target material, resulting in similar erosion damage. 


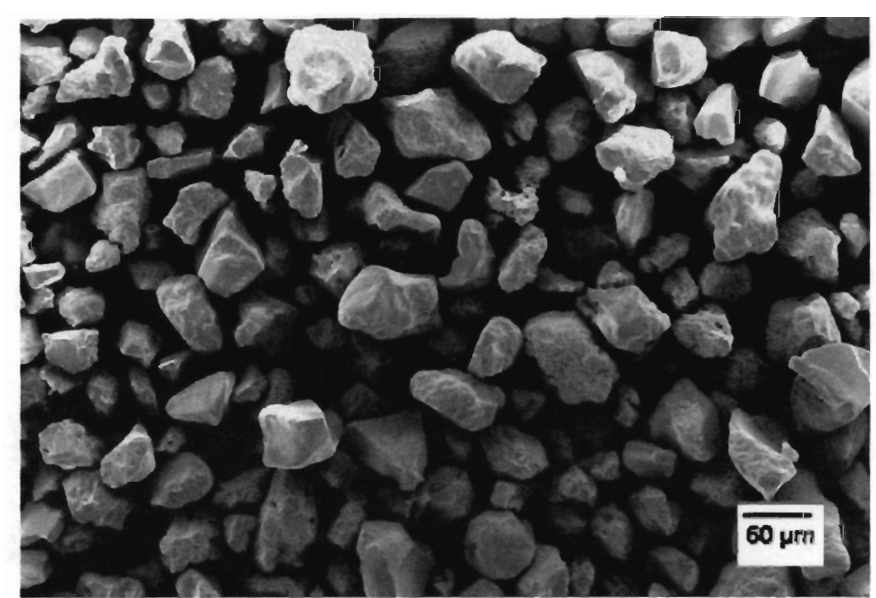

$106-125 \mu \mathrm{m}$

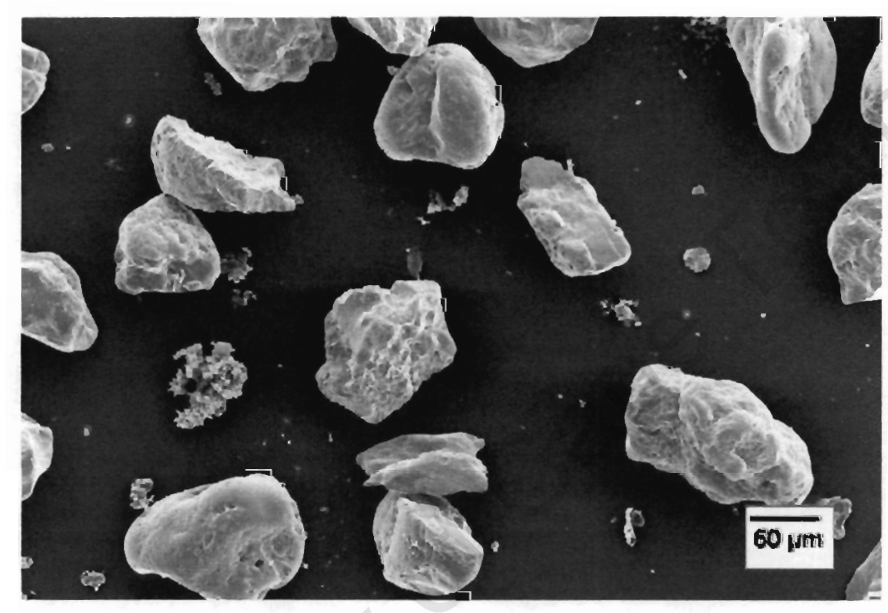

$63-106 \mu m$

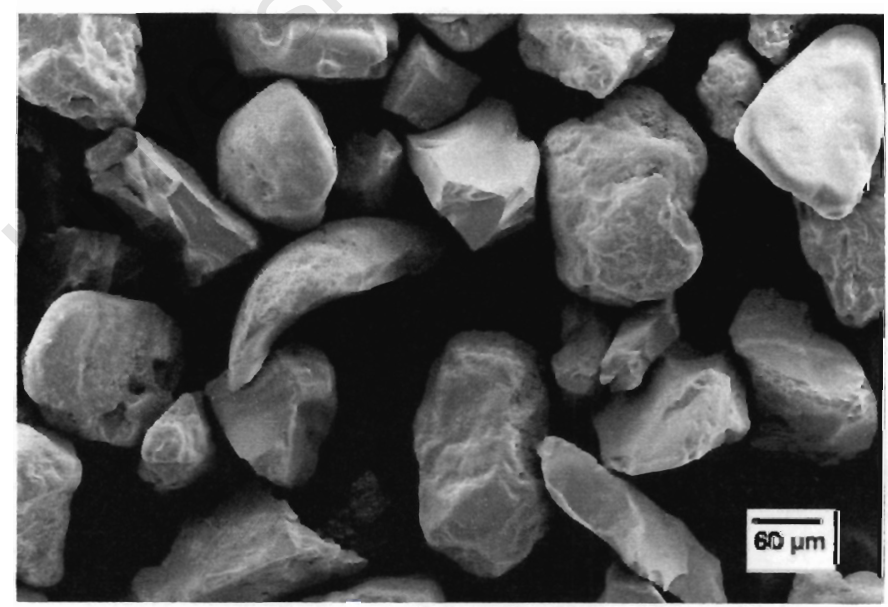

$125-180 \mu \mathrm{m}$

Figure 5.1: SEM micrographs showing the morphologies of different size ranges of silica sand erodent particles. 
The apparent small decrease of the erosion rates with an increase in erodent size is consistent with the work done by Palasamundram and Bahadur, who observed no significant effect on the erosion rate due to the particle size when it exceeds $60 \mu \mathrm{m}^{69}$. The reason given is that at higher velocities, typically $20-60 \mathrm{~m} \cdot \mathrm{s}^{-1}$, the effect of particle mass is less than that of the velocity because of the direct proportionality of the erosion rate to $\mathrm{V}^{n}$.

The above discussion has positive implications regarding the use of alumina ceramics for protection against fly-ash erosion. Most of the fly-ash particles are rounded and very small, typically less than $60 \mu \mathrm{m}$ and although this means they can be more easily accelerated, they are very fragile, perhaps more fragile than silica sand particles. This means they have a low ability to concentrate stresses and as a result they will result in less extensive cracking or no cracks at all ${ }^{15}$. Furthermore, the gas velocities in the hoppers are very low at less than $20 \mathrm{~m} . \mathrm{s}^{-1}$, meaning the effect of the fly-ash particles could become even more negligible, owing to low kinetic energy. This will result in very low rates of erosion and consequently prolonged use of the alumina ceramic tiles.

\subsubsection{THE EFFECT OF MICROSTRUCTURE}

\subsubsection{Room Temperature Erosive Wear}

It is widely believed that the use of mechanical properties such as hardness, fracture toughness, flexural modulus and strgenth is not satisfactory enough to explain the behavior of alumina ceramics. In the present study, lack of significant differences in such properties and erosion rates between target materials makes it difficult, if not impossible, to conclusively determine the dependence of erosion behaviour of target materials on such properties. Furthermore, the fact that the target materials differ in terms of $\mathrm{Al}_{2} \mathrm{O}_{3}$ composition, yet show similar erosion behaviour suggests that composition alone has a minor effect on the erosion behaviour. 
The microstructure has been increasingly appreciated as having a controlling effect on the erosion behaviour. In this study, it has been show that the dominant mechanism of material removal on the erosive wear of aluminas is intergranular fracture, particularly when they were eroded by SiC. BSED images also showed that the materials are characterized by holes or pores in between some grains on the surface, which are indicative of porosity. The SEM micrograph in figure 5.2 confirms this. This means that during erosive wear, damage can occur without the need for crack initiation. This explains why most of the eroded surfaces are characterized by erosion pits, without any evidence of cracking. Instead, the stress created by impact loosens the grains but is not concentrated sufficiently for initiation and propagation of cracks $^{70}$. This is the mode of material removal that was observed after impact by silica sand and alumina particles as well, the only difference being the ratio of fracture to plastic deformation.

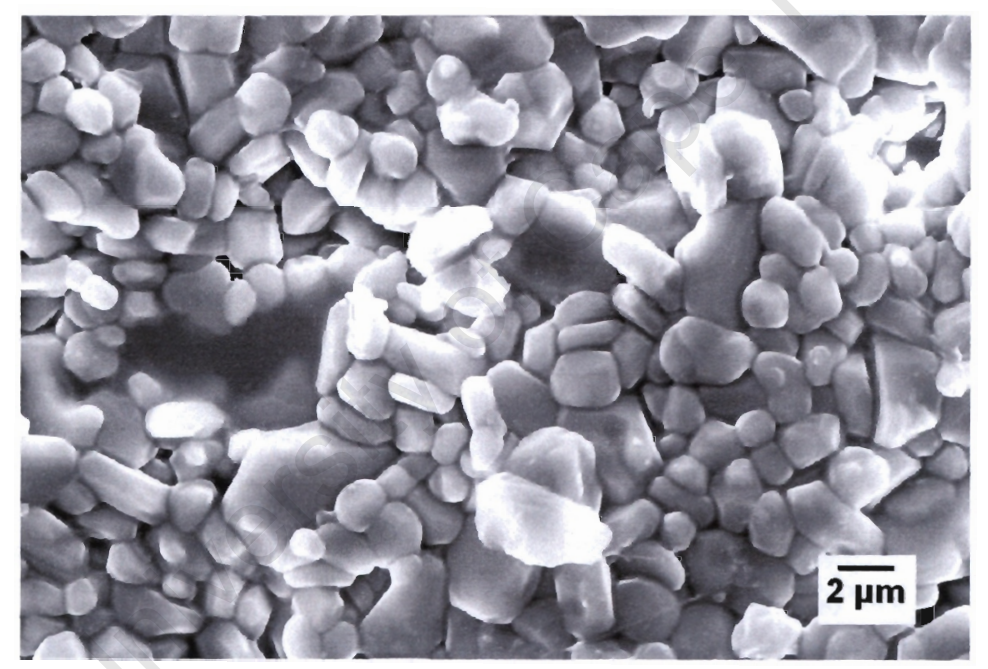

Figure 5.2: SEM micrograph showing the representative features of the surfaces of the alumina materials in the as-received condition.

The different erosion rates between the materials are probably because of differences in their porosity, which may be related to composition. This also explains why the $96 \%$ alumina dry pressed body (MP96) has the highest erosion resistance at almost all angles of impact. MP96 has the highest density, meaning it is less porous. As a result, it is more difficult to remove the grains in MP96 than in the rest of the materials. This suggests that all the three variables; composition, microstructure and the processing route, need to be carefully considered if erosive wear is to be controlled. However, this factor needs to be investigated in greater detail. 
In the case of $\mathrm{SiC}$ particulate composites, microscopic examination has revealed that prolonged exposure to erosion resulted in progressive removal of the matrix and subsequent removal of unsupported $\mathrm{SiC}$ particulates. This means that once sufficient matrix is removed, the unsupported grains are removed from the surface. The area of the matrix between the SiC grains renders the material susceptible to loss by the impacting erodent. This would be expected to give rise to increased erosion rates, especially as more of the larger SiC particulates are removed. However, results have indicated that erosion rates of the target materials remain constant from the onset. These can be attributed to the small size of the SiC particulates, which makes them not to have a significant effect on the erosion rate when they are removed.

\subsubsection{Elevated Temperature Erosive Wear}

The erosion rates of most alumina are believed to be almost unaffected by changes in temperature below $400^{\circ} \mathrm{C}^{38}$. In this study, however, a significant increase in the erosion rates of the target materials was observed when the test conditions were changed from room temperature to only $150^{\circ} \mathrm{C}$, with materials having less than $95 \%$ $\mathrm{Al}_{2} \mathrm{O}_{3}$ showing as high an increase as $40 \%$ or more. An improvement in ductility, which is associated with an increase in temperature, has been cited as the possible cause of the lack of significant changes in erosion rate of some materials with an increase in temperature.

An improvement in ductility is also believed to compete with a decrease in strength, which results in increased erosion rates. Also, it has been shown that the yield strength of alumina drops dramatically with an increase in temperature, and that the decline in strength is more if a substantial amount of glassy phase is present ${ }^{38}$. This will take place at much lower temperatures because of softening of the glassy phase. In this study, no evidence of the glassy phase was observed and so it is not clear what might have caused a rapid decline in strength, as suggested by increased erosion rates. Such a decrease in strength led to increased penetration of particles on impact and surface damage and thus decreased erosion resistance of the materials. 
Ritter et al developed a theory based on the erosion and strength degradation of alumina at $1000^{\circ} \mathrm{C}^{71}$. The theory predicts the dependence of both erosion rate and strength degradation on the kinetic energy of erodent particles. It is therefore most probable that, in this work, the apparent strength degradation at elevated temperatures is due to the increased particle impact velocity because of the expansion of the erodent carrying gas. This is consistent with the fact that the air velocity increases with temperature, leading to increased particle velocity and hence increased kinetic energy ${ }^{18}$. The almost non-existence of cracks may be the result of improved ductility.

\title{
5.2 THE EFFECT OF LOAD AND SPEED ON ABRASIVE WEAR
}

\begin{abstract}
Abrasion test results on the target materials have shown that the wear rates increase with an increase in both the applied load and the abrasion test speed. Such effects have also been observed in the past and have been attributed to contact pressure and subsequent stresses involved during the abrasion process. These stresses are said to be determined by the load, the roughness of the surfaces and the friction coefficient. In the present study, the roughness of the abrading surfaces and the friction coefficient were assumed to remain constant since the test specimens were continually exposed to the fresh surface of the abrasive belt. Therefore the different contact stresses originated from varying either the speed of the abrasive belt or the applied load.
\end{abstract}

It is a well known phenomenon that wear occurs because of the contacting asperities. As a result, the abrasive wear rate is proportional to the number of contacting asperities, which increases when the load is increased. This is the trend observed in this study, although it is not clear whether or not there is a linear relationship between the abrasive wear rate and the load. The fact that the observed fracture does not involve the entire contact area is indicative of spaces that exist between abrasive particles on the abrasive belt. 
Some researchers have indicated that at very high loads, the abrasives become damaged considerably, so that their abrading capability is greatly reduced ${ }^{52}$. Since a monotonous variation is observed in this study, between the abrasive wear rate and the load, the conclusion is that the highest load used, $40 \mathrm{~N}$, was not enough to damage both the alumina and the SiC abrasives. This was confirmed by optical examination of the belts prior to and after the tests.

An increase in abrasive wear rate with speed observed in this study is consistent with past research findings ${ }^{52}$. Even at the lowest speed, material removal takes place through severe wear, characterized by fracture and grain pull-out, coupled with the formation of grooves. As has been pointed out in the literature, this is attributed to larger stresses induced at the higher speeds ${ }^{54}$.

\subsection{ABRASIVE WEAR BEHAVIOUR}

There is a general assumption amongst researchers that a ceramic with a higher alumina content will be more wear resistant than one with a lower alumina content. This is because alumina is generally harder than any of the second phases commonly found in these ceramics. Such predictions are supported by this study, although MP96 showed a higher abrasion resistance than M97. Other studies have revealed that grain size range is a better predictor of wear behaviour than alumina composition $^{28}$. In this work, the materials differ very little in terms of microstructure and therefore the observed differences in abrasive wear behaviour can be attributed to differences in alumina content.

It has been shown in the present study that the abrasive wear manifests itself by fracture and the formation of grooves. The grooves observed are mostly due to plastic deformation of the surface and they generate very little or no wear debris. The wear debris, visible as white particles, are the result of fracture and are agglomerates of much smaller wear particles. In ceramics, the wear debris are normally soft and their role is to distribute stresses and accommodate shear movement ${ }^{72}$. As a result, they reduce surface fracture and material removal takes 
place through mild wear in the form of cutting and ploughing. However, this was not observed in this study. Even at a low load and speed, severe wear, which takes place through fracture and grain pull-out, was the dominant mechanism of material removal. It is therefore possible that the wear debris in this case underwent enough plastic deformation to cause intimate contact between the test specimen and the abrasive belt. This has also been observed in the case of metallic materials ${ }^{71}$.

It is evident from microscopic examination of the abraded surfaces that microcracks or fracture are the major cause of material removal. Several small grains were pulled out and the surfaces are characterized by subgrain cracks. When these microcracks are connected to facets of grain boundaries, wear particles are generated. This is attributed to the tribological stress which exceeds the critical crack stress or the fracture stress. Such a crack controlled wear process usually produces higher material removal rates than the plastic deformation controlled wear process.

\subsection{COMPARISON BETWEEN EROSIVE AND ABRASIVE WEAR}

A couple of similarities and differences have emerged between the two kinds of wear tests. For erosive wear, there is no definite trend amongst the materials at all angles of impact, while the abrasive wear resistance generally increases with an increase in alumina content. It was also interesting to note that in both tests, MP96 emerged as having the best wear resistance, mainly because of its relatively lower porosity.

It is also evident that both erosive and abrasive wear manifests themselves in not so different ways. Erosion surfaces are characterised by erosion pits with very little evidence of cracking. In fact, the only piece of evidence of cracking was observed at higher angles of impact. In the case of abrasive wear damage, fracture and grain pull-out were accompanied by the formation of grooveson the surfaces. As explained earlier, these modes of material removal can be attributed to different contributions of the kinetic energy of erodent particles and abrasive belts. 


\section{CHAPTER 6}

\section{CONCLUSIONS}

Based on the results obtained and discussions from this work, the following conclusions are reached:

- The erosion rates of the tested alumina ceramics increase with an increase in impact angle, reaching a maximum at $90^{\circ}$. Because of its lower porosity, the high purity 96\% alumina dry-pressed body (MP96) has the best average erosion resistance at most impact angles, while the $92 \%$ alumina dry pressed body (MP92) has the worst average erosion resistance.

- The erosion rates also increased with an increase in particle impact velocity, resulting in a velocity exponent $(n)$ value of 1.5 . This may be attributed to the different test conditions, including a different test rig.

- The erosion rates decreased slightly with an increase in particle size range. This may be attributed to slight changes in the particle angularity as the particle size range increases. Furthermore, a $72 \%$ and $64 \%$ decreases in the erosion rate were observed when the erodent particle type was changed from silicon carbide to alumina and from alumina to silica sand, respectively. The softer silica sand particles were unable to inflict significant damage accumulation on the target materials.

- At all angles of impact, solid particle erosion of the target materials is dominated by intergranular fracture and surfaces are characterized by erosion pits. However, there is very little evidence of cracking on the eroded surfaces.

- Alumina ceramics behave much better than $\mathrm{SiC}$ particulate composites in terms of erosion resistance. The area of the matrix between the SiC grains renders the target material susceptible to matrix removal by the impacting erodent. 
- The five alumina target materials show a marked increase in erosion rates when the test temperature is increased from ambient to $150^{\circ} \mathrm{C}$. This may be due to an increase in kinetic energy of erodent particles, owing to an increase in particle velocity.

- The abrasive wear rates for the materials increased with both applied load and abrasive speed, owing to increased tribological stresses at the contacting asperities. There is also a general trend of increasing abrasion resistance with increasing alumina content.

- Severe wear, characterized by fracture and grain pullout, is the dominant mechanism of material removal during abrasive wear. This was accompanied by the formation of grooves on the wear surfaces.

000000000000 


\section{CHAPTER 7}

\section{RECOMMENDATIONS}

The following specific recommendations are made:

- Of all the materials tested, the alumina ceramics are the best materials to utilize if both erosive and abrasive wear are to be reduced. $\mathrm{SiC}$ particulate composites should not be considered because of their extremely high erosion rates.

- The elevated temperature erosive behaviour of the target materials should be studied in greater detail, this time taking into account the effects of gas expansion, which result in an increase in velocity. If the apparent strength degradation of the materials at $150^{\circ} \mathrm{C}$ is only due to an increase in the kinetic energy of erodent particles, it should be safe to use the materials for the purpose of reducing fly-ash erosion.

- A plant visit, for the purposes of on-site examination, would be of great benefit. This will allow direct comparison between mechanisms of material removal from tiles in chutes and hoppers and laboratory results.

- Despite their differences in chemical composition and processing methods, the alumina target materials tested in this study showed little differences in terms of mechanical and wear behaviour. It will therefore be beneficial to compare alumina ceramics with other materials such as hard coatings and other ceramics.

- Both solid particle erosion and abrasion have been shown to occur synergistically with corrosion. Therefore the design of a laboratory test rig that can evaluate such synergistic effects would be of uttermost importance if wear damage in power plants is to be further reduced.

000000000000 


\section{REFERENCES}

1. uww.eia.doe.gov/neic/press/press235.html

2. www.personal.psu.edu/users/d//djit171/Josh5of8.html

3. www.eskom.co.za

4. www.personal.psu.edu/users/a/t/atr112/images

5. J. Stringer. Wear 186-187 (1995) $11-27$.

6. M. Suckling and C. Allen. Wear 186-187 (1995) 266-272.

7. J. D. Gates. Wear 214 (1998) $139-146$.

8. G.W. Stachowiak and A.W. Batchelor. Engineering Tribology, Tribology Series 24, Elsevier Science Publishers, Nertherlands (1993).

9. B. A. Lindsley and A.R. Marder. Wear 225-229 (1999) 510-516.

10. Q. Chen and D.Y. Li. Wear 254 (2003) $203-210$.

11. J.G. Chacon-Nava, F.H. Stott, S.D. de la Torre and A. Martinez-Villafane. Materials Letters 55 (2002) 269-273.

12. www.surfaceengineering.com/Solutions-Solidlmp

13. H. Wensink and M.C. Elwenspoek. Wear 253 (2002) 1035-1043.

14. P.H. Shipway and I.M. Hutchings. Wear 193 (1996) 105-113.

15. Z. Feng and A. Ball. Wear 233-235 (1999) 674-684. 
16. D.E. Alman, J.H. Tylczak, J.A. Hawk and J.H. Schneibel. Materials Science and Engineering A329-331 (2002) 602-609.

17. S.E. Fewell. The Particle Erosion of Steel by Magnetite. MSc (Eng) Thesis, University of Cape Town, 2002

18. A.L. Ham, J.A. Yeomans and J.F. Watts. Wear 233-235 (1999) 237-245.

19. W. Tabakoff and V. Shanov. Surface and Coatings Technology 76-77 (1995) $75-$ 80.

20. Z. Huang, Z.Z. Li and X. Yuan. Wear 249 (2001) $1046-1050$.

21. R.J.K. Wood. Materials and Design 20 (1999) $179-191$.

22. M. Talia, H. Lankarani and J.E. Talia. Wear 225-229 (1999) $1070-1077$.

23. Y. Zhang, Y.B. Cheng and S. Lathabai. Wear 240 (2000) $40-51$.

24. P.H Shipway and I.M. Hutchings. Wear 174 (1994) $169-175$.

25. P.R. Krishnamoorthy, S. Seetharamu and P. Sampathkumaran. Wear 165 (1993) $151-157$.

26. M. Suckling and C. Allen. Wear $203-204$ (1997) $528-536$.

27. C. Allen and A. Ball. Tribology Intemational 29 (1996) $105-116$.

28. C.P. Dogan and J.A. Hawk. Wear 225 - 229 (1999) $1050-1058$.

29. S. Wada and N. Watanabe. J. Ceram. Soc. Jpn. Int. Ed. 95 (1987) 783 - 787.

30. I. Hussainova, J. Kubarsepp and J. Pirso. Wear 250 (2001) $818-825$.

31. D.F. Wang, J.H. She and Z.Y. Ma. Wear 180 (1995) $35-41$.

32. U. Beste, L. Hammerstrom, H. Engqvist, S. Rimlinger and S. Jacobson. Wear 250 (2001) $809-817$. 
33. B.F. Levin, J.N. DuPont and A.R. Marder. Wear 238 (2000) $160-167$.

34. Q. Chen and D.Y. Li. Wear 255 (2003) $78-84$.

35. M. Dundar, O.T. Inal and J. Stringer. Wear 233 - 235 (1999) 727 - 736.

36. G.L. Sheldon and I. Finnie (1966) in H. Wensink and M.C. Elwenspoek. Wear 253 (2002) $1035-1043$.

37. C.S. Yust and R.S. Crouse. Wear 51 (1978) 193 - 196.

38. J. Zhou and S. Bahadur. Wear $181-183$ (1995) $178-188$.

39. A.F. Colclough and J.A. Yeomans. Wear 209 (1997) $229-236$.

40. A.L. Ham, J.A. Yeomans and J.F. Watts. Wear 203 - 204 (1997) 387 - 392.

41. L. Fang, Q. Zhou and Q. Li. Wear 219 (1998) 188 - 194.

42. S.J. Quirke. Abrasive Wear Testing of Steels in Soil. MSc (Applied Science) Thesis, University of Cape Town, 1997.

43. K. Kato and K. Adachi. Wear 253 (2002) 1097 - 1104.

44. Y. Berriche, J. Vallayer, R. Trabelsi and D. Treheux. Joumal of the European Ceramic Society 20 (2000) $1311-1318$.

45. S.G. Roberts. Scripta Materialia 40 (1) (1999) 101 - 108.

46. G.Y. Lee, C.K.H. Dharan and R.O. Ritchie. Wear 252 (2002) $322-331$.

47. J. Larsen-Basse. Scripta METALLURGICA et MATERIALIA 24 (1990) 821 - 826.

48. Y. Wang and S.M. Hsu. Wear 195 (1996) $112-122$.

49. G. Sundararajan. Wear $162-164$ (1993) $773-781$. 
50. L. Fang, J. Xing, W. Liu, Q. Xue, G. Wu and X. Zhang. Wear 251 (2001) 1356 1360

51. D.S. Mao, J. Li, S.Y. Guo and Z.Y. Mao. Wear 209 (1997) $153-159$.

52. M.A. Verspui and G. de With. Journal of the European Ceramic Society 17 (1997) $473-477$.

53. X. Ma, R. Liu and D.Y. Li. Wear 241 (2000) $79-85$.

54. L. Esposito and A. Tucci. Wear 205 (1997) 88 - 96.

55. K.M. Shorowordi, A.S.M.A. Haseeb and J.P. Celis. Wear $256(11-12)$ (June 2004), $1176-1181$.

56. M. Terheci. Wear 211 (1997) $289-301$.

57. E. Medvedovski. Wear 249 (2001) $821-828$.

58. C.P. Dogan and J.A. Hawk. Wear 250 (2001) $256-263$.

59. B. Venkataraman and G. Sundararajan. Acta Materialia 44 (2) (1996) 451 - 460.

60. K.H. Zum-Gahr. Tribology International 31 (10) (1998) 587 - 596.

61. R. Colaco and R. Vilar. Wear 254 (2003) $625-634$.

62. S.W. Date and S. Malkin. Wear 40 (1976) $223-235$.

63. R. Gahlin and S. Jacobson. Wear 224 (1999) $118-125$.

64. J.J. Wells, F. Wigley, D.J. Foster, W.H. Gibb and J. Williamson. Fuel 83 (2004) 359 -364 .

65. M.A. Verspui, G. de With, P.G.Th. van der Varst and M. Buijs. Wear 188 (1995) 102 $-107$.

66. H. Sin, N. Saka and N.P. Suh. Wear 55 (1979) $163-190$. 
67. D.V. De Pellegrin and G.W. Stachowiak. Tribology International 37 (2004) 255 270.

68. M. Suckling. High Temperature Erosive Wear of Boiler Tube Steel. MSc (Eng) Thesis, University of Cape Town, 1996.

69. S.L. Palasamudram and S. Bahadur. Wear 203 - 204 (1997) 455 - 463.

70. S. Srinivasan and R.O. Scattergood. Wear 142 (1991), $115-133$.

71. J.E. Ritter, L. Rosenfeld and K. Jakus. Wear 111 (4) (4 October 1986), 335 - 346.

72. T.E. Fischer, Z. Zhu, H. Kim and D.S. Shin. Wear 245 (2000) $53-60$. 


\title{
APPENDICES: \\ COMPARATIVE VOLUME LOSS CURVES FOR BOTH SOLID PARTICLE EROSION AND ABRASIVE WEAR
}

\author{
APPENDIX I
}

THE EFFECT OF IMPACT ANGLE 


\section{$20^{\circ}$ IMPACT ANGLE}

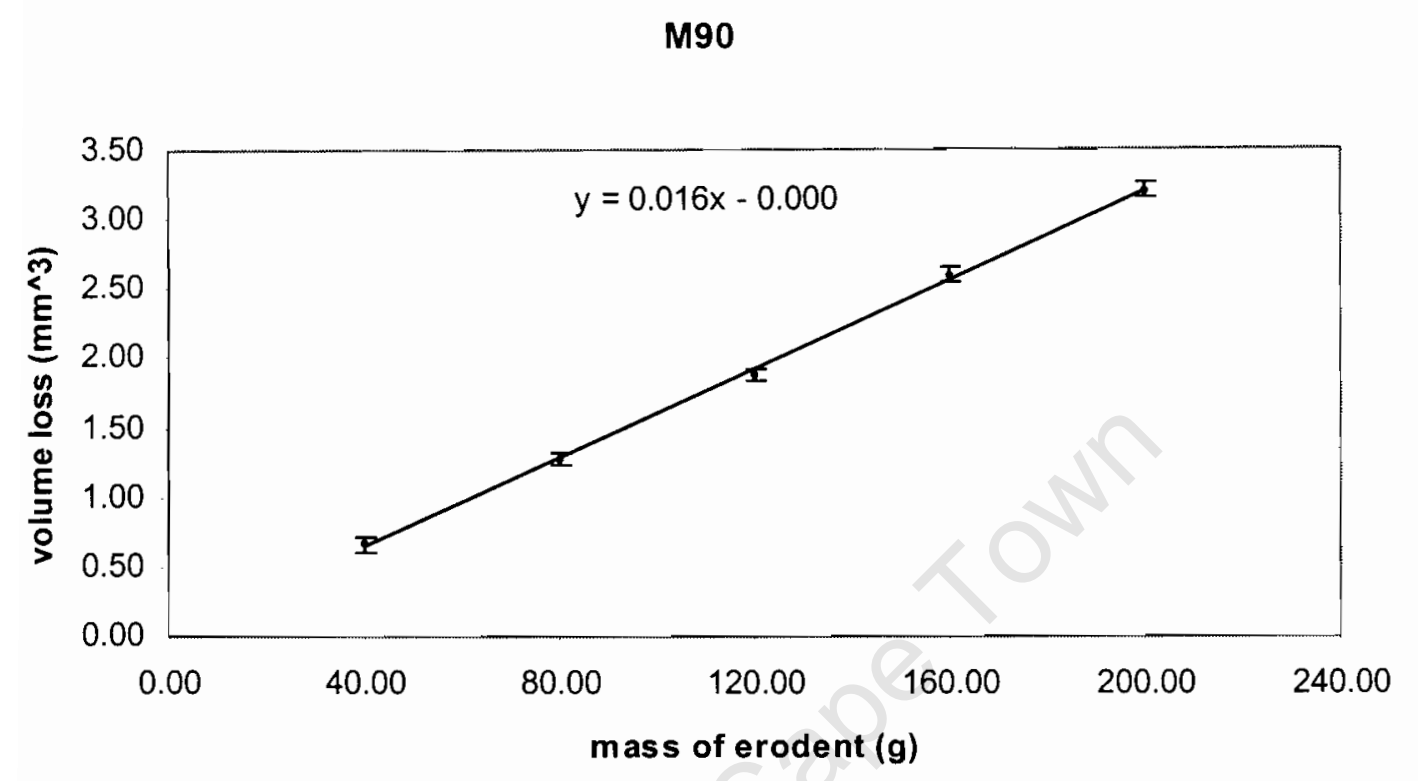

MP92

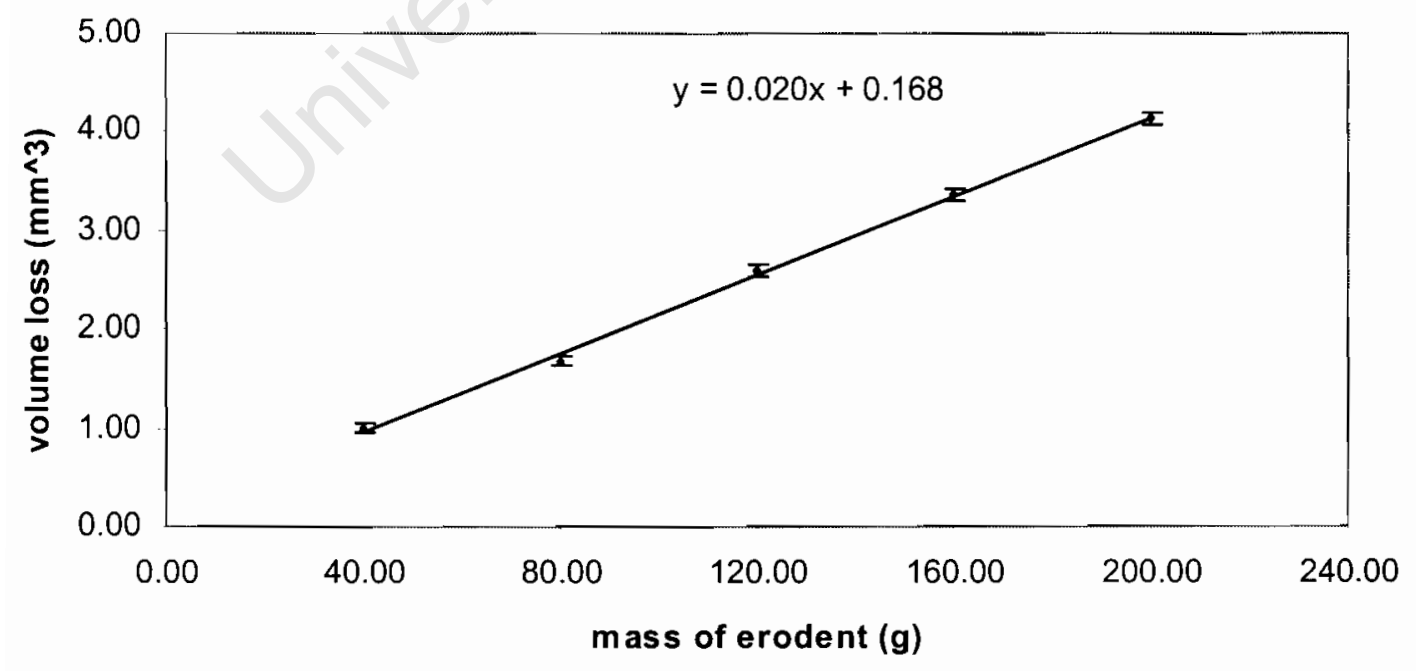




\section{$20^{\circ}$ IMPACT ANGLE}

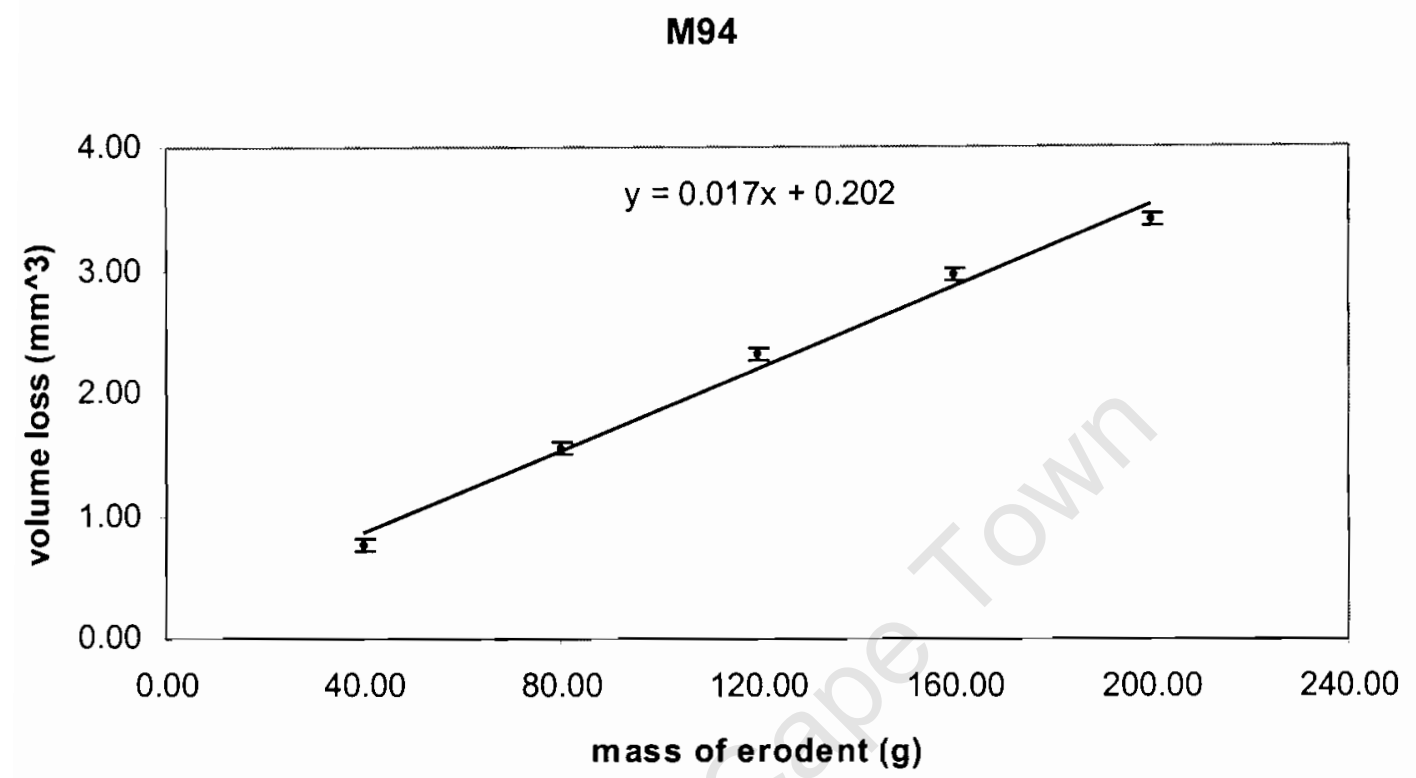

MP96

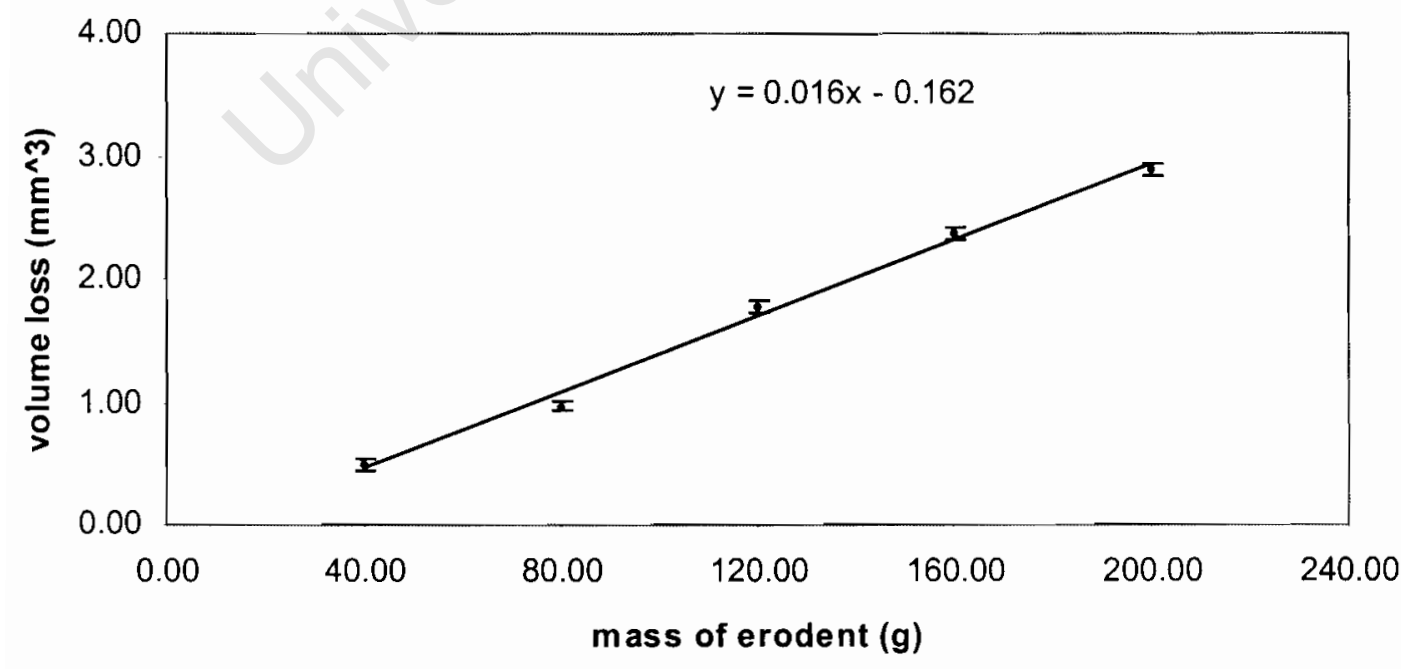




\section{$20^{\circ}$ IMPACT ANGLE}

M97

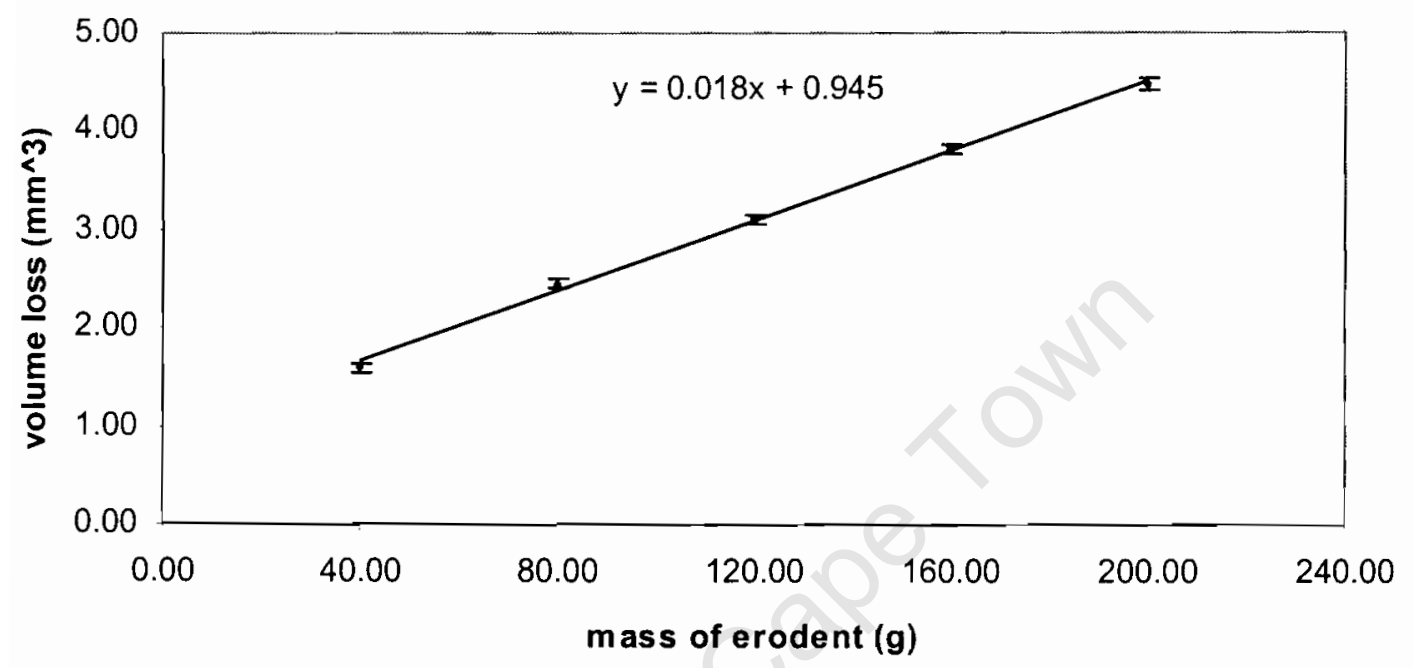




\section{$45^{\circ}$ IMPACT ANGLE}

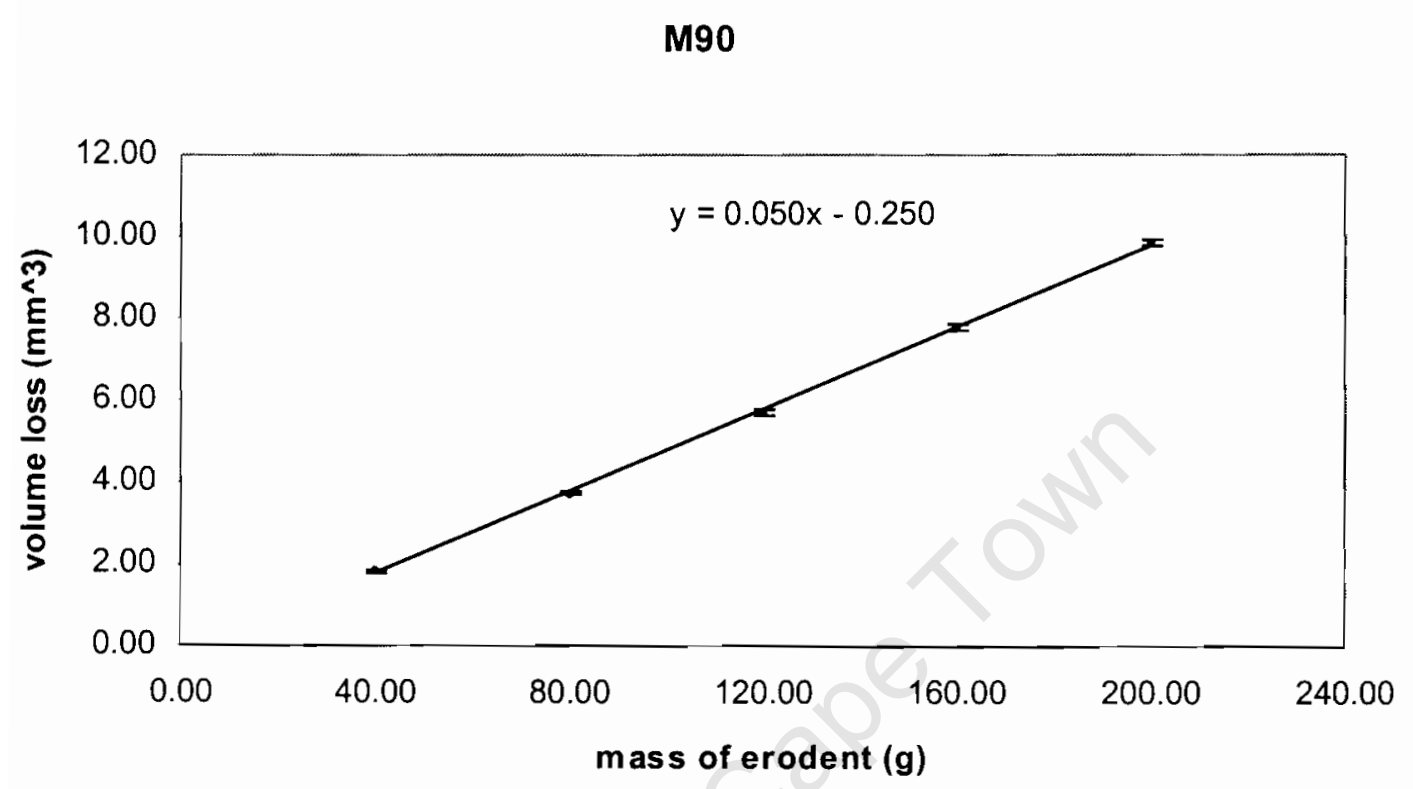

MP92

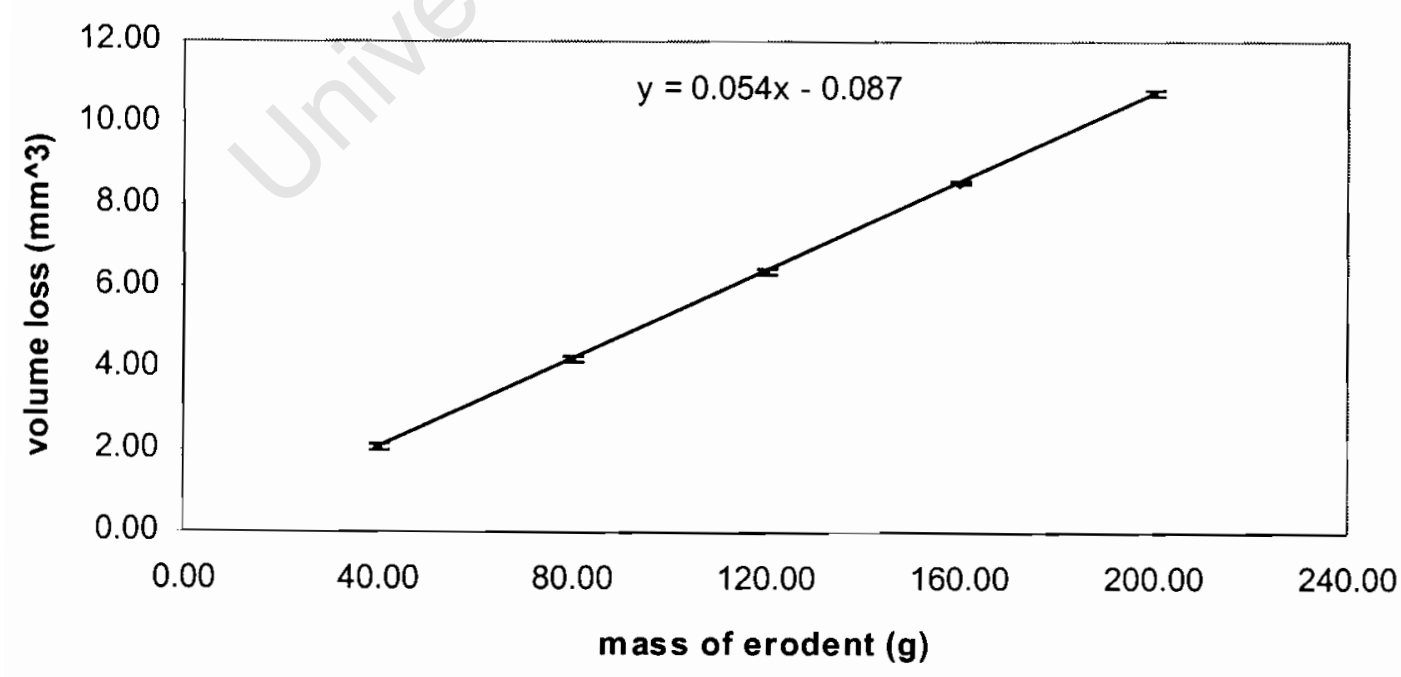




\section{$45^{\circ}$ IMPACT ANGLE}

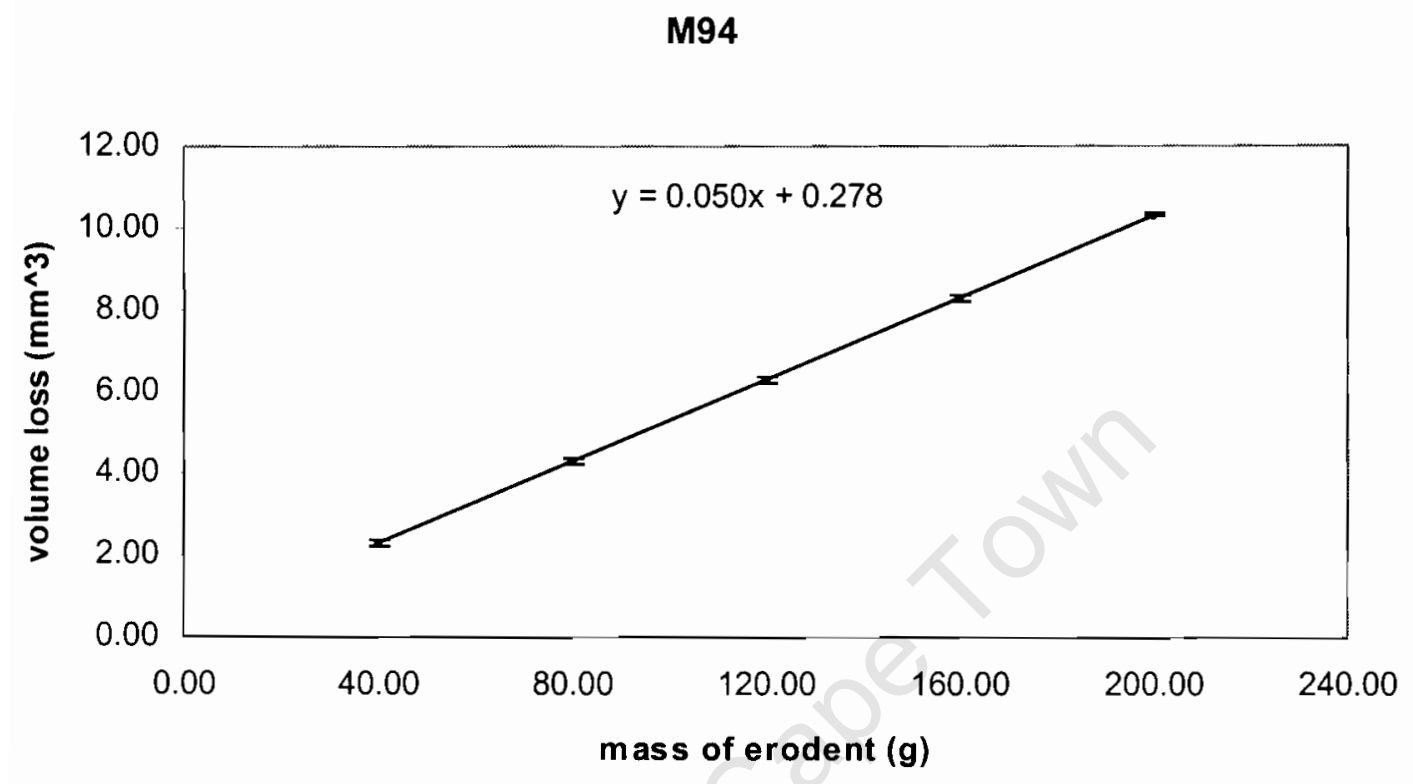

MP96

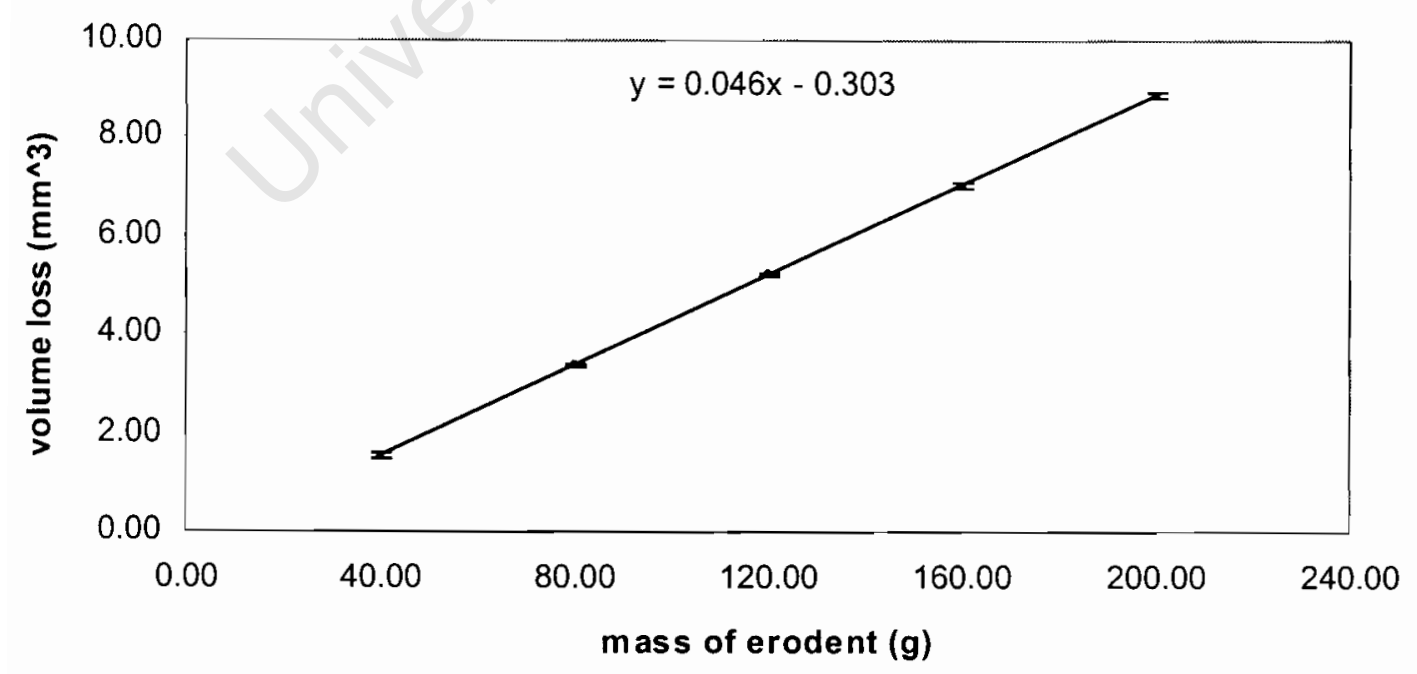




\section{$45^{\circ}$ IMPACT ANGLE}

M97

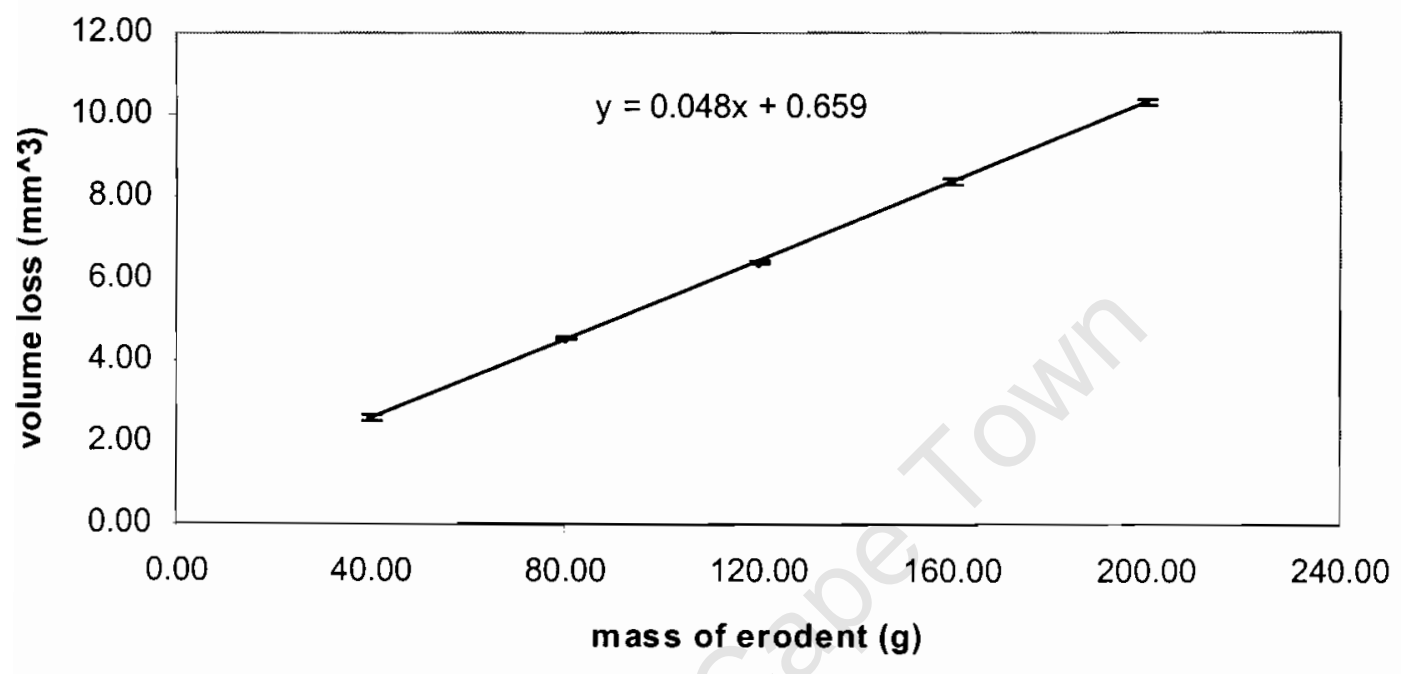




\section{$60^{\circ}$ IMPACT ANGLE}

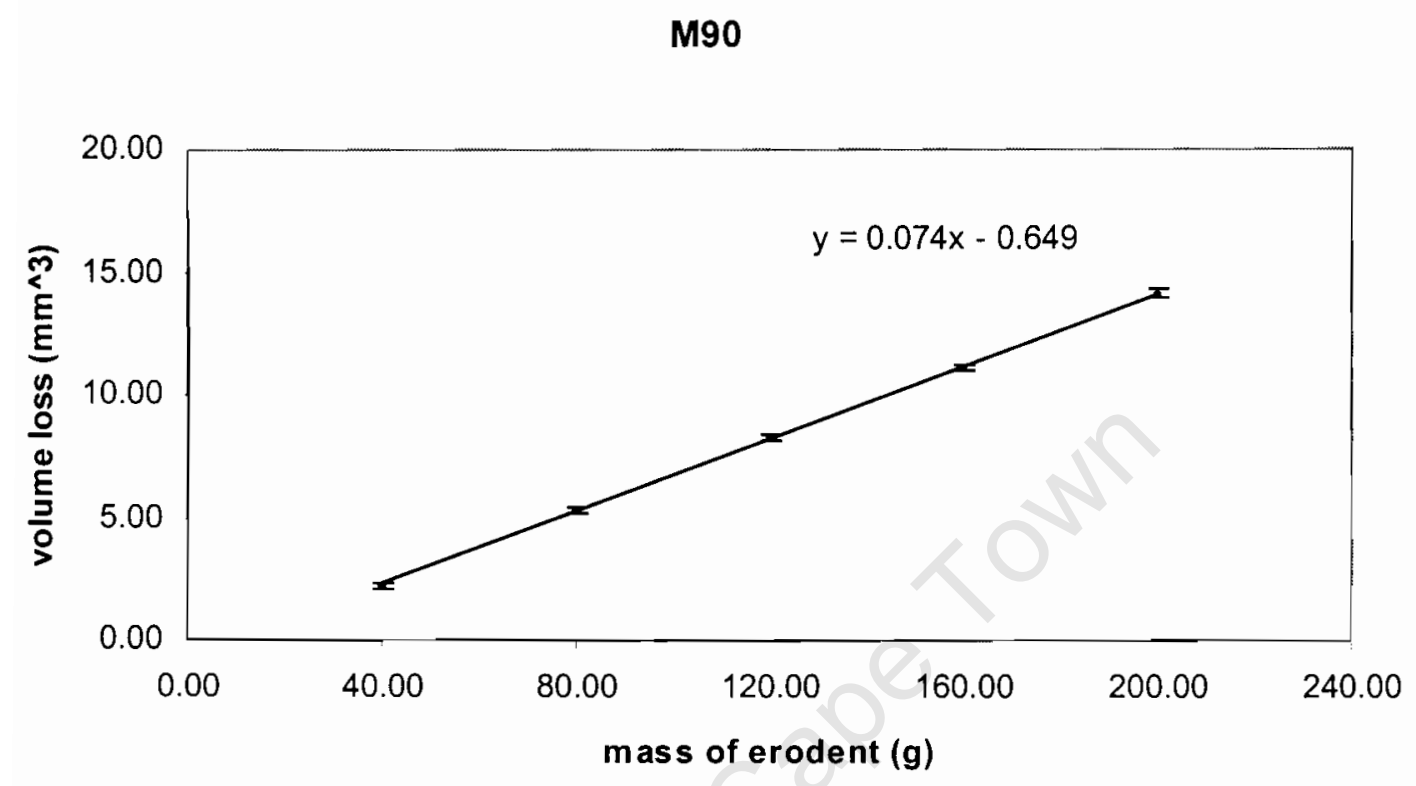

MP92

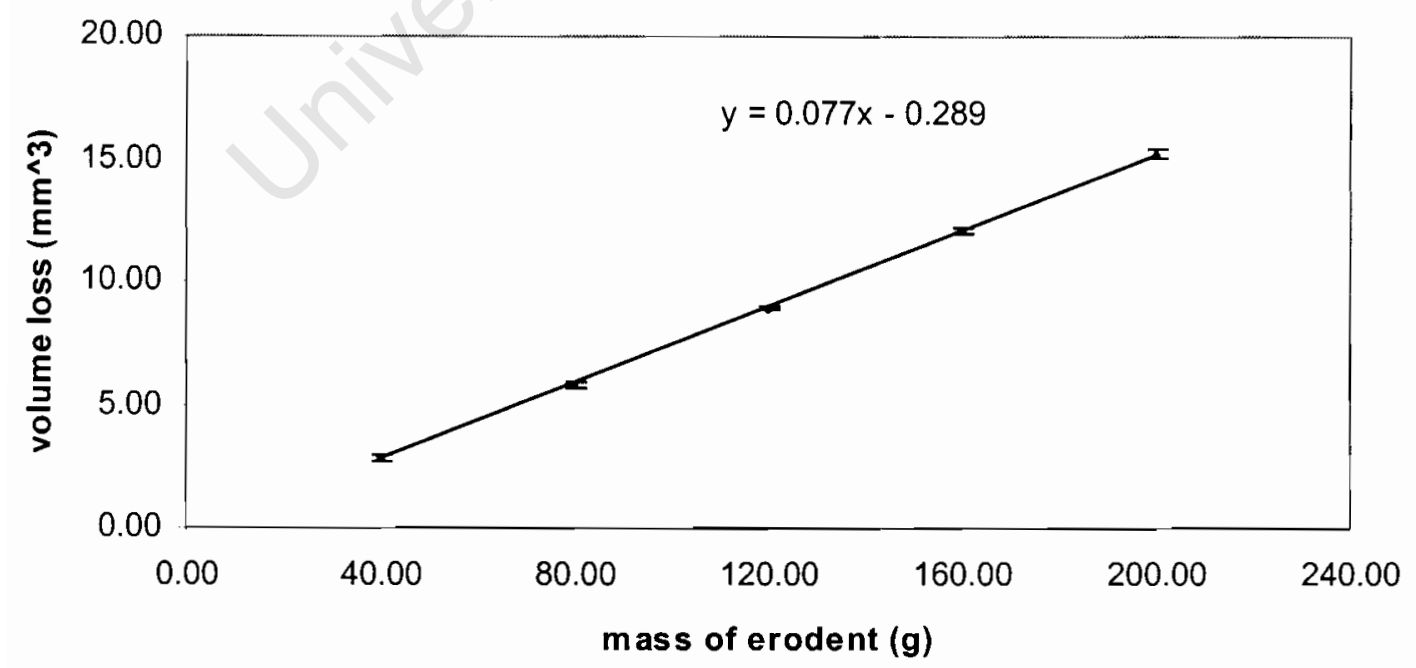




\section{$60^{\circ}$ IMPACT ANGLE}

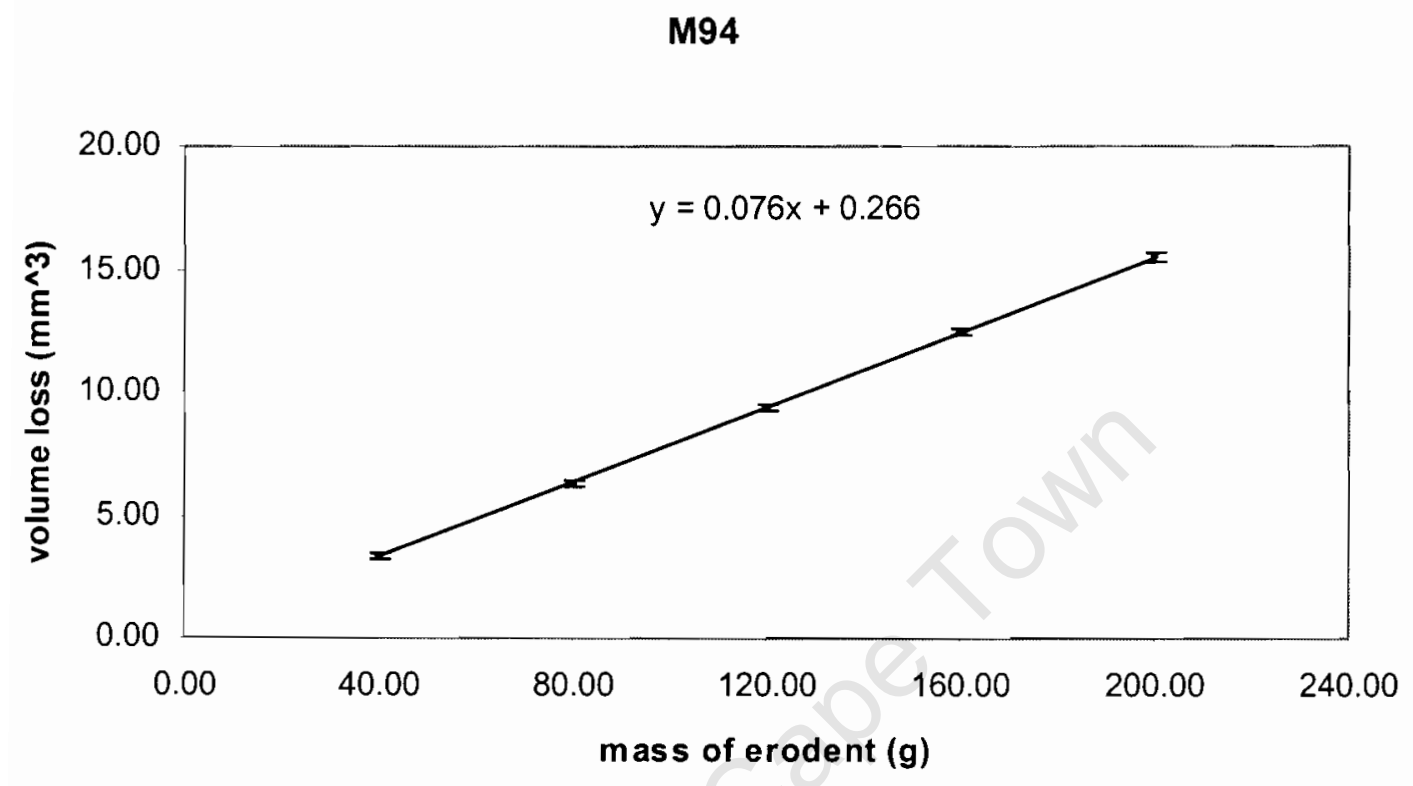

MP96

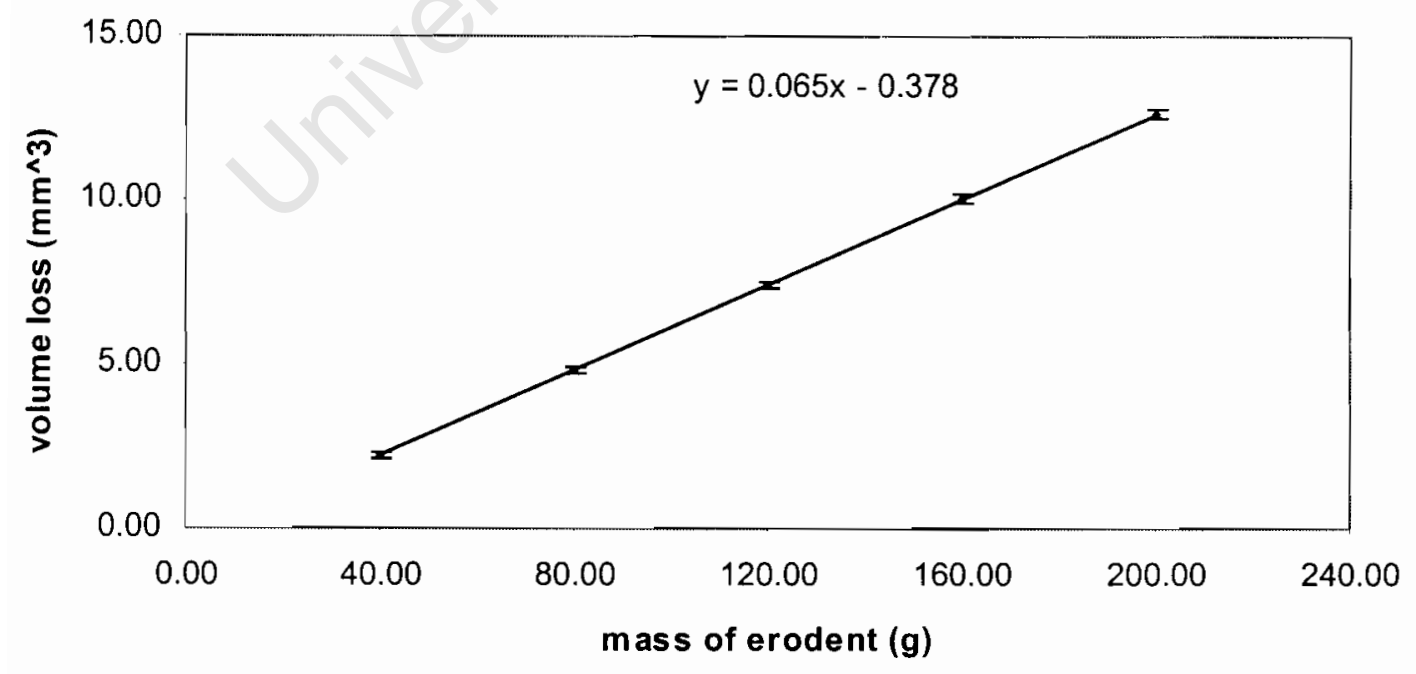




\section{$60^{\circ}$ IMPACT ANGLE}

M97

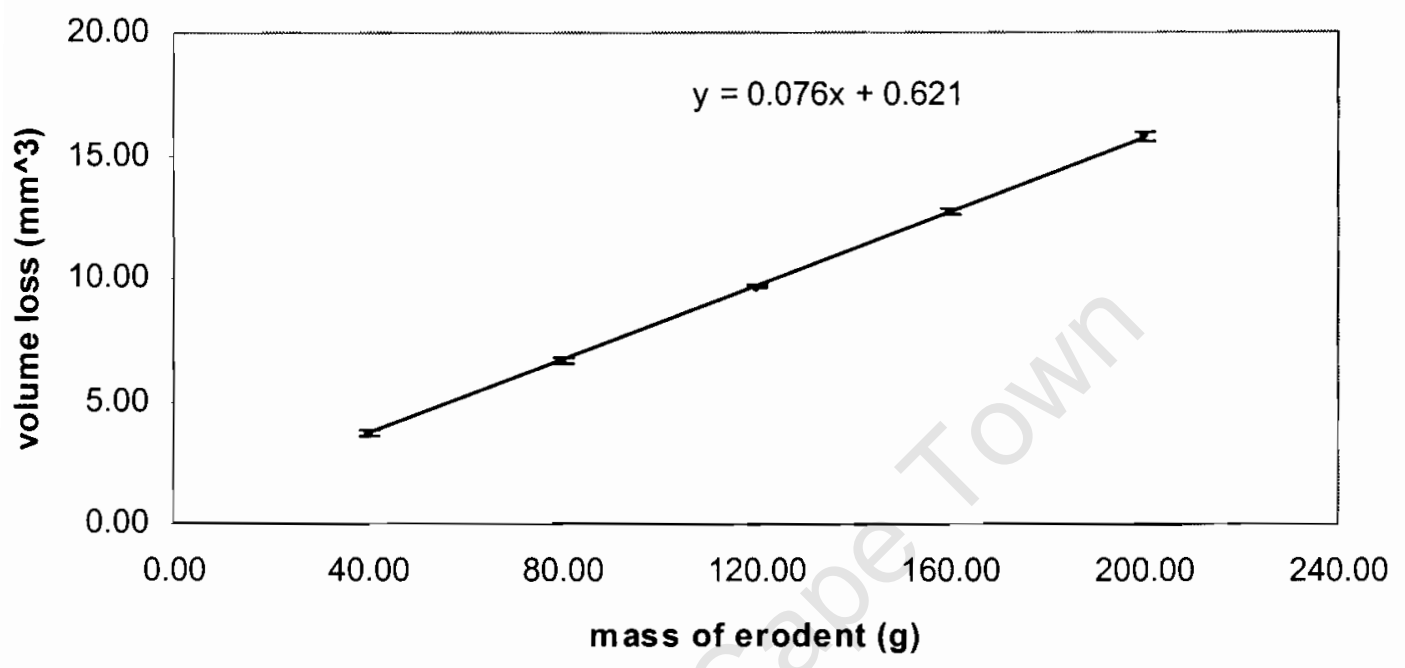




\section{$80^{\circ}$ IMPACT ANGLE}

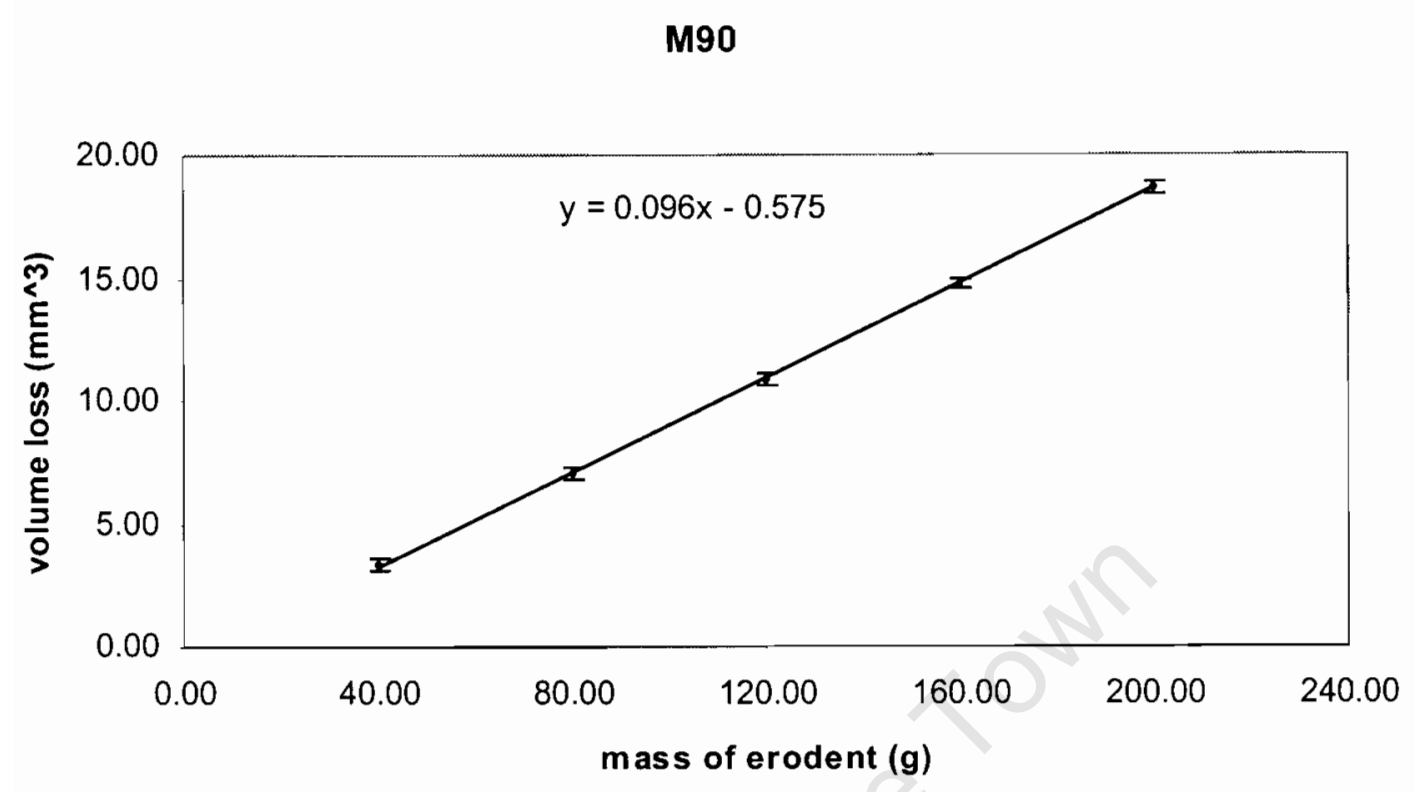

MP92

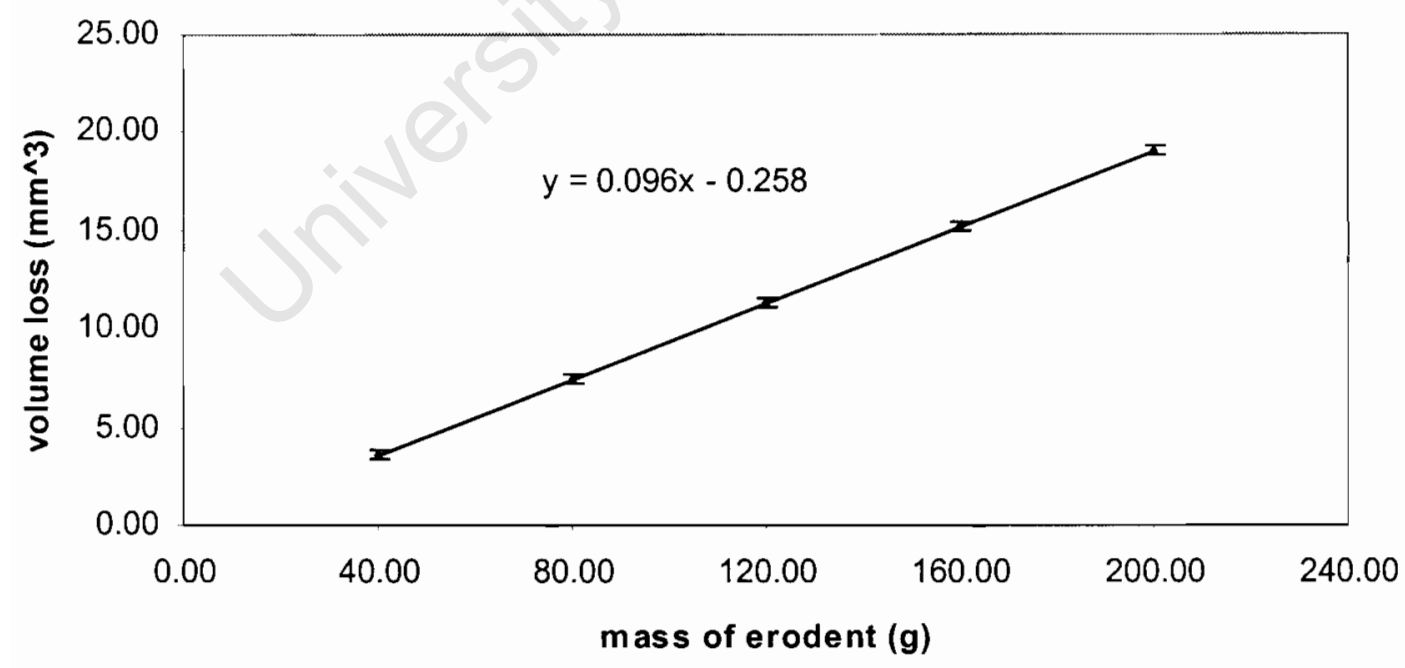




\section{$80^{\circ}$ IMPACT ANGLE}

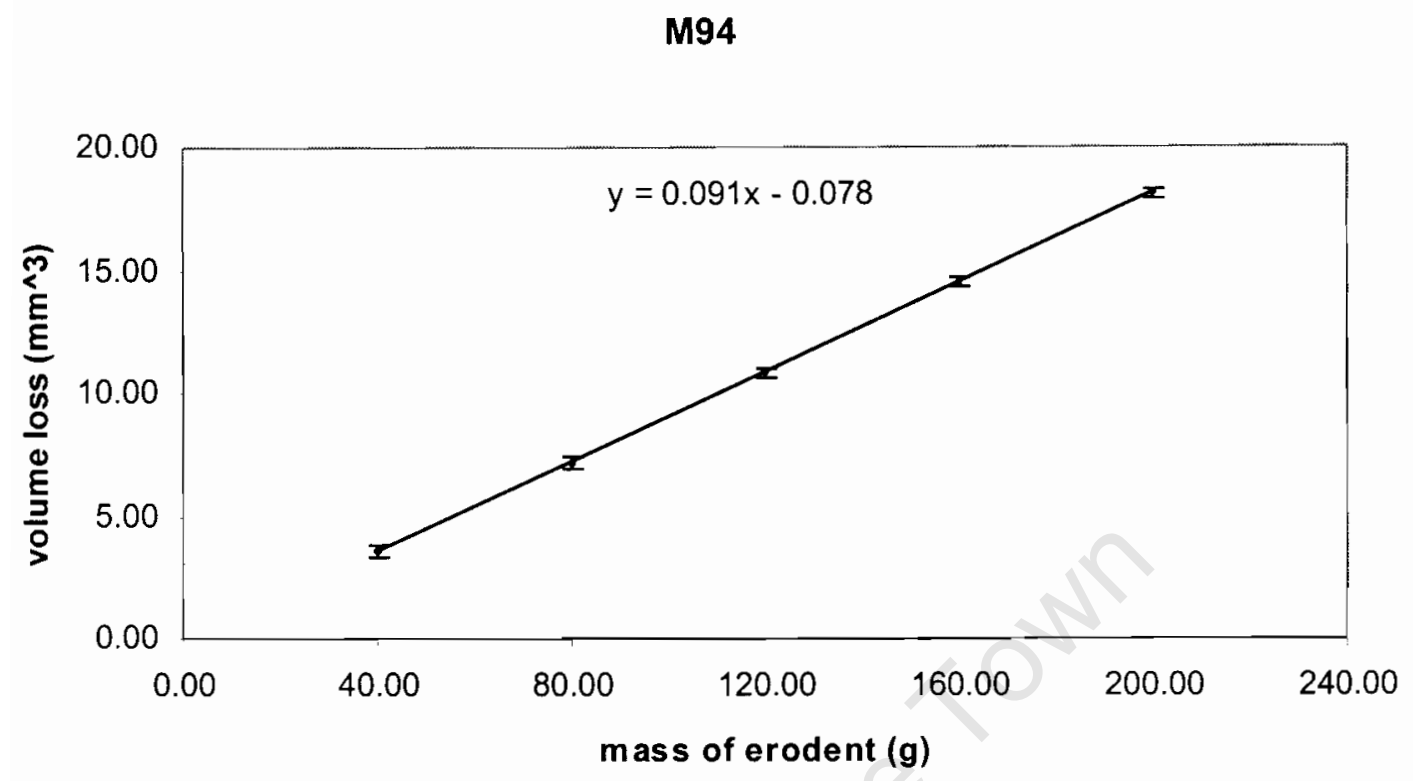

MP96

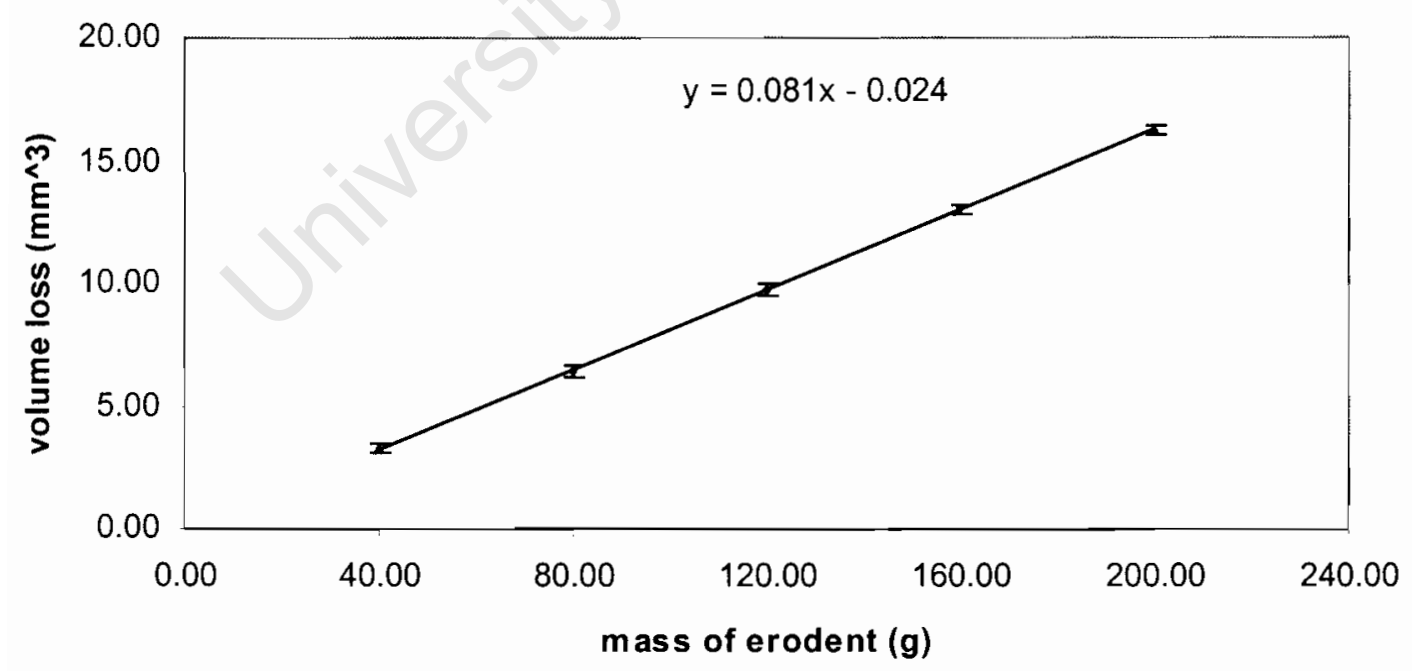




\section{$80^{\circ}$ IMPACT ANGLE}

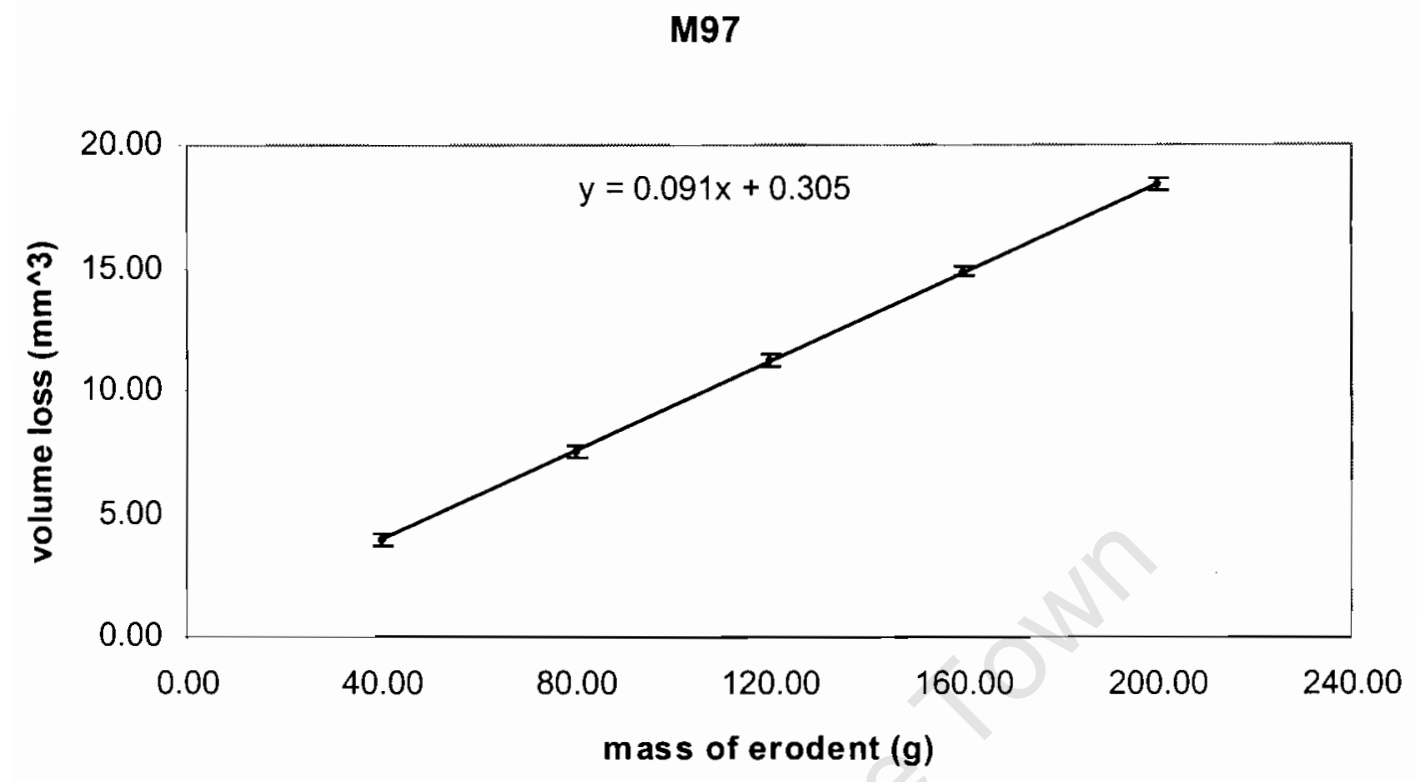




\section{$90^{\circ}$ IMPACT ANGLE}

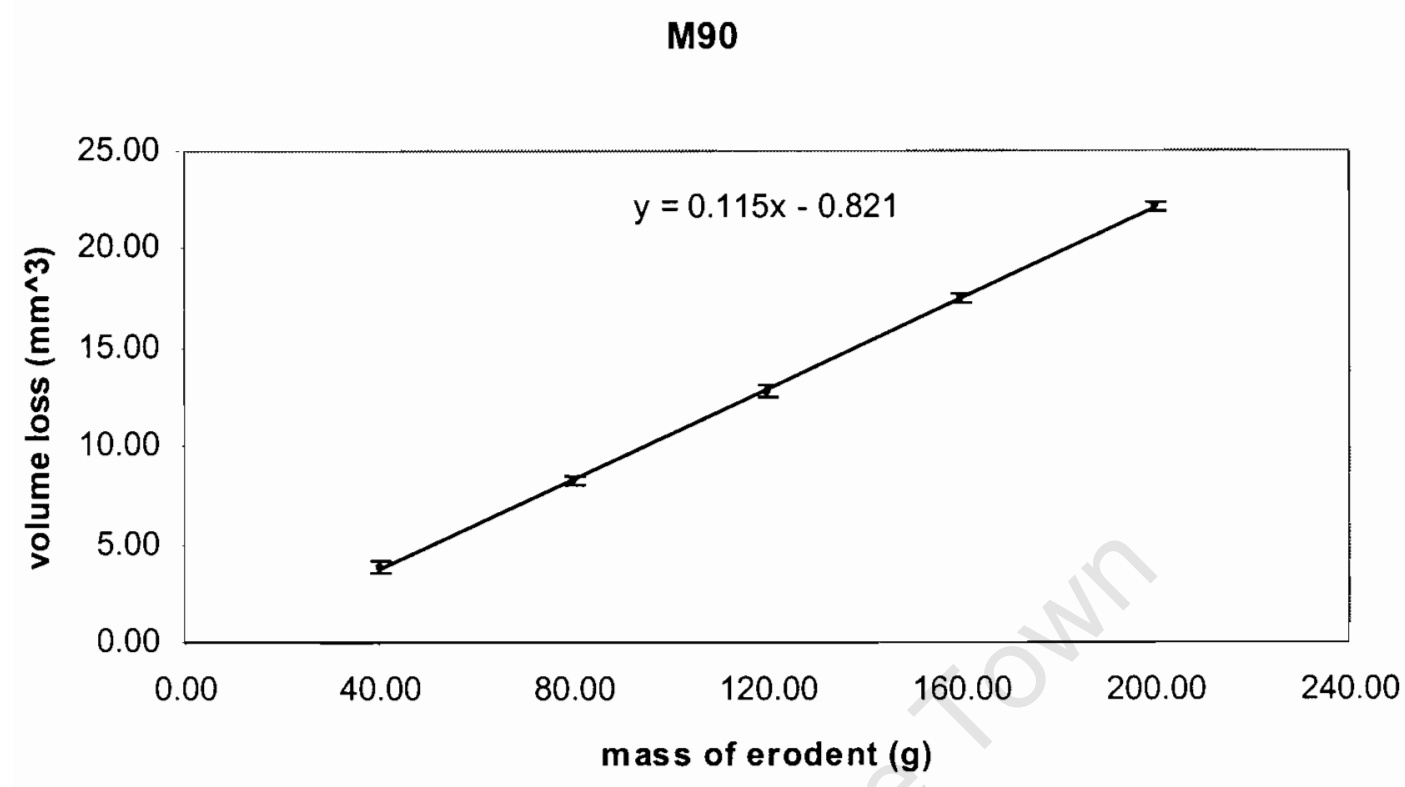

MP92

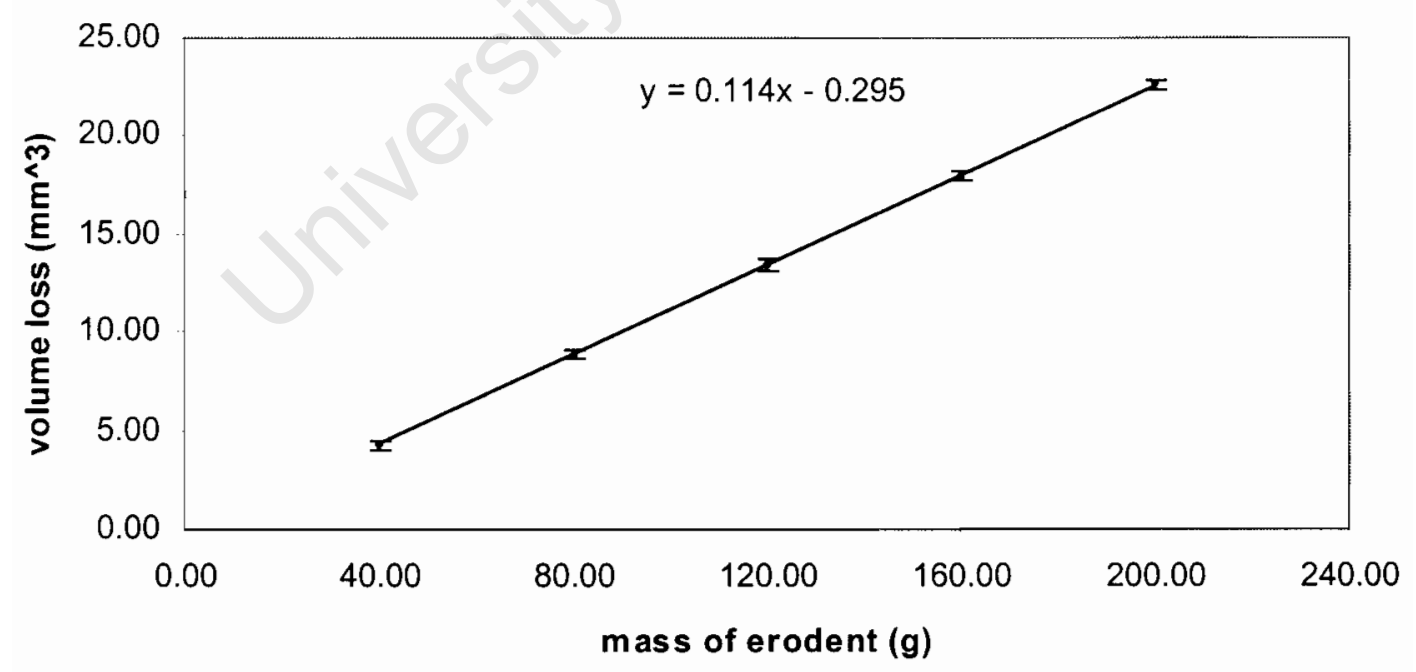




\section{$90^{\circ}$ IMPACT ANGLE}
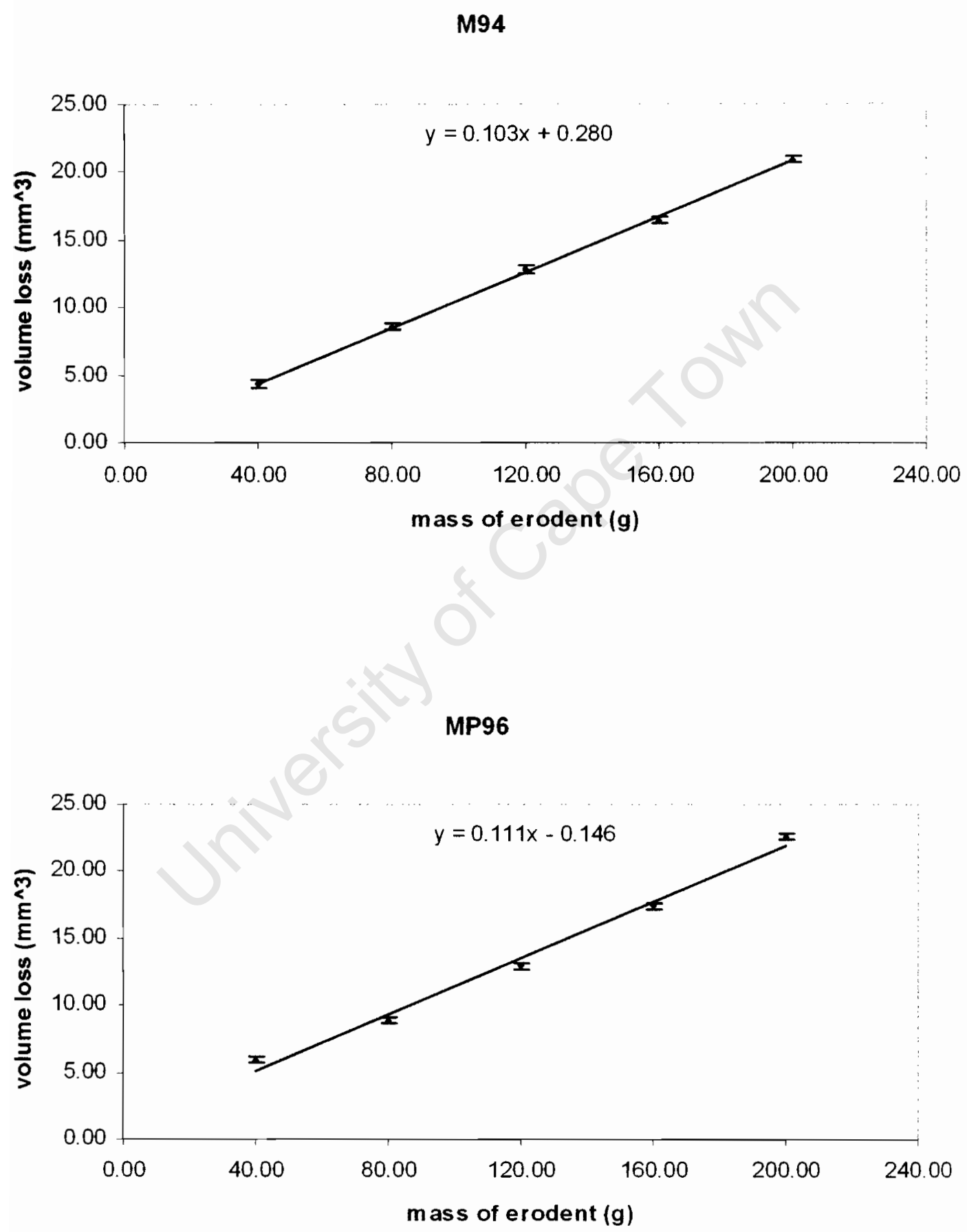


\section{$90^{\circ}$ IMPACT ANGLE}

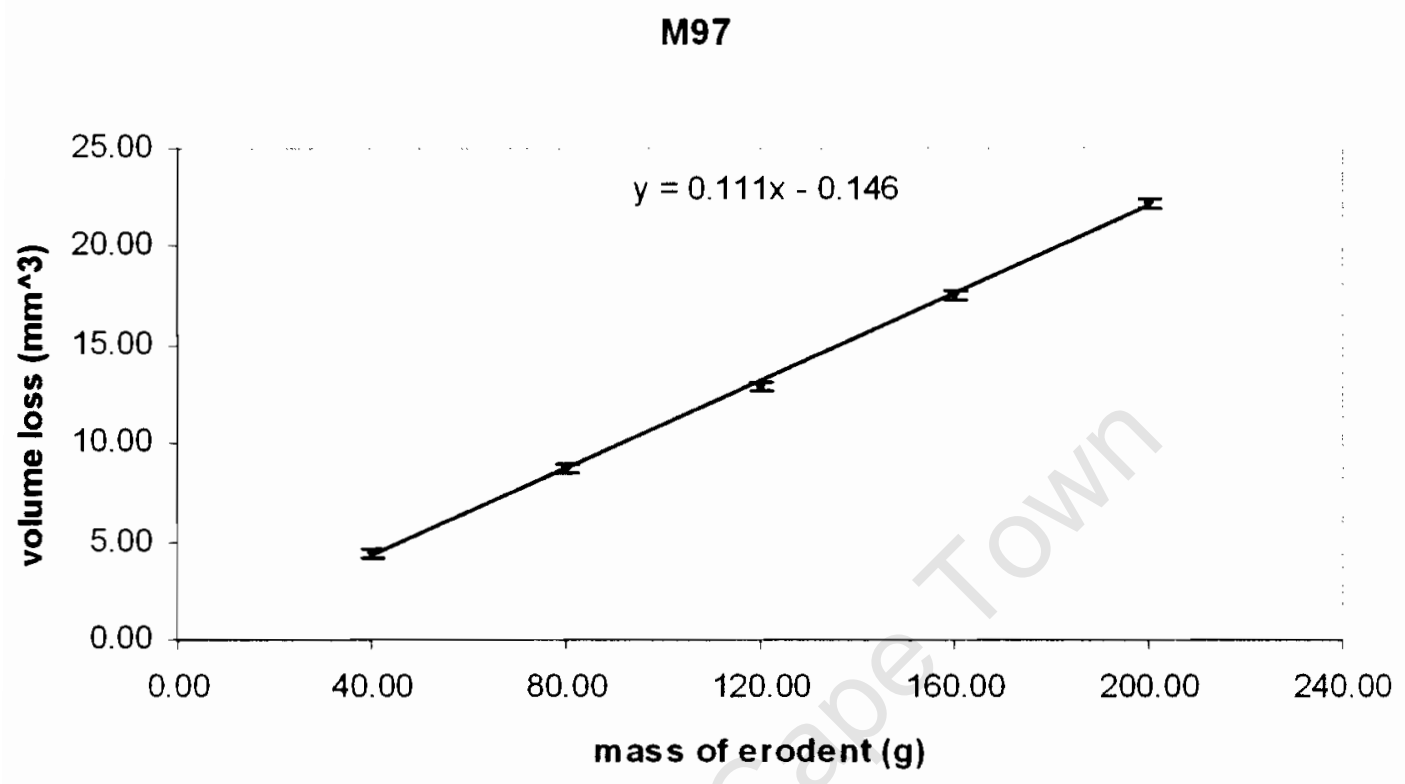

APPENDIX II

THE EFFECT OF VELOCITY 


\section{MP92}

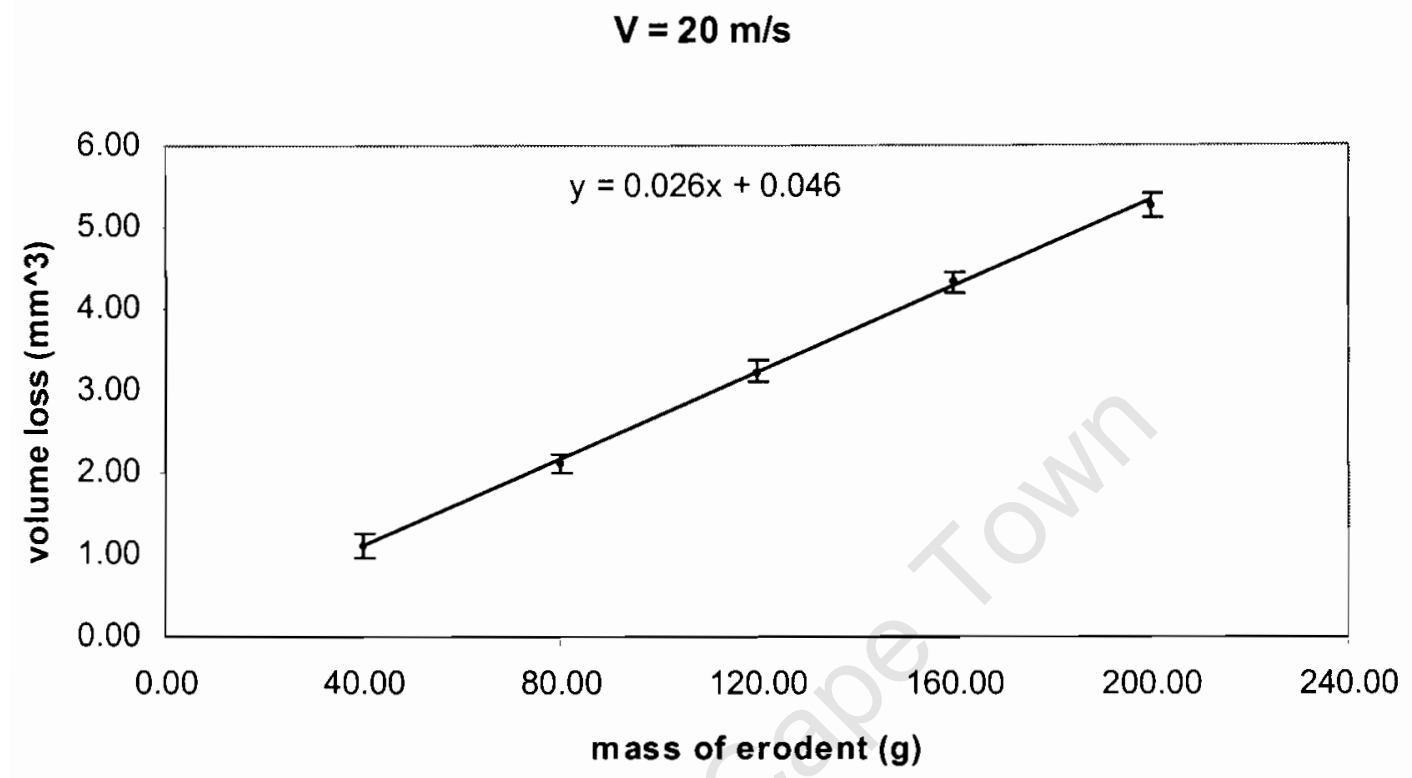

$$
V=30 \mathrm{~m} / \mathrm{s}
$$

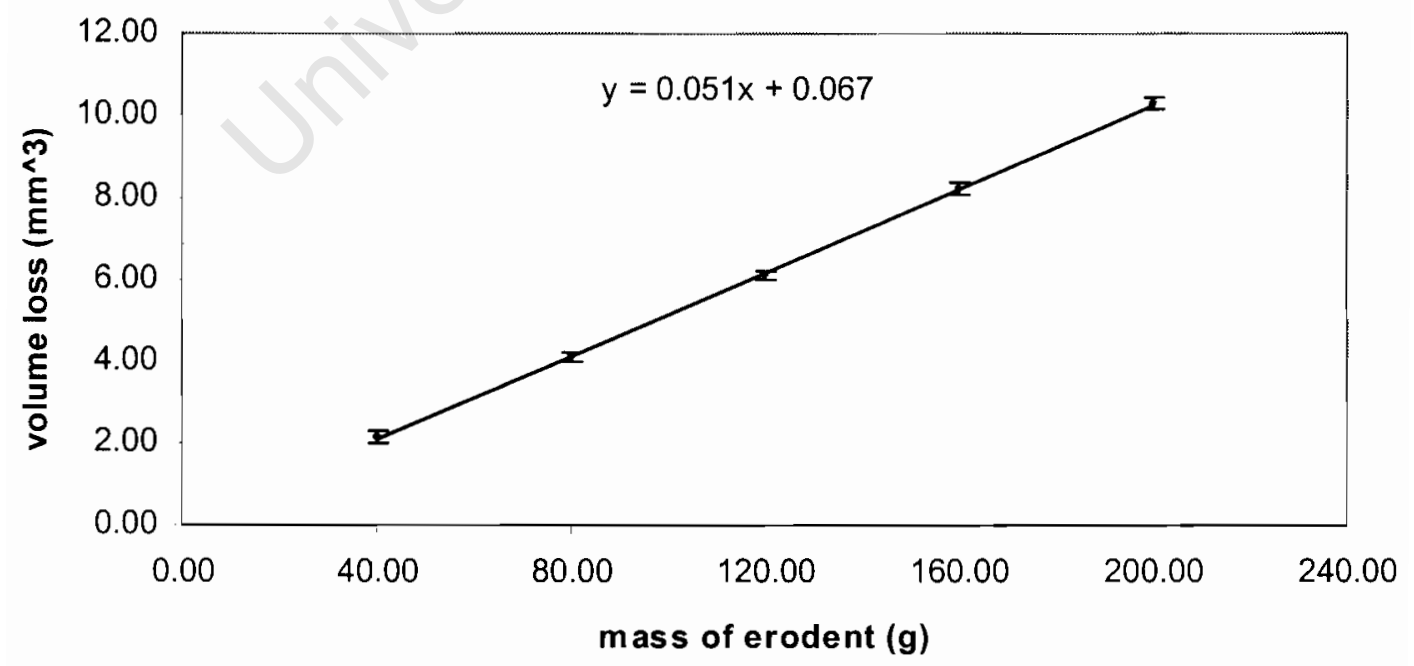




\section{MP92}

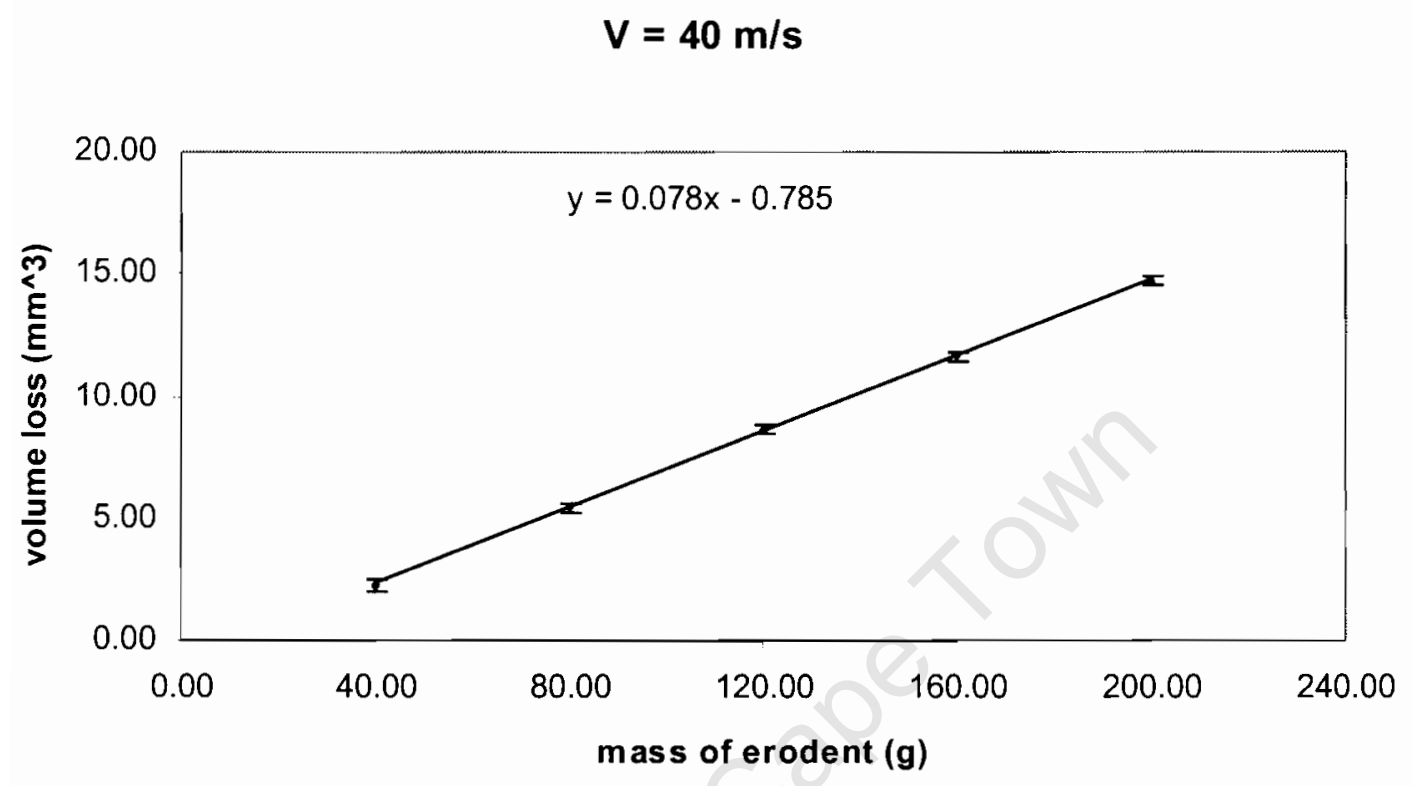

MP92

$$
V=60 \mathrm{~m} / \mathrm{s}
$$

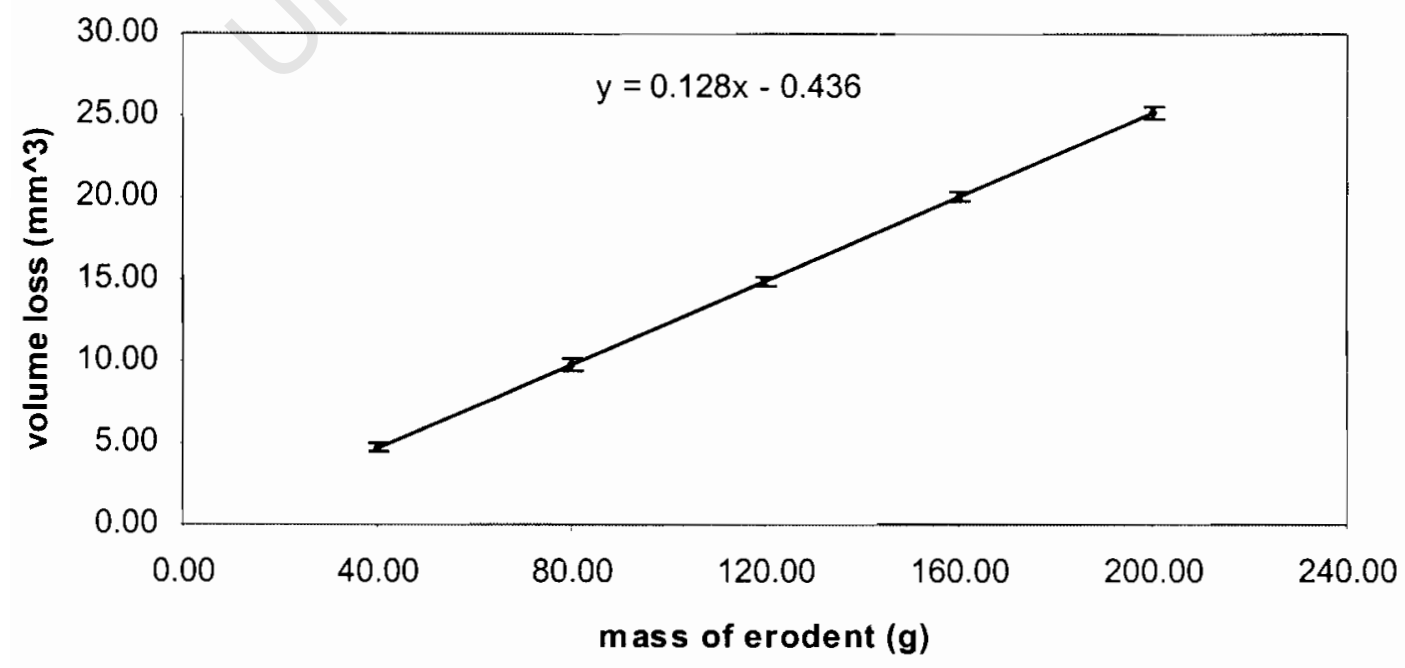


APPENDIX III

\section{THE EFFECT OF \\ PARTICLE SIZE AND \\ DIFFERENT ERODENT PARTICLES}




\section{M94}

63-106 microns silica sand

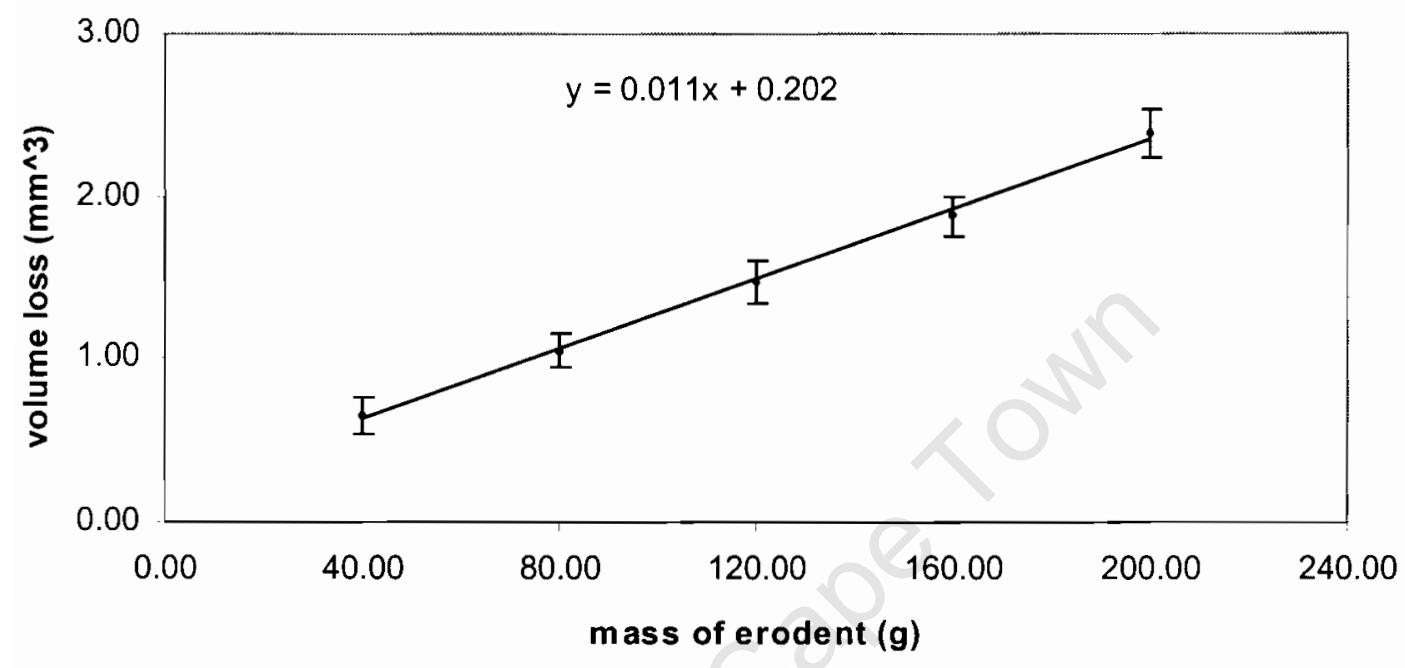

106-125 microns silica sand

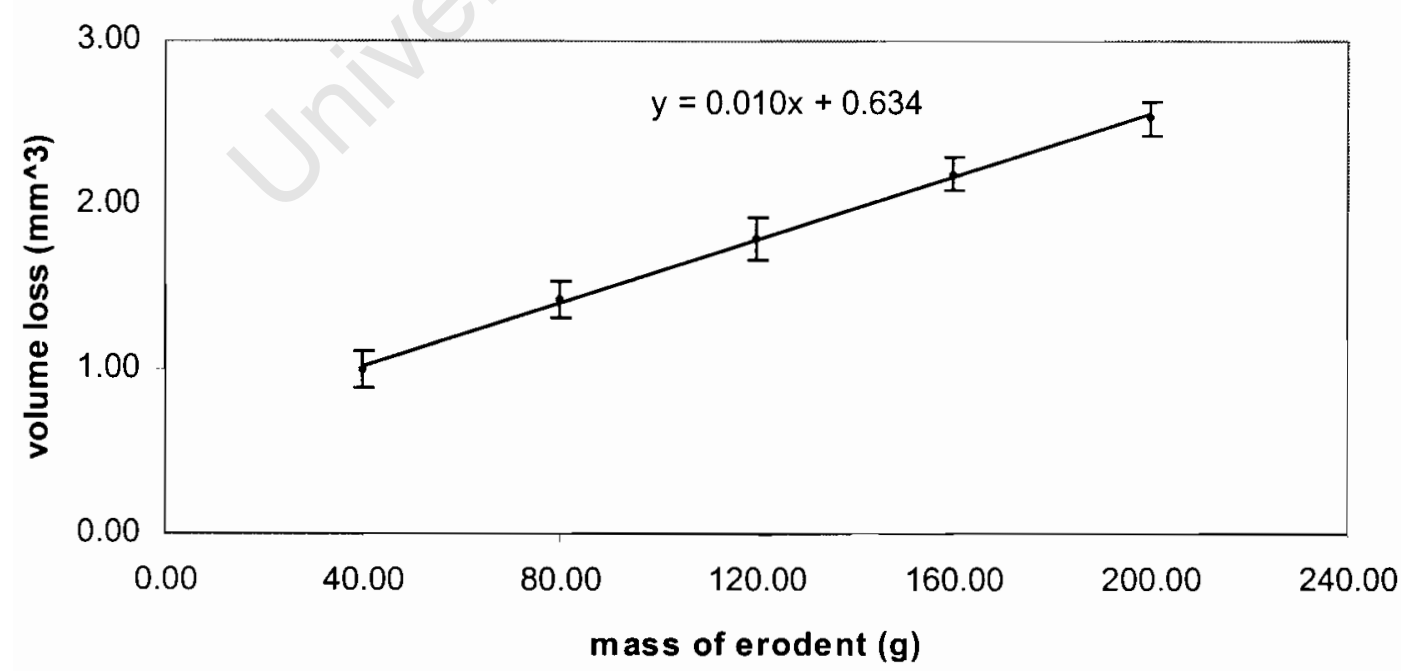




\section{M94}

125-180 microns silica sand

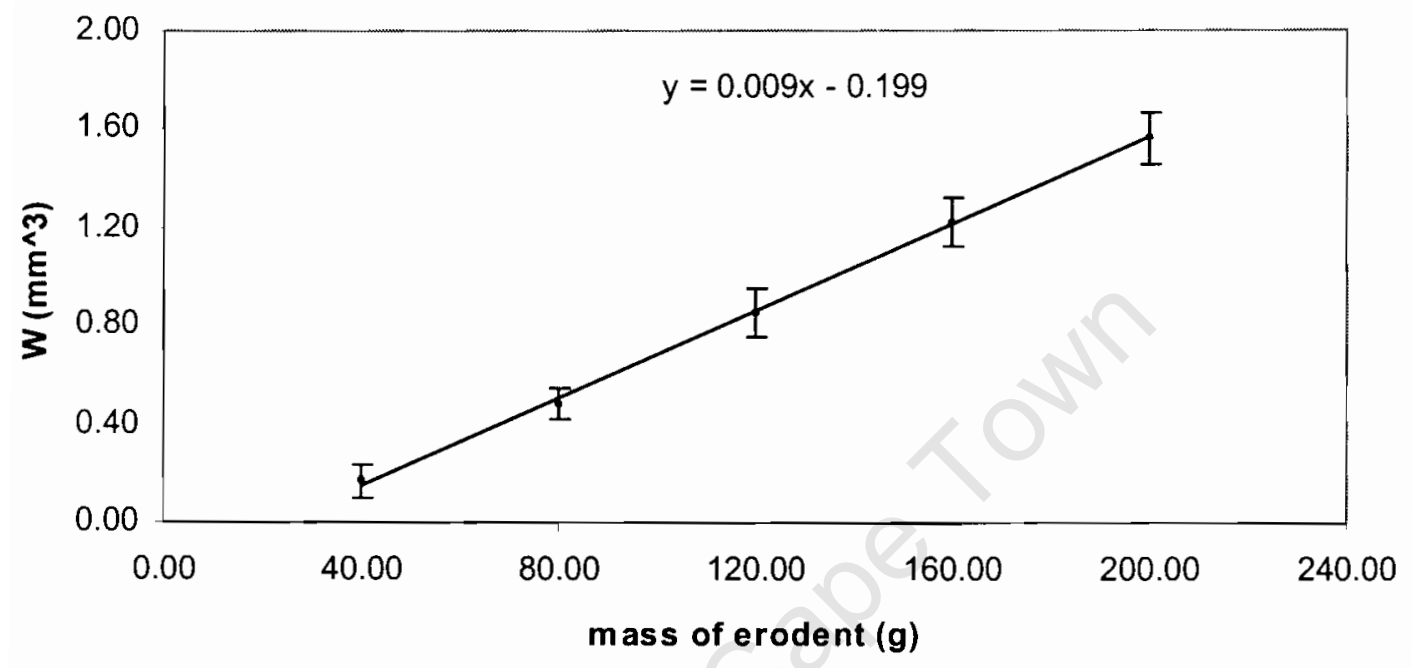

106-125 microns alumina

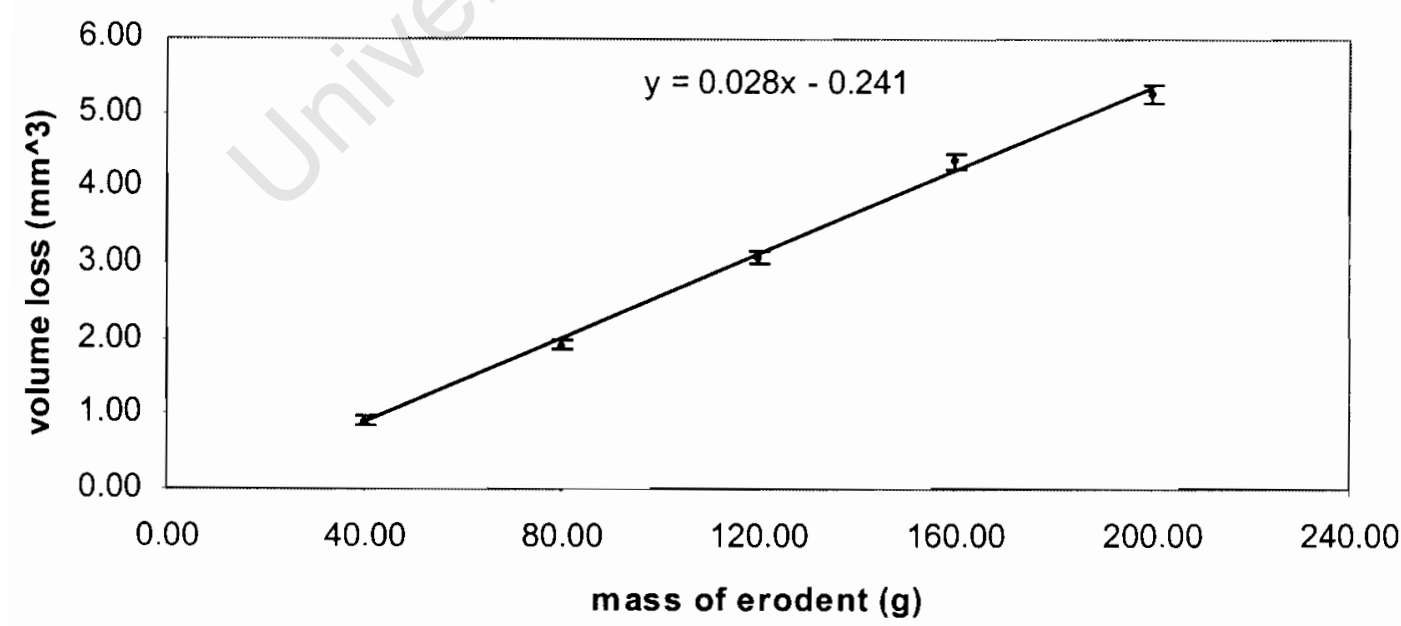




\section{APPENDIX IV}

\section{ELEVATED TEMPERATURE}


M90

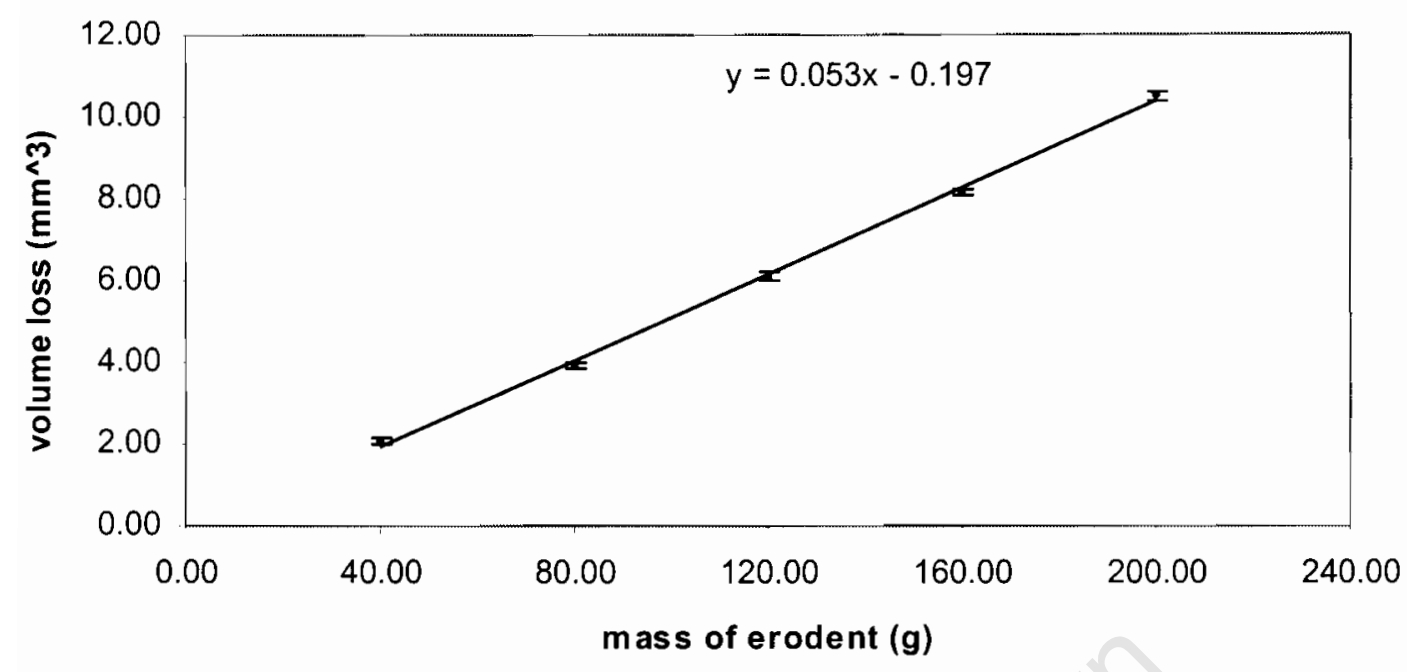

MP92

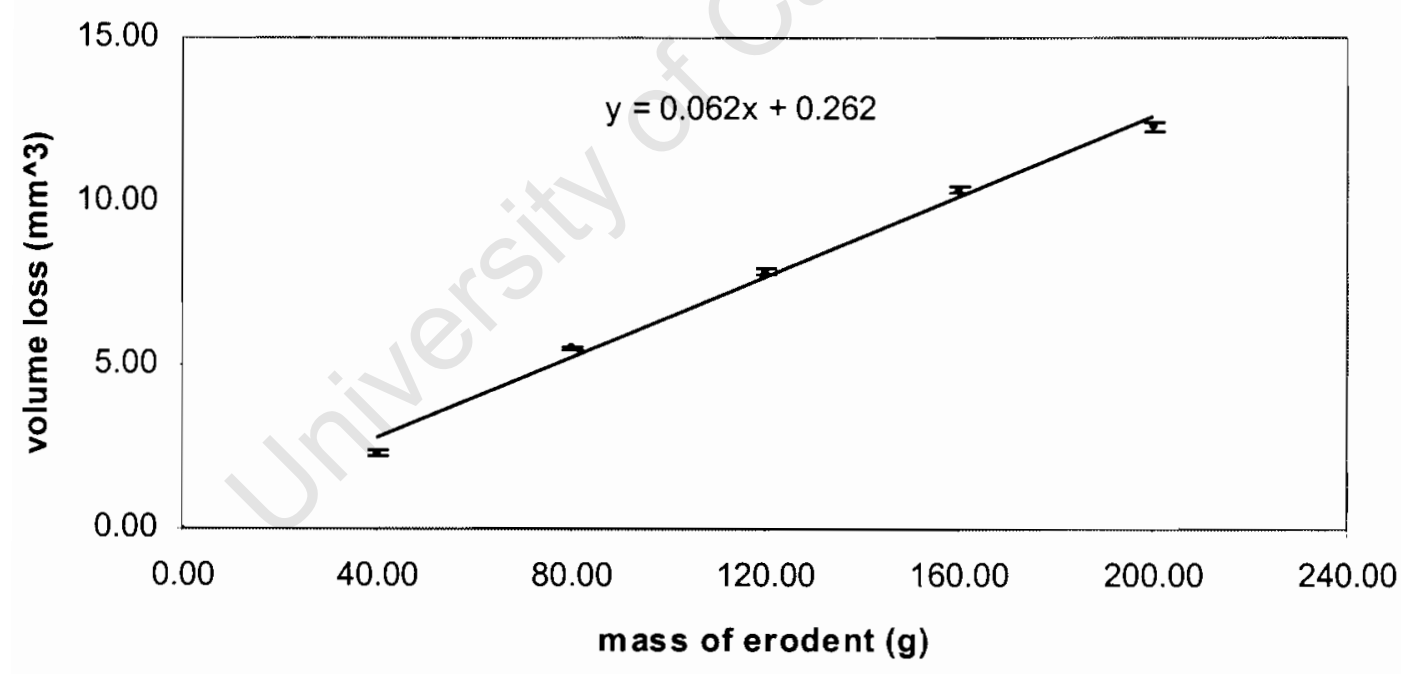




\section{M94}

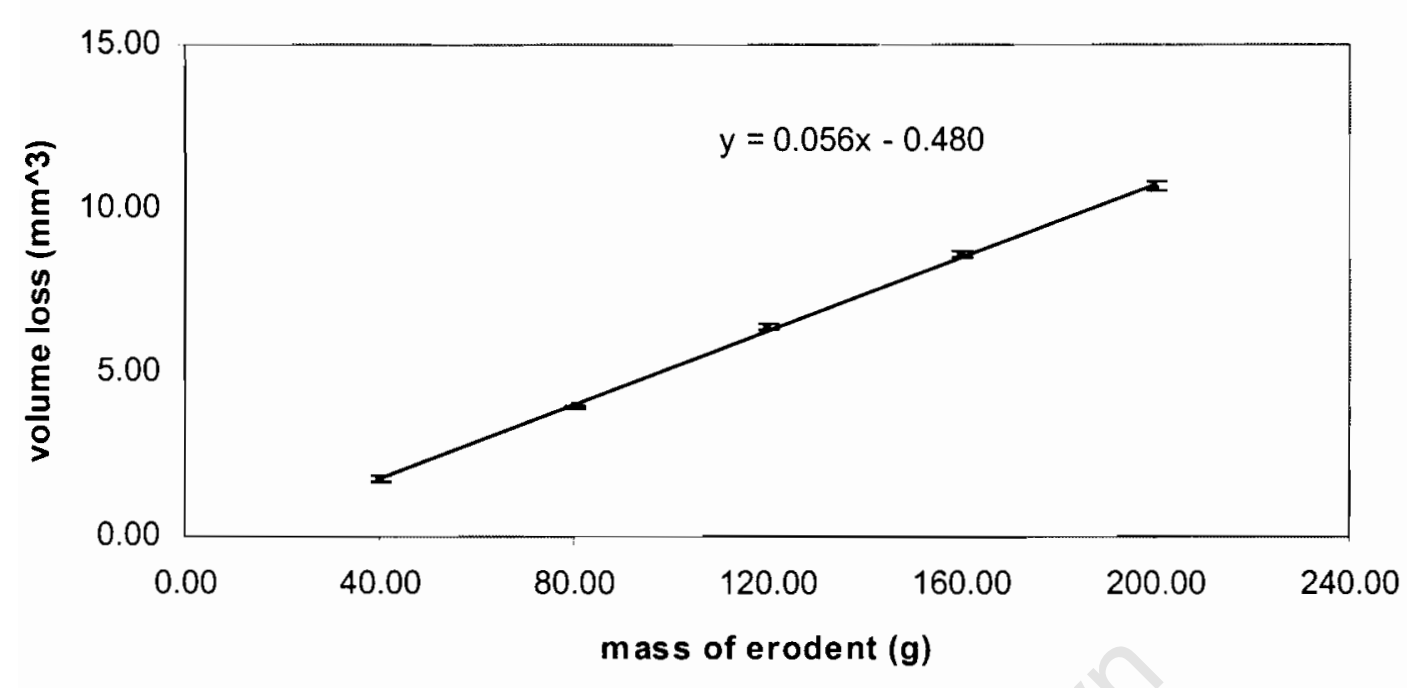

MP96

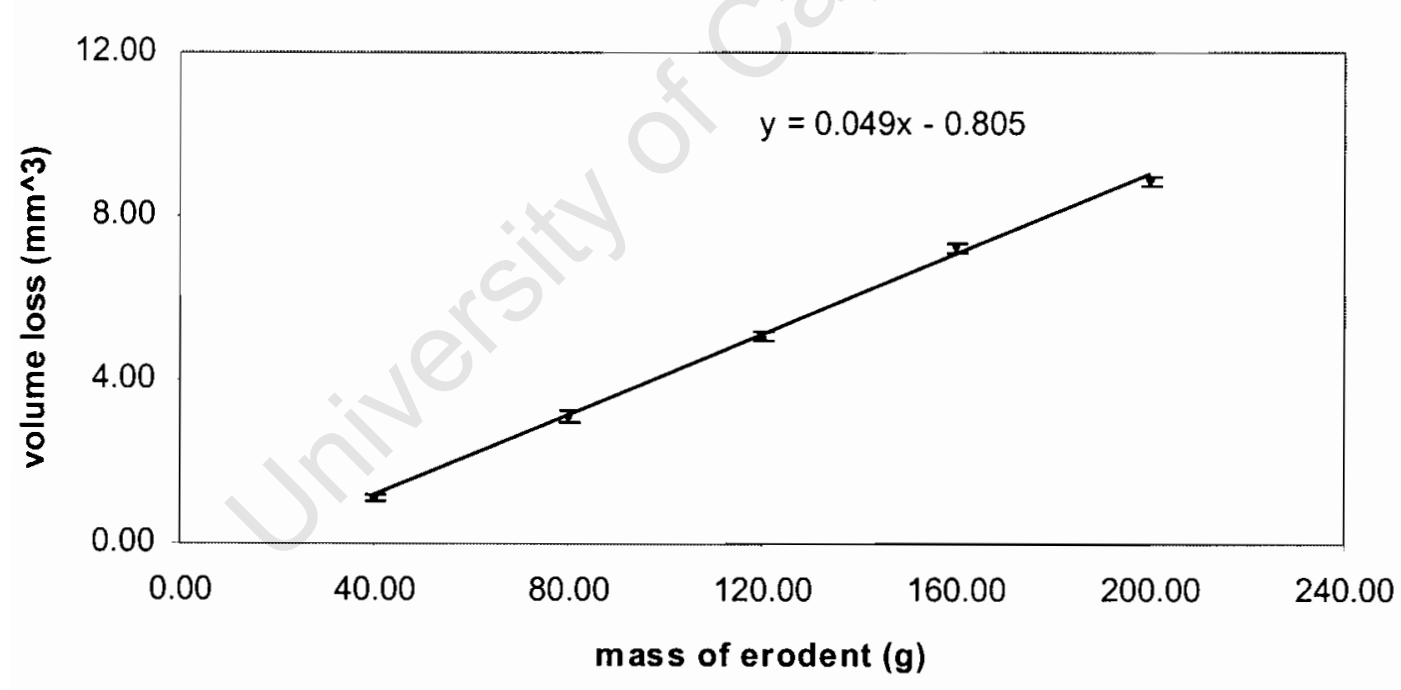


M97

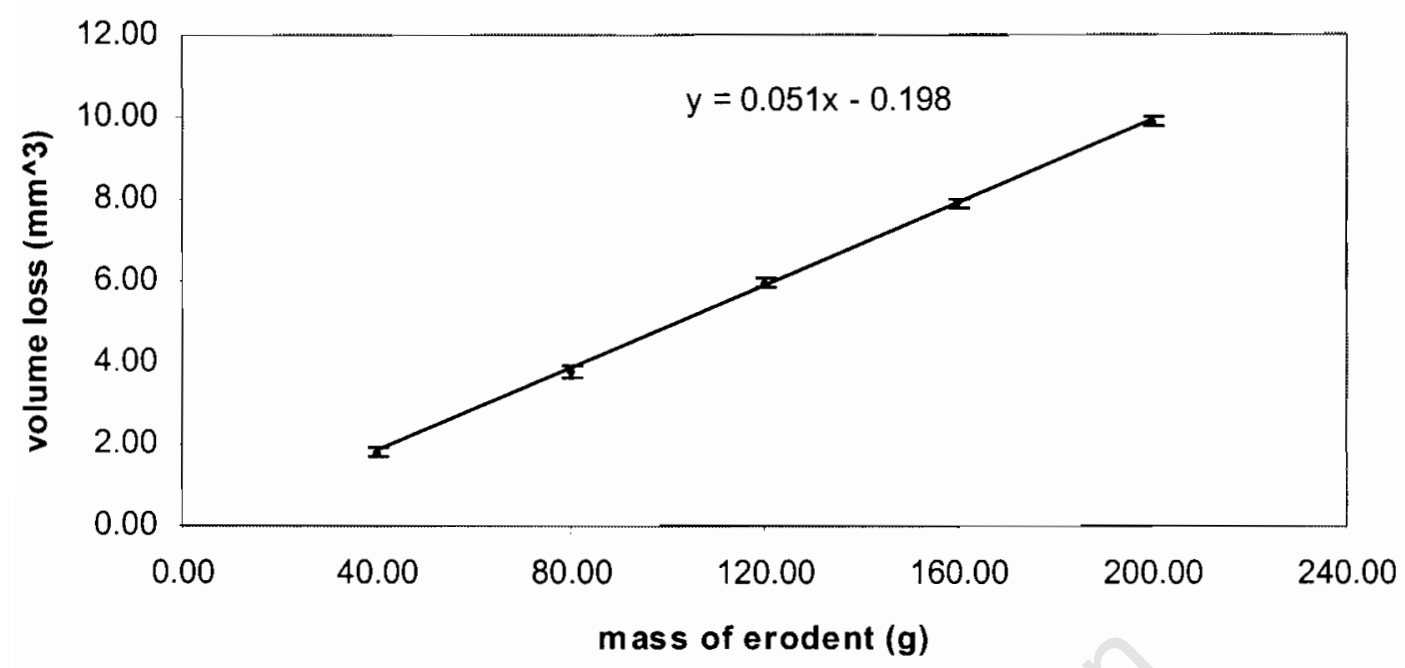




\section{APPENDIX V}

\section{THE EFFECT OF APPLIED \\ LOAD AND SPEED}




\section{$15 N$}

\section{M90}

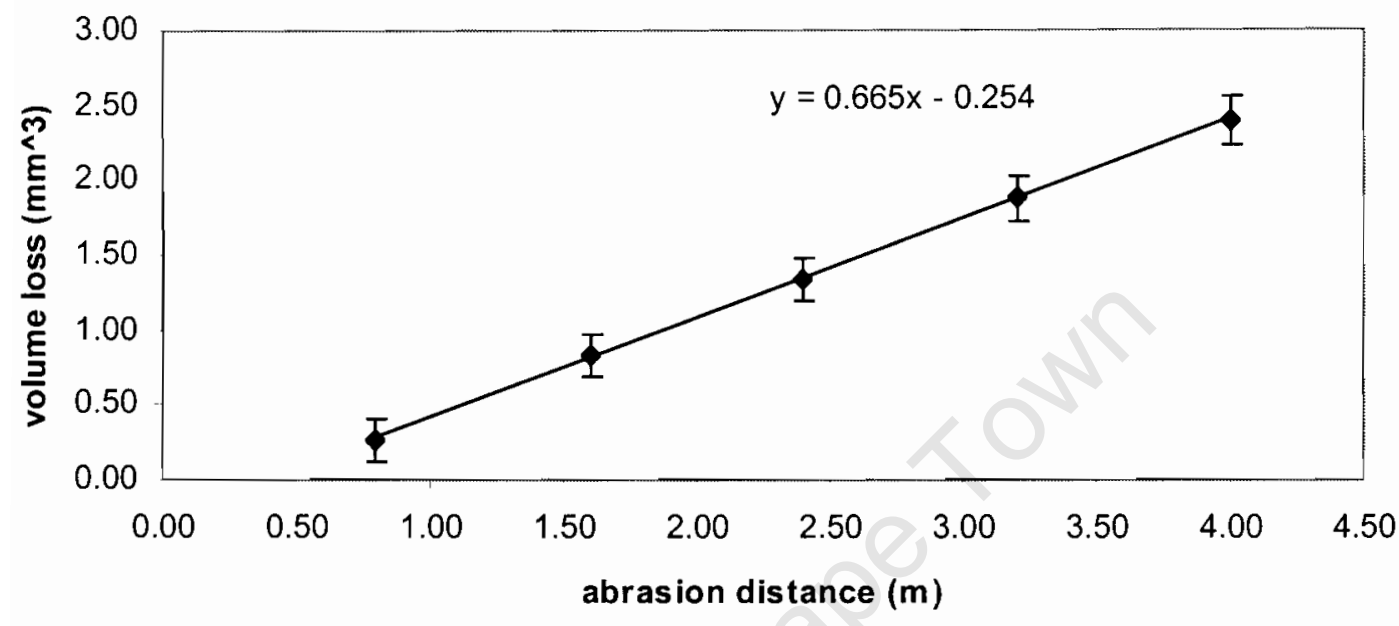

MP92

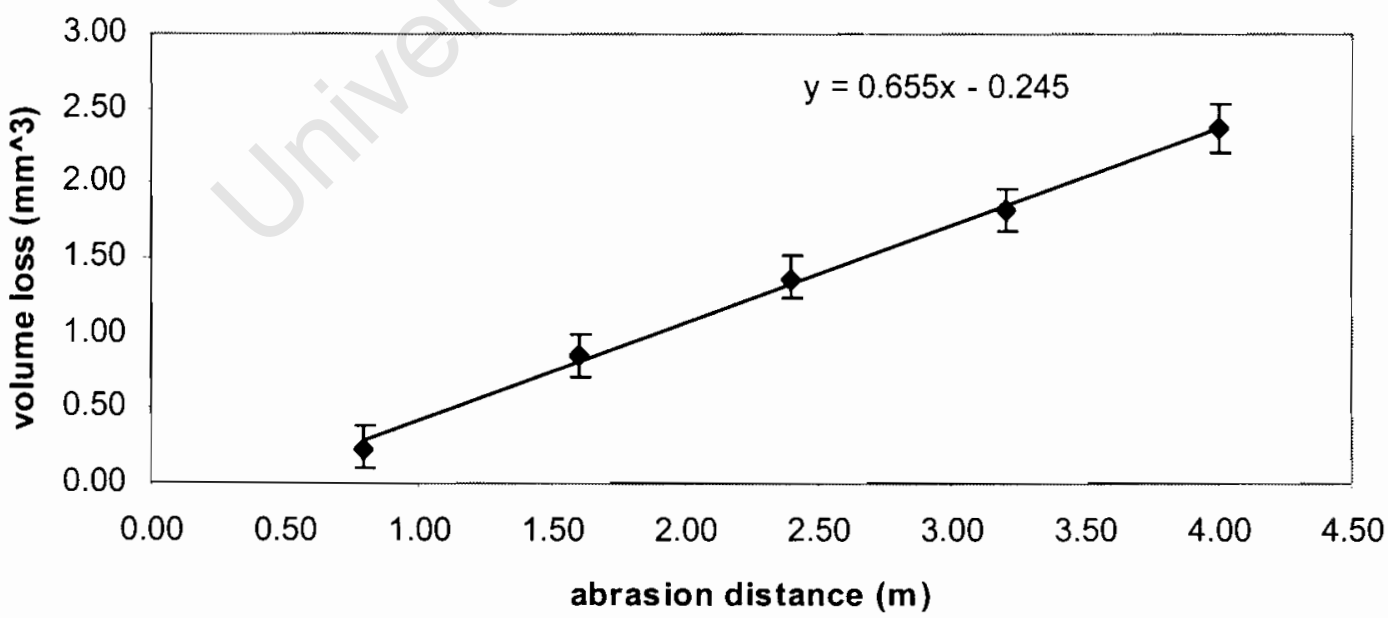




\section{$15 N$}

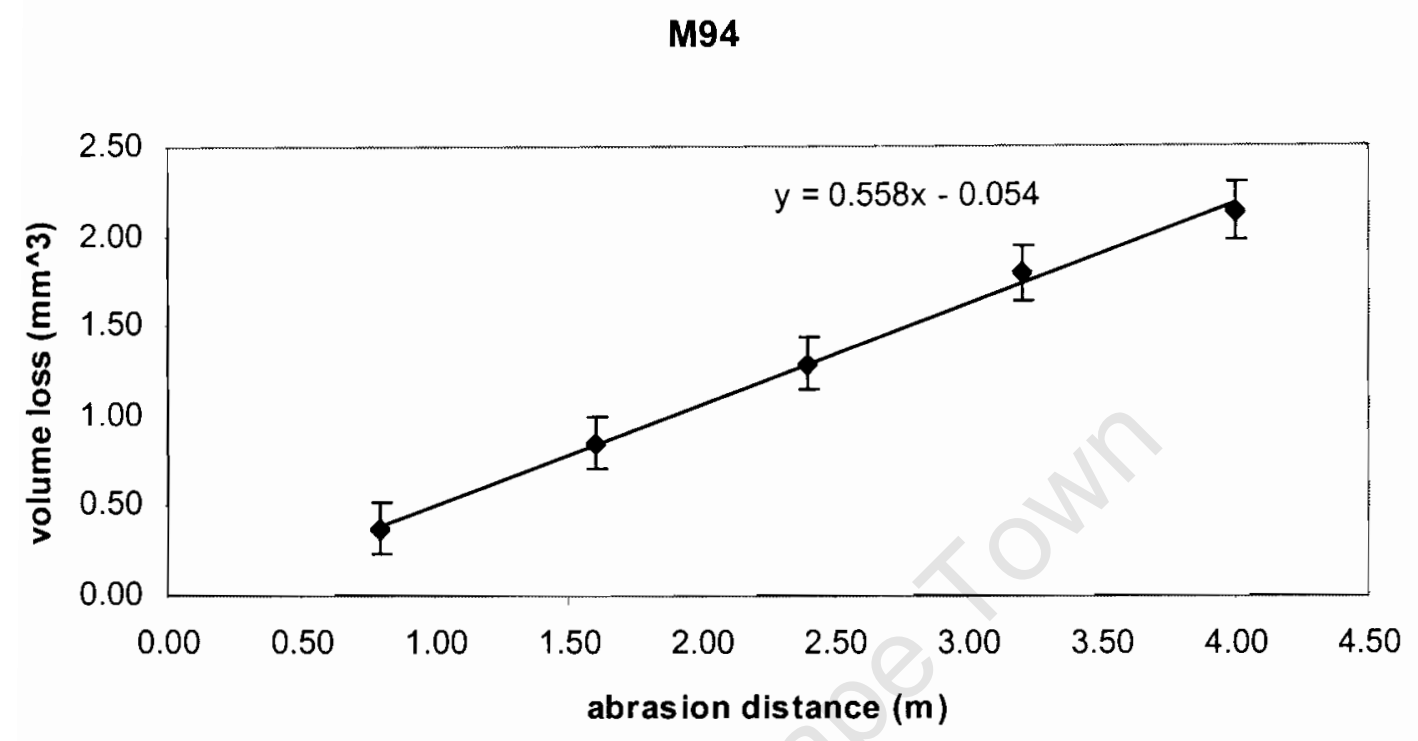

MP96

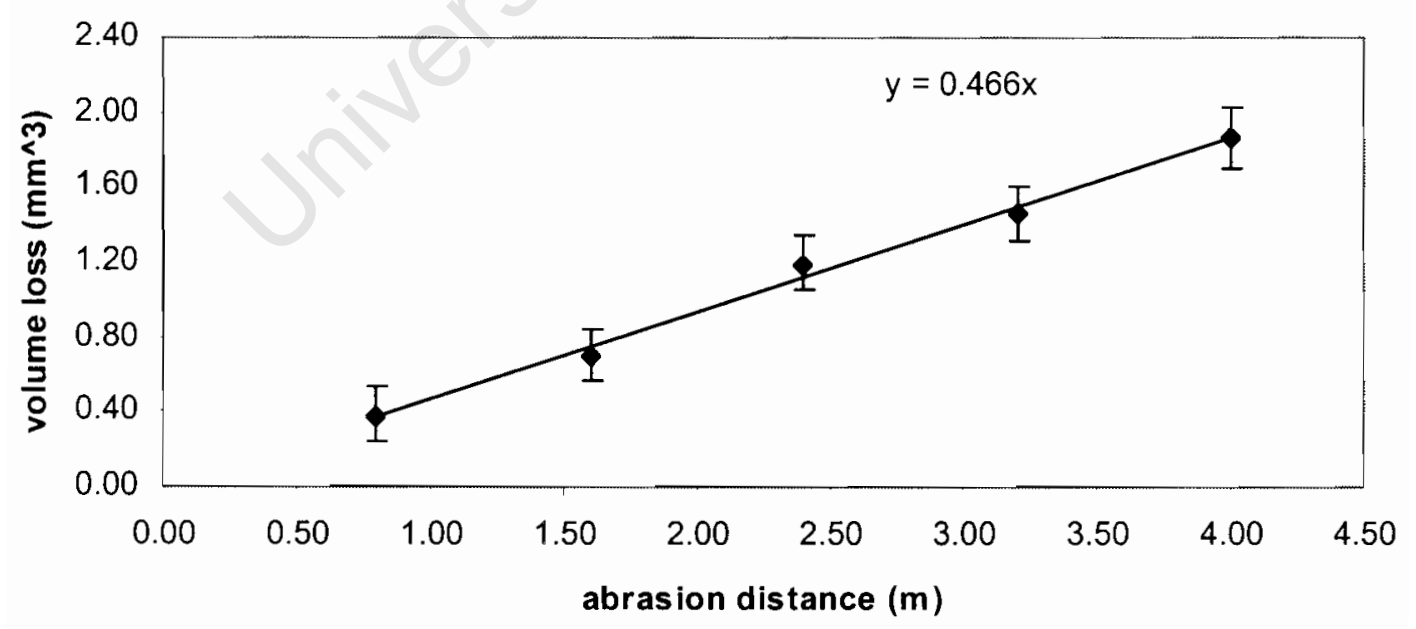




\section{$15 N$}

M97

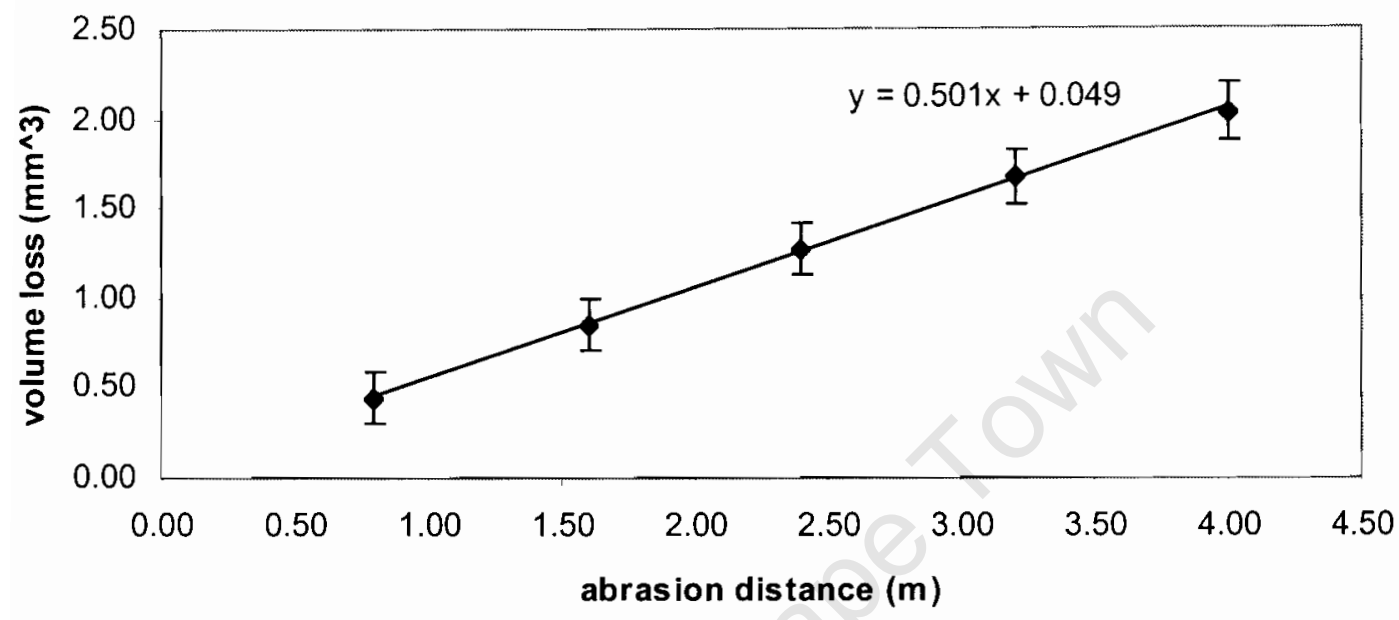

$30 \mathrm{~N}$

M90

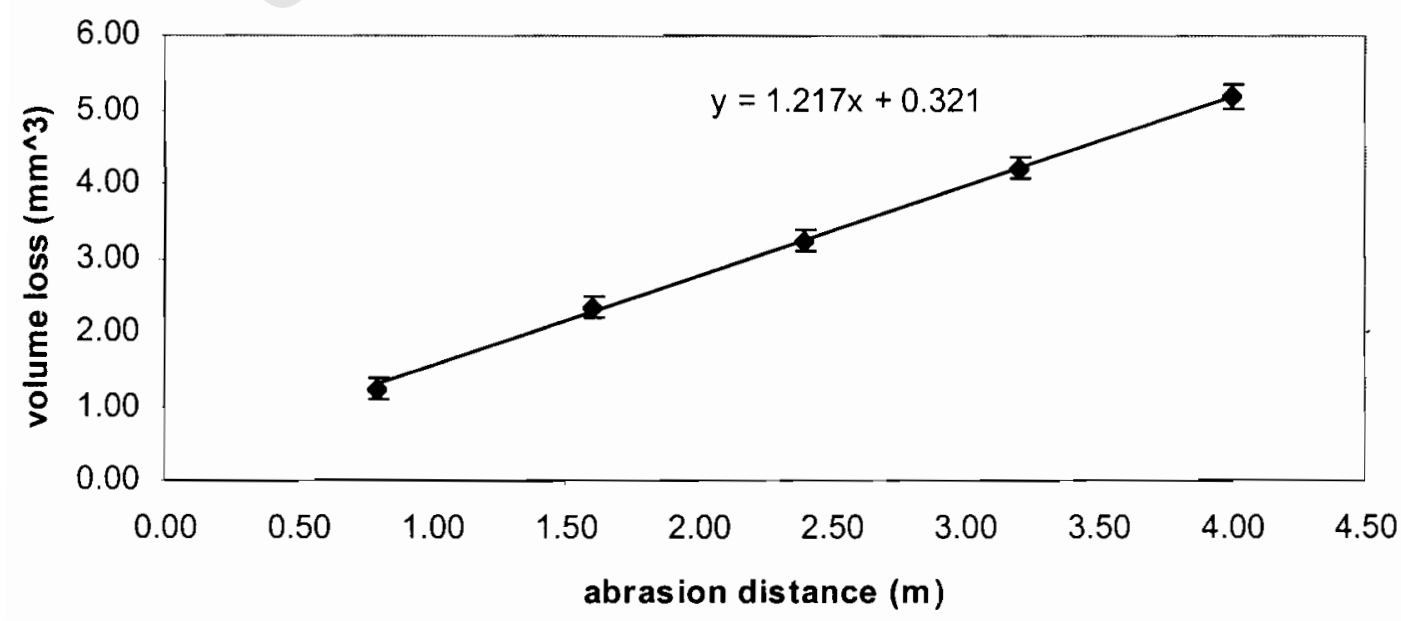




\section{$30 \mathrm{~N}$}

\section{MP92}

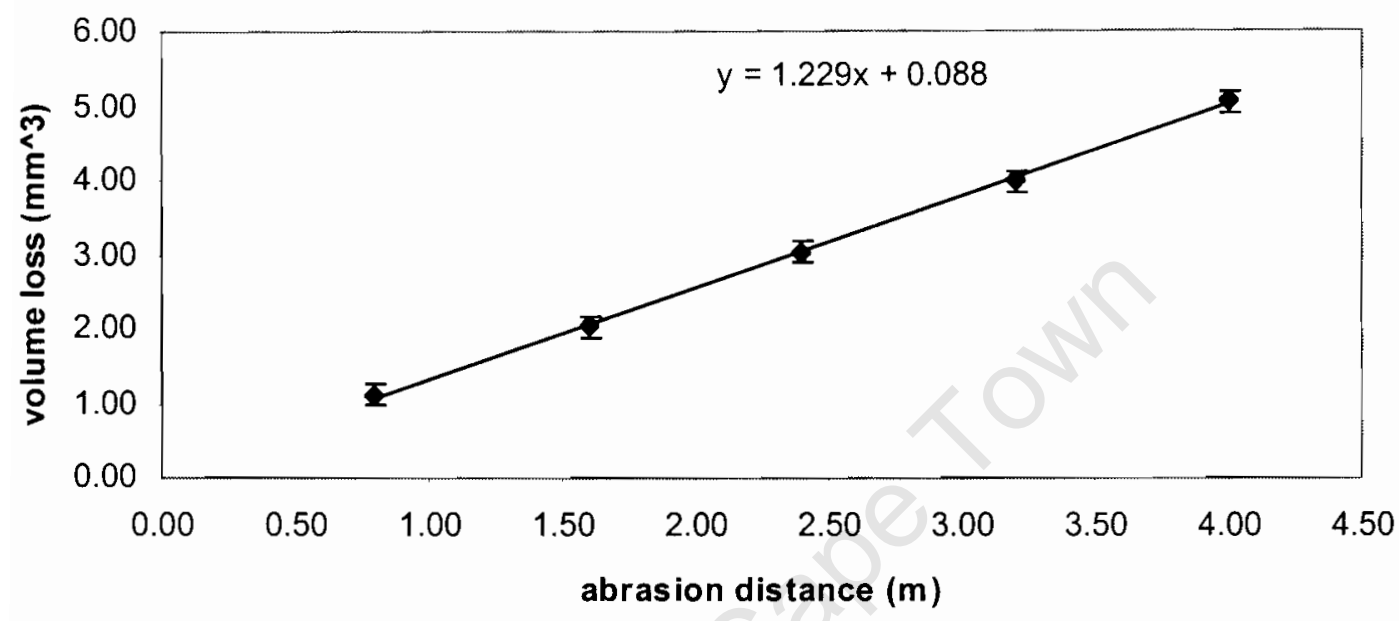

M94

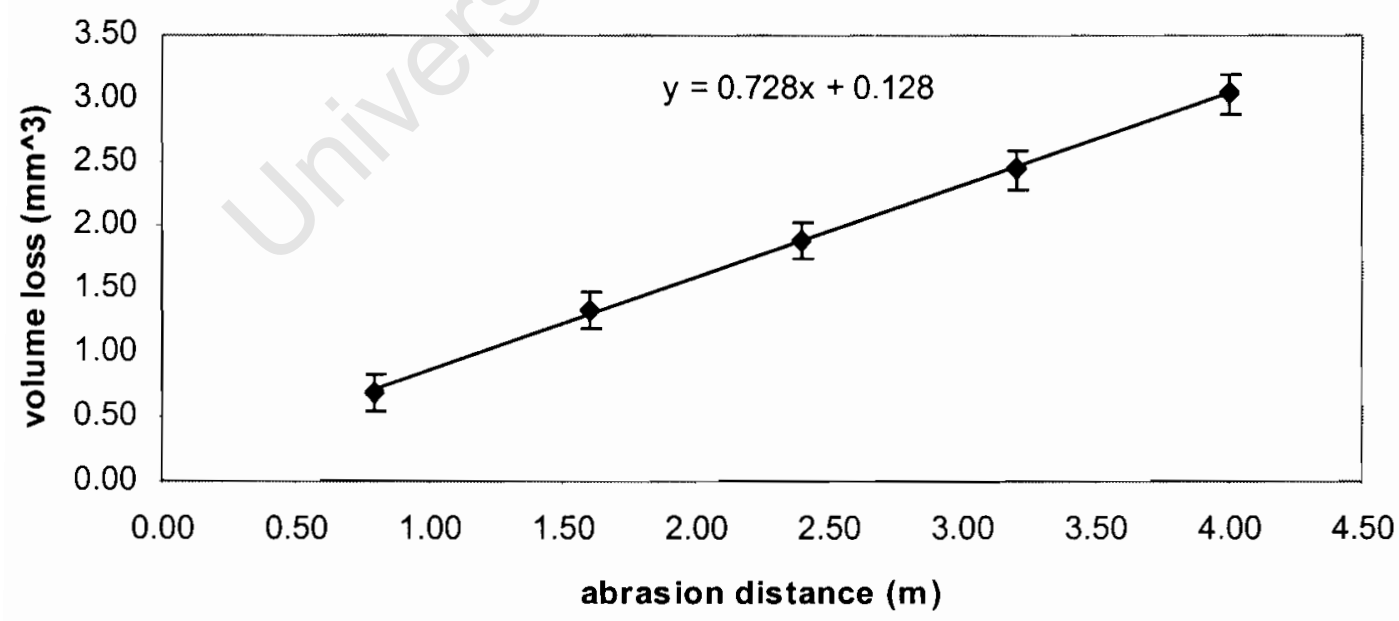




\section{$30 \mathrm{~N}$}

\section{MP96}

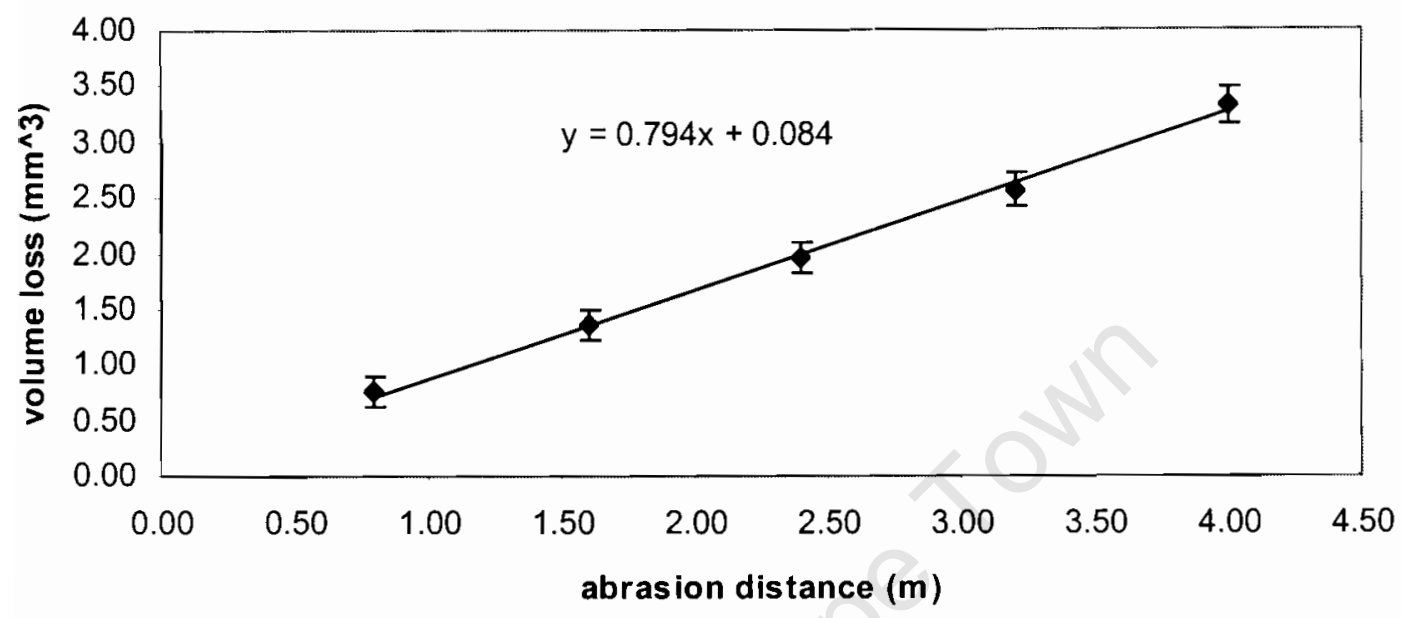

\section{M97}

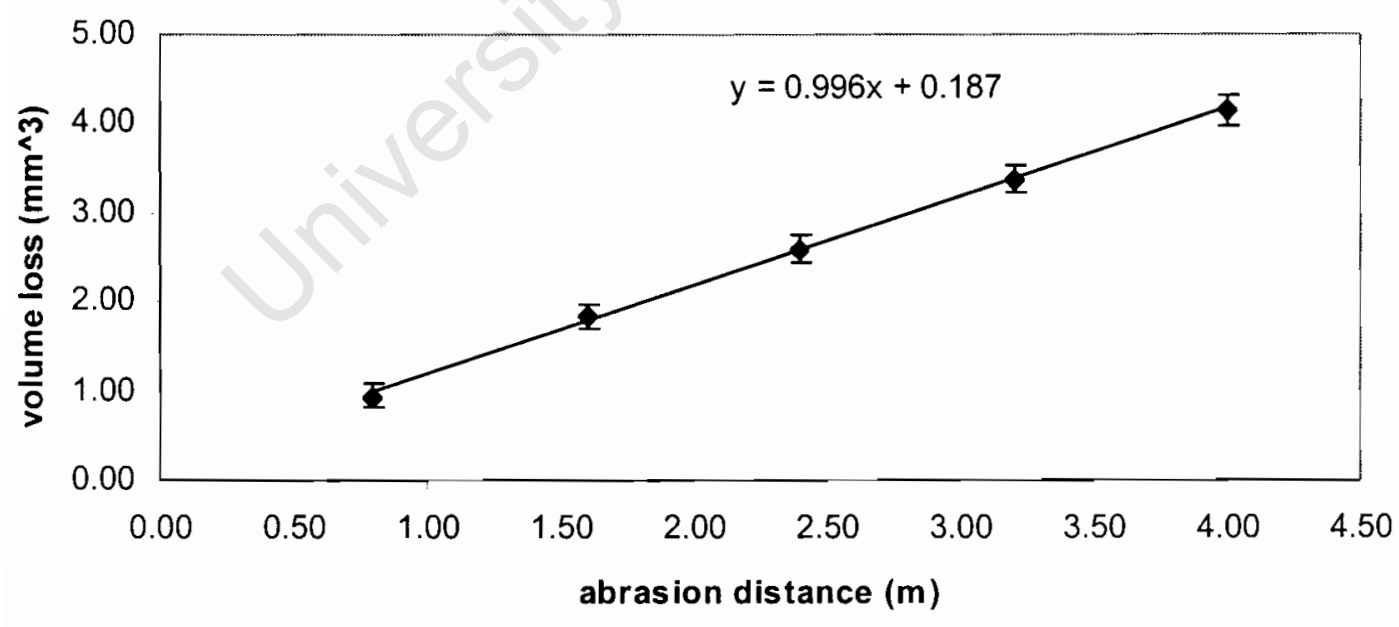




\section{$40 N$}

\section{M90}

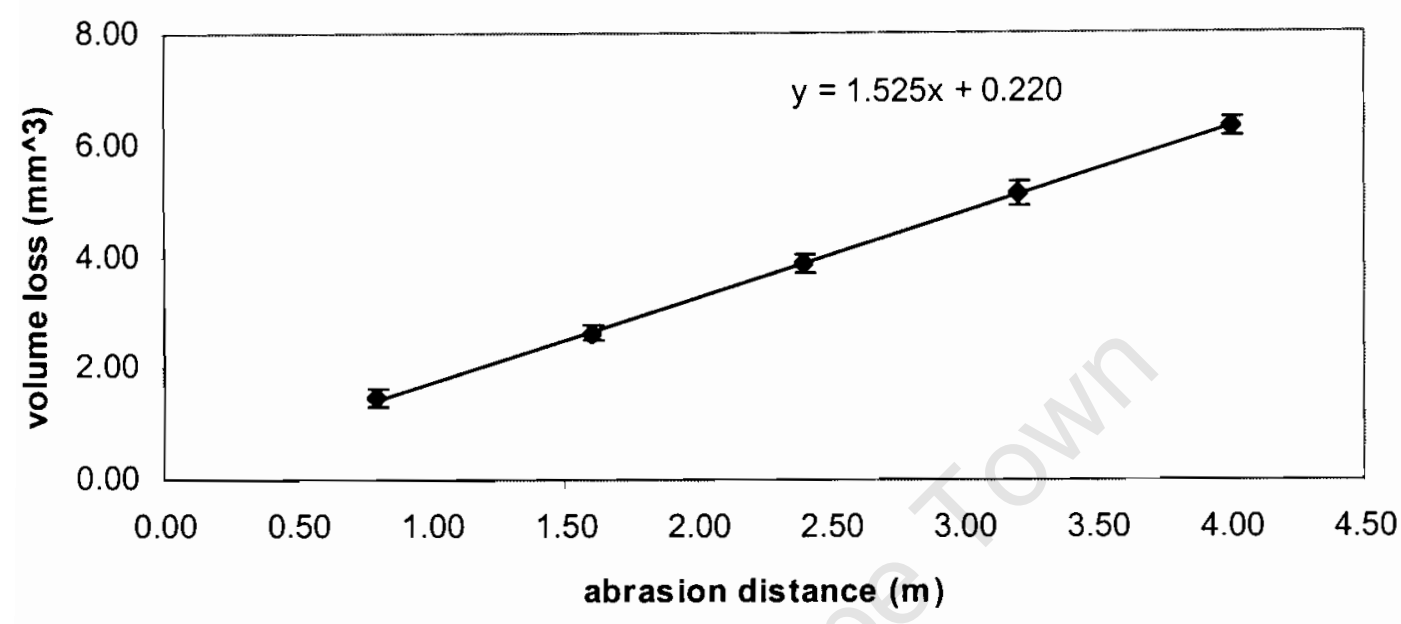

MP92

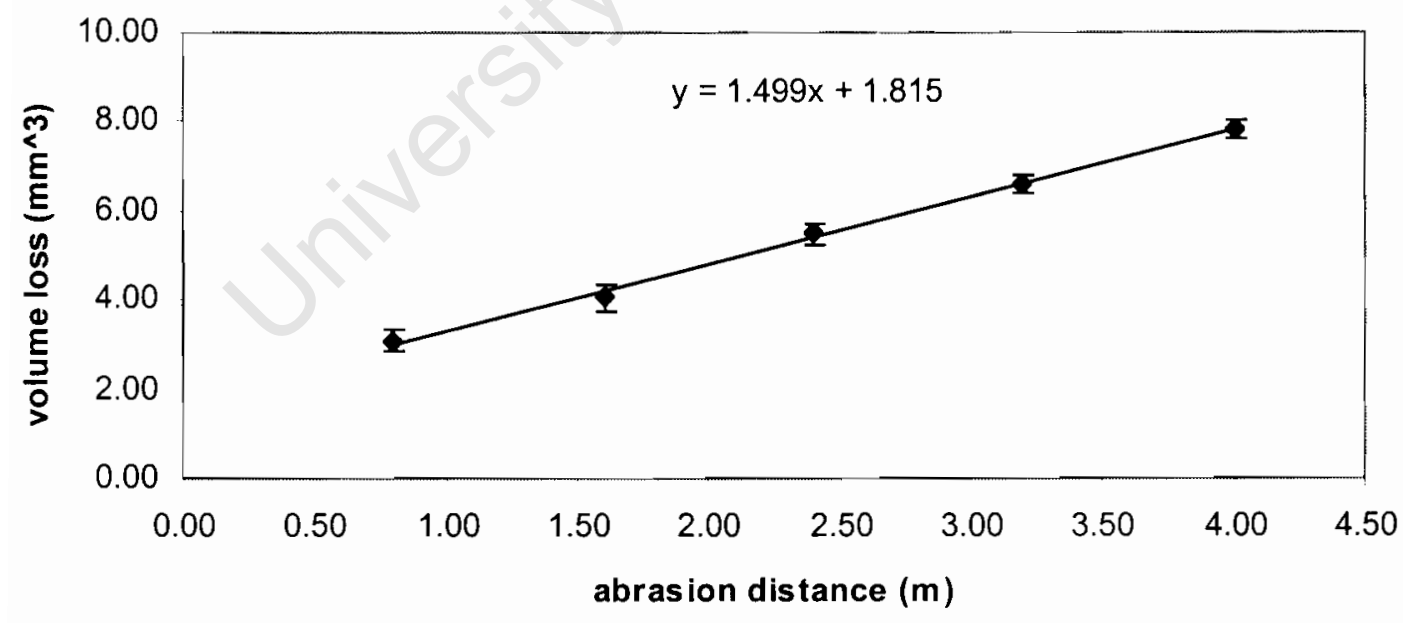




\section{$40 \mathrm{~N}$}

\section{M94}

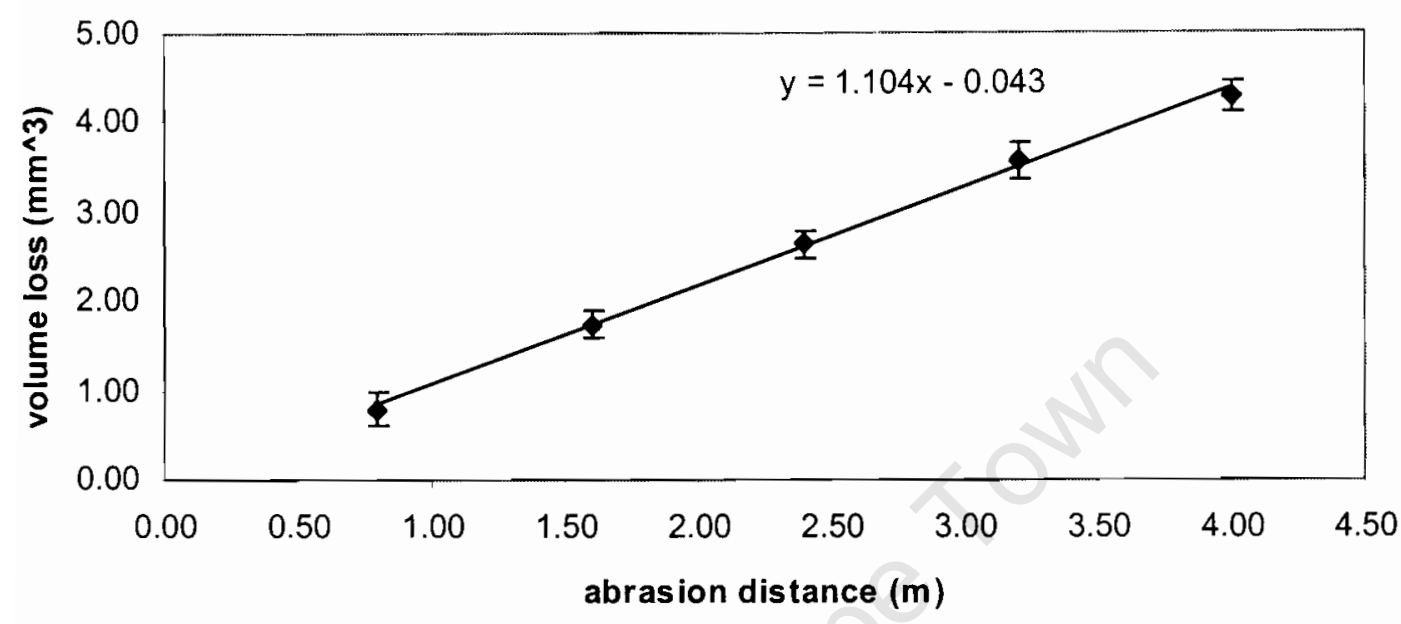

MP96

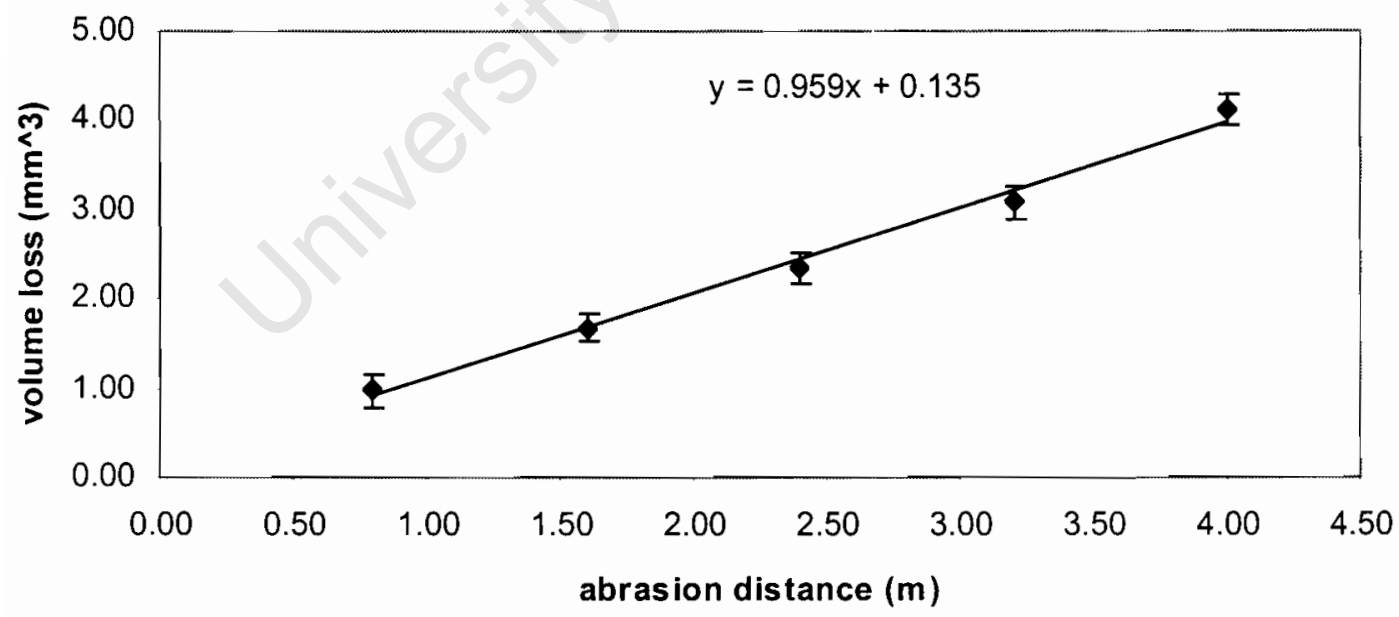




\section{$40 \mathrm{~N}$}

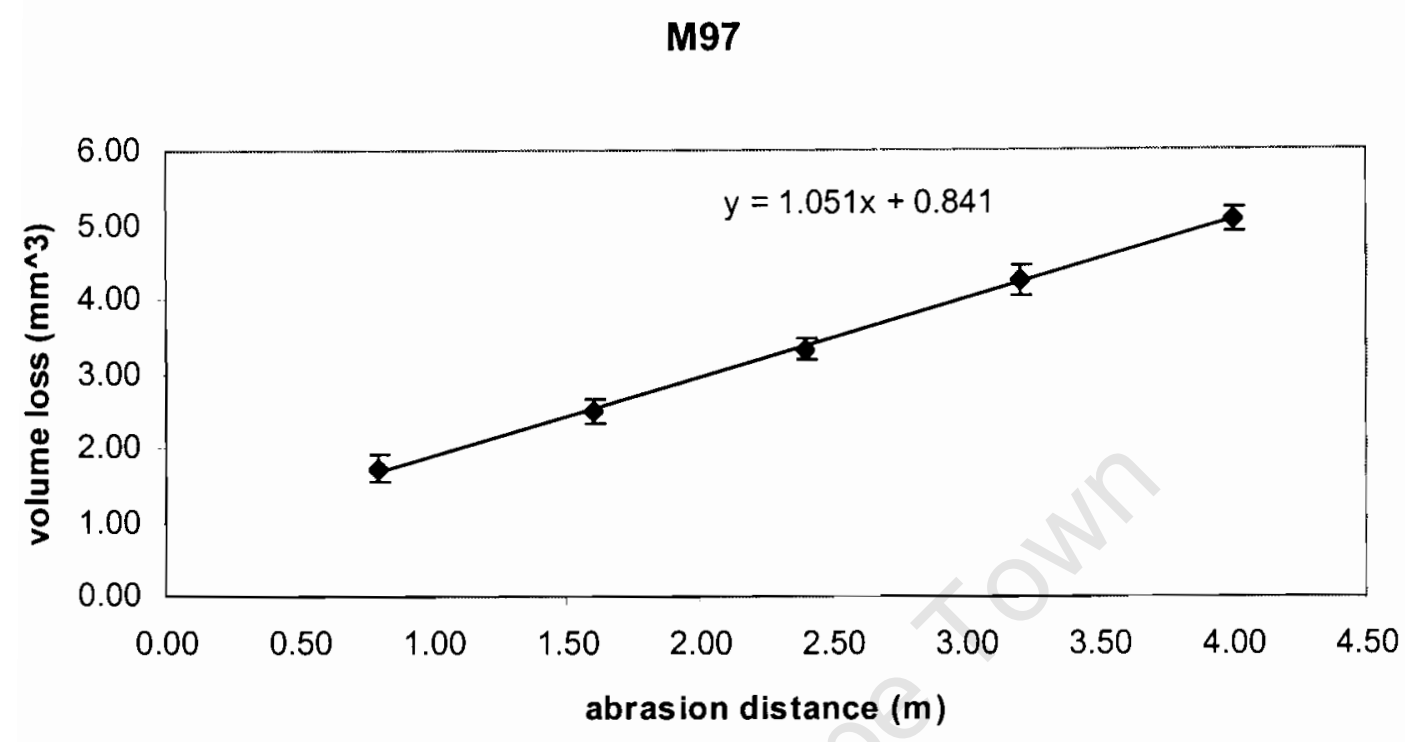

\section{$25 \mathrm{~cm} / \mathrm{s}$}

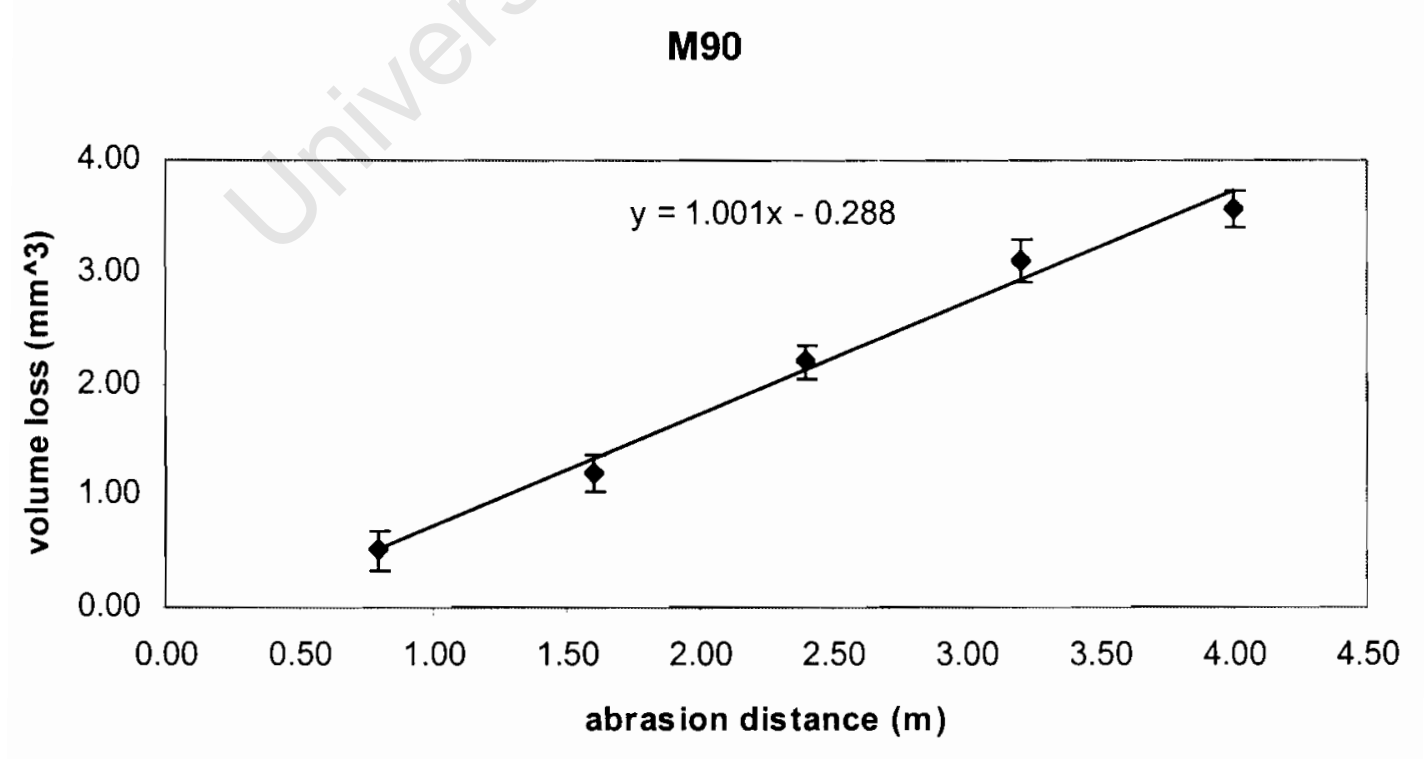




\section{$25 \mathrm{~cm} / \mathrm{s}$}

\section{MP92}

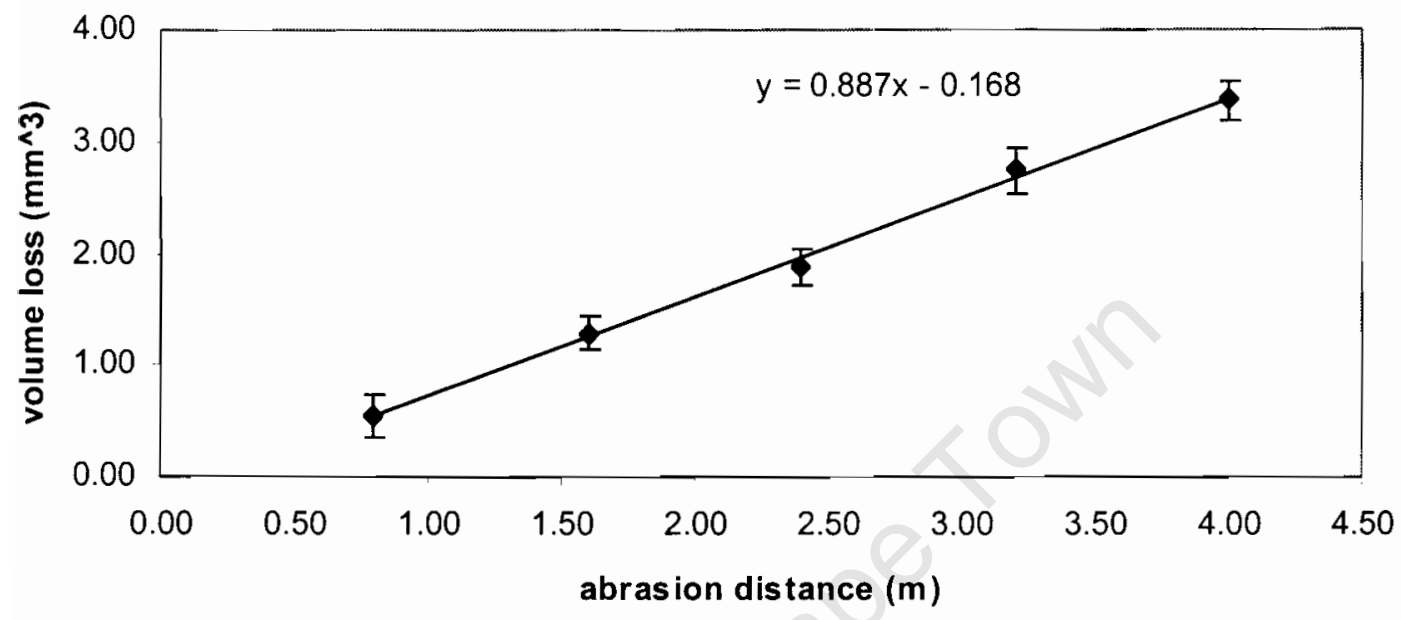

M94

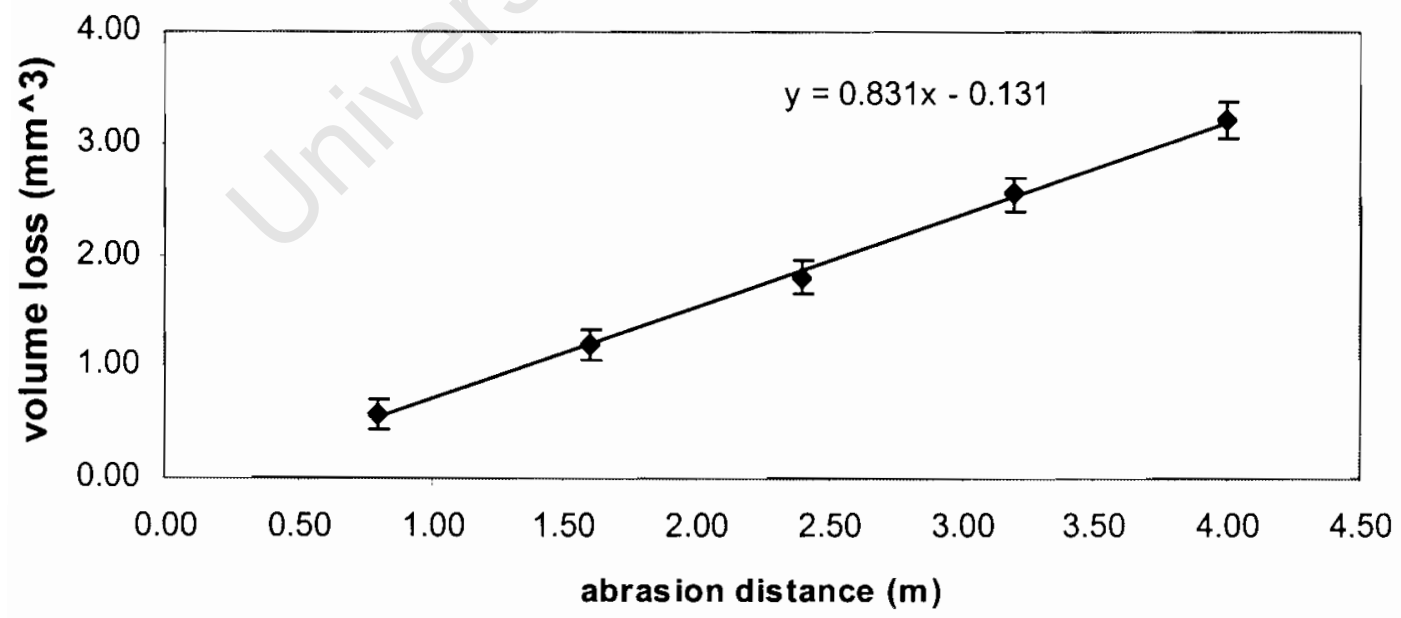




\section{$25 \mathrm{~cm} / \mathrm{s}$}

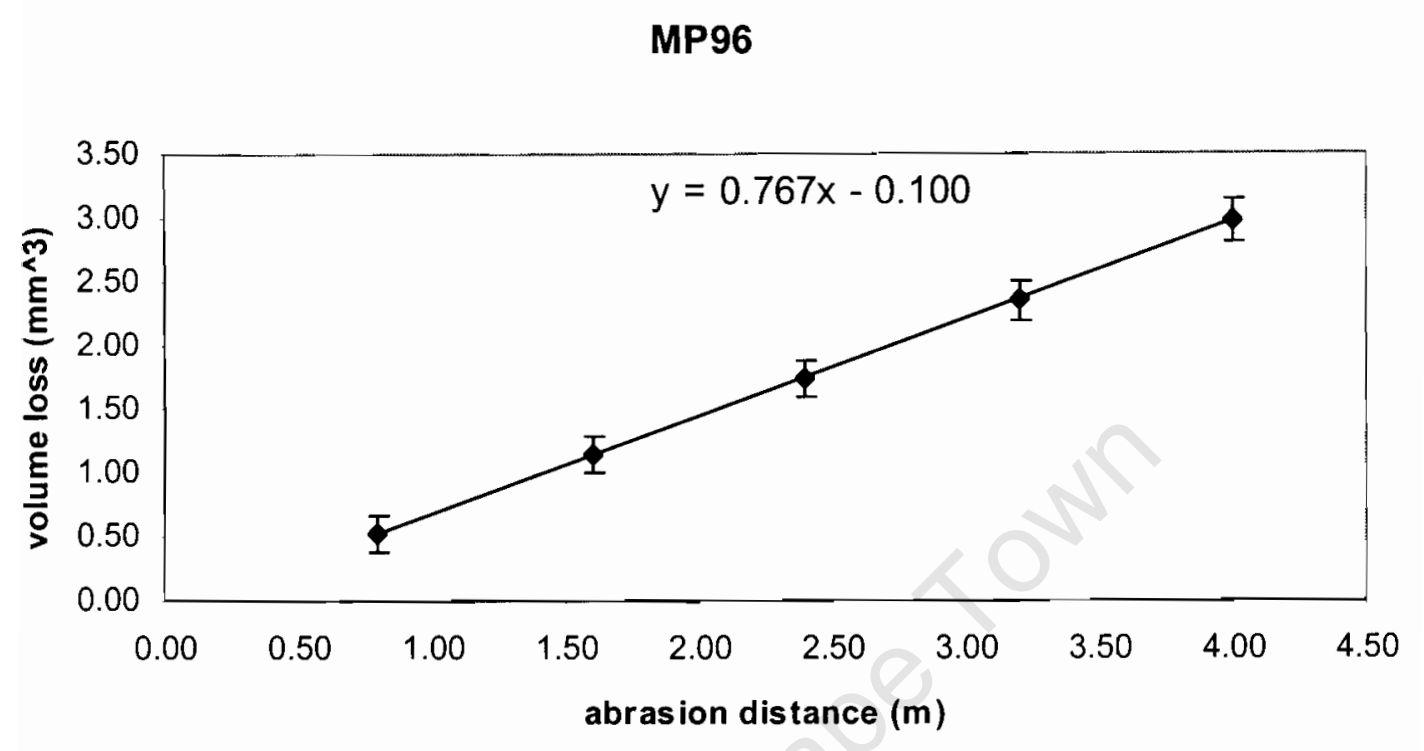

\section{M97}

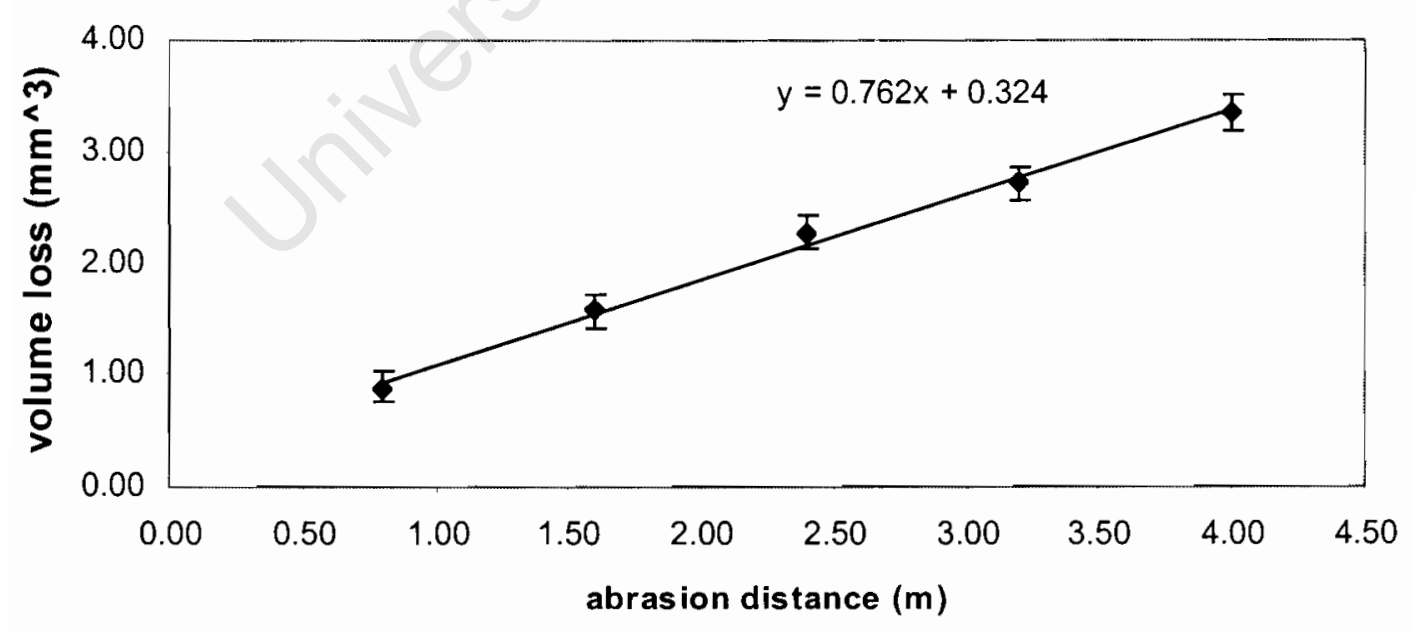




\section{$45 \mathrm{~cm} / \mathrm{s}$}

M90

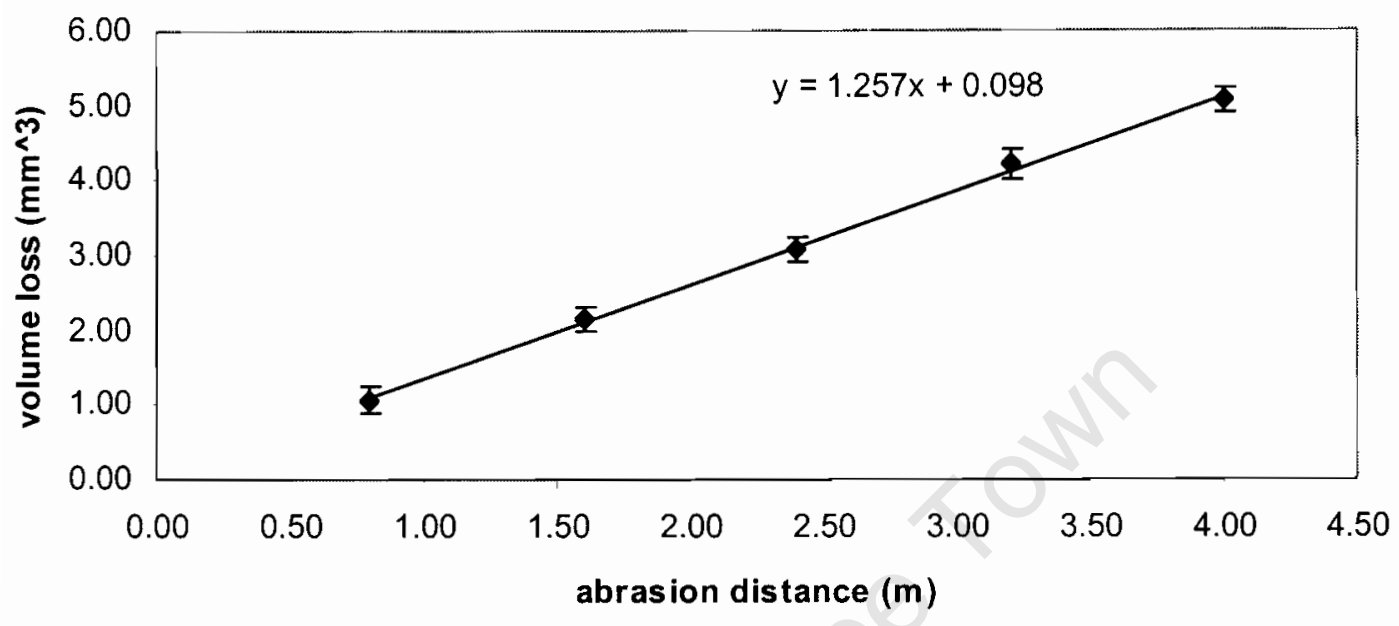

MP92

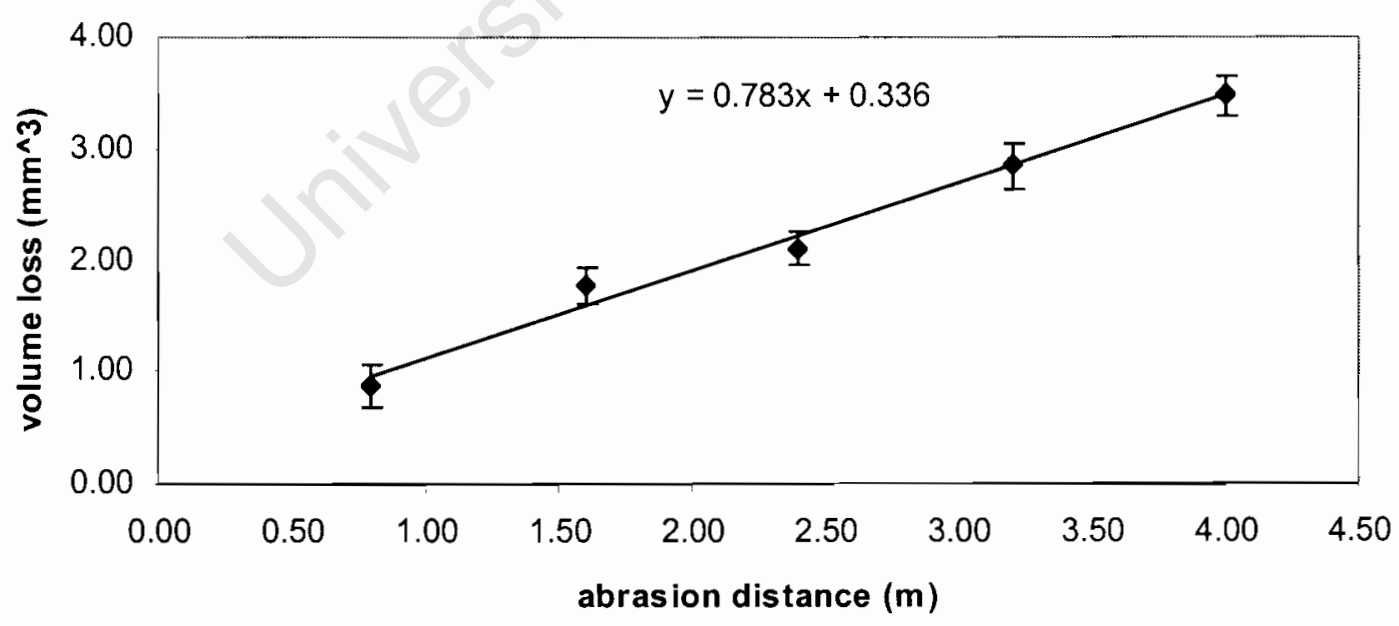




\section{$45 \mathrm{~cm} / \mathrm{s}$}

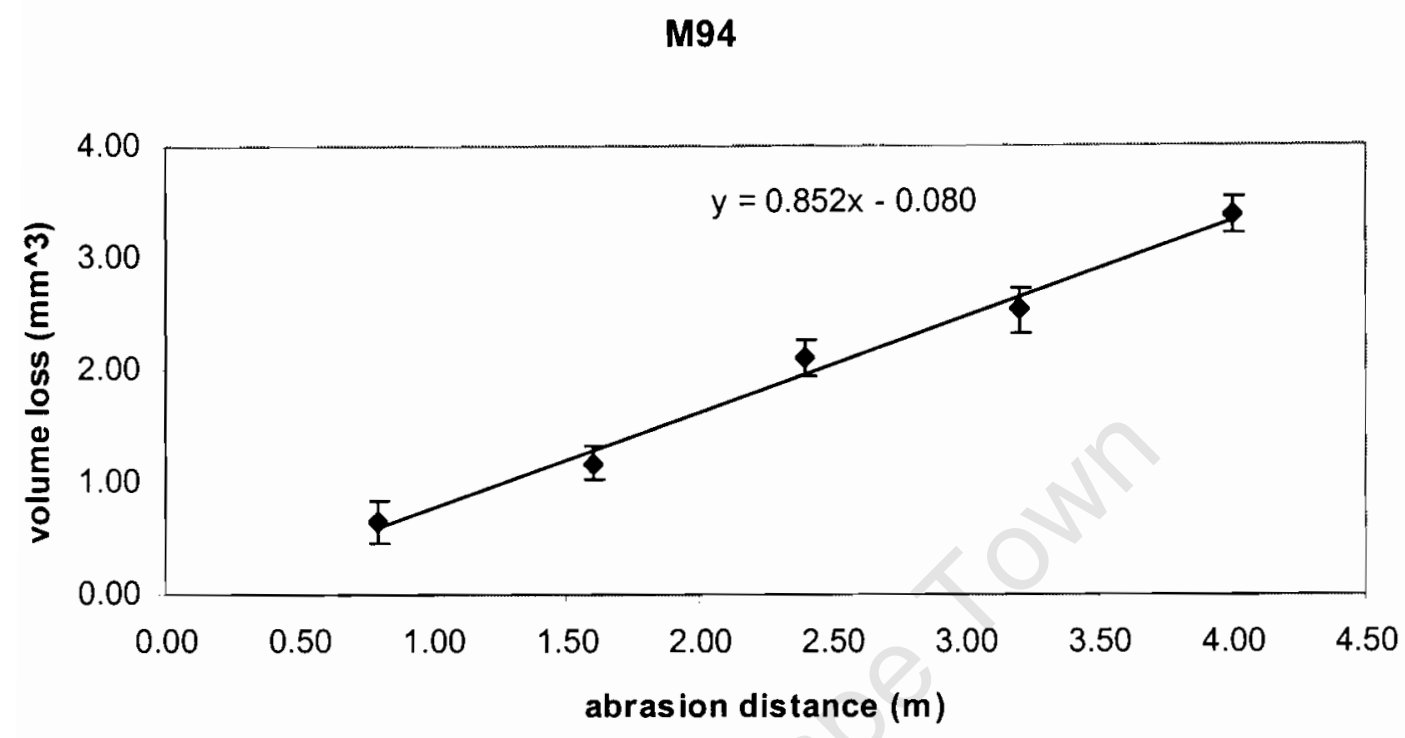

MP96

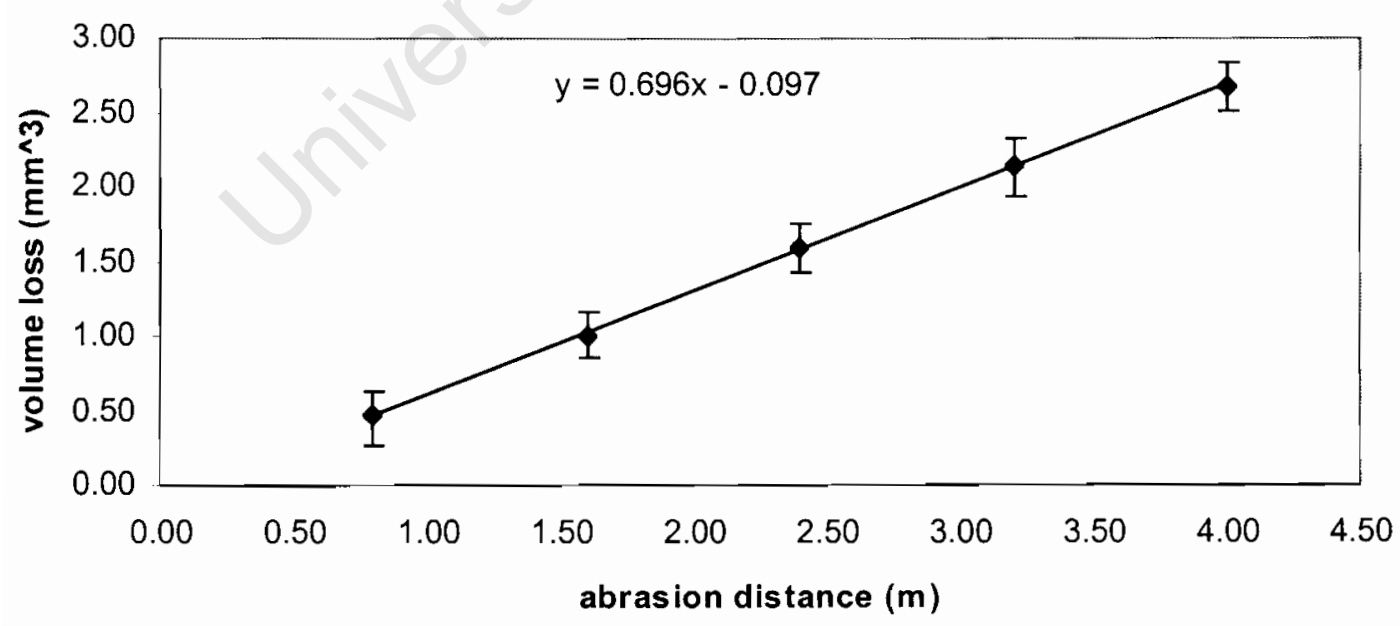




\section{$45 \mathrm{~cm} / \mathrm{s}$}

M97

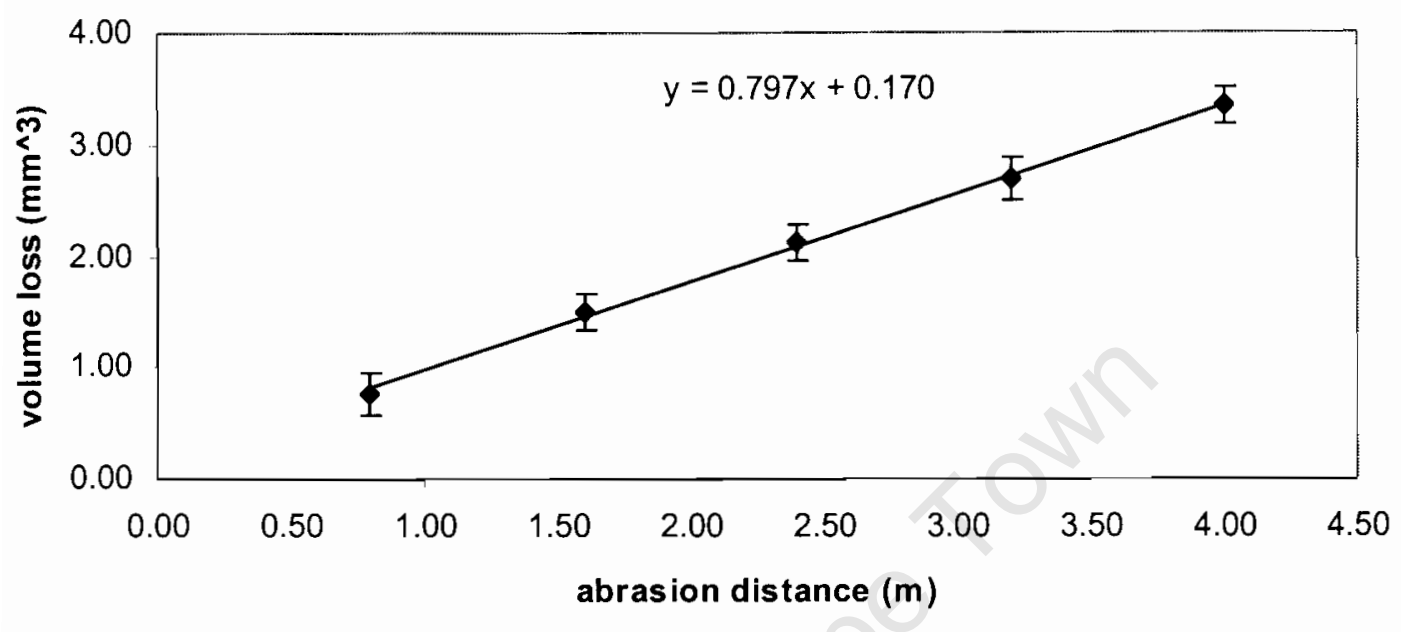

